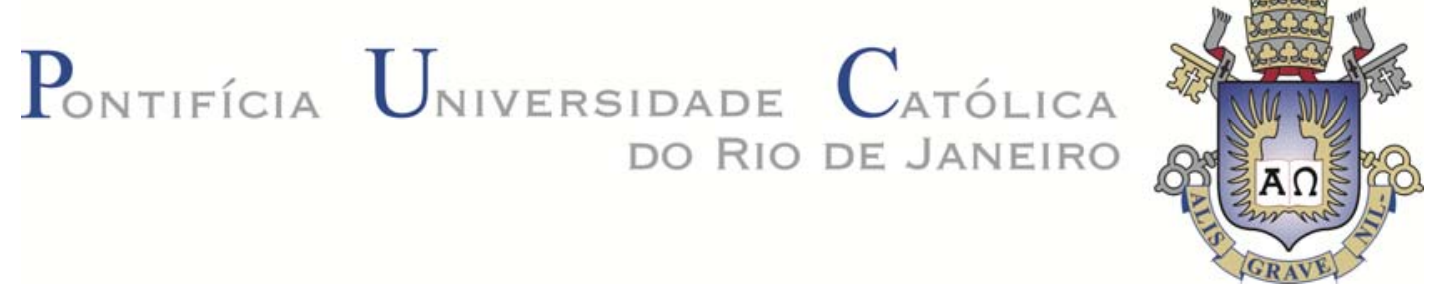

Helder Antônio da Silva

O Impacto das Características dos Gestores sobre a Exportação de Pequenas e Médias Empresas

Tese apresentada ao Programa de Pós-graduação em Administração de Empresas da PUC-Rio como requisito parcial para obtenção do grau de Doutor em Administração de Empresas.

Orientador: Prof. Jorge Manoel Teixeira Carneiro

Rio de Janeiro Novembro de 2016 
Helder Antonio da Silva

\section{O Impacto das Características dos Gestores sobre a Exportação de Pequenas e Médias Empresas}

Tese apresentada como requisito parcial para obtenção do grau de Doutor pelo Programa de Pós-graduação em Administração de Empresas da PUC-Rio. Aprovada pela Comissão Examinadora abaixo assinada.

Prof. Jorge Manoel Teixeira Carneiro Orientador Departamento de Administração - PUC-Rio

Prof. Jorge Ferreira da Silva Departamento de Administração - PUC-Rio

Prof. Fernando Antonio Ribeiro Serra Uninove

Prof. Luis Antonio da Rocha Dib Instituto Coppead de Administração/UFRJ

Prof. Rafael Guilherme Burstein Goldszmidt FGV

Profa. Mônica Herz Vice-Decana de Pós-Graduação do CCS Rio de Janeiro, 28 de novembro de 2016 
Todos os direitos reservados. É proibida a reprodução total ou parcial do trabalho sem autorização da universidade, do autor e do orientador.

\section{Helder Antônio da Silva}

Possui graduação em Engenharia Industrial Mecânica pela Fundação de Ensino Superior de São João Del Rei (1997) e mestrado em Engenharia Mecânica, na linha de pesquisa em Gestão e Otimização, pela Universidade Estadual Paulista Júlio de Mesquita Filho (2009).

Ficha Catalográfica

Silva, Helder Antônio da

O Impacto das características dos gestores sobre a exportação de pequenas e médias empresas / Helder Antônio da Silva ; orientador: Jorge Manoel Teixeira Carneiro. - 2016.

252 f. ; $30 \mathrm{~cm}$

Tese (doutorado)-Pontifícia Universidade Católica do Rio de Janeiro, Departamento de Administração, 2016.

Inclui bibliografia

1. Administração - Teses. 2. Internacionalização. 3. Exportação. 4. Pequenas e médias empresas. 5. PMEs. 6. Características gerenciais. I. Carneiro, Jorge Manoel Teixeira. II. Pontifícia Universidade Católica do Rio de Janeiro. Departamento de Administração. III. Título. 
Às minhas protetoras: Nossa Senhora Aparecida, Santa Teresinha e Nhá Chica.

Ao meu protetor Frei Galvão

Às mulheres mais importantes da minha vida:

Helen, minha filha;

Cristina, minha esposa;

Ilma, minha mãe.

Ao meu pai, Waldyr Silva (in memorian). 


\section{Agradecimentos}

Primeiramente a Deus, agradeço todas as minhas conquistas.

À minha família: minha esposa, Cristina Faria da Silva e minha filha, Helen Cristina Faria da Silva, minha mãe, Ilma Evangelista da Silva e ao meu pai, Waldir Antônio da Silva (in memoriam), agradeço os sacrifícios, incentivos e parcerias feitos em prol da minha formação.

Ao meu orientador, Prof. Dr. Jorge Manoel Teixeira Carneiro, agradeço a paciência, dedicação, amizade e por me acolher em seu lar. Sem ele este trabalho não existiria.

Ao Prof. Rafael Guilherme Burstein Goldszmidt, agradeço a valiosa contribuição nos testes estatísticos.

Agradeço à colega Carla Albuquerque, que compartilhou seu conhecimento e trouxe valiosa contribuição para a elaboração dos questionários.

Aos membros da banca Prof. Jorge Ferreira da Silva, Fernando Antônio Ribeiro Serra, Prof. Luís Antônio da Rocha Dib, agradeço as críticas construtivas, que muito contribuíram para melhoria deste trabalho.

Às minhas irmãs agradeço a paciência, o carinho e a união.

Agradeço aos meus sobrinhos e sobrinhas, que me mostram a simplicidade da infância e da adolescência.

Aos meus tios e tias agradeço a acolhida, os ensinamentos, os exemplos e a experiência de vida.

Agradeço aos meus amigos, em especial, Ronaldo Souza, Lázaro e Eroni, a grande amizade.

Agradeço à amiga Nicássia, que foi praticamente uma irmã, compartilhando seu conhecimento e amizade.

Ao Prenassi e amigos do grupo de canto da Comunidade Nossa Senhora da Conceição, agradeço as orações.

Aos profissionais das organizações participantes da pesquisa, agradeço a compreensão, dedicação e disponibilidade de precioso tempo.

Meus agradecimentos aos colegas de estudo, do DINTER, que compartilharam seus conhecimentos.

Aos alunos da empresa Ello Júnior, que muito ajudaram na elaboração da planilha com os dados das empresas para envio do questionário.

Aos profissionais da secretaria do IAG PUC-Rio de Janeiro, em especial a Teresa e o Fábio, sempre ajudando com os registros escolares.

Aos colegas do IF Sudeste MG - Campus Barbacena e Campus Juiz de Fora, da INB, IMBEL, Prefeitura Municipal de Santos Dumont, Centro de Formação Profissional, ETEPI, Escola Polivalente e Colégio Pio X, que compartilharam os bons momentos da vida profissional. 


\section{Resumo}

Silva, Helder Antônio da; Carneiro, Jorge Manoel Teixeira. O Impacto das Características dos Gestores sobre a Exportação de Pequenas e Médias Empresas. Rio de Janeiro, 2016. 252p. Tese de Doutorado - Departamento de Administração, Pontifícia Universidade Católica do Rio de Janeiro.

Em pequenas e médias empresas (PMEs), que sofrem de falta de recursos para busca de informações e sua análise, as decisões de internacionalização se encontram, muitas vezes, concentradas em um único decisor - o gerente de exportação, que, com frequência, sofre de restrição de acesso a informações. Este estudo investiga se as características pessoais deste decisor - em particular, sua idade, seu capital humano (formação educacional, domínio de língua estrangeira e experiência internacional) e seu capital social (relacionamentos pessoais e profissionais que lhe permitem ter acesso a fontes de informação e a outros recursos) - afetam as decisões de exportação de PMEs, especificamente, a precocidade do início da atividade de exportação, a velocidade de crescimento das vendas internacionais, o número de países atendidos e a intensidade das vendas internacionais. São investigados efeitos diretos das características do gestor, bem como efeitos mediados pela sua propensão a risco e sua percepção de risco (da exportação). A literatura apresenta argumentos e resultados empíricos parcialmente contraditórios acerca do impacto das características gerenciais sobre a trajetória de internacionalização das PMEs. Os dados deste estudo foram coletados por meio de uma survey online, enviada para mais de 6.000 exportadores, cujos e-mails foram obtidos da base da Brazil4export (http://www.brazil4export.com/), disponibilizada pela CNI (Confederação Nacional da Indústria). De um total de 241 questionários respondidos, foram desconsiderados 118 (por corresponderem a empresas (grandes) ou respondentes (não gestores de exportação) não elegíveis para o estudo ou a questionários com mais de $15 \%$ de dados ausentes), tendo restado 123 casos; destes, apenas 71 correspondem a empresas cujo gestor de exportação que respondeu ao questionário já trabalhava na empresa há pelo menos três anos quando a empresa iniciou suas exportações. O modelo foi estimado com a técnica PLS (Partial Least Squares), que é robusta a amostras pequenas, e foram utilizadas três variáveis de controle - indústria, tamanho da empresa e do grau de satisfação com o 
desempenho das operações domésticas. Os resultados do estudo sugerem que idade tem impacto negativo (como esperado) e estatisticamente significativo sobre a velocidade de internacionalização, mas não significativo sobre a propensão a risco e o grau de internacionalização. O conjunto dos componentes do capital humano tem impacto positivo (como esperado), porém, estatisticamente não significativo sobre a propensão ao risco, o grau de internacionalização e a velocidade de internacionalização. Com relação aos componentes do capital social, os relacionamentos apresentaram efeito estatisticamente significativo sobre a propensão ao risco (como esperado), porém, não significativo sobre a percepção de risco ou sobre a velocidade de internacionalização e o grau de internacionalização. Por seu turno, propensão a risco e percepção de risco não se mostraram significativamente associados à velocidade de internacionalização e nem no grau de internacionalização. O pequeno tamanho da amostra, no entanto, torna baixo o poder do teste, ou seja, a probabilidade de se rejeitar uma hipótese nula, caso ela seja de fato falsa. O software $G^{*}$ Power indicou que, para o modelo explicativo deste estudo e este tamanho de amostra (71 casos), o poder do teste seria de apenas $71 \%$ para se detectarem efeitos médios $\left(f^{2}>=0,15\right)$ ao nível de $10 \%$.

\section{Palavras-chave}

Internacionalização; exportação; pequenas e médias empresas; PMEs; características gerenciais. 


\section{Abstract}

Silva, Helder Antônio da; Carneiro, Jorge Manoel Teixeira (Advisor). The Impact of Managers' Characteristics on Exports of Small and MediumSized Enterprises. Rio de Janeiro, 2016. 252p. Tese de Doutorado Departamento de Administração, Pontifícia Universidade Católica do Rio de Janeiro.

In small and medium-sized enterprises (SMEs), which suffer from lack of resources to search for and to analyze information, internationalization decisions are often concentrated in a single decision maker - the export manager, who often has limited access to information. This study investigates whether the personal characteristics of the decision maker - in particular his/her age, human capital (educational background, foreign language expertise and international experience) and his/her social capital (personal and professional relationships that facilitate his/her access to information sources and other resources) - affect the export decisions of SMEs, specifically regarding earliness of export activity, growth rate of international sales, number of countries served and intensity of international sales. This study examines both the direct effects of the manager's characteristics and the mediated effects through risk propensity and risk perception (about exports). The literature presents arguments and empirical results about the impact of the manager's characteristics on the path of internationalization of SMEs that are partially contradictory. Data were collected through an online survey sent to more than 6,000 exporters, whose e-mails were obtained from the Brazil4export (http://www.brazil4export.com/) database, provided by CNI (National Confederation of Industry). A total of 241 questionnaires were responded, of which 118 were discarded (because they corresponded to companies (large) or respondents (not export managers) not eligible for the study or the questionnaire had more than $15 \%$ missing data) and there remained 123 cases; of these, only 71 corresponded to companies whose export manager who answered the questionnaire had been working at the company for at least three years when the company started exporting. The model was estimated with the PLS (Partial Least Squares) technique, which is robust to small samples; three control variables were used - industry, company size and degree of satisfaction with the performance of 
domestic operations. The results of the study suggest that age have negative impact (as expected) and statistically significant about the speed of globalization, but not significant on the propensity to risk and the degree of intrancionalização. All the components of human capital has positive impact (as expected), but statistically not significant on the propensity to risk, the degree of internationalization and the speed of internationalization. With respect to the components of the social capital, only relationships (but not information sources) showed statistically significant effect on the share capital and this showed significant positive effect on the propensity to risk (as expected) but not significant on the perception of risk or about the speed of internationalization and the degree of internationalization. Propensity to risk and risk perception were not significantly associated with internationalization speed and also with the degree of internationalization. The small sample size implies a reduced statistical power, that is, the probability of rejecting the null hypothesis if it is in fact false. The $\mathrm{G}^{*}$ Power software indicated that for the explanatory model of this study and this sample size ( 71 cases), the power of the test was only $71 \%$ to detect medium effects $\left(f^{2}>=0.15\right)$ at the $10 \%$ significance level.

\section{Keywords}

Internationalization; exports; small and medium-sized enterprises; SMEs; manager's traits. 


\section{Sumário}

1. Introdução 16

1.1. Relevância do Tema 16

1.2. Objetivos do estudo 19

1.3. Delimitação do estudo 20

1.4. Contribuições deste estudo 21

1.5. Organização do estudo 22

2. Revisão da Literatura 23

2.1. Características dos decisores e a internacionalização 23

2.2. Grau de internacionalização 26

2.3. Capital humano 30

2.4. Capital social 36

3. Modelo Conceitual e Hipóteses do Estudo 41

3.1. O impacto da idade do decisor na propensão ao risco 42

3.2. Impacto da idade do decisor na velocidade de internacionalização 46

3.3. Impacto do capital humano na propensão ao risco 50

3.4. Impacto do capital humano no grau de internacionalização 57

3.5. Impacto do capital humano na velocidade de internacionalização 66

3.6. Impacto do capital social na propensão ao risco 73

3.7. Impacto do capital social na percepção de risco 77

3.8. Impacto do capital social na velocidade de internacionalização 81

3.9. Impacto do capital social no grau de internacionalização 86

3.10. O impacto da propensão ao risco 90

3.11. O impacto da percepção de risco do decisor 100

3.12. Variáveis de controle 111

4. Métodos e Dados 113

4.1. Mensuração das variáveis $\quad 115$

4.1.1. Operacionalização das variáveis independentes 116

Idade do gestor 117

4.1.2. Operacionalização das variáveis dependentes 130

4.1.3. Variáveis de controle 134

4.2. Procedimento de coleta de dados 135

4.3. Amostra 141

4.4. Técnica para analise de dados 147

4.4.1. Validação empírica do modelo teórico 150

4.4.2. Procedimentos para a verificação da variância de método comum (CMV) 151

4.4.3. Análise do modelo de mensuração e estrutural 153

4.5. Limitações do método 158 
5. Apresentação dDos Resultados 160

5.1. Depuração do modelo de mensuração 160

5.2. Estimação do modelo estrutural 165

5.3. Avaliação do impacto da CMV 170

6. Discussão dos Resultados 173

7. Considerações Finais 191

8. Referências Bibliográficas 196

Apêndice A - questionário aplicado 243 


\section{Lista de tabelas}

Tabela 1: Número de empresas exportadoras classificadas conforme o

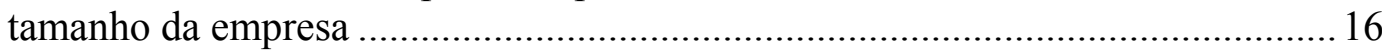

Tabela 2: Classificação do porte de empresas. Fonte: MDIC (2009)................... 142

Tabela 3: Envio de e-mails para PMEs exportadoras CNI.................................. 144

Tabela 4: Envio de e-mails para PMEs exportadoras CIEMG ............................ 144

Tabela 5: Sugestão de tamanho de amostra .......................................................... 146

Tabela 6: Verificação do poder estatístico do modelo ........................................ 147

Tabela 7: Colinearidade (VIF) do modelo de mensuração formativo .................. 160

Tabela 8: Cargas "w" e estatística " $t$ " dos construtos formativos ....................... 161

Tabela 9: Consistência interna e AVE dos construtos reflexivo do modelo

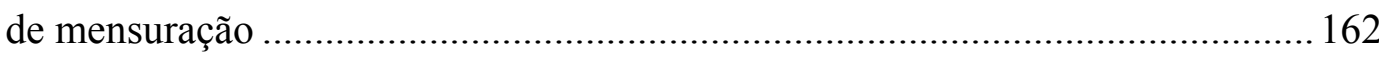

Tabela 10: Cargas "l" dos indicadores nos construtos do modelo de

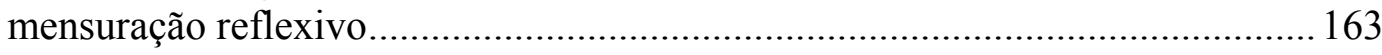

Tabela 11: Correlações entre os construtos do modelo de mensuração

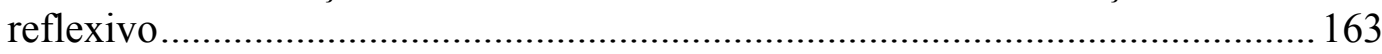

Tabela 12: Colinearidade (VIF) do modelo de mensuração reflexivo ................ 164

Tabela 13: Coeficientes $\mathrm{R}^{2}$ dos construtos preditores em relação aos demais

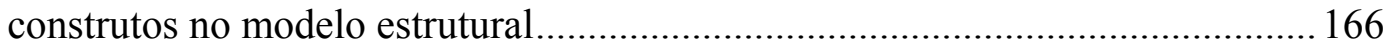

Tabela 14: Estatística t dos construtos relacionados no modelo estrutural ......... 167

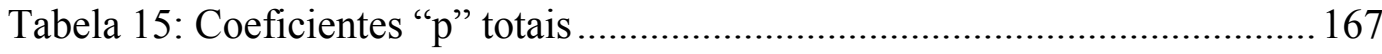

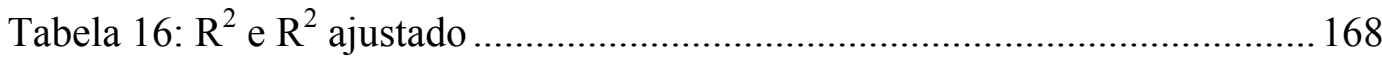

Tabela 17: Tamanho do efeito de $\left(\mathrm{f}^{2}\right)$ dos construtos relacionados no modelo

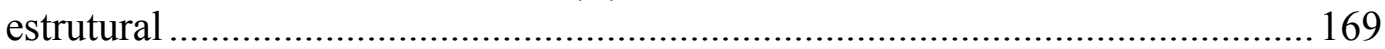

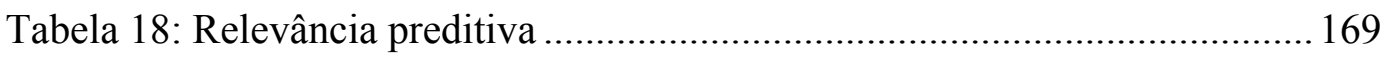

Tabela 19: Efeito de $\mathrm{q}^{2}$ dos construtos relacionados no modelo estrutural ......... 170

Tabela 20: Estatística "t" das relações entre construtos com e sem variável

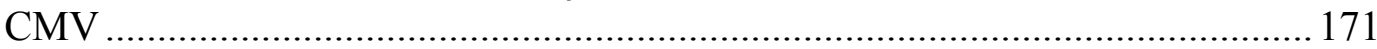

Tabela 21: Coeficientes " $p$ " das relações entre os construtos do modelo

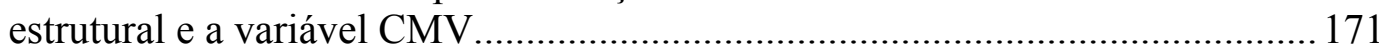

Tabela 22: Cargas "l" mínimas e máximas dos indicadores dos construtos do modelo

Tabela 23: Cargas " 1 " dos indicadores nos seus construtos do modelo e na variável controle. 


\section{Lista de quadros}

Quadro 1: Relações entre a teoria do capital humano e a internacionalização das PME....

Quadro 2: Relações entre a teoria do capital social e a internacionalização das PME

Quadro 3: Alternativas para operacionalização do construto Capital Humano... 117

Quadro 4: Alternativas para operacionalização do construto Capital Humano... 119

Quadro 5: Alternativas para operacionalização do construto capital social........ 123

Quadro 6: Alternativas para operacionalização do construto propensão ao risco do gestor

Quadro 7: Alternativas para operacionalização do construto percepção de

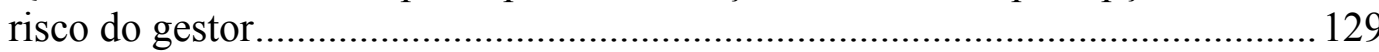

Quadro 8: Alternativas para medir profundidade de internacionalização ........... 131

Quadro 9: Alternativas para medir abarangência da internacionalização ........... 132

Quadro 10: Alternativas para medir precocidade da internacionalização ............ 133

Quadro 11: Alternativas para medir o crescimento do volume de vendas no

Quadro 12: Definição dos tipos de validades . 


\section{Lista de figuras}

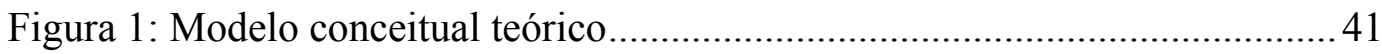

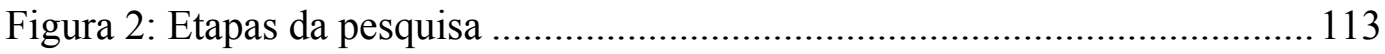

Figura 3: Porte das empresas respondentes da pesquisa.................................... 145

Figura 4: Relações de mensuração e estruturais no modelo depurado ................. 165 
"A ciência pode purificar a religião de erros e superstições. A religião pode purificar a ciência de idolatrias e erros absolutos."

Papa João Paulo II 


\section{1 \\ Introdução}

\section{1.}

\section{Relevância do tema}

O tema da internacionalização de empresas desperta cada vez mais a atenção de governos, dos acadêmicos e do setor privado no mundo todo. São muitas as teorias e argumentos utilizados para defender ou criticar tal fenômeno. A experiência internacional sobre o papel do governo no processo de internacionalização varia bastante e suscita discussões mais aprofundadas, como o grau de intervenção do Estado na economia, por exemplo, principalmente em se tratando de países emergentes como o Brasil (BRASIL, 2009).

Segundo o SEBRAE (2014), no Brasil existem 6,3 milhões de empresas. Desse total, 99\% são micro, pequenas e médias empresas. Os pequenos negócios (formais e informais) respondem por mais de dois terços das ocupações do setor privado. É esperado um aumento ainda maior do impulso da internacionalização das pequenas e médias empresas devido à economia mundial estar se tornando cada vez mais integrada a partir do contínuo declínio das barreiras impostas pelo governo, também pelos muitos e contínuos avanços da tecnologia, além das dificuldades econômicas internas que vêm ocorrendo no país desde 2013. A Tabela 1 apresenta o número de empresas exportadoras e seu porte de 1998 a 2011.

Tabela 1: Número de empresas exportadoras classificadas conforme o tamanho da empresa

\begin{tabular}{|c|c|c|c|c|c|c|c|c|c|c|c|c|c|c|}
\hline & 1998 & 1999 & 2000 & 2001 & 2002 & 2003 & 2004 & 2005 & 2006 & 2007 & 2008 & 2009 & 2010 & 2011 \\
\hline TAMANO & \multicolumn{14}{|c|}{ NUMERODEEMPRESAS } \\
\hline Micro & 3.855 & 4.345 & 4.773 & 5.262 & 5.527 & 5.681 & 6.267 & 6.072 & 5.935 & 5.883 & 5.524 & 5.487 & 5.313 & 5.058 \\
\hline Pequena & 4.917 & 5.484 & 6.033 & 6.563 & 6.678 & 7.086 & 7.705 & 7.474 & 7.091 & 7.123 & 6.927 & 6.697 & 6.525 & 6.467 \\
\hline Micro \& Pequena & 10.770 & 11.828 & 12.806 & 13.826 & 14.207 & 14.770 & 15.976 & 15.551 & 15.032 & 15.013 & 14.459 & 14.193 & 13.848 & 13.536 \\
\hline MP especial & 854 & 953 & 1.019 & 1.082 & 1.146 & 1.342 & 1.557 & 1.548 & 1.499 & 1.476 & 1.371 & 1.148 & 1.192 & 1.165 \\
\hline Méda & 2.821 & 2.930 & 3.121 & 3.236 & 3.236 & 3.320 & 3.583 & 3.565 & 3.604 & 3.708 & 3.709 & 3.639 & 3.680 & 3.733 \\
\hline Grande & 1.386 & 1.429 & 1.465 & 1.517 & 1.526 & 1.607 & 1.734 & 1.772 & 1.791 & 1.554 & 1.957 & 1.982 & 2.099 & 2.099 \\
\hline Näo classificada & 87 & 69 & 81 & 115 & 267 & 166 & 184 & 57 & 36 & 47 & 309 & 319 & 465 & 200 \\
\hline Total empressas exportadoras (1) & 13.920 & 15.210 & 16.492 & 17.775 & 18.380 & 19.202 & 21.030 & 20.488 & 19.956 & 20.191 & 19.797 & 19.272 & 19.274 & 18.722 \\
\hline
\end{tabular}

Fonte: SEBRAE (2014). 
As pequenas e médias empresas possuem grande importância socioeconômica para qualquer país. Isto ocorre devido a diferentes fatores como a redução de barreiras aos produtos estrangeiros e a facilidade de acesso a recursos tecnológicos. Estes fatores têm levado as pequenas e médias empresas (PMEs) a considerarem a internacionalização - em específico, a exportação - como possível estratégia gerencial para aumentar o desempenho, principalmente o desempenho econômico e a sustentabilidade dos negócios, fazendo destas empresas uma fonte de conhecimento de grande importância para a área de negócios internacionais (WOLFF; PETT, 2006; FERNÁNDEZ-ORTIZ; LOMBARDO, 2009).

Segundo Francioni, Musso e Cioppi (2015) o número de pequenas e médias empresas envolvidas com atividades internacionais vem crescendo continuamente no mundo, fazendo aumentar o interesse da comunidade acadêmica no fenômeno da internacionalização deste tipo de empresa. Entretanto, a pequena e a média empresa ainda são caracterizadas por elevado nível de falhas em relação ao contexto internacional, implicando desempenho insatisfatório devido à inadequação da estratégia e tomada de decisão internacional (JOCUMSEN, 2004; FRANCIONI; MUSSO; CIOPPI, 2015).

A PME é por diversas vezes confrontada com recursos limitados, enfrentando escassez interna de informações, capital, gerenciamento de tempo e experiência, além de restrições decorrentes de sua vulnerabilidade às mudanças ambientais. As deficiências intrínsecas em recursos e capacidades impõem restrições sobre a internacionalização das PMEs. Essas restrições fazem a internacionalização se tornar um desafio intimidante para as PMEs, devido aos riscos e incertezas existentes no processo de internacionalização (JAVALGI; TODD, 2011).

É importante ressaltar também que as estratégias de negócios internacionais para PME são afetadas por condições econômicas; assim, a crise econômicofinanceira pode afetar o comportamento estratégico. Isto é particularmente verdadeiro se considerarmos que a PME tradicionalmente tem uma pequena base financeira, um foco interno e um alcance geográfico limitado (BARRINGER; GREENING, 1998). Com isto, os estudos em relação à internacionalização têm ganhado maior espaço entre pesquisadores da área de negócios internacionais (COLAPINTO et al., 2015). 
No entanto, a internacionalização das PMEs, no que diz respeito aos seus comportamentos e estratégias, pode ser influenciada pelas características dos decisores. Desta forma, vários estudos sugerem que a posse de habilidades específicas por parte dos decisores facilita a adoção de estratégias inovadoras como a internacionalização da empresa, especialmente no início do processo, que é o caso das exportações (JONES, 2001; LI et al., 2004; OMRI; BECUWE, 2014).

Várias pesquisas têm examinado a internacionalização com foco nos fatores das empresas, tais como tamanho, diversificação de produtos, e nos fatores externos às empresas como a cultura. No entanto, poucos estudos têm examinado o papel dos gestores e empreendedores no processo de internacionalização das empresas, principalmente das PMEs (HSU et al., 2013; OMRI; BECUWE, 2014).

As decisões importantes, especialmente aquelas relacionadas a operações internacionais, são feitas por decisores, endossadas e lideradas por escalões de liderança da empresa. Essas decisões são tomadas por indivíduos que, dependendo do tipo de empresa envolvida, como a pequena empresa, às vezes variam substancialmente em termos de fundo cultural e educacional, idade, experiência e assim por diante. As características dos decisores, bem como o modo que eles se relacionam, escolhem, agem e interagem, têm sido pouco pesquisadas (FOSS; PEDERSEN, 2014; BUCKLEY et al., 2016).

O padrão de internacionalização das empresas (tempo, seleção de mercados estrangeiros, escolha de modos de entrada) foi investigado por abordagens distintas, mas complementares, como i) base econômica - por exemplo, a teoria de internalização de Buckley e Casson (1998) e o paradigma eclético da produção internacional (DUNNING, 1980); ii) comportamental - por exemplo, o modelo do processo de internacionalização de Uppsala (UIPM) (JOHANSON; VAHLNE, 1977) e o empreendedorismo internacional (MCDOUGALL; OVIATT, 2000); e iii) a rede - por exemplo, Covielo e Munro (2007), Vahlne e Johanson (2013). Enquanto alguns estudos examinaram a importância das características gerenciais sobre o processo de internacionalização de pequenas e médias empresas (PMEs), sendo a evidência empírica ainda escassa e pouco clara (ACEDO; JONES, 2007; MANOLOVA et al., 2002). 
A teorias de internacionalização com base econômica desconsideram o papel do tomador de decisões individual, ao invés de assumir que existem algumas "regras de decisão" (por exemplo, com base nos custos de transação) que seriam seguidas por quem toma as decisões. Por outro lado, algumas teorias comportamentais (por exemplo, UIPM) consideram que as empresas são avessas ao rico e assim levaria um a caminho gradual que diminui os riscos - mesmo que isso pode não produza o maior retorno (esperado). No entanto, o nível de propensão ao risco não é um fenômeno do nível da empresa, mas de um indivíduo - o decisor - particularmente nas pequenas e médias empresas, onde as decisões tendem a concentrar-se nas mentes do fundador ou do gestor de topo. Abordagens de rede indicam explicitamente que os relacionamentos (pessoais ou profissionais) dos fundadores/gestores são um importante direcionador da internacionalização.

Os primeiros passos na internacionalização são considerados uma inovação na empresa (REID, 1981), mas tal esforço implica riscos (OVIATT; MCDOUGALL, 2005; FELZENSZTEIN et al., 2015). Como tal, o nível de propensão ao risco dos decisores em uma PME tende a afetar o caminho e a intensidade de progresso de exportação. Cavusgil (1984) relatou que a atitude dos gerentes ao assumir riscos é positivamente associada à intensidade da atividade de exportação, enquanto Axinn (1988) concluiu que as percepções negativas sobre risco funcionariam como uma barreira para as exportações e Jones e Coviello (2005) postulou que o nível de tolerância ao risco do empreendedor afeta o sucesso de exportação da empresa. O nível de propensão ao risco de uma pessoa, no entanto, está relacionado com suas características sociodemográficas. Sendo assim, um decisor de PME pode apresentar comportamentos e características que irão impactar de forma diferente no processo de internacionalização, desde a exportação (JAVALGI; TODD, 2011).

\section{2.}

\section{Objetivos do estudo}

Vários estudos apontam que o processo de internacionalização de PME recebe a influência de diversos fatores internos e externos, sendo que o decisor é o principal responsável pela elaboração das estratégias a serem adotadas pela PME (FELZENSZTEIN et al., 2015; JAVALGI; TODD, 2011; OMRI; BECUWE, 2014). Entretanto, é possível que o decisor possua algumas características 
gerenciais, tais como o capital humano, o capital social, propensão ao risco e percepção de risco, que variam de níveis, podendo influenciar a tomada de decisão no sentido de internacionalizar a PME.

Sendo assim, a pesquisa tem como objetivo principal investigar se há relação entre as características gerenciais do decisor e a exportação de pequenas e médias empresas (PMEs).

Para alcançar o objetivo principal, alguns objetivos intermediários deverão ser alcançados, tais como:

- revisão da literatura com objetivo de desenvolver o modelo teórico conceitual;

- levantamento de PMEs com potencial de participação da pesquisa;

- elaboração e aplicação de questionário para PMEs brasileiras;

- validação empírica do modelo por meio da Modelagem de Equações Estruturais (SEM) utilizando a técnica dos Mínimos Quadrados Parciais (PLS).

\section{3. \\ Delimitação do estudo}

Considerando a complexidade que envolve a temática relativa às características gerenciais dos decisores e a internacionalização de PMEs, neste estudo foi definida a seguinte delimitação do fenômeno:

- Serão consideradas somente pequenas e médias empresas exportadoras de bens e serviços, excluindo, assim, as multinacionais e grandes empresas brasileiras;

- Serão consideradas apenas pequenas e médias empresas com produção no Brasil e com controle sobre o capital que sejam de pessoa jurídica brasileira;

- O período de tempo a ser considerado inclui os últimos três anos. 
A inclusão apenas de pequenas e médias empresas exportadoras é devido ao fato de que estas empresas, geralmente, suportam os custos relativos à colocação de sua produção por meio de canais de exportação, não tendo condições, na maioria das vezes, de estabelecer, por exemplo, uma subsidiária em um país estrangeiro, a qual implica em custos e riscos (GUIMARÃES, 2001).

A delimitação do período de tempo foi devido ao prazo para finalização da elaboração desta tese, uma vez que o foco do estudo é investigar se há relação entre as características gerenciais do decisor e a exportação da PME, o que envolve um levantamento e a avaliação de dados retrospectivos dos decisores destas empresas.

\section{4.}

\section{Contribuições deste estudo}

Child e Hsieh (2014) e Francioni et al. (2015) enfatizam que os decisores de PMEs desempenham um papel significativo, e que suas características podem influenciar as suas decisões estratégicas, incluindo o contexto internacional. No entanto, a literatura e as pesquisas sobre negócios internacionais realizadas até o momento tenderam a negligenciar a relevância deste tópico. Portanto, o estudo contribui para a literatura de negócios internacionais, fornecendo evidências empíricas que podem ser úteis para a compreensão do desenvolvimento da exportação de PMEs, sendo influenciadas pelas características de seus decisores.

O presente trabalho traz contribuições para o meio empresarial, especialmente o das pequenas e médias empresas; para o meio acadêmico; para o Governo. As principais contribuições deste trabalho para o meio acadêmico são: a integração de conceitos e pesquisas que envolvem a área de Negócios Internacionais, Gestão Estratégica e Recursos Humanos, considerados de extrema importância para a Administração e para a grande área de Ciências Sociais Aplicadas; entender os efeitos de características pessoais sobre a exportação é uma questão relevante considerando que a opção por mercados estrangeiros é complexa e apresenta ainda divergências entre os estudos. 
Este estudo centra-se no nível individual, em contraste com a maioria dos estudos anteriores, pois pode apresentar resultados que sugerem que algumas características dos gestores de pequenas e médias empresas pode não ser suficientes para fazer estas empresas iniciar e manter as atividades de exportação, contradizendo assim parte da literatura sobre negócios internacionais.

Este estudo pode contribuir para o governo, trazendo alternativas para a elaboração e implementação de políticas públicas visando o desenvolvimento das características gerenciais para pequenos empreendedores, como exemplo a realização de cursos de preparação em incubadoras de instituição de ensino público.

\section{5 .}

Organização do estudo

Esta tese está organizada em cinco capítulos, sendo este primeiro capítulo a introdução. A seguir, no capítulo dois, é apresentada uma revisão da literatura com o objetivo de apresentar os conceitos relativos ao grau de internacionalização, as características gerenciais, o capital humano e o capital social e. Em seguida é apresentado o modelo conceitual teórico e as hipóteses a serem validadas empiricamente. O capítulo quatro apresentam os métodos utilizados para coleta de dados, a medição dos construtos, amostragem, os procedimentos de validação empírica e técnicas de análises estatísticas. No capítulo cinco são apresentados os resultados. O capítulo seis apresenta a discussão dos resultados e no capítulo sete são apresentadas as considerações finais deste estudo. 


\section{2 Revisão da literatura}

O objetivo da revisão da literatura a seguir é apresentar conceitos e uma fundamentação teórica para a geração do modelo conceitual a ser testado empiricamente.

\section{1.}

\section{Características dos decisores e a internacionalização}

De acordo com Andersson e Florén (2011), as linhas de pensamento sobre internacionalização não conseguem abordar o papel do gerente como um ator estratégico que afeta o desempenho internacional de PME. Relativamente pouca atenção tem sido dada à possibilidade de que o gestor, o CEO e o fundador da PME podem ser um fator-chave na compreensão do comportamento destas empresas em relação à internacionalização (OMRI; BECUWE, 2014).

Estudos prévios (WESTHEAD et al., 2001) sugerem que o gestor de topo tem mais habilidades, conhecimento e redes de contato, sendo significativamente mais provável que tenha comportamento inovador, bem como comportamento exportador. Mumford (2002), bem como Omri e Becuwe (2014), destaca que a capacidade do gerente de encorajar as equipes para inovação e internacionalização depende não apenas do contexto, mas também da alteração das suas características gerenciais.

A literatura de negócios internacionais associa a diversificação internacional com diversos benefícios. Estes incluem a capacidade de tirar proveito das economias de escala, escopo e experiência (KOGUT, 1985a), a disseminação dos riscos de mercado, a capacidade de conseguir entradas menos caras e a alavancagem de poder de mercado para reduzir os custos de entrada e controlar a saída dos mercados (GOMES; RAMASWAMY, 1999; KOGUT, 1985a; TALLMAN; LI, 1996). No entanto, alguns estudos também sugerem que a diversificação internacional está associada a riscos significativos. Reeb, Kwok e Baek (1998) e Kochhar e Hitt (1995) associam a diversificação internacional a 
consideráveis ambiguidades, complexidades e riscos. $\mathrm{O}$ aumento dos riscos, em particular, pode ser atribuído a uma variedade de fatores, incluindo informação assimétrica, incerteza provocada pelas mudanças políticas e risco de câmbio. Em resumo, a diversificação internacional pode ser complexa e difícil de gerir, com o aumento da dispersão internacional, resultando em maiores requisitos de processamento de informações gerenciais (JONES; HILL, 1988). Os desafios associados, por sua vez, têm implicações importantes para as habilidades cognitivas desejadas, orientação e competências entre os gestores envolvidos na diversificação internacional (HERRMANN; DATTA, 2005).

O reconhecimento do papel do gestor no desenvolvimento internacional das PMEs foi identificado em estudos empíricos sobre empreendedorismo (REUBER; FISCHER, 1997, NAKOS et al., 1998; CHETTY, 1999; APFELTHALER, 2000; LLOYD-REASON; MUGHAN, 2002). Além disso, várias das principais revisões de literatura focadas na exportação e pesquisa internacional (AABY; SLATER, 1989; CHETTY; HAMILTON, 1993; LEONIDOU; KATSIKEAS, 1996; ZOU; STAN, 1998; FILLIS, 2001) concluem que o gestor tem uma função significativa sobre atividades internacionais. O gestor também é visto como responsável no modo, na direção e na velocidade com que a empresa avança ao longo do caminho internacional (LEONIDOU et al., 1998). Na maioria dos modelos de desenvolvimento de exportação o tomador de decisão é visto como o fator-chave por trás da progressão da empresa de uma fase para outra, particularmente através da interação das decisões envolvendo conhecimento de mercado externo, comprometimento e as características do gestor (REID, 1981; CAVUSGIL, 1982; BARRETT; WILKINSON, 1986; HOLMUND; KOCK, 1998; ANDERSSON, 2000).

Discute-se também que as relações nas redes sociais, formadas e mantidas pelo gestor, não só conduzem à internacionalização, mas também influenciam o padrão e a direção do investimento (COVIELLO; MUNRO, 1997). Mais frequentemente, são analisados o impacto das oportunidades individuais e as circunstâncias que levam a PME a um determinado padrão de expansão (LANZARA, 1987), caracterizado por um menor grau de determinismo e um papel mais ativo, dado que os decisores da empresa obtêm recursos e informações que permitem à PME se envolver no mercado internacional de alguma forma 
(WELCH; LUOSTARINEN, 1988; DALLI, 1994, HUTCHINSON; QUINN; ALEXANDER, 2006).

O principal problema observado em vários estudos é que não existe uma combinação perfeita para uma situação específica, então é necessário considerar alguns aspectos que afetam as decisões, bem como o resultado final. Quando as empresas decidem utilizar estratégias de internacionalização para abrir novas oportunidades, essas empresas devem ter algum conhecimento sobre o país ou países de destino, visto que, dependendo da situação das empresas, o comprometimento de recursos será maior. Isso significa que quando as empresas têm mais conhecimento e experiência anterior, elas podem considerar estratégias complexas sabendo que tipo de recursos e investimentos são necessários para internacionalizar a empresa. Estas decisões devem ser estudadas e avaliadas em profundidade, o que torna a equipe de gestores de topo fundamental para a tomada de decisões adequadas para aplicar as medidas necessárias ao processo de internacionalização (BURILO; MORENO, 2013).

Vida et al. (2000) destacam que as percepções gerenciais orientam a tomada de decisões. É duvidoso que as decisões para o crescimento em mercados não domésticos sejam feitas, a menos que o gestor demonstre uma visão positiva em relação às oportunidades e barreiras potenciais envolvidas na expansão internacional. O estudo desenvolvido por Vida et al. (2000) reforça as conclusões de Williams (1992), que indica que a falta de experiência e atitudes etnocêntricas do gestor conduzem frequentemente a uma abordagem reativa à internacionalização do varejo e à subestimação dos potenciais obstáculos no processo.

Leonidou et al. (1998) realizaram uma revisão da literatura referente às características do gestor e o subsequente impacto na internacionalização das PMEs e verificaram que dois conjuntos de fatores gerenciais, ou seja, objetivos (formação, experiência e exposição do país estrangeiro do tomador de decisões) e subjetivos (percepções, atitudes e o comportamento do decisor) foram as características mais frequentemente citadas na literatura.. 
Entre as linhas de pesquisa sobre internacionalização, serão avaliadas as características gerenciais dos gestores nas pequenas e médias empresas que buscam a ampliação dos negócios no mercado internacional. No modelo proposto, as características gerenciais serão vistas por meio de cinco principais fatores: idade do gestor, capital humano, capital social, propensão ao risco e percepção de risco do gestor.

\section{2.}

\section{Grau de internacionalização}

O envolvimento internacional da firma, segundo Floriani (2010), é demonstrado de diversas maneiras, como o grau de diversificação internacional (HITT et al., 1997), a multinacionalidade, a atitude gerencial e o processo de aprendizagem, o tamanho, a regularidade das exportações, entre outras.

A justificativa para uma variável do grau de internacionalização é o seu potencial para ajudar a explicar as críticas antecedentes e consequências da expansão global. Uma vez que integra diversas variáveis, é esperado que seja melhor do que muitas das medidas individuais utilizadas em estudos anteriores. Como destaca Sullivan (1994) e Ramaswamy e Kroeck (1996), com o uso de uma escala multi-itens, é mais provável que se atinja um conjunto mais amplo de conteúdos válidos, significando o construto total de DOI (Degree of Internationalization) de uma empresa.

$\mathrm{O}$ uso de vários componentes do construto reflete nas práticas metodológicas. Para tanto, a escolha dos indicadores deve ser teoricamente defensável e mostrar traços comuns que justifiquem a agregação. Se essas condições não forem atendidas, o índice resultante seria suscetível à inflação ou deflação, devido a fatores conceitualmente irrelevantes, uma falha que Sullivan (1994) e Ramaswamy e Kroeck (1996) sugerem ser comum nas medidas de item único.

O grau de internacionalização, índice sugerido por Sullivan, é composto por cinco variáveis usadas para medir três atributos de internacionalização: um atributo estrutural, um atributo de desempenho e um atributo de atitude. As cinco variáveis que compõem o índice são a proporção de vendas externas para o total de vendas, a proporção de ativos externos para ativos totais, a proporção de subsidiárias no exterior para totais subsidiárias, experiência internacional dos 
gestores da alta administração e dispersão psíquica das operações internacionais (RAMASWAMY; KROECK, 1996).

A medida mais comumente usada para examinar o grau de internacionalização é a profundidade que pode ser a proporção de vendas para o mercado estrangeiro no total de vendas (GERINGER; BEAMISH; DA COSTA, 1989; GRANT, JAMMINE; THOMAS, 1988; HSU; BOGGS, 2003). Outras medidas que têm sido utilizadas em estudos anteriores são a proporção de ativos estrangeiros em ativos totais (RAMASWAMY, 1993) e a relação entre a quantidade de empregados em locais estrangeiros e empregados totais (KIM et al., 1989; HSU; BOGGS, 2003). Todas as medidas acima tendem a capturar a profundidade da internacionalização. (HSU; BOGGS, 2003).

Algumas pesquisas investigaram a abrangência da internacionalização, examinando a dispersão geográfica das operações em todos os países. As empresas multinacionais tendem a aproveitar as vantagens de localizações bases para melhorar o seu desempenho (KOGUT, 1985b). Ramaswamy (1993) propôs medir a abrangência por meio do número de plantas operando no exterior e esta configuração encontrou uma relação positiva significativa de desempenho, sendo amplamente adotada. (HSU; BOGGS, 2003).

Os resultados de Hsu e Boggs (2003) são particularmente convergentes com a literatura (DANIELS; BRACKER, 1989; GERINGER; BEAMISH; DACOSTA, 1989; SULLIVAN, 1994, RAMASWAMY (1995); GOMES, RAMASWAMY, 1999), mostrando que o grau de internacionalização quando medido pela abrangência e quando medido pela profundidade consegue-se avaliar as interações destas medidas com as medidas de desempenho da empresa como ROE e ROA, principalmente no que tange aos negócios internacionais.

Allen e Pantzalis (1996) propõem duas dimensões para medir o grau de internacionalização e seu impacto no desempenho da empresa: abrangência e profundidade. Sendo que a abrangência é medida pelo número de países estrangeiros, onde uma empresa tem filial, enquanto a profundidade é medida pelo número de subsidiárias estrangeiras em um determinado país dividido pelo número total de subsidiárias estrangeiras. Allen e Pantzalis (1996) destacam que a abrangência pode ter um efeito de aumento de valor de internacionalização, mas, profundidade pode ter um efeito de redução do valor de internacionalização no desempenho da empresa. 
Abrangência (ou escopo) também é definida como a variedade de locais onde a empresa desenvolve a sua atividade (ZAHRA; GEORGE 2002), cobrindo os mercados e/ou países onde vende ou fabrica seus produtos e serviços (WELCH; LUOSTARINEN, 1988). O grau de internacionalização de empresa pode ser medido pelo número de países aos quais exporta seus produtos, o número no qual a empresa possui subsidiária, a diversificação dos seus mercados estrangeiros e a distância física e/ou cultural entre os países onde está operando. A clássica abordagem sequencial pressupõe que as empresas iniciam seu processo de internacionalização em apenas alguns países que estão fisicamente e culturalmente próximos de seus próprios mercados internos e progressivamente, atinge países mais distantes com o avanço de processos de internacionalização (ANDERSEN, 1993; JOHANSON; VAHLNE, 1977, 1990; JOHANSON; WIEDERSHEIMPAUL, 1975): assim, o número, à distância e a variedade de países podem ser usados como indicadores do grau de internacionalização da empresa (CASILAS; ACEDO, 2013; DOW; KARUNARATNA, 2006).

A terceira dimensão do grau de internacionalização, a velocidade, pode ser encontrada de três formas no processo de internacionalização (SULLIVAN, 1994; ZAHRA; GEORGE 2002). Os dois primeiros referem-se à intensidade de internacionalização da empresa, enquanto a terceira refere-se ao seu grau. Estes três tipos de velocidade são: (1) a velocidade do crescimento da intensidade de comercio internacional da empresa; (2) a velocidade de seu aumento no comprometimento de recursos no exterior; e (3) a velocidade da mudança na abrangência de seus mercados internacionais (CASILAS; ACEDO, 2013).

A velocidade de crescimento internacional (intensidade de exportação) pode ser definida como o crescimento da proporção de vendas da empresa derivado de países estrangeiros, durante um determinado período de tempo. No caso de empresas exportadoras, a velocidade pode ser medida como o crescimento de sua intensidade de exportação entre dois momentos específicos no tempo (BONACCORSI, 1992; CASILAS; ACEDO, 2013). Entretanto, para Sullivan (1994) e Casilas e Acedo (2013), quando as empresas têm filiais estrangeiras, esta medida se torna mais complexa, sendo necessário conhecer a proporção da renda do grupo derivada de subsidiárias estrangeiras em dois pontos no tempo e, em seguida, medir o crescimento dessa proporção. 
A velocidade do comprometimento maior de recursos na atividade estrangeira (JOHANSON; VAHLNE, 1977, 2009) pode ser medida por diversos indicadores simples, tais como aumentos na proporção dos bens da empresa retidos no exterior ou de seus trabalhadores empregados em empresas estrangeiras (SULLIVAN, 1994). O modo de entrada no mercado externo também pode ser um indicador adequado para medir a velocidade, devendo-se considerar o número de subsidiárias estabelecidas no exterior, o número de plantas de produção instalada no exterior ou o número de empresas estrangeiras adquiridas entre dois momentos específicos. Essa velocidade é conhecida como velocidade da mudança do comprometimento de recursos no exterior ao longo de um período específico (ASMUSSEN et al., 2009; CASILAS; ACEDO, 2013).

Velocidade de dispersão (crescimento na abrangência) dos mercados internacionais é definida como o aumento, ao longo do tempo, do número, da variedade e da distância dos países onde a empresa está operando (CASILAS; ACEDO, 2013; ASMUSSEN et al., 2009; JONES; COVIELLO, 2005) e pode ser medido por meio de indicadores diferentes: o número de novos países, para onde a empresa exporta ou como é feito o investimento de capital (subsidiárias, plantas de produção); o aumento da diversificação geográfica das vendas; ou a distância física e/ou cultural média dos países de sua base (CASILAS; ACEDO, 2013; SULLIVAN, 1994; ZHANG et al., 2010).

O tempo tem sido tradicionalmente marginal em estudos de negócios internacionais (ANCONA et al., 2001; ZUCCHELLA; PALAMARA; DENICOLAI, 2007), mas agora estão surgindo novos campos de investigação que colocam o tempo em sua essência. A expansão internacional tem significados diferentes, podendo referir-se ao início precoce de atividades internacionais (conhecido como precocidade de exportação) e a velocidade de crescimento internacional (rapidez). Precocidade de exportação tem sido operacionalizada como o número de anos desde a fundação da empresa foi necessário para o início das vendas internacionais. Empresas que começaram a exportar nos primeiros três anos (MADSEN; SERVAIS, 1997) foram classificadas como precoces e são representativos de born globals e INVs (ZUCCHELLA; PALAMARA; DENICOLAI, 2007). 


\section{4. \\ Capital humano}

Becker (1964) define o capital humano como o conjunto de habilidades e conhecimentos adquiridos por um indivíduo por meio da educação e experiência, sendo esta incorporada na maneira de executar o trabalho a fim de produzir valor econômico (BECKER, 1964). A teoria do capital humano afirma que conhecimentos adquiridos e competências podem levar a um melhor desempenho, como é inerente a qualquer tipo de capital (LIN, 2001). O capital humano também é definido como o capital investido em indivíduos (educação, experiência e habilidades naturais), que não é facilmente transferível para outras pessoas, e as formas pelas quais se tornam propriedade pública (o estoque de conhecimento no domínio público) (PIAZZA-GEORGI, 2002). O capital humano pode ser refletido por atributos (por exemplo, educação) relevantes para o desempenho em diversas áreas (atividades econômicas) e contextos mais específicos (por exemplo, experiência profissional) (WESTHEAD et al., 2005; ZHANG, 2010; JANSEN et al. 2011).

Devido à natureza altamente centralizada da tomada estratégica de decisões em PME, o capital humano é especialmente importante para o desempenho econômico, mas não é necessariamente produtivo para a sobrevivência das pequenas empresas (GIMENO et al., 1997). Pesquisa sobre o papel do capital humano para explicar o desenvolvimento empresarial tem mostrado que ele é mais importante na fase de inicial e menos importante para o progresso empresarial em relação ao capital social (DAVIDSSON; HONIG, 2003). No entanto, isso não significa que se torna totalmente sem importância em fases posteriores. O conhecimento pré-existente, as habilidades gerenciais e de sistemas, baseiam-se na sua experiência profissional anterior e na formação acadêmica do indivíduo (HAMBRICK; FUKUTOMI, 1991), o que significa que o processamento de informações em uma situação de decisão específica será afetado pelo conhecimento e procedimentos que fazem parte da cognição individual dos tomadores de decisão (KOR; SUNDARAMURTHY, 2009). Portanto, o capital humano ajuda a explicar as escolhas estratégicas e inclinações da equipe de gestão (HAMBRICK et al., 2005; JANSEN et al., 2011). 
O conceito de capital humano ganhou notoriedade acadêmica a partir da década de 1960 por Schultz em 1961, Becker em 1962 e 1964, e Kiker em 1965. Kiker (1965) estabeleceu que o conceito de capital humano estivesse centrado no "main-stream" do pensamento econômico até Marshall, tendo desconsiderada a noção irrealista do termo. Alguns economistas da época consideravam os seres humanos ou suas habilidades adquiridas como capital, lista que inclui nomes conhecidos na história da economia como Petty, Smith, Von Thunen, Roscher, Bagehot, Engel, Sldgwlck, Ualras, Fisher e Clark. A maioria desses economistas categorizava o ser humano como capital, enquanto alguns deles incluíam apenas suas competências e habilidades adquiridas como capital. A distinção entre as duas noções parece envolver diferentes pontos de vista da riqueza. Aqueles que incluem todas as coisas de valor, seja produzida ou não, parecem incluir a pessoa. Aqueles que fazem a distinção entre meios produzidos originais de produção parecem incluir as competências e habilidades.

Sendo assim, o capital humano enfatiza os custos do trabalho em relação à rentabilidade genérica versus investimento específico para desenvolver habilidades; transferir habilidades e conhecimentos para o desenvolvimento de outros funcionários (competências, educação e treinamento). Os empregados também possuem o seu próprio capital humano, obtido por meio dos empregos que trabalharam anteriormente, sendo que as empresas procuram se proteger da transferência de seus investimentos em capital humano para outras empresas. Desta forma, os investimentos no desenvolvimento de competências genéricas são incorridos pelos trabalhadores e os investimentos em treinamento específico da empresa são incorridos pela empresa (BECKER, 1964; FLAMHOLTZ; LACEY, 1981; SCHULTZ, 1961, LEPAK; SNELL, 1999).

A teoria do capital humano defende a ideia de que o conhecimento fornece aos indivíduos aumentos em suas habilidades cognitivas e leva a um aumento na produtividade e eficiência nas atividades (DAVIDSSON; HONIG, 2003). Wiklund e Shepherd (2008) destacaram que o capital humano, voltado para o conhecimento e desenvolvimento de habilidades, ajudou as empresas a se engajarem com êxito em novos mercados estrangeiros. Ruzzier et al. (2007) afirmam que o capital humano representa um investimento na educação e no desenvolvimento em habilidades específicas, melhorando as capacidades das empresas como um todo. De forma semelhante, mas ligeiramente diferente em 
termos de expressão, Sturman, Walsh e Cheramie (2008) referem-se ao capital humano como recursos intangíveis pessoais incorporados aos indivíduos (empresários e gestores) que desenvolveram através da educação, formação e experiência, e está intimamente ligada ao know-how. Ambas as obras parecem convergir em um conceito que associa o capital humano às habilidades desenvolvidas através da educação e experiência. Uma revisão da literatura realizada por Sousa et al. (2008) revelou que a educação gerencial e a experiência internacional de fato afetaram o desempenho das empresas em mercados de exportação.

O capital humano é um importante fator de crescimento econômico (NOVAK; BOJNEC, 2005). A aquisição de capital humano melhora as condições para um indivíduo agir de novas maneiras (COLEMAN, 1990). Quando as oportunidades são economicamente rentáveis para novas atividades, o indivíduo com um nível mais elevado de capital humano deve ser melhor na identificação e desenvolvimento destas oportunidades. Uma vez que se dedicam ao processo de internacionalização, esses indivíduos também devem ter uma capacidade superior para explorar essas oportunidades (DAVIDSSON; HONIG, 2003; RUZZIER et al., 2007).

Rauch e Rijsdijk (2013) confirmam que o capital humano pode ser aplicado em diferentes contextos e aumenta os custos de oportunidade. Estas premissas levaram à conclusão de que o capital humano deve estar positivamente relacionado ao sucesso da empresa. Os pesquisadores concluem que o maior nível de educação aumenta a crença de que os esforços empresariais irão gerar o resultado desejado (MANOLOVA et al., 2007). Portanto, a educação formal contribui significativamente para o aumento da produtividade e do acúmulo de conhecimentos e habilidades.

De acordo com a visão baseada em recursos (RBV), o capital humano é o único inimitável e específico recurso da empresa que contribui para a obtenção da vantagem competitiva para empresa. Portanto, o capital humano, como recurso específico de uma empresa, é visto como fator de impacto sobre o crescimento da empresa e o potencial gerador de rendas para as empresas (GREENE et al., 2001). O crescimento da empresa oferece sustentação para a internacionalização e os conceitos de internacionalização e crescimento são vistos como inter-relacionados (BUCKLEY; GHAURI, 1993). Portanto, os recursos humanos parecem ser dos 
mais importantes recursos na internacionalização das PMEs. Desta forma, o capital humano tem importância fundamental para o reconhecimento e a exploração de ambas as oportunidades de negócios nacionais e internacionais (CERRATO; PIVA, 2012).

Análises empíricas que incluem o capital humano gerencial frequentemente usam indicadores tais como experiência, educação e reconhecimento de oportunidade internacional do gestor ou CEO das PMEs. Desta forma, algumas pesquisas sobre internacionalização apresentam uma conexão entre as características gerenciais tais como as experiências dos gestores (um dos componentes do capital humano) e a atuação internacional das empresas. (ANDERSON; EVERS, 2015).

Em outros estudos apresentam o efeito positivo da educação e da experiência internacional na internacionalização da empresa (ATHANASSIOU; NIGH, 2002; HERRMANN; DATTA, 2005). Além disso, pesquisas sobre exportação também fornecem suporte para a proposição de que a experiência internacional prévia de gerentes de exportação, e, portanto, o capital humano, é um indicador de internacionalização das PMEs, influenciando o envolvimento da empresa em atividades de exportação e posteriores atividades internacionais (IBEH; YOUNG, 2001).

Como argumentado por Armario et al. (2008), a experiência torna-se um fator crucial para fomentar atividades inovadoras e, portanto, a estratégia de internacionalização das PMEs, visto que pode reduzir o nível de incerteza e de riscos relacionados à tomada de decisões no mercado externo. Alguns estudos confirmam a ligação entre internacionalização e inovação, ligação na qual os recursos humanos são suscetíveis ao comportamento de ser crítico para o sucesso das PMEs.

Omri e Becuwe (2014) enfatizam que muitos estudos na literatura sugerem que as empresas com grau mais elevado de capital humano alcançarão maior desempenho organizacional por causa de seus gestores com vasta experiência e elevados níveis educacionais. Além disso, o capital humano é importante para o crescimento do empreendimento e para explorar melhores oportunidades empresariais. Em relação à internacionalização, o capital humano significa as habilidades, talento, educação e experiência voltadas para criação de valor para a empresa. 
Vários estudos apresentaram uma ligação entre internacionalização e os recursos humanos, dando a ideia de serem críticos tais recursos. Pesquisas feitas em economias desenvolvidas forneceram evidências empíricas da relação positiva entre capital humano e a internacionalização das PMEs (WESTHEAD et al. 2001; HERRMANN; DATTA, 2005). Algumas pesquisas sobre exportação também têm mostrado o suporte à ideia de que a experiência internacional prévia de gerentes de exportação, que é uma dimensão do capital humano em diversos estudos, tem dado rumo para a internacionalização das PMEs, influenciando seu envolvimento em atividades de exportação, sendo a exportação uma das formas de entrada no mercado estrangeiro (IBEH; YOUNG, 2001).

O Quadro 1 apresenta as relações entre o capital humano e a internacionalização das PME.

\begin{tabular}{|c|c|c|c|c|}
\hline $\begin{array}{c}\text { Capital } \\
\text { Humano }\end{array}$ & $\begin{array}{c}\text { Os } \\
\text { principais } \\
\text { fatores }\end{array}$ & $\begin{array}{c}\text { Relações com } \\
\text { internacionalização }\end{array}$ & $\begin{array}{c}\text { Fatores que } \\
\text { contribuem para } \\
\text { internacionalização }\end{array}$ & Autores \\
\hline $\begin{array}{c}\text { Capital } \\
\text { Humano } \\
\text { Geral }\end{array}$ & Educação & $\begin{array}{l}\text { A educação do } \\
\text { empreendedor nos campos } \\
\text { econômicos e de gestão está } \\
\text { positivamente relacionada à } \\
\text { internacionalização. }\end{array}$ & $\begin{array}{l}\text { Os anos de graduação } \\
\text { e pós-graduação nos } \\
\text { campos econômicos e } \\
\text { gerenciais }\end{array}$ & $\begin{array}{l}\text { Javalgi; } \\
\text { Todd } \\
(2011) ; \\
\text { Evald et al. } \\
(2011)\end{array}$ \\
\hline & $\begin{array}{c}\text { Experiência } \\
\text { Internacional }\end{array}$ & $\begin{array}{l}\text { O empreendedor com mais } \\
\text { experiência internacional (ou } \\
\text { a equipe de gestores), mais } \\
\text { cedo inicia expansão } \\
\text { internacional de empresa. }\end{array}$ & $\begin{array}{l}\text { Habilidades em } \\
\text { negócios } \\
\text { internacionais }\end{array}$ & $\begin{array}{l}\text { Reuber, } \\
\text { Fischer } \\
\text { (1997); } \\
\text { Manolova } \\
\text { et al. (2002); } \\
\text { Ruzzier et } \\
\text { al. } \\
\text { (2007); } \\
\text { Javalgi; } \\
\text { Todd } \\
\text { (2011); } \\
\text { Evald et al. } \\
\text { (2011) }\end{array}$ \\
\hline & $\begin{array}{c}\text { Experiência } \\
\text { Internacional }\end{array}$ & $\begin{array}{l}\text { A experiência internacional } \\
\text { é positivamente relacionada } \\
\text { com a internacionalização }\end{array}$ & $\begin{array}{l}\text { Habilidades com } \\
\text { culturas diferentes; } \\
\text { facilidade de } \\
\text { negociação }\end{array}$ & $\begin{array}{l}\text { Fernández- } \\
\text { Ortiz; } \\
\text { Lombardo } \\
(2009) ; \\
\text { Suárez- } \\
\text { Ortega; } \\
\text { Álamo-Vera } \\
(2005)\end{array}$ \\
\hline & $\begin{array}{l}\text { Conhecimen } \\
\text { to de línguas } \\
\text { estrangeiras }\end{array}$ & $\begin{array}{l}\text { O conhecimento de línguas } \\
\text { estrangeiras é positivamente } \\
\text { relacionado com a } \\
\text { internacionalização }\end{array}$ & $\begin{array}{l}\text { Habilidades com } \\
\text { culturas diferentes; } \\
\text { facilidade de } \\
\text { negociação, } \\
\text { facilidade de } \\
\text { comunicação }\end{array}$ & $\begin{array}{l}\text { Fernández- } \\
\text { Ortiz; } \\
\text { Lombardo } \\
(2009) ; \\
\text { Suárez- } \\
\text { Ortega; } \\
\text { Álamo-Vera } \\
(2005)\end{array}$ \\
\hline
\end{tabular}




\begin{tabular}{|c|c|c|c|c|}
\hline & $\begin{array}{l}\text { Orientação } \\
\text { internacional }\end{array}$ & $\begin{array}{l}\text { A orientação internacional } \\
\text { do empreendedor (ou a } \\
\text { equipe de gestores) é } \\
\text { positivamente relacionada } \\
\text { com a internacionalização }\end{array}$ & $\begin{array}{l}\text { Distância psíquica } \\
\text { para mercados } \\
\text { estrangeiros, } \\
\text { proficiência em } \\
\text { línguas estrangeiras, } \\
\text { viagens para o } \\
\text { exterior, tolerância ao } \\
\text { risco }\end{array}$ & $\begin{array}{l}\text { Manolova et } \\
\text { al. } \\
(2002)\end{array}$ \\
\hline \multirow[t]{3}{*}{$\begin{array}{l}\text { Capital } \\
\text { humano } \\
\text { específic } \\
\text { o }\end{array}$} & $\begin{array}{l}\text { Experiência } \\
\text { específica na } \\
\text { indústria }\end{array}$ & $\begin{array}{l}\text { Experiência de trabalho } \\
\text { específico prévia na } \\
\text { indústria está relacionada } \\
\text { positivamente à } \\
\text { internacionalização; } \\
\text { experiência de trabalho em } \\
\text { outras indústrias não } \\
\text { contribui para a } \\
\text { internacionalização }\end{array}$ & $\begin{array}{l}\text { Conhecimento } \\
\text { específico na } \\
\text { indústria }\end{array}$ & $\begin{array}{l}\text { Westhead et } \\
\text { al. } \\
(2001)\end{array}$ \\
\hline & $\begin{array}{l}\text { Experiência } \\
\text { anterior } \\
\text { como } \\
\text { empregado }\end{array}$ & $\begin{array}{l}\text { Experiência prévia como } \\
\text { empregado está } \\
\text { positivamente relacionada à } \\
\text { identificação e exploração } \\
\text { de oportunidades de } \\
\text { negócios no exterior }\end{array}$ & $\begin{array}{l}\text { Habilidades } \\
\text { gerenciais, reputação } \\
\text { reforçada, melhor } \\
\text { acesso para financiar } \\
\text { e em instituições } \\
\text { obtidos por meio de } \\
\text { redes de contato com } \\
\text { outras empresas }\end{array}$ & $\begin{array}{l}\text { Wright et al. } \\
(2007)\end{array}$ \\
\hline & $\begin{array}{l}\text { Experiência } \\
\text { anterior em } \\
\text { gestão de } \\
\text { negócios }\end{array}$ & $\begin{array}{l}\text { A experiência anterior em } \\
\text { gestão pode não ter sido } \\
\text { associada ao sucesso } \\
\text { internacional (se a } \\
\text { experiência anterior foi } \\
\text { obtida em empresa de } \\
\text { grande porte) }\end{array}$ & $\begin{array}{l}\text { Habilidades } \\
\text { gerenciais }\end{array}$ & $\begin{array}{l}\text { Wright et al. } \\
(2007)\end{array}$ \\
\hline
\end{tabular}

Quadro 1: Relações entre a teoria do capital humano e a internacionalização das PME Fonte: Adaptado de Ruzzier et al. (2007)

O Quadro 1, adaptado de Ruzzier et al. (2007), resume as principais conclusões de trabalhos que consideram as relações entre a teoria do capital humano e a internacionalização das pequenas e médias empresas. Portanto, observa-se que o capital humano, tanto do empreendedor quanto dos gestores, pode contribuir positivamente para a internacionalização das PMEs. Desta forma, o capital humano é visto como um recurso estratégico fundamental e possível fonte de internacionalização de pequenas e médias empresas.

Nesta tese o capital humano é um construto formado pelo nível de educação formal, experiência internacional e a proficiência em línguas estrangeiras do decisor de pequenas e médias empresas, sendo apresentado o impacto destes fatores na propensão ao risco do decisor, no grau de internacionalização e na velocidade de internacionalização da PME. 


\section{4. \\ Capital social}

Gao, Sung e Zhang (2011) afirmam que o "capital social foi um conceito desenvolvido originariamente na Sociologia e agora tem sido amplamente utilizado em muitas outras disciplinas (tais como contabilidade, economia, comportamento organizacional, ciência política etc.), referindo-se às conexões dentro e entre redes sociais, bem como conexões entre os indivíduos”. De acordo com Nahapiet e Ghoshal (1998), a definição de capital social é: "a soma dos recursos reais e potenciais incorporados, dentro de e derivado de uma rede de relacionamentos, possuídas por uma unidade individual ou social”. Segundo Bastié, Cieply e Cussy (2013) o “capital social refere-se a redes de relacionamentos nas quais os contatos pessoais e organizacionais são intimamente incorporados".

O conceito de capital social tornou-se cada vez mais popular em diversas de disciplinas das ciências sociais. Um número crescente de economistas, cientistas políticos e sociólogos têm invocado o conceito de capital social na busca de respostas para diversas questões, sendo confrontados em seus próprios campos. $\mathrm{O}$ capital social pode ser entendido mais ou menos como a boa vontade que é decorrente das redes de relações sociais e que pode ser mobilizada para facilitar o acesso à informação, ao estudo das famílias, aos problemas de comportamento da juventude, escolarização e educação, saúde pública, vida comunitária, democracia e governança, desenvolvimento econômico e problemas gerais de ação coletiva (JACKMAN; MILLER, 1998; PORTES; SENSENBRENNER, 1993; WOOLCOCK, 1998; ADLER; KWON, 2002).

A amplitude do conceito de capital social reflete uma característica primordial da vida social que são os tipos de laços sociais (por exemplo, amizade) que muitas vezes pode ser usado para fins diferentes (por exemplo, apoio moral e material, trabalho e conselhos). Coleman (1988) definiu isto como apropriação da estrutura do capital social. Isto é, a apropriação legítima de uma estratégia conceitual para trazer a noção de muito do que tem sido estudado sobre os conceitos de organização informal, confiança, cultura, apoio social, suporte social, recursos sociais, contratos relacionais, redes sociais e redes entre empresas (ADLER; KWON, 2002). 
O capital social, em sua forma contemporânea, foi identificado primeiro como tal por Jane Jacobs, em 1961, por Pierre Bourdieu e Jean-Claude Passeron, em 1970, e por Glenn Loury em 1977. Desde então, foi desenvolvido mais extensivamente por James Coleman (1988), Ronald Burt (1990), Robert Putnam (1995) e Alejandro Portes (1993), assumindo uma grande variedade de significados. O termo tem sido citado em um número rapidamente crescente de estudos sociais, estudos políticos e econômicos, mas como tantas vezes acontecem com promissores novos termos nas ciências sociais, com limitada atenção crítica, sendo dada a sua história intelectual ou seu estatuto ontológico e conceitual. Essas aplicações indiscriminadas do capital social e de outros capitais são parte do que é depreciativamente referido por Baron e Hannon (1997) como o recente surgimento de 'uma infinidade de capitais sociológicos'. Eles começaram referindo-se a praticamente todas as características da vida social como uma forma de capital e apontaram que, no caso do capital social, várias deficiências teóricas e empíricas emergem como resultado (WOOLCOCK, 1998).

A expressão "capital social” foi utilizada para um propósito muito diferente das propostas econômicas de Alfred Marshall e John Hicks, que iam ao sentido de distinguir entre estoques de capital físico temporário e permanente - embora a ideia de que as normas de cooperação eram necessárias para guiar a mão invisível de transações comerciais. Mesmo aqui, no entanto, como Hirschman (1977) e, mais recentemente, Platteau (1991) têm mostrado que havia considerável ambivalência.

Os recursos disponíveis para atores em uma rede de relacionamentos são conhecidos também por capital social (ADLER; KWON, 2002). Isto significa que os laços sociais entre os indivíduos podem ser usados para uma variedade de finalidades que pode resultar em benefícios para os atores dentro da rede (ADLER; KWON 2002; NAHAPIET; GHOSHAL, 1998). Burt (1992) argumenta que o capital social, ao invés de capital humano ou financeiro, é o fator mais significativo, contribuindo para o sucesso competitivo em todos os tipos de empresas (KONTINEN; OJALA, 2011). 
O capital social é dinâmico, uma vez que muda ao longo do tempo (LARSON; STARR, 1993). Pode aumentar ou diminuir à medida que as empresas aprofundam as relações existentes, estabelecem novos contatos e solucionam problemas relacionados à competição no mercado (RAUCH, 2001). No entanto, o capital social não é um "recurso universalmente benéfico" (NAHAPIET; GHOSHAL, 1998). Uma rede fechada pode limitar o acesso do grupo a novas informações e novas maneiras de fazer as coisas, levando à diminuição do desempenho da empresa. O capital social em uma rede com menos empresas fica mais exposto ao comportamento oportunista e é mais difícil para se construir relacionamentos de longo prazo (WALKER et al., 1997, KONTINEN; OJALA, 2011).

Vários pesquisadores argumentaram que a dimensão estrutural do capital social se refere ao padrão de conexões entre atores e a dimensão relacional se refere aos recursos atingíveis através da dimensão estrutural, tais como confiança e confiabilidade. Em estudos sobre as relações externas, em outras palavras, uma ligação distante ou "fraca" do capital social, o foco está nas relações que um ator mantém com atores fora da sua rede de contatos (ADLER; KWON, 2002). Em estudos sobre os laços entre atores dentro de uma comunidade, o foco está na capital social interno ou ligação próxima ou "forte" (ADLER; KWON, 2002; YLI-RENKO et al., 2002, KONTINEN; OJALA, 2011; LEVY et al., 2013).

A teoria do capital social, atualmente, enfatiza a importância das redes sociais, desenvolvidas por comunidades e redes de relações organizacionais (DAVIDSSON; HONIG, 2000). Apesar de existirem definições diferentes na literatura em gestão de negócios, Korsakiene et al. (2014) adotam a visão de que o capital social "é a soma dos recursos reais e potenciais incorporados, disponibilizados e derivados da rede de relacionamentos obtidos por meio de uma unidade individual ou social". A teoria do capital social está fundamentada na teoria das redes sociais e deve ser considerada em nível do indivíduo e em nível de empresa. Além disso, as redes sociais permitem que os decisores desenvolvam recursos críticos e necessários para o crescimento da empresa. 
Os estudiosos distinguem diferentes aspectos do capital social. A confiança, a credibilidade e as dimensões cognitivas são possíveis componentes do capital social (JOHANSON; VAHLNE, 2006). Johanson e Vahlne (2006) adotaram a visão que esses ativos de capital social não podem ser explorados individualmente e são compartilhados pelos parceiros que pertencem à rede de empresas.

O Quadro 2 apresenta as relações entre a teoria do capital social e a internacionalização das PME.

\begin{tabular}{|c|c|c|c|c|}
\hline $\begin{array}{l}\text { Capital } \\
\text { Social }\end{array}$ & $\begin{array}{l}\text { Os principais } \\
\text { fatores }\end{array}$ & $\begin{array}{c}\text { Relações com } \\
\text { internacionalização }\end{array}$ & $\begin{array}{c}\text { Fatores que } \\
\text { contribuem para } \\
\text { internacionalização }\end{array}$ & Autores \\
\hline $\begin{array}{l}\text { Capital } \\
\text { Social } \\
\text { Interno }\end{array}$ & $\begin{array}{l}\text { Qualidade das } \\
\text { relações entre } \\
\text { os indivíduos } \\
\text { dentro de uma } \\
\text { empresa }\end{array}$ & $\begin{array}{l}\text { Contribui positivamente } \\
\text { para o crescimento } \\
\text { internacional. }\end{array}$ & $\begin{array}{l}\text { Laços fortes versus } \\
\text { laços fracos. } \\
\text { Ligações distantes } \\
\text { versus ligações } \\
\text { próximas. }\end{array}$ & $\begin{array}{l}\text { Yli-Renko et } \\
\text { al. } \\
\text { (2002); Levy } \\
\text { et al. (2013) }\end{array}$ \\
\hline \multirow[t]{6}{*}{$\begin{array}{l}\text { Capital } \\
\text { Social } \\
\text { Externo }\end{array}$} & $\begin{array}{l}\text { Contatos de } \\
\text { gestão }\end{array}$ & $\begin{array}{l}\text { Laços de gestão mais } \\
\text { fortes contribuem } \\
\text { positivamente para o } \\
\text { crescimento } \\
\text { internacional. }\end{array}$ & $\begin{array}{l}\text { Número de laços } \\
\text { fortes versus laços } \\
\text { fracos. } \\
\text { Número de laços } \\
\text { fortes versus laços } \\
\text { fracos }\end{array}$ & $\begin{array}{l}\text { Yli-Renko et } \\
\text { al. } \\
\text { (2002) Levy } \\
\text { et al. (2013) }\end{array}$ \\
\hline & $\begin{array}{l}\text { Envolvimento } \\
\text { com clientes }\end{array}$ & $\begin{array}{l}\text { Laços mais fortes com } \\
\text { clientes contribuem } \\
\text { positivamente para o } \\
\text { crescimento } \\
\text { internacional }\end{array}$ & $\begin{array}{l}\text { Número de laços } \\
\text { fortes versus laços } \\
\text { fracos }\end{array}$ & $\begin{array}{l}\text { Yli-Renko et } \\
\text { al. } \\
(2002)\end{array}$ \\
\hline & $\begin{array}{l}\text { Envolvimento } \\
\text { com } \\
\text { fornecedores }\end{array}$ & $\begin{array}{l}\text { Laços mais fortes com } \\
\text { fornecedores contribuem } \\
\text { positivamente para o } \\
\text { crescimento } \\
\text { internacional }\end{array}$ & $\begin{array}{l}\text { Número de laços } \\
\text { fortes versus laços } \\
\text { fracos }\end{array}$ & $\begin{array}{l}\text { Yli-Renko et } \\
\text { al. } \\
(2002)\end{array}$ \\
\hline & $\begin{array}{l}\text { Experiência } \\
\text { anterior na } \\
\text { formação de } \\
\text { capital social }\end{array}$ & $\begin{array}{l}\text { Laços obtidos por } \\
\text { relacionamento anterior } \\
\text { contribuem } \\
\text { positivamente para o } \\
\text { acúmulo de } \\
\text { conhecimento do } \\
\text { mercado internacional }\end{array}$ & $\begin{array}{l}\text { Número de laços } \\
\text { fortes versus laços } \\
\text { fracos obtidos } \\
\text { anteriormente }\end{array}$ & $\begin{array}{l}\text { Chetty, } \\
\text { Campbell- } \\
\text { Hunt (2003), } \\
\text { Han } \\
(2006)\end{array}$ \\
\hline & $\begin{array}{l}\text { Fontes de } \\
\text { informações }\end{array}$ & $\begin{array}{l}\text { Obtenção de informações } \\
\text { que pode levar a empresa } \\
\text { a se internacionalizar }\end{array}$ & $\begin{array}{l}\text { Tipos de fontes: } \\
\text { clientes, fornecedores, } \\
\text { governo e empresas } \\
\text { da rede de contatos. }\end{array}$ & $\begin{array}{l}\text { Levy et al. } \\
\text { (2013); } \\
\text { Felzensztein } \\
\text { et al (2015) }\end{array}$ \\
\hline & $\begin{array}{l}\text { Tipo de } \\
\text { relações }\end{array}$ & $\begin{array}{l}\text { Com quais atores o } \\
\text { gestor se relaciona para } \\
\text { internacionalizar a } \\
\text { empresa. }\end{array}$ & $\begin{array}{l}\text { Tipos de relações: } \\
\text { associações nacionais } \\
\text { e internacionais, } \\
\text { contatos no exterior, } \\
\text { instituições formais } \\
\text { no exterior. }\end{array}$ & $\begin{array}{l}\text { Hoang e } \\
\text { Antonicic } \\
\text { (2003); Evald } \\
\text { et al. (2011); } \\
\text { Bastié et al. } \\
\text { (2013). }\end{array}$ \\
\hline
\end{tabular}

Quadro 2: Relações entre a teoria do capital social e a internacionalização das PME Fonte:

Adaptado de Levy et al (2013). 
O Quadro 2, adaptada de Levy et al. (2013), resume as principais conclusões de trabalhos que consideram as relações entre o capital social e a internacionalização das PMEs. Observa-se, por meio da literatura científica, que o capital social é visto como uma fonte importante para a internacionalização das PMEs. Por outro, lado a natureza dinâmica do capital social não permite explicar o êxito internacional em longo prazo das PMEs, podendo ser considerado um recurso insuficiente para o melhor desempenho das PMEs como um todo. 


\section{3 \\ Modelo conceitual e hipóteses do estudo}

Nesta seção são apresentados o modelo conceitual teórico e as hipóteses geradas pela revisão da literatura referentes ao impacto da idade, capital humano, capital social, propensão ao risco e a percepção de risco do gestor sobre a velocidade de internacionalização (em termos de precocidade e de crescimento do volume de vendas internacionais) e o grau de internacionalização (em termos de abrangência e de profundidade).

A Figura 1 apresenta o modelo conceitual teórico.

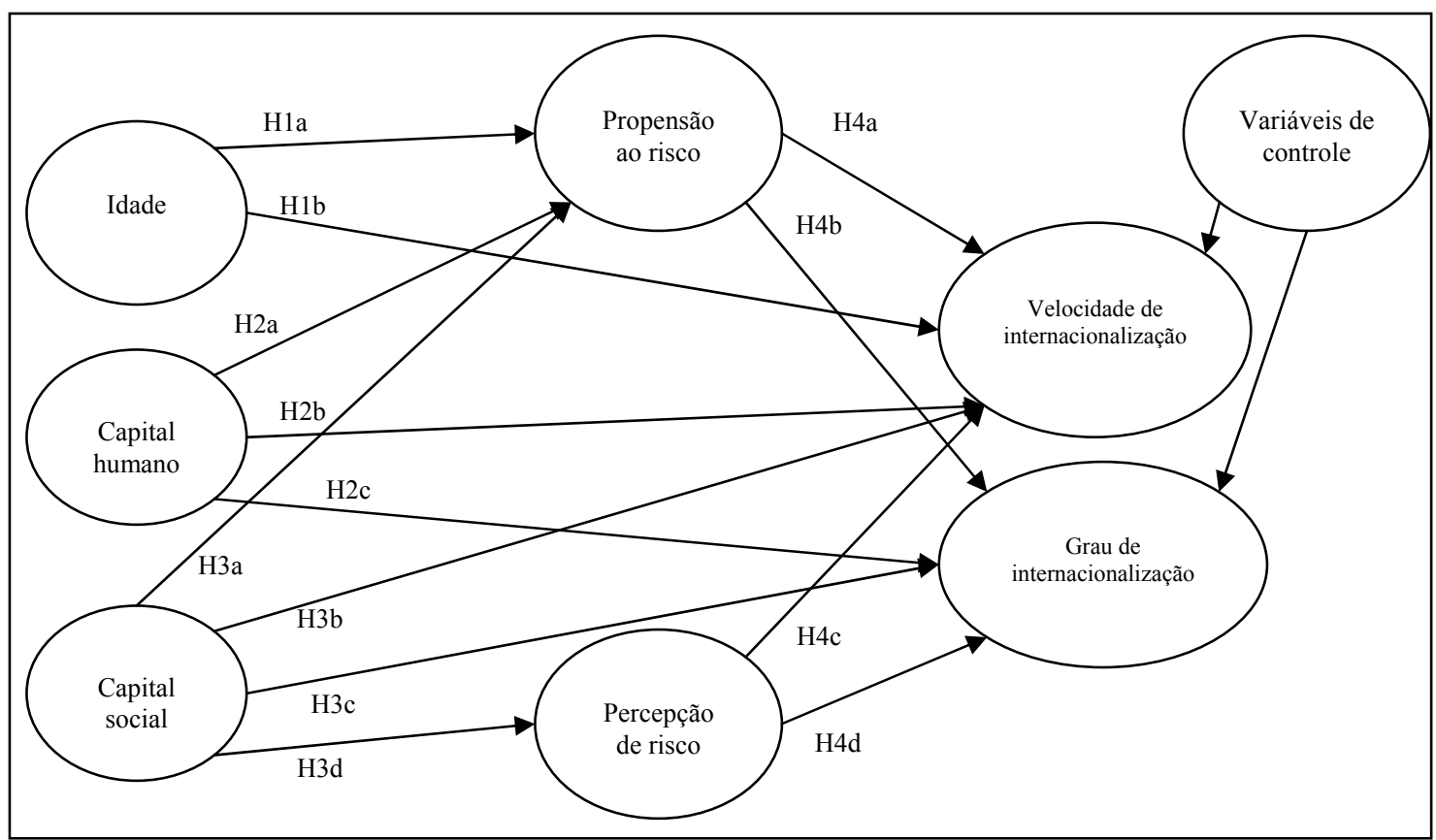

Figura 1: Modelo conceitual teórico

Fonte: Própria

A seguir são apresentadas as hipóteses do modelo conceitual teórico proposto. 


\section{1. O impacto da idade do decisor na propensão ao risco}

A pesquisa Hambrick e Mason (1984) indica que a idade influencia a tomada de decisão estratégica. A idade pode ser considerada tanto um proxy para o grau de experiência e um sinal da propensão de uma pessoa para correr risco. A literatura sobre a influência do alto escalão (HAMBRICK; MASON, 1984) sugere que a juventude está associada com maior propensão ao risco. Os executivos mais velhos são tipicamente menos propensos ao risco, exibindo uma preferência para maior segurança financeira e profissional do que os executivos mais jovens e tendem a evitar empreendimentos mais arriçados (HERMANN; DATTA, 2005).

Alguns autores (DICHTL; KOEGLMAYR; MUELLOR, 1990; HERMANN; DATTA, 2005; KARAMI; ANALOUI; KAKABADSE, 2006) argumentam que decisores mais jovens se mostram mais flexíveis e possuem maior capacidade para processar muitas informações, além de terem maior propensão aos riscos existentes nas mudanças e na diversificação internacional, sendo, portanto, mais propensos a influenciar as decisões estratégicas mais arriscadas como o processo de internacionalização de uma empresa. (FERNÁNDEZ-ORTIZ; LOMBARDO, 2009).

O decisor jovem tende a ser mais orientado para o risco e mais associado a políticas de crescimento da empresa (CHILD, 1975). A exportação requer considerável quantia de energia sendo, portanto, associada ao decisor jovem. Percebe-se que o decisor mais velho se importa mais com a segurança de sua carreira e pode ser menos agressivo, sendo menos propenso ao risco associado com a exportação (CAUGHEY; CHETTY, 1994; SERRA et al., 2012).

A idade da pessoa que toma decisões sobre questões internacionais é importante para o desenvolvimento da empresa. Os jovens são mais inclinados a tomar decisões arriscadas, porque sua aversão ao risco é menor. Os mais jovens tem perspectivas inovadoras e contribuem com ideias menos tradicionais e mais originais. No entanto, os jovens tem menos experiência, e pode não saber agir em situações difíceis e de elevado níveis de risco. (BURILLO; MORENO, 2013). 
A maneira como os jovens são educados desde tenra idade e as habilidades transferíveis que desenvolvem durante seu ensino superior estão relacionadas com características geralmente associadas com comportamento empreendedor (CASSON, 1982; GIBB, 1996; RONSTADT, 1985). A idade do decisor é um fator importante que influencia como o empreendedor lida com a start-up e o crescimento do negócio (HATCH; DYER, 2004), proporcionando a criação de um quadro cognitivo que facilita o reconhecimento de padrões e contribui para a gestão dos riscos associados ao comportamento empreendedor. Desta forma o decisor mais jovem tende a ser mais propenso ao risco na internacionalização da start-up. (ALTINAY; WANG, 2011).

Andersson (2000); Westhead, Ucbasaran e Wright (2001) afirmam que as habilidades, competências, relacionamentos e o ganho de experiência dos decisores podem influenciar a decisão de entrar em mercados estrangeiros. (FERNÁNDEZ-ORTIZ; LOMBARDO, 2009). Tal constatação é devido ao fato de que decisores mais velhos têm maior experiência de negócios e, portanto, eles estarão dispostos a correr certos riscos, que os decisores mais jovens não terão, desde que eles tenham experimentado situações semelhantes no passado, sendo assim, capazes de prever possíveis resultados da sua decisão. (PAVIC; VOJINIC, 2012).

Ursic e Czinkota (1989) encontraram que a idade do decisor é negativamente relacionada com a propensão ao risco e intensidade de exportação. É possível que quando uma pessoa fique mais velha se torna mais conservadora. Isto remete ao estereótipo comum de que decisores jovens são impacientes em comparação com os mais velhos. Essa crença é baseada no pressuposto em que se uma pessoa assume riscos, geralmente ela tem ideia de que pode acabar mal, uma pessoa mais velha tem menos oportunidade de começar de novo, enquanto uma pessoa jovem tem muito tempo para tentar de novo. Vários estudos têm mostrado que quanto maior a idade menor é a propensão ao risco do gestor. (KOGAN; WALLACH, 1964, MACCRIMMON; WEHRUNG, 1986; PAVIC; VOJINIC, 2012). 
Fernández-Ortiz; Lombardo (2009) encontraram "suporte empírico para confirmar que idade do decisor foi negativamente correlacionada com os níveis de diversificação internacional das PMEs". Em resumo, os resultados obtidos por estes autores revelaram uma relação negativa entre a idade do decisor e o nível de diversificação internacional das PMEs estudadas. Para estes autores, "isto sugere que quanto mais jovens os decisores de PMEs internacionalizadas, mais provável que estes decisores venham a empreender estratégias de diversificação de mercado mais ativas no exterior.” (FERNÁNDEZ-ORTIZ; LOMBARDO, 2009, p. 143). Além disso, os decisores mais jovens podem ser mais propensos a assumir riscos e aceitar novos projetos de investimento para conduzir seu crescimento e o crescimento da PME em mercados estrangeiros. (FERNÁNDEZORTIZ; LOMBARDO, 2009).

No estudo de Serra et al. (2012) foi avaliado se idade do decisor é uma variável que influencia propensão de risco na exportação. O primeiro grupo incluíam os decisores com 35 anos de idade ou menos. O segundo grupo consistia de decisores entre 36 e 50 anos de idade. O último grupo incluía os decisores que tinham mais de 50 anos de idade. As evidências empíricas deste estudo não apresentaram nenhuma relação entre a idade média e propensão à exportação. Sendo assim a hipótese que empresas com decisores mais jovens têm uma maior propensão ao risco de exportar não foi suportada.

Andersson et al. (2004) encontrou que a idade mais jovem de CEOs explicou por que as pequenas empresas crescem em suas atividades internacionais. Pode haver uma nova geração de CEOs que são educadas em um mundo mais global, com as redes internacionais de estudos e de viagem, e, portanto, podem mais facilmente ver e tirar proveito das oportunidades empresariais em mercados estrangeiros. Estes empreendedores são mais proativos e propensos a assumir riscos no processo de internacionalização, enquanto os técnicos focam no desenvolvimento de tecnologia.

Felício (2013) descobriu por meio de seu estudo que os gestores jovens com uma predisposição para risco destacam-se na indústria de alimentos e indústria têxtil portuguesa. Neste caso, eles investiram particularmente o desenvolvimento de produtos existentes, novos mercados geográficos e canais de distribuição. Também nesta indústria, os gestores jovens concentraram seus investimentos nos produtos ou linhas de produtos, pesquisa e marketing. Os gestores mais jovens 
tem maior propensão ao risco de investir em produtos ou linhas de produtos novos para diversificar seu mercado no exterior.

MacCrimmon e Wehrung (1986) analisaram a influência de certas características socioeconômicas na propensão ao risco, como a idade do gestor. Os resultados sugerem que gerentes mais velhos são mais avessos ao risco em comparação com os gerentes mais jovens. Este estudo também mostrou que os gerentes com maior autoridade são mais propensos ao risco. Gerentes com maior antiguidade na empresa são mais avessos ao risco do que os gerentes com menor antiguidade e gerentes de grandes empresas são mais avessos ao risco do que gerentes de médias empresas. $\mathrm{O}$ estudo mostrou que os gerentes mais bem sucedidos assumem mais riscos quando comparado aos gerentes menos bem sucedidos.

Pavic e Vojinic (2012) em um modelo de regressão ordinal encontraram que o coeficiente da variável idade do decisor é negativo, sugerindo que enquanto a idade aumenta, diminui a pontuação na variável dependente ordinal propensão ao risco. Portanto, os resultados empíricos destes autores ressalta uma contradição na existência da relação entre a idade do decisor e a propensão ao risco deste decisor. Para estes autores os gerentes mais velhos têm maior experiência nos negócios e, portanto, eles estarão mais dispostos a tomar certos riscos, que os gerentes mais jovens não estarão.

Segundo Obben e Magagula (2003) pode haver alguma faixa etária dentro da qual a propensão a exportar aumenta com a idade e em algum momento a propensão a exportar pode ter uma queda com a idade. O modelo empírico proposto por Obben e Magagula (2003) mostra que quando a idade do decisor aumenta a probabilidade de uma PME ser uma exportadora também aumenta. Isto sugere que é provável que os decisores mais velhos sejam tomadores de risco maiores em comparação aos gerentes mais jovens, devido a sua maior experiência. Isto significa que os resultados não estão em conformidade com a crença comum que as pessoas mais velhas são avessas aos riscos (OBBEN; MAGAGULA, 2003).

Considerando os argumentos dos estudos descritos anteriormente, pode-se postular que:

$H_{1 a}$ : A idade do gestor apresenta uma relação negativa com sua propensão ao risco. 


\section{2.}

\section{Impacto da idade do decisor na velocidade de internacionalização}

Para Bantel e Jackson (1989) e Camelo-Ordaz et al. (2006), a idade está especificamente associada com inovação. Assim, o comportamento complexo dos gerentes é reflexo de suas características individuais e sua formação, idade e experiência, sendo que o fator idade pode influenciar a formação e a experiência do decisor, levando a internacionalização da empresa de forma precoce quando mais jovens (CAMELO-ORDAZ et al., 2006).

A idade do decisor tem sido apontada como um fator que influencia o comportamento de exportação da empresa, pois decisores mais jovens tendem a pensar de forma mais global e cosmopolita que decisores mais velhos. Além disso, a idade dos decisores está negativamente associada com a tomada de decisão em que há um risco elevado e positivamente associada com a habilidade de analisar novas informações, sendo que estes fatores são requisitos importantes para atividades de exportação (MOON; LEE, 1990; SUÁREZ-ORTEGA; ÁLAMO-VERA, 2005; TAYLOR, 1975; WROON; PAHL, 1971).

Alguns pesquisadores argumentam que empresas com decisores mais jovens tendem a adotar estratégias mais inovadoras, que é o caso das estratégias de internacionalização (FERNÁNDEZ-ORTIZ; LOMBARDO, 2009; HAMBRICK; MASON, 1984; KARAMI 2005). Há ainda autores que argumentam que decisores mais jovens desempenham um papel mais ativo no sentido de fazer a empresa aumentar o volume de exportação (FERNÁNDEZ-ORTIZ; LOMBARDO, 2009; NORBURN; BIRLEY 1988). Além disso, decisores sêniores tendem a ser mais avessos ao risco, se comparado com decisores jovens, sendo que estes decisores jovens propõem estratégias de crescimento mais arriscadas para a empresa (FERNÁNDEZ-ORTIZ; LOMBARDO, 2009; GUTHRIE; OLIAN, 1991). Obben e Magagula (2003) assim como FernándezOrtiz e Lombardo (2009) destacam que decisores sêniores são menos comprometidos com atividades de exportação do que os decisores mais jovens. 
Quando uma PME se internacionaliza precocemente deve aprender a operar em novas configurações institucionais e culturais. Os gestores são necessários para adaptar seus mapas mentais e, consequentemente, as estruturas, sistemas e processos enraizados nestes mapas para adequar a nova configuração internacional (NOHRIA; GHOSHAL, 1994). Portanto, gestores mais velhos, tendo menos resistência física e mental, podem não ser capazes de mudar seus mapas mentais facilmente, resultando em um menor grau de capacidade do que os gestores mais jovens (HERRMANN; DATTA, 2002) no processamento de informações (TAYLOR, 1975). Isso pode limitar a compreensão de culturas estrangeiras, a compreensão do comportamento do consumidor e dos regulamentos locais e pode reduzir os benefícios da rápida internacionalização.

Na PME o poder de decisão, muitas vezes está concentrado nas mãos de uma ou poucas pessoas, e o CEO tem um papel único e influente na organização. A idade do CEO pode refletir a experiência ao longo da vida e a rede pessoal de um indivíduo. Andersson et al. (2004) encontrou que os CEOs mais jovens eram chefes de empresas internacionais. Oviatt e McDougall (1994) apontam que uma visão global vinda desde o início da empresa é, provavelmente, a característica mais importante associada com os gestores e não somente a idade do decisor da born global. (ANDERSSON; FLORÉN, 2011).

O estudo de Chen (2011) mostrou que a idade do time de gestores (decisores) é associada negativamente com a internacionalização da empresa (aumento do volume de vendas). Outros estudos confirmam esta previsão, sugerindo que o time de gestores mais jovens é mais propenso a apoiar a ampliação do mercado da empresa por meio da ida para o exterior mais rápida. Esta constatação pode indicar que tal time de gestores não só têm habilidades superiores na análise, processamento, integração e aprendizagem pela informação, mas também estão mais dispostos a assumir os riscos associados com a rápida internacionalização. (CHEN, 2011).

As conclusões do estudo de Herrmann e Datta (2005) mostram que a idade foi negativamente relacionada com o nível de velocidade de internacionalização, sugerindo que o decisor mais jovem tem prazos relativamente mais curtos, são mais propensos a ser ativo e entusiasmado na procura de oportunidades. Este fenômeno pode ser atribuído ao fato de que decisores mais jovens não só apresentam maior flexibilidade e têm maior capacidade de processamento de 
informações, mas também estão mais dispostos a assumir os desafios e riscos associados ao mercado internacional. (HERRMANN E DATTA, 2005).

O estudo de Suárez-Ortega e Álamo-Vera (2005, p. 271) mostrou que "a idade do decisor é negativamente associada com o nível de desenvolvimento de exportação das PMEs (intenção, propensão, e/ou intensidade). Sendo assim, quanto mais jovem é o decisor, maior é a intensidade, a propensão e a intenção das exportações destas PMEs.

Os resultados do estudo de Evald et al. (2011) mostram que decisores de born globals com mais de 50 anos são mais propensos a promover a exportação precoce destas empresas do que os decisores mais jovens do que 30 , contrariando a premissa de decisores mais jovens tendem a fazer as pequenas empresas exportarem precocemente.

Hsu, Chen e Cheng (2013) constataram um efeito negativo na relação entre a idade e o desempenho internacional vindo do crescimento das vendas internacionais, sugerindo que os decisores mais jovens podem ser superiores aos decisores mais velhos em relação ao desempenho de internacionalização. Por outro lado, a idade do gestor é geralmente correlacionada com sua experiência de trabalho, estabilidade organizacional e conhecimento do setor (TYLER; STEENSMA, 1998), por conseguinte, pode aumentar suas capacidades de processamento de informações. A idade mínima dos decisores entre 36 e 40, sugere que os CEOs podem ter total conhecimento e experiência para lidar com operações internacionais.

A pesquisa de Andersson e Evangelista (2006) mostra que os decisores de empresas que se internacionalizaram precocemente eram jovens e com experiência no setor para poder expandir internacionalmente. No entanto, nem todos os fundadores todos os fundadores das born globals pesquisa tinham experiência profissional anterior. Alguns fundadores eram jovens com pouca experiência, mas com fortes ambições para expandir um negócio próprio. Estes empreendedores tinham a capacidade de cooperar com outros que conheciam sobre como fazer negócios no exterior. (ANDERSSON; EVANGELISTA, 2006). 
Leonidou et al. (1998) avaliaram por meio de uma revisão da literatura a hipótese que a idade do tomador de decisão pode ser inversamente relacionada ao volume de vendas corporativas no exterior, sendo que os decisores mais jovens tem maior potencial para explorar as possibilidades de exportação (URSIC; CZINKOTA 1989). No entanto, a hipótese acima não foi validada pela pesquisa empírica, sendo que dos 17 estudos avaliados com essa variável, apenas cinco revelaram uma relação significativa entre a idade do gestor e o volume de exportação. Especificamente, três estudos encontraram que as empresas exportadoras têm gerentes mais jovens do que as empresas não exportadoras (MCCONNEL 1979; DICBTL et al. 1990); um estudo concluiu que gestores jovens têm maiores possibilidades de influenciar a atividade de exportação durante os estágios iniciais de internacionalização (CAVUSGIL, 1982).

O estudo de Nakos et al. (1998, p. 37), apresenta um resultado na qual destaca que as empresas com decisores mais jovens teriam melhor desempenho internacional. Os coeficientes de regressão mostram relações significativas e negativas para a medida de rentabilidade do desempenho, mas sem relação significativa com a medida de tamanho das vendas. Assim, a hipótese de que as empresas com decisores mais jovens iria realizar um desempenho melhor internacionalmente é apenas parcialmente suportada.

Os resultados de Robson et al. (2012) são em parte semelhantes aos encontrado por Nakos et al. (1998) na qual não houve relação significativa entre a idade dos decisores (idade 31 -45) e o crescimento da exportação. Assim, não há evidências suficientes para apoiar a hipótese que decisores com idade entre $31 \mathrm{e}$ 45 anos são mais propensos a aumentar as vendas no exterior.

O estudo de Manolova et al. (2002) mostrou que a idade do gerente não teve nenhuma influência significativa sobre a atividade de exportação. Este resultado sugere a noção de que a associação entre idade do gerente (juventude) e certas características tais como uma atitude menos conservadora em relação à exportação (TAYLOR, 1975) não foi confirmada. 
Os resultados de Francioni et al. (2015, p. 2238) apresentaram uma relação não significativa entre idade e racionalidade nas atividades envolvendo o crescimento de exportação da empresa. A idade não influencia a racionalidade nas exportações e indica que a idade não é um dos fatores mais relevantes na determinação do comportamento racional no processo de tomada de decisão estratégico internacional.

Considerando os argumentos dos estudos descritos anteriormente, pode-se postular que:

$H_{1 b}$ : A idade do gestor apresenta uma relação negativa com a velocidade de internacionalização da empresa (em termos de precocidade e de crescimento do volume de vendas internacionais).

\section{3.}

\section{Impacto do capital humano na propensão ao risco}

Nesta seção é apresentada a revisão da literatura relativa ao impacto do capital humano em termos de nível de educação formal, experiência internacional e proficiência em línguas estrangeiras sobre a propensão ao risco.

\section{Impacto do nível de educação na propensão ao risco}

A redução das incertezas e riscos associados à diversificação internacional é resultante de um trabalho gerencial mais diversificado e complexo. Consequentemente, as capacidades sociocognitivas dos decisores, relacionadas ao nível de educação formal, ampliam a capacidade de processamento de informação, flexibilidade e a receptividade a novas ideias por parte do decisor, contribuindo para assegurar o sucesso da empresa no contexto internacional (HERRMANN; DATTA, 2005).

Existem estudos que encontraram uma relação positiva entre o nível de educação formal e a propensão ao risco dos decisores (KNIGHT et al., 2003; SCHWER; YUCELT, 1984). De acordo com esses pesquisadores, a educação formal leva a arriscar com confiança, porque o pensamento crítico e raciocínio são competências adquiridas através da educação e ajudam estes indivíduos a melhorarem seu entendimento de que eles sabem mais e preveem com precisão os resultados de suas decisões (ALTINAY; WANG, 2011). 
O nível educacional do decisor tem sido associado com receptividade à inovação e a aceitação de riscos normalmente existentes nas decisões envolvendo estratégias internacionais. Desta forma, o modo de entrada da empresa no mercado internacional normalmente envolve extensa análise de projeto e exige uma avaliação mais precisa dos valores a serem investidos pela empresa, sendo esta tarefa de elevado grau de risco para o decisor, exigindo maior nível de educação (FINKELSTEIN; HAMBRICK, 1996; HERRMANN; DATTA, 2002; KOGUT, 1988).

Níveis mais elevados de educação conduzem a uma maior necessidade de abrangência; no entanto, dada a baixa disponibilidade de recursos nas PMEs, essa necessidade pode comprometer o cumprimento dos objetivos e o desempenho. Níveis mais elevados de educação de indivíduos que desempenham um papel significativo na identificação de riscos, como os decisores, ajudam a esclarecer a situação arriscada (WINCH; MAYTORENA, 2009); portanto, os níveis de aceitação de risco podem ser maiores em indivíduos que possuem níveis mais elevados de escolaridade (JANSEN et al., 2011).

Decisores mais altamente educados têm a capacidade de analisar o conjunto de fatores complexos e aceitar os riscos associados aos modos de entrada envovlvendo maior comprometimento financeiro para a empresa. Por outro lado, os decisores com níveis educacionais mais baixos são mais propensos a optar por modos de entrada de controle compartilhado, que exigem menos processamento de informações e implicam menos risco. Os resultados de pesquisas anteriores (MACCRIMMON; WEHRUNG, 1986, 1990) mostram que os decisores com formação pós-graduada aceitam riscos maiores (são mais propensos ao risco) do que os decisores com apenas um diploma de ensino médio (PAVIC; VOJINIC, 2012).

O estudo de Pavic e Vojinic (2012) mostra que decisores que têm formação universitária aceitam correr maiores riscos (são mais propensos ao risco) em comparação com decisores com ensino médio. Os resultados empíricos de Jansen et al. (2011) são similares, mostrando que o nível de educação formal tem um efeito positivo sobre a eficácia da decisão através da mediação do nível de aceitação de risco, bem como o nível de confiança. Isto significa que os níveis mais elevados de educação levam a decisões que podem beneficiar a empresa pelo 
fato de os decisores serem mais confiantes e dispostos a aceitar os mais elevados níveis de risco.

\section{Impacto da experiência internacional na propensão ao risco}

Como argumentado por Armário et al. (2008) e Omri e Becuwe (2014), a experiência internacional torna-se um fator crucial para fomentar atividades inovadoras e, portanto, a estratégia de internacionalização das PMEs, porque pode reduzir o nível de incerteza e de riscos relacionados à tomada de decisões vinculadas ao mercado externo. Além disto, a experiência internacional pode desempenhar um papel fundamental na descoberta de novas oportunidades de mercado em países estrangeiros e na implementação de atividades inovadoras fora do mercado doméstico através de redes sociais dos decisores, aumentando ainda mais a abrangência do mercado internacional da empresa.

Decisores com mais experiência internacional identificam com maior facilidade as oportunidades de comércio exterior (ZOU; STAN, 1998) e são mais tolerantes a riscos associados à estratégia de exportação (GRAY, 1997), uma vez que a percepção do risco das transações internacionais diminui à medida que aumenta a experiência internacional. Alguns autores argumentam que a experiência acumulada pelos decisores proporciona contatos profissionais desenvolvidos pelos decisores no mercado externo, aumentando as chances de alcançar o crescimento das exportações (REID, 1983), além de enriquecer a capacidade de tomada de decisão com foco nos resultados da empresa. (FERNÁNDEZ-ORTIZ; LOMBARDO, 2009; PLA-BARBER; ESCRIBÁESTEVE, 2006).

Ruzzier et al. (2007) sugerem que o decisor adquire uma perspectiva internacional mais ampla através da experiência internacional, o que aumenta a sua propensão de risco associado à venda em mercados estrangeiros e aumenta o conhecimento de como vender melhor nesses mercados. Além disso, os empreendedores das empresas internacionalizadas conseguem distinguir melhor as competências internacionais. Tais competências empreendedoras são uma combinação de conhecimentos, habilidades e experiências, sendo razoável esperar que os ativos de capital humano sejam importantes para vender mais produtos no exterior. 
As experiências internacionais do decisor inevitavelmente geram um baixo nível de incerteza e risco em torno de atividades de negócios no país estrangeiro. Estes decisores naturalmente trazem sensibilidade e interesse, em outros países, bem como o conhecimento e habilidades, tais como a proficiência em linguagem estrangeira (LIESCH et al., 2011; SIMMONDS; SMITH, 1968). Portanto, os decisores estabelecem e desenvolvem experiência internacional através da participação ativa nos mercados estrangeiros, aumentando o desenvolvimento do comprometimento com a internacionalização (JOHANSON; VAHLNE, 1977, 1990, 2006). Eles direcionam suas empresas através do processo de internacionalização, com uma visão para o futuro, tendo uma resposta rápida em relação aos acontecimentos que se assemelham com o passado, incluindo perspectivas desenvolvidas sobre riscos e incertezas associadas à internacionalização (LIESCH et al., 2011).

Os níveis de aceitação de riscos serão maiores mediante os maiores níveis de experiência porque os decisores sabem o que vai ocorrer e que, com base na sua experiência prévia, podem trabalhar para vencer os desafios a fim de obter maiores níveis de eficácia da decisão. (JANSEN et al., 2011). Os decisores experientes são capazes de avaliar as informações relacionadas à decisão por relacioná-las à experiência anterior e, desta forma, podem elaborar ideias mais complexas e precisas (IEDERAN et al., 2009; SMITH et al., 2009). Isto irá aumentar a confiança dos decisores no processo de decisão, dado que mais conhecimento pode levar a superar dúvidas relacionadas a crenças que impediriam a ação (HEAVEY et al., 2009, p. 1293). Em outras palavras, mais informações e análises aumentam o nível de confiança na decisão tomada, aumentando, assim, a propensão ao risco do decisor (ADIDAM; BINGI, 2000; JANSEN et al., 2011).

Os decisores acreditam que quando eles são mais bem informados e competentes é maior o risco que eles estão dispostos a aceitar, ou maior a confiança nas decisões que comprometerão o alcance de suas metas (HEATH; TVERSKY, 1991; MULLINS; FORLANI, 2005). Além disso, eles também percebem mais oportunidades (ERIKSON, 2002; KRUEGER; DICKSON, 1994). Em conclusão, níveis mais elevados de experiência levam ao aumento das habilidades de processamento de informações, permitindo que os níveis mais elevados de desempenho para o indivíduo (COLEMAN, 1988; KOR; 
SUNDARAMURTHY, 2009) e para a organização (DAVIDSSON; HONIG, 2003; JANSEN et al., 2011).

Desse modo, o nível de aceitação do risco será maior com maior nível de experiência, porque os decisores de certa forma sabem o que vai ocorrer e, com base em sua experiência prévia, podem trabalhar a fim de obterem maiores níveis de eficácia da decisão (JANSEN et al., 2011). Portanto, o decisor com maior experiência é mais propenso ao risco e tende a tomar uma decisão mais eficaz também em relação ao processo de internacionalização da PME, fazendo com que a PME amplie o seu grau de internacionalização, ampliando o número de países em que se estabelecerão e também a velocidade na qual esta ampliação deverá ocorrer (JANSEN et al., 2011).

A experiência internacional do gestor tem uma importante influência na percepção de risco gerencial. Os gerentes com pouca ou nenhuma experiência internacional têm menos habilidades para gerenciar e controlar operações no exterior (CAVUSGIL; NAOR, 1987). A falta de confiança, muitas vezes, contribui para o aumento da percepção dos potenciais riscos associados à diversificação internacional, enquanto subestimam potenciais retornos. Dada a maior confiança em sua habilidade de estimar corretamente os riscos e retornos, gerentes com experiência internacional podem ser mais agressivos ao buscarem recursos na diversificação internacional (HERRMANN; DATTA, 2005). Desta forma, um gestor com nenhuma experiência internacional não conseguirá se relacionar e obter recursos em uma rede de contatos, percebendo riscos elevados nas oportunidades proporcionadas no mercado exterior, e diminuirá ou eliminará a possibilidade de diversificação internacional da empresa até que ganhe confiança para reduzir os riscos envolvidos nessas oportunidades.

Pesquisas anteriores identificaram a experiência internacional dos gestores como uma medida da capacidade da empresa para controlar e gerenciar uma operação internacional, e, assim, influenciar o seu grau de internacionalização (ANDERSON; GATIGNON, 1986; VERNON, 1985). Embora Miller (1992) não inclua a experiência do gestor em seu quadro de gestão integrada de riscos internacionais, a literatura indica que essa experiência tem um impacto direto nas preferências de risco (AHMED et al., 2002) e, assim, na propensão ao risco. A experiência do gestor é tratada pela literatura como um item importante no capital 
humano e, portanto, uma característica importante dos gestores e/ou do empreendedor (ARMARIO et al., 2008).

O resultado do estudo de Jansen et al. (2011) mostra que o nível de experiência tem um efeito negativo sobre a eficácia da decisão através da mediação do nível de propensão ao risco, considerando que tem um efeito positivo do nível de confiança. Sendo assim, se o decisor aceita os baixos níveis de risco sendo mais experiente, terá um impacto negativo sobre a eficácia da decisão. Se o decisor está confiante, níveis mais elevados de experiência tem impacto positivo sobre a eficácia da decisão. Além disso, como destacado por Liesch et al. (2011), a experiência pessoal, incluindo diferentes tipos de envolvimento internacional, pode preparar o decisor de várias formas para as incertezas e riscos a serem enfrentados quando as empresas buscam a internacionalização.

\section{Impacto da proficiência em lingua estrangeira na propensão ao risco}

Alguns gerentes têm um talento que facilita a adoção de exportação nas suas organizações. Tal talento é expresso em termos de interesse na compreensão de culturas estrangeiras, fluência em línguas estrangeiras e uma tendência para socializar com pessoas estrangeiras e um forte interesse em viajar para o exterior. Isso é mais provável de ser encontrado entre os gerentes que aceitavam riscos, inovador e mente aberta (LEONIDOU et al., 1998). Além disso, a proficiência em línguas estrangeiras favorece o conhecimento e manuseio de documentação e procedimentos de exportação, também pode atuar como um estímulo de exportação, diminuindo o risco existente de equívocos na obtenção de informações importantes (LEONIDOU et al., 2007).

As diferenças de idioma, cultura, e leis representa um elevado risco para os parceiros ao tomar decisões em diversas áreas e alternativas (STYLES; AMBLER, 1994; VERWAAL; DONKERS, 2002). Daí, a fim de ser capaz de aumentar a propensão ao risco a intensidade de exportação, o conhecimento em línguas estrangeiras é necessário. As relações internacionais e os seus efeitos podem diferir entre os locais de exportação das empresas, tendo maior risco quando as culturas e idiomas se diferenciam muito, sendo necessário o desenvolvimento das habilidades de línguas estrangeiras dos decisores (STUCK, 2016). 
Morgan (1997) encontraram diferenças na literatura entre o sucesso dos decisores de empresas exportadoras indicando que a proficiência em línguas eram muitas vezes insignificantes. Havia pouca diferença entre as respectivas realizações de exportação dos decisores com proficiência em língua estrangeira exportadores (ou os decisores com interesse em exportar) e os exportadores que não tinham proficiência em língua estrangeira. Muitas vezes estes decisores tinham habilidades de língua estrangeira superior, tinham mais experiência de vida e viajavam mais para o exterior, tinham níveis mais elevados de educação e eram mais avessos ao risco.

Morgan (1997) e Knowles et al. (2006) destacam que decisores com habilidades de língua estrangeira superior, viajam mais para o exterior e, portanto, adquire mais experiência em relação a exportação e foram avessos a riscos quando comparado com decisores que não possuem proficiência em línguas estrangeiras. Além disso, o conhecimento de língua estrangeira também pode fazer com que os contatos pessoais com decisores estrangeiros sejam ampliados, podendo assim, desenvolver uma relação de confiança; que proporciona ao decisor melhor compreensão das práticas de negócios de um país estrangeiro, aumentando a propensão ao risco e melhora das habilidades para uma negociação de sucesso com os estrangeiros (ENDENVICK; AKOORIE, 1994; NAKOS et al., 1998).

Proficiência em língua estrangeira é muito importante nos negócios internacionais. Sem essa proficiência, as transações tornam-se muito difíceis e arriscadas. A proficiência em língua estrangeira pode contribuir para a realização social e contatos de negócios no exterior, melhorar a comunicação e interação com clientes estrangeiros, melhorar a compreensão das práticas de negócios estrangeiros, facilitam o efetivo planejamento e controle das atividades arriscadas de exportação. Isso pode conduzir a uma abordagem mais versátil para as decisões de mercado envolvendo riscos. Os gerentes que possuem habilidades linguísticas são mais propensos a avaliar e assumir riscos existentes nos novos mercados em relação aos demais gerentes que não possuem esta habilidade (WILLIAMS; CHASTON, 2004). Assim, os gerentes com proficiência em língua estrangeira podem ser capazes de alcançar o melhor sucesso na exportação (SOUSA et al., 2008), pois são mais propensos ao risco. 
O estudo de Obben e Magagula (2003) mostrou que a proficiência na língua inglesa dos decisores é um importante determinante da probabilidade de uma PME tornar-se exportadora. Além disso, esses decisores percebem as vendas de exportação como sendo mais arriscadas em comparação com vendas no mercado interno são também aqueles que são mais propensos a se envolver em exportar, sugerindo que os decisores de PMEs exportadores são claramente propensos aos riscos por serem também fluentes na língua inglesa (MAKRINI, 2015).

Considerando os argumentos dos estudos descritos anteriormente, pode-se postular que:

\section{$H_{2 a}$ : $O$ capital humano do gestor apresenta uma relação positiva com} sua propensão ao risco

\section{4.}

\section{Impacto do capital humano no grau de internacionalização}

Nesta seção é apresentada a revisão da literatura relativa ao impacto do capital humano em termos de nível de educação formal, experiência internacional e proficiência em línguas estrangeiras sobre o grau de internacionalização (profundidade e abrangência).

\section{Impacto do nível de educação no grau de internacionalização}

Decisores com nível mais elevado de educação são mais compreensivos e interessados nos assuntos ligados aos mercados externos, sendo assim, mais dispostos a avaliar objetivamente as vantagens e desvantagens da exportação (GARNIER, 1982), bem como possuem mais conhecimento gerencial (SCHLEGELMILCH, 1986), que podem melhorar o desempenho de exportação de pequenas e médias empresas (SUÁREZ-ORTEGA; ÁLAMO-VERA, 2005). Sendo assim, o nível de educação do decisor torna-se um aspecto particularmente interessante em pequenas e médias empresas que operam além de seus mercados domésticos. Trata-se de uma característica chave para o desempenho a longo prazo por desenvolver a capacidade de construir uma visão global, formular objetivos estratégicos consistentes e desenvolver atitudes positivas em relação ao risco por meio do conhecimento de mercado internacional. (FERNÁNDEZORTIZ; LOMBARDO, 2009). 
A educação formal dos decisores pode ser considerada um reflexo das capacidades dos decisores (DATTA; RAJAGOPALAN, 1998; WIERSEMA; BANTEL 1992), e tem sido positivamente correlacionada ao forte comprometimento da empresa para mercados estrangeiros. Um decisor mais bem qualificado pode obter mais conhecimentos sobre países estrangeiros, bem como obter diferentes mercados e culturas, aumentando o comprometimento com a internacionalização da empresa por meio de maior investimento em atividades de exportação (FERNÁNDEZ-ORTIZ; LOMBARDO, 2009).

Um decisor com nível educacional mais elevado possui a capacidade de aprendizagem ampliada e será mais voltado às atividades no exterior, estando, portanto, mais disposto a explorar oportunidades em mercados estrangeiros, influenciando também a disposição da empresa em procurar mercado no exterior. $\mathrm{O}$ aumento de aprendizagem do gestor bem como da empresa faz com que esta também amplie a intensidade de exportação da pequena e média empresa (EVALD et al., 2011; FERNÁNDEZ-ORTIS; LOMBARDO, 2009).

Prahalad e Bettis (1986) assim como Herrmann e Datta (2005) argumentam que a estratégia das empresas é significativamente influenciada pela lógica dominante dos decisores, por meio do seu nível de educação. Portanto, há uma ligação entre o nível educacional e a lógica dominante do decisor, ou seja, a educação em nível mais elevado do decisor resultará em uma mentalidade que enfatiza a diversificação internacional na tomada de decisão estratégica, fazendo a empresa se internacionalizar para diversos países.

Javalgi e Todd (2011) encontraram em seu estudo que o capital humano é positivamente relacionado ao grau de internacionalização de PME na Índia. Para esses autores, o nível de educação do gestor/empreendedor foram preditores significantes do grau de internacionalização. Uma possível explicação para esse achado, segundo os autores, é que o gestor/empreendedor com maior experiência internacional se comporta como uma empresa que se internacionaliza conforme o modelo de Uppsala (JOHANSON; VAHLNE, 1990), o qual estabelece que a empresa que possui maior experiência internacional tende a empregar maior esforço para se internacionalizar. Da mesma forma com o nível educacional: o gestor/empreendedor com nível mais elevado de educação possui mais facilidade de aprendizagem. Portanto, como no modelo de Uppsala, o decisor com maior aprendizagem tende a se esforçar mais para internacionalizar. 
No estudo de Fernández-Ortiz e Lombardo (2009) a hipótese da relação entre o nível de educação da equipe de gestores (decisores) e a intenção estratégica de diversificação internacional da PME foi confirmada. Estes resultados mostram que o nível mais elevado de educação formal do decisor influencia desde o início das atividades da PME no mercado internacional por meio da exportação. Isto se deve, segundo Obben e Magagula (2003), e também Fernández-Ortiz e Lombardo (2009), ao fato de que o nível de qualificação do decisor aumenta a tolerância ao risco e o torna mais receptivo a mudanças, aumentando a confiança da PME no processo de tomada de decisão, fornecendo um grande número de alternativas estratégicas para a PME.

O resultado de Herrmann e Datta (2005) apresenta uma associação positiva e significante entre o nível de escolaridade média do time de gestores (decisores) e o nível de diversificação internacional. Os resultados indicam o suporte para a noção de que os recursos avançados de processamento de informações, a maior flexibilidade e a abertura a novas experiências estão associadas aos níveis educacionais mais elevados dos executivos, favorecendo a diversificação internacional (HERRMANN; DATTA, 2005). No entanto, a relação entre o nível de educação do decisor e a escolha do modo de entrada não foi confirmada. Embora a relação fosse na direção esperada (positiva), não foi estatisticamente significativa. Sendo assim, o nível de educação formal do decisor pode influenciar a abrangência da exportação da PME, mas não se pode afirmar em termos do estabelecimento de atividades com maior comprometimento com a internacionalização, como o estabelecimento de subsidiárias no país estrangeiro.

Suárez-Ortega e Álamo-vera (2005) descobriram que o nível de educação formal dos decisores aumenta com o nível de desenvolvimento da exportação; no entanto, o teste de Scheffé mostra que há diferenças significativas entre desinteressados e não exportadores e cada grupo. Este resultado sugere a falta de associação entre o nível de educação formal do decisor e a propensão à exportação, além da intensidade de exportação das PMEs.

O resultado de Omri e Becuwe (2014, p. 32) mostra que as variáveis relacionadas com o capital humano (nível de educação) não se relacionaram significativamente com a propensão para inovar e subsequentemente para exportação. Para esclarecer estes resultados, os autores da pesquisa constataram que quando um decisor adquire conhecimento por meio da experiência e da 
formação durante sua carreira, este decisor também desenvolve importantes redes sociais que limita a criatividade e a autoeficiência, que são essenciais às atividades de inovação dos produtos e implica na redução da abrangência da exportação.

\section{Impacto da experiência internacional no grau de internacionalização}

A experiência internacional dos decisores é vista como um recurso que influencia as PMEs a se envolverem em atividades que levam a um maior grau de internacionalização. As empresas com equipes de gestores com experiência internacional usam parceiros estratégicos estrangeiros e conseguem obter vendas para mercados estrangeiros logo após a sua criação, o que leva a um maior grau de internacionalização (REUBER; FISCHER, 1997).

O fator que explica o aumento da abrangência de internacionalização, segundo Cerrato e Piva (2012), é o capital humano; especificamente, a habilidade em negócios internacionais adquiridas por meio de experiência do decisor impacta positivamente o grau de internacionalização de pequenas e médias empresas; ou seja, esta habilidade do gestor deve ser plenamente explorada pela PME que também deseja explorar oportunidades em mercados internacionais. A experiência internacional do decisor é a força de uma empresa que se envolve em mercados estrangeiros devido aos benefícios em termos de orientação em longo prazo e a valorização de princípios como compromisso, coesão, sentido de dever e devoção ao trabalho. Esses princípios são fundamentais para reforçar a capacidade da empresa de responder de forma eficaz aos desafios da concorrência internacional.

A experiência do decisor no exterior tem sido considerada um fator importante, que pode explicar a propensão e a intensidade de exportação, porque envolve a exposição dos gerentes a culturas estrangeiras, que permite o acúmulo de conhecimento experiencial maior sobre mercados internacionais (LEONIDOU et al., 1998; SUÁREZ-ORTEGA; ÁLAMO-VERA, 2005).

O decisor com certa experiência de gestão de operações de exportação na gestão das operações e/ou que passou um tempo a trabalho no exterior terá uma percepção próxima do mercado exterior, bem como maior exposição em culturas diferentes. A experiência internacional dos decisores, portanto, é considerado um fator influente na determinação do nível de comprometimento das empresas com mercados estrangeiros (BOURANTAS; HALIKIAS 1991; FERNÁNDEZORTIZ; LOMBARDO, 2009). 
As habilidades e conhecimentos em negócios internacionais adquiridos por meio da experiência em mercados estrangeiros, especialmente através da execução de atividades em empresas multinacionais, expõem o decisor a informações e contatos com empresas e outros decisores em mercados estrangeiros. Os decisores mais expostos a culturas estrangeiras, através de viagens ou residência no exterior, acumulam conhecimento experiencial das características do mercado internacional, que irão beneficia-los quando internacionalizar suas empresas. Desta forma, os decisores com experiência internacional podem compensar algumas deficiências e concentrar maior esforço nas atividades de venda de produtos específicos para alguns mercados préestabelecidos, aumentando, assim, a competitividade da empresa no mercado internacional, fazendo a PME se internacionalizar para vários países (QIAN, 2002; RUZZIER et al., 2007).

O conhecimento tácito é um ativo individual que se obtém por meio de experiências pessoais e interações. Este conhecimento via experiência internacional é trocado principalmente através de contatos interpessoais, tais como comunicações, negociações, colaboração empresarial, participação em seminários, feiras etc. Isso ocorre também na PME por meio da transmissão e absorção de conhecimento e experiência internacional, sendo que, uma vez aumentada a experiência internacional da empresa, esta empresa tende a ter maior profundidade de internacionalização, como ocorre no processo de internacionalização de Uppsala (JOHANSON; VAHLNE, 1990; ANDERSSON; JOHANSON, 2010).

O conhecimento pode ser adquirido por meio de experiências pessoais específicas no mercado internacional (ATHANASSIOU; NIGH, 2000). O conhecimento dos mercados estrangeiros desenvolvidos através da experiência é importante para superar as barreiras associadas a diferenças de língua, cultura, práticas de negócios e legislação (MOROSINI; SHANE, 1998). A habilidade em negócios internacionais obtida por meio da experiência em mercados internacionais, especialmente por meio do envolvimento com multinacionais ou organizações internacionais, expõe o empreendedor/gestor ao contato com informações sobre os mercados internacionais. Além disso, o conhecimento dos mercados estrangeiros aumenta a probabilidade de expansão por meio de exportação (REID, 1983), aumenta a propensão a usar investimento para adquirir controle completo das atividades internacionais (HERRMAN; DATTA, 2002), e 
tem um impacto positivo sobre a profundidade e o grau de internacionalização (REUBER; FISCHER, 1997; RUZZIER et al., 2007).

Outros estudos mostram que a experiência desempenha um papel importante na descoberta de novas oportunidades de mercado em países estrangeiros e na implementação de atividades inovadoras fora do mercado doméstico (OMRI; BECUWE, 2014; WESTHEAD et al., 2001). Assim, decisores educados e com experiência internacional de fato podem ajudar uma empresa a implementar e introduzir produtos e serviços inovadores internacionalmente, aumentando o volume de vendas para o exterior (OMRI; BECUWE, 2014).

Leonidou et al. (2002) identificaram as características gerenciais como importantes fatores responsáveis pelo sucesso de exportação. Bloodgood et al. (1996) encontraram que a maior experiência de trabalho internacional entre os gestores de topo foi fortemente associada à atuação internacional de novos empreendimentos de alto potencial nos Estados Unidos. Além disso, McDougall et al. (2003) e Madsen e Servais (1997), em seus estudos, concluíram que a experiência anterior dos empreendedores tem grande influência sobre a criação de PME e sua rápida internacionalização.

O estudo de Suárez-Ortega e Álamo-Vera (2005) mostrou que a diversificação internacional foi positivamente relacionada com a experiência internacional do decisor. Estes autores destacam que a experiência profissional ou acadêmica obtida no exterior pelo decisor leva a empresa a ser mais envolvida com a exportação, sendo positivamente associada com a propensão à exportação. Em seguida, ela influencia positivamente a intensidade de exportação.

As evidências empíricas do estudo de Fernández-Ortiz e Lombardo (2009) confirmaram que a diversificação internacional das PMEs foi positivamente relacionada com o nível de experiência internacional de seus decisores. Os decisores com experiência em mercados internacionais tinham melhor percepção dos mercados internacionais, isto proporcionou aos decisores melhor conhecimento dos mercados e os métodos mais eficazes para fazer negócios, reduziu os seus níveis de risco percebido, e teve um impacto importante na orientação cognitiva destes decisores. Para estes autores isto confirma a necessidade de as PMEs terem decisores com experiência internacional, adquirida enquanto estes trabalhavam anteriormente em empresas estrangeiras ou em 
empresas nacionais que desenvolveram estratégias internacionais por algum tempo.

Javalgi e Todd (2011) encontraram em seu estudo que o capital humano é positivamente relacionado ao grau de internacionalização de PME na Índia. Para esses autores, o nível de educação e a experiência internacional do gestor/empreendedor foram preditores significantes do grau de internacionalização. Uma possível explicação para esse achado, segundo os autores, é que o gestor/empreendedor com maior experiência internacional se comporta como uma empresa que se internacionaliza conforme o modelo de Uppsala (JOHANSON; VAHLNE, 1990), o qual estabelece que a empresa que possui maior esperiência internacional tende a empregar maior esforço para se internacionalizar. Da mesma forma com o nível educacional, o gestor/empreendedor com nível mais elevado de educação possui mais facilidade de aprendizagem. Portanto, como no modelo de Uppsala, com maior aprendizagem, tende a se esforçar mais para internacionalizar.

O resultado de Omri e Becuwe (2014, p. 32) mostra que as variáveis relacionadas ao capital humano (experiência internacional) não se relacionaram significativamente com a propensão para inovar e subsequentemente para exportação. Para esclarecer estes resultados, os autores da pesquisa constataram que quando um decisor adquire conhecimento por meio da experiência e da formação durante sua carreira, este decisor também desenvolve importantes redes sociais que limita a criatividade e a autoeficiência, que são essenciais às atividades de inovação de produtos e implica a redução da abrangência da exportação.

Impacto da proficiência em línguas estrangeiras no grau de internacionalização

A habilidade em negócios internacionais pode ser adquirida indiretamente, em particular por meio da habilidade com línguas estrangeiras, que é um importante fator para a internacionalização de PME. Os meios aplicados para os empreendedores desenvolverem as habilidades em negócios internacionais apresentam grandes diferenças. Decisores que possuem essa habilidade possuem também um nível elevado de orientação internacional, o que fará com que a PME tenha maior profundidade de internacionalização. Além disso, esses decisores 
investem no recrutamento, treinamento e buscam reter pessoas com essas habilidades, apesar dos recursos limitados deste tipo de empresa (GOXE, 2010).

Segundo Leonidou et al. (1998), bem como Suárez-Ortega e Álamo-Vera (2005), a proficiência em língua estrangeira é positivamente associada com o desenvolvimento da exportação, uma vez que contribui para a realização de contatos sociais e de negócios no exterior, melhora a comunicação e interação com clientes estrangeiros, auxiliar na compreensão de práticas de negócios estrangeiros e facilita o planejamento eficaz e controle nos mercados internacionais em vários países.

De acordo com Araújo e Neira (2006), um conhecimento de línguas estrangeiras pode influenciar os resultados das exportações de várias maneiras: (1), ajudando a estabelecer contatos no estrangeiro; (2), melhorando a interação com clientes estrangeiros; e (3), ajudando a compreender os regulamentos comerciais de outros países e outras culturas. Além disso, Araújo e Neira (2006) concordam com o modelo causal proposto por Holzmüller e Stöttinger (1996), o qual demonstra que o conhecimento de língua estrangeira afeta o desempenho da exportação por meio da integração entre a intensidade de exportação e o dinamismo da exportação, e ambos impactam diretamente e indiretamente por meio de seu efeito sobre a tolerância do gerente ao estresse psicológico e ao risco, no apoio às atividades de exportação.

Altinay e Altinay (2006) e Altinay (2008) também encontraram uma relação positiva entre a fluência em língua estrangeira (neste caso o inglês) e o crescimento das pequenas empresas de origem turca no Reino Unido. Os resultados mostraram que a sobrevivência e o crescimento das pequenas empresas turcas que operam no setor de restauração é altamente dependente dos clientes atuais e futuros. Por este motivo, a proficiência em língua estrangeira contribui para a propensão a exportação de várias formas: facilita contatos sociais, auxilia na compreensão das práticas éticas e de negócios de um mercado com diferenças culturais e melhora a comunicação entre os decisores (SERRA et al., 2012; TURNBULL; WELHAM, 1985). 
Para Harzing (2005) e López-Duarte e Vidal-Suárez (2010) torna-se particularmente difícil separar os efeitos da proficiência em línguas estrangeiras das influências culturais mais amplas, tanto quanto a influência dos valores culturais e de gestão em contextos internacionais (WEST; GRAHAM, 2004): não é apenas a linguagem que uma pessoa aprende, mas também a influência de valores e a forma de pensar. Portanto, essa diversidade de linguagem pode influenciar ou condicionar a distância cultural percebida entre os decisores de países com vários aspectos diferentes, mas pode não ser relevante para a empresa em termos de ampliar seu escopo de atuação internacional.

A pesquisa de Knawles et al. (2006) descobriu que os decisores do grupo bem-sucedido na internacionalização eram muito mais propensos a ter competências em língua estrangeira do que os menos bem-sucedidos, e estas habilidades eram frequentemente em um nível mais elevado. Portanto, os decisores com competências linguísticas têm maiores condições de avançar no comércio internacional a um grau que aqueles sem proficiência em línguas não conseguem obter. Decisores com proficiência em línguas estrangeiras são capazes de fazer uso de uma ligação cultural; e muitas vezes demonstram uma mentalidade internacional favorável à ampliação da profundidade de internacionalização de sucesso (KNAWLES et al., 2006).

Smallbone et al. (2001) e Altinay (2008) destacam que a falta de proficiência em língua pode ser uma barreira para a difusão das informações sobre questões de suporte aos negócios, fazendo com que os decisores de pequenas e médias empresas não se sintam confortáveis com o idioma do país de acolhimento, dado que os decisores com habilidades de comunicação em língua estrangeira têm um maior nível de confiança em si mesmos, facilitando a procura por aconselhamento de bancos, instituições financeiras e conselheiros de negócios nos países que estão recebendo o empreendimento (ALTINAY, 2008; COLEMAN, 2005).

Com os dados de uma amostra de PMEs exportadores no setor alimentar, o estudo de Araújo e Neira (2006) mostrou que o nível de conhecimento de línguas dos gestores responsáveis pelas decisões de exportação não tem uma influência significativa na sua atitude de exportação e, portanto, não faz a empresa aumentar a profundidade e a abrangência destas exportações. Isso pode ser devido à homogeneidade da educação e da formação dos gestores da amostra: a formação 
dos gestores é provavelmente influenciada por variáveis como o tamanho ou a presença de capital estrangeiro.

No estudo de Makrini (2015), a relação entre a proficiência em línguas estrangeiras e a abrangência das exportações (grau de internacionalização) não foi significativa; sendo assim, a hipótese que previu uma relação positiva entre a proficiência de língua estrangeira e sucesso de exportação não foi suportada. Verificou-se que o número de línguas faladas que poderia determinar o sucesso da empresa em exportação não é suficiente para que isso ocorra, mas, sim, o comprometimento de exportação e orientação para o cliente.

Portanto, considerando os argumentos apresentados anteriormente, pode-se propor que:

$H_{2 b}$ : $O$ capital humano do gestor apresenta uma relação positiva com o grau de internacionalização da empresa (em termos de abrangência e de profundidade).

\section{5 Impacto do capital humano na velocidade de internacionalização}

Nesta seção é apresentada a revisão da literatura relativa ao impacto do capital humano em termos de nível de educação formal, experiência internacional e proficiência em línguas estrangeiras sobre a velocidade de internacionalização (precocidade e crescimento do volume de vendas internacionais).

\section{Impacto do nível de educação na velocidade de internacionalização}

Seguindo esta linha de pensamento, o nível mais elevado de educação do decisor faz aumentar a confiança do decisor e da empresa no processo de tomada de decisão, fornecendo maior visão de mercado e aumentando a tolerância ao risco do decisor, tornando-o mais receptivo a mudanças provocadas pelas atividades internacionais (OBBEN; MAGAGULA, 2003). Além disso, o nível de educação do decisor influencia não só a realização da globalização real, como previamente observado, mas também as intenções de tornar a empresa global ainda na fase de pré-fundação, fazendo com que a empresa tenha uma internacionalização precoce. (EVALD et al., 2011). 
Entretanto, Finkelstein e Hambrick (1996) e Herrmann e Datta (2002) destacam que o nível de educação formal do decisor pode não necessariamente desempenhar um papel importante nas escolhas estratégicas porque eles normalmente completam sua educação formal muitos anos antes de serem nomeados para cargos estratégicos de decisão na empresa, e, consequentemente, podem tomar a decisão de abrir seu prórpio negócio internacional muitos anos após ter concluído a sua formação. Desta maneira, o nível mais elevado de educação do gestor não impacta diretamente a precocidade da internacionalização da PME.

Para Bantel e Jackson (1989) e Camelo-Ordaz et al. (2006) a educação está especificamente associada com inovação. Assim, o comportamento complexo dos gerentes é reflexo de suas características individuais e sua formação, idade e experiência. $\mathrm{O}$ fator idade pode influenciar a formação e a experiência do decisor e tende a levar à internacionalização da empresa de forma precoce, quando mais jovens.

O resultado do estudo de Evald et al. (2011) mostra que é possível que o nível de escolaridade dos empreendedores afete o comportamento de exportação já na fase de pré-fundação da PME, onde as intenções de exportação estão sendo formadas. Este resultado, segundo Evald et al. (2011) está em conformidade com pesquisas anteriores (LEONIDOU et al., 1998; KUNDU; KATZ, 2003) que mostraram que o nível de escolaridade dos decisores está associado à sua probabilidade de se envolver em atividades de exportação. Kundu e Katz (2003), e também Evald et al. (2011), argumentam que os decisores com níveis mais elevados de educação estão "olhando mais para o exterior" e, portanto, são mais dispostos a se envolver em atividades de exportação. Portanto, decisores com nível mais elevado de educação irão fazer a PME exportar precocemente.

No estudo de Ughetto (2016) em 242 born globals mostrou que a presença da heterogeneidade dos gestores em relação a educação afetou negativamente o rápido crescimento destas empresas. Esta evidência foi interpretada da seguinte forma pela autora. Os gestores com origens de educação diferentes podem não compartilhar as mesmas percepções de oportunidades de crescimento, especialmente em circunstâncias em que a informação é distribuída uniformemente e a incerteza é elevada (como é o caso das empresas à 
internacionalização precocemente). Portanto, a educação formal pode interferir negativamente a rápida internacionalização destas empresas.

Impacto do nível da experiência internacional na velocidade de internacionalização

Toften e Olsen (2003) argumentam que a experiência prévia de exportação fornece ao decisor uma visão de negócio que facilita a busca pelo tipo de informação de mercado de exportação mais importante, e para qual finalidade específica a informação deve ser adquirida. Assim, a experiência prévia de exportação fornece aos decisores um ponto de vista orientado para o exterior combinado com uma redução na "distância psíquica" em relação aos outros mercados e culturas. Portanto, decisores com experiência prévia internacional permanecem internacionalmente orientados desde as primeiras fases da start-up buscando oportunidade no mercado estrangeiro e também nas ações subsequentes da start-up, ou seja, estes decisores permanecerão "olhando para o exterior", como expresso por Kundu e Katz (2003) e levarão a start-up a se internacionalizar rapidamente. (EVALD et al., 2011).

Habilidades em negócios internacionais, bem como a experiência internacional, são conhecimentos e competências que contribuem para superar os obstáculos associados com diferenças na língua, cultura, práticas de negócios e legislação (MOROSINI et al., 1998; RUZZIER et al., 2006). O conhecimento sobre gestão empresarial inclui as competências e a experiência adquirida pelo empreendedor na gestão da empresa (nível nacional), permitindo-lhe introduzir as melhores práticas de recursos humanos, empreender estratégias competitivas mais promissoras e identificar as oportunidades mais promissoras em mercados estrangeiros fazendo aumentar as vendas para o mercado internacional (RUZZIER et al., 2006, WESTHEAD et al., 2001).

Os decisores que veem menos risco ao competir em mercados internacionais devido a sua experiência internacional, parecem mais propensos a responderem a oportunidades de rápida exportação e internacionalização. Essas conclusões no que diz respeito à influência da experiência internacional e a percepção ambiental de risco, neste caso, o risco envolvido no processo de internacionalização, são consistentes com outros resultados semelhantes encontrados em estudos anteriores (MANOLOVA et al., 2002). 
Os gerentes e fundadores com razoável experiência internacional, quando iniciam as atividades de uma empresa própria, podem inverter a inclinação, tornando a relação negativa com a rápida internacionalização. Gerentes e fundadores experientes e conhecedores do mercado internacional percebem riscos nos mercados de tecnologia estrangeira e, assim, hesitam ou até mesmo são dissuadidos a testar as oportunidades estrangeiras (AGARWAL et al., 2004; LI; QIAN; QIAN, 2012). Eles entendem que a percepção de novas oportunidades em mercados estrangeiros é apenas o primeiro passo e precisam implantar recursos substanciais para competir contra poderosos concorrentes do país hospedeiro, a fim de explorar as oportunidades, retardando a ida para o mercado internacional (LI; QIAN; QIAN, 2012; MATHEWS; ZANDER, 2007).

Algumas pesquisas mostraram ser mais provável encontrar interesse por negócios internacionais entre decisores que passaram algum tempo em país estrangeiro, adquirindo experiência. Isso também é mais evidente entre os decisores que têm anterior experiência positiva com exportação em outras organizações, bem como experiência adquirida em um ambiente global, através do envolvimento, por exemplo, em empresas multinacionais (LEONIDOU et al., 1998; LEONIDOU et al., 2007). Esses decisores, ao abrirem uma empresa, tenderão a exportar precocemente para aumentar os seus ganhos.

A relação entre a experiência internacional e o crescimento do volume de venda das PMEs foi significativa no estudo de Javalgi e Todd (2011). Para estes autores a experiência do decisor é similar ao que ocorre nas empresas que se internacionalizaram conforme o modelo de Uppsala, desenvolvido por Johanson e Vahlne (1990), que destacam que as empresas com alguma experiência em mercados internacionais tenderão a empenhar mais esforços na internacionalização. A constatação de Javalgi e Todd está em acordo com a pesquisa de Ibeh e Young (2001), que também fornece evidências de que a experiência internacional dos decisores de exportação é um direcionador para a internacionalização das PMEs, influenciando o envolvimento da empresa em atividades de exportação. 
Evald et al. (2011) mostram em seu estudo que a experiência internacional prévia não melhora incondicionalmente as intenções de exportação da PME. Os decisores que anteriormente começaram um negócio são propensos a iniciar os tipos similares de negócios, seguindo a lógica que eles usaram em empreendimentos anteriores. Estes resultados são consistentes com o estudo de McDougall et al (2003), mostrando que a experiência do gestor de start-up, com ou sem exportação, parece não determinar se as futuras empresas se tornarão internacionais ou não. Os decisores estabelecem e desenvolvem experiência internacional através da participação ativa nos mercados estrangeiros, aumentando gradativamente o desenvolvimento do comprometimento com a internacionalização da empresa, sendo esta mais lenta (JOHANSON; VAHLNE, 1977, 1990, 2006).

\section{Impacto da proficiência em línguas na velocidade de internacionalização}

Clarke (2000) e Bal e Kunday (2014) afirmam que o conhecimento da língua estrangeira é uma das necessidades fundamentais para haver altos níveis de exportação. O conhecimento de línguas estrangeiras é um pré-requisito para decisores das PMEs que desejam assumir um papel ativo nos mercados internacionais. Em outras palavras, os relacionamentos de negócio internacional atual exigem decisores altamente qualificados e com conhecimento de língua estrangeira. As barreiras linguísticas entre os países de origem e de acolhimento são parte da responsabilidade do decisor (BAL; KUNDAY, 2014; LUO; SHENKAR, 2006) que podem influenciar significativamente as decisões de internacionalização, influenciando também a escolha do modo de entrada e a velocidade de entrada no mercado internacional (BAL; KUNDAY; 2014).

A inserção cognitiva, que diz respeito ao desenvolvimento dos membros da rede de representações compartilhadas, interpretações e sistemas de significação que lhes permitem a melhor compreensão mútua (NAHAPIET; GHOSHAL, 1998) também pode influenciar a velocidade com que as PMEs entram em mercados estrangeiros e seu desempenho. Um elemento-chave de inserção cognitiva é a uniformização da linguagem entre os membros da rede. A proficiência linguística é importante do ponto de vista da comunicação efetiva, levando ao aprendizado sobre os mercados estrangeiros e reduzindo a distância 
psíquica percebida entre mercados estrangeiro e doméstico (SWIFT, 1991; TERPSTRA, 1983; MUSTEEN et al., 2010; WILLIAMS; CHASTON, 2004). A proficiência em línguas estrangeira também minimiza a probabilidade de malentendidos e de conflitos interculturais, além de levar a outros benefícios que facilitam internacionalização mais rápida (MUSTEEN et al., 2010).

Eriksson et al. (1997) observou que a proficiência em língua estrangeira do decisor geralmente resulta em uma avaliação mais favorável dos desafios e custos associados à internacionalização, e proporciona uma internacionalização mais rápida por parte das PMEs. Além disso, segundo Musteen et al. (2010), os gerentes que estão em uma posição para comunicar eficazmente com os seus laços de rede internacional sem a ajuda de tradutores são propensos a desenvolver relacionamentos mais próximos com tais laços, porque eles podem ser emocionalmente mais expressivos e mais facilmente interpretam as formas verbais e não verbais, o que, por sua vez, torna mais fácil reunir informações essenciais sobre as oportunidades de mercado externo, facilitando a internacionalização mais rápida (MUSTEEN et al., 2010).

O estudo de Nakos et al. (1998) mostrou que empresas com decisores fluentes em mais de um idioma fazem o desempenho de exportação atingir patamares superiores de volumes de vendas. O conhecimento de língua estrangeira também pode fazer com que o decisor tenha contato pessoal com possíveis estrangeiros e pode desenvolver uma relação de confiança; pode permitir que o decisor amplie a compreensão das práticas de negócios de um país estrangeiro e melhore suas habilidades para negociar com sucesso com os estrangeiros (ENDENVICK; AKOORIE, 1994; NAKOS et al., 1998).

Suárez-Ortega e Álamo-Vera (2005) descobriram que a probabilidade a proficiência em uma língua estrangeira é positivamente associada com propensão de exportação e com a intensidade de exportação. Um estudo similar de Serra et al. (2012) aponta que as empresas que empregam gestores com uma maior capacidade de falar línguas estrangeiras têm maior propensão de exportação. Isto se deve ao fato de que os decisores com habilidades de boa comunicação por meio da proficiência em língua estrangeira têm um maior nível de confiança em si mesmos e conseguem relações de confiança com decisores de empresas estrangeiras que podem facilitar a entrada precoce da empresa no mercado estrangeiro (ALTINAY, 2008). 
Os resultados de Musteen et al. (2010) indicam que linguagem em comum entre os decisores de PMEs e seus laços facilita a internacionalização mais rápida. Isso reitera a importância da capacidade de linguagem no contexto de negócios internacionais. A capacidade de se comunicar com contatos estrangeiros numa língua comum, sem ter que depender de intérpretes, representa um recurso importante que facilita a aquisição de valiosos insights sobre possíveis oportunidades em mercados internacionais; que, juntamente com uma melhor compreensão dos mercados internacionais, o que vem com a habilidade da língua, fornecendo aos decisores de PME confiança para entrar em mercados estrangeiros logo após a fundação de suas empresas. Entretanto, contrariando as expectativas, a linguagem em comum não resultou em desempenho superior direto da internacionalização. Esta constatação pode ser atribuída ao fato de que o desempenho da empresa depende mais das características do conhecimento que está sendo comunicado e não necessariamente pela qualidade e volume de conhecimento a ser adquirido pelo decisor (MUSTEEN et al., 2010).

Os achados do estudo de Altinay (2008) indicaram que os decisores turcos exploram seus antecedentes culturais a fim de ganhar vantagem competitiva e contribuir para a economia no Reino Unido. Aqueles que têm origens culturais fortes (ou seja, linguagem) buscam oportunidades no resto do mundo liberal. Portanto, é importante a influência da proficiência em línguas estrangeiras em suas práticas de gestão, visto que propiciou a rápida ida de PMEs turcas para o Reino Unido.

A relação entre o conhecimento de línguas estrangeiras do decisor e o grau de internacionalização da empresa, mais especificamente a profundidade de internacionalização, mostrou-se estatisticamente significante no estudo de Bal e Kunday (2014). Este achado está em concordância com o estudo de Clarke (2000), que também afirmou que o conhecimento de língua estrangeira é uma das necessidades fundamentais para a empresa ter níveis de exportação elevado. $\mathrm{O}$ conhecimento de línguas estrangeiras é um pré-requisito para gerentes ou proprietários das PMEs que desejam assumir um papel ativo nos mercados internacionais. Em outras palavras, os relacionamentos de negócio internacional atual exigem decisores qualificados, com conhecimento de língua estrangeira para fazer a empresa se internacionalizar rapidamente. 
Hutchinson, Quinn e Alexander (2006) encontraram que para uma determinada empresa com operações internacionais, a capacidade o decisor de falar línguas estrangeiras não era tão importante quanto a capacidade de compreender o negócio local. O diretor desta empresa explicou que habilidades encontradas em compreender o negócio transcendem a capacidade de falar línguas estrangeiras. Desta forma a empresa não aumenta o volume de vendas no mercado internacional.

Considerando os argumentos apresentados anteriormente, pode-se propor que:

$H_{2 c}$ : O capital humano do gestor apresenta uma relação positiva com a velocidade de internacionalização da empresa (em termos de precocidade e de crescimento do volume de vendas internacionais).

\section{6.}

\section{Impacto do capital social na propensão ao risco}

A literatura mostra que os decisores consistentemente usam redes para reunir informações sobre as oportunidades oriundas de outros mercados em diversos locais (BASTIÉ et al, 2013; BIRLEY 1985; HOANG; ANTONCIC 2003). Além disso, os decisores com alto capital social têm maior conhecimento do mercado e de transferências de negócios, e talvez melhor conhecimento também das oportunidades para iniciantes. A atitude em relação a risco pode explicar o motivo pelo qual as pessoas com uma grande rede empresarial são mais propensas a iniciar uma nova empresa (BASTIÉ et al., 2013).

O capital social pode ter efeitos psicológicos sobre os gestores, deixando-os mais bem preparados para agir em situações de risco (EISENHARDT, 1989; JANSEN et al., 2011). A representação mental construída através desses fatores de produção fornece a base para julgar e tomar uma decisão posteriormente. A interpretação e representações inequívocas aumentam a confiança nos processos de decisão (HASTIE, 2001; JANSEN et al., 2011; LEE; DRY, 2006), em geral, com maiores níveis de confiança, mais recursos e tempo para implementar as decisões estratégicas necessárias para a empresa (ADIDAM; BINGI, 2000; JANSEN et al., 2011), aumentando a probabilidade de que as consequências dessas decisões sejam favoráveis. Uma linha semelhante de raciocínio aplica-se à aceitação de risco (JANSEN et al., 2011). 
A confiança fomenta a cooperação. O capital social dos decisores é baseado em confiança e permite a livre troca de informações e conhecimentos (KALE et al., 2000). Ou seja, a confiança facilita que haja maior intensidade, frequência e eficiência de troca de informações (YLI-RENKO; JANAKIRAMAN, 2008). A confiança também induz uma maior vontade de arriscar-se no intercâmbio de informações, criando uma sensação de segurança que conhecimento não será explorado além do seu uso pretendido (COLEMAN, 1988; PRASHANTHAM, DHANARAJ, 2014). Se as partes externas confiam no decisor da empresa, as partes externas apreciam a redução da incerteza e são mais propensas a se envolverem em um comportamento cooperativo. Quando o decisor cultiva relações de solidariedade com entidades externas (por exemplo, parceiros de distribuição), o perigo do comportamento oportunista é reduzido e a cooperação entre as empresas torna-se menos arriscada, bem como o comportamento das outras empresas torna-se mais previsível (KEMPER et al., 2011; LINGHUI; KOVEOS 2008).

O grau de comprometimento de capital social reflete a propensão dos decisores para o risco de seu investimento e é proporcional ao risco potencial, sendo que os laços sociais através de redes prolongadas podem reduzir o receio provocado pelos ambientes incertos num mercado estrangeiro. Este raciocínio deriva o papel central dos decisores na redução da incerteza e pela superação ou enfraquecimento de dependências externas (PFEFFER; SALANCIK, 1978; ZHAO; HSU, 2007).

A identificação de riscos, como resultado de ter um quadro mais abrangente, será mais fácil (JANSEN et al., 2011; WINCH; MAYTORENA, 2009). Portanto, níveis de aceitação de riscos serão mais elevados quando a amplitude de capital social for maior devido à crença dos decisores de que eles avaliaram com precisão a situação de decisão. Em termos avaliativos, isto significa que quanto maior a amplitude do capital social, mais precisão terá o julgamento, aumentando assim as chances de elevação dos níveis de eficácia da decisão. A visão abrangente irá facilitar a identificação de riscos e fornecer confiança na situação de decisão podendo esta decisão ser sentido da internacionalização da empresa. (JANSEN et al., 2011). 
O nível de inserção em uma rede pode afetar a decisão de internacionalização, através do seu impacto na percepção de risco, dado que "[...] as redes são pontos de referência importantes no sentido de lidar com os riscos pessoais sobre decisões importantes e poderia agir para moderar o grau de risco que um decisor individual sente" (LIESCH; WELCH; BUCKLEY, 2011, p. 858). Além disso, as redes proporcionam "aumentos no compromisso de operações internacionais" (LIESCH et al., 2011, p. 856) e ajudam a construir "confiança mútua e significado compartilhado [que] diminui a incerteza" (JOHANSON; VAHLNE, 2006, p. 171). Sendo assim, os decisores assumem o que pode ser consideradas iniciativas mais arriscadas, como exportar. Além disso, Bastié et al. (2013, p. 875) argumentam que pertencer a uma rede aumenta o comportamento de risco, "uma atitude em favor de risco", e a propensão para assumir iniciativas inovadoras como a exportação.

A estrutura de rede em si tende a controlar o risco porque os membros da rede geralmente compartilham as rendas e conhecimento (OVIATT; MCDOUGALL, 1994). O estudo de Freeman et al. (2006) mostra que os gerentes podem usar os modos de entrada e as redes de contatos em diferentes países para mitigar o risco. Estes autores observaram que, durante a crise econômica, os gestores foram capazes de usar uma estratégia de redução de risco, movendo-se para o exterior (exportação), permitindo-lhes permanecer ligados e, depois, para restabelecer a relação com maior comprometimento, partiram para o desenvolvimento de Joint Venture. Foi observada ainda a existência de dois tipos de risco: o risco associado à diversificação e o risco de perder um relacionamento valioso por causa da crise econômica. As pequenas empresas e seus gestores perceberam que o último tipo de risco é mais importante do que o anterior. Tal risco foi percebido como originário de uma cultura empreendedora dentro de cada pequena empresa (DIMITRATOS; PLAKOYIANNAKI, 2003; FREEMAN et al., 2006), habilitando os gerentes a permanecerem ligados à rede de contatos e empresas, tornando-os atores visíveis e importantes nos principais mercados internacionais, apesar dos fatores ambientais negativos. 
O estudo de Jansen et al. (2011) mostra que o capital social tem um efeito positivo sobre a eficácia da decisão através da mediação do nível de aceitação de risco, bem como o nível de confiança. As informações obtidas a partir de fontes e canais de relações em redes levam à obtenção de decisões mais benéficas para a empresa por causa de decisores confiantes e dispostos a aceitar os mais elevados níveis de risco. Sendo assim, a eficácia da decisão, em termos do alcance dos objetivos, no sentido de internacionalizar a empresa, pode ser influenciada pela amplitude do capital social (JANSEN et al., 2011).

Li et al. (2015) descobriram que a organização de informações no nível de empresa é dependente da capacidade de resposta em combinação com propensão de assumir riscos dos decisores, motivando outros decisores para agir imediatamente no sentido de internacionalizar precocemente a PME, porque eles têm o apoio da empresa e são confiantes sobre a eficiência de suas redes de informação. A propensão ao risco e os relacionamentos via rede são cada vez mais reforçados, fazendo a PME acelerar a internacionalização.

Os resultados de Kollmann e Christofor (2014) mostram que dois grupos de decisores com maior aceitação ao risco percebem que uma rede internacional pessoal é muito importante. Isto sugere que a rede apoia e promove a entrada no mercado estrangeiro, e, uma vez que os decisores aceitam riscos, eles estão dispostos a usar a sua rede. Decisores de pequenas empresas confiam na sua rede e são propensos ao risco para compensar os passivos existentes no uso da rede para a internacionalização da empresa.

A pesquisa de Gao et al. (2011) mostrou que o capital social baseado puramente em relações pessoais influencia a capacidade do decisor de correr risco para obter melhor desempenho para a PME. A capacidade de usar redes informais existentes para acessar habilidades, conhecimentos e recursos adicionais é crucial para as PMEs administrarem de forma eficaz o risco. No âmbito da dimensão cognitiva, a comunicação é necessária para acessar e usar o capital social por meio de intercâmbio de informações, identificação de problemas e gerenciamento de conflitos por parte dos decisores.

Considerando os argumentos dos trabalhos apresentados anteriormente, pode-se postular que:

$H_{3 a}$ : $O$ capital social do gestor está positivamente associado com a sua propensão ao risco. 


\section{7.}

\section{Impacto do capital social na percepção de risco}

As redes são capazes não só de fornecer recursos (como informações) mas, também modifica a percepção e os modelos mentais dos empreendedores de born globals. O impacto nas cognições dos empreendedores pode ser nas percepções de risco e/ou incertezas e na confiança na obtenção de oportunidades internacionais. Os empreendedores menos experientes possivelmente irão se beneficiar menos de suas redes de contatos. Desta forma, os empreendedores novatos percebem menos riscos e formam novos empreendimentos internacionais, facilitando a sua transição de reconhecimento da oportunidade para o empenho na exploração da oportunidade. Portanto, as redes afetam as percepções de riscos de oportunidades internacionais que variam em relação à sua experiência prévia de negócios internacionais (NOWINSKI; RIALP, 2016).

Os decisores, no entanto, não trabalham isoladamente. O contexto imediato do grupo mais amplo de redes de empresas são pontos de referência importantes no sentido de lidar com os riscos pessoais sobre decisões importantes e poderiam agir para moderar o grau de risco que decisor individualmente percebe. Redes de contatos expandidas internacionalmente reduzem tanto as percepções de incertezas quanto as de riscos; assim, melhoram o clima de decisão e apoiam aumentos no comprometimento com as operações internacionais. (LIESCH; WELCH; BUCKLEY, 2011).

As redes de relacionamentos, particularmente quando há confiança, são um importante antídoto às incertezas e aos riscos, como se fosse um refúgio que ajuda a resolver problemas, para apontar os caminhos futuros, para obter conhecimento, para acessar novas redes em outros países e gerar a garantia sobre o comportamento das partes conectadas. Portanto, estas redes são uma importante arena de ação gerencial no desenrolar do processo de internacionalização para uma empresa. Elas afetam e são afetadas pela atividade internacional e seus resultados, interagindo com a incerteza e com o risco no sentido de reduzi-los (LIESCH; WELCH; BUCKLEY, 2011; WELCH; WELCH, 1996). 
Welch e Welch (1996), bem como Liesch, Welch e Buckley (2011), afirmam que o uso de rede de relacionamento pode transformar uma situação aparentemente altamente incerta e arriscada, como a entrada no mercado externo, em um passo relativamente confortável. Eles podem ser agentes de informações inquietantes, aumentando, desse modo, a incerteza percebida e trazendo mais risco. As empresas podem ser introduzidas para redes em mercados estrangeiros que se tornar inútil, nem exploração, novamente acentuando a incerteza e aumentando o risco. No entanto, segundo Covielo e Munro (1997), os decisores devem ser cautelosos com quais relações e como estas relações são estabelecidas, e quais habilidades de gerenciamento de rede são necessárias ao longo do tempo. Os decisores devem compreender os benefícios e os riscos associados à externalização das atividades com parceiros da rede, dada a aparente confiança em relacionamentos via rede para o crescimento internacional.

Uma maior amplitude de laços auxilia na avaliação da situação de decisão, desde que as informações recebidas suplementem ou validem as informações que o decisor já tem. Sendo assim, a maior amplitude de laços da rede, por um lado, reduz as limitações de recursos e ajuda a superar as limitações cognitivas do indivíduo; por outro, fornece aos decisores uma avaliação mais completa e exata da situação a ser decidida (JANSEN et al., 2011).

Ao aplicar o aspecto relacional do capital social inicial da internacionalização, verifica-se que este possa influenciar a avaliação do risco associado à internacionalização logo após a fundação. Estreitos laços pessoais com seus contatos internacionais podem atenuar a percepção do risco associado à internacionalização precoce entre CEOs de PMEs. Como os gerentes da PME possuem recursos limitados, suas decisões de internacionalização se baseiam na análise de sistemática de risco-retorno (PAPADOPOULOS, 1988). Portanto, estes gestores muitas vezes se voltam com informações pessoais de fontes "confiáveis" para orientação. Neste contexto, as relações e interações com contatos internacionais podem fornecê-los informações ricas (UZZI, 1997) sobre as condições do mercado externo, incluindo potenciais oportunidades e armadilhas. O conhecimento que as PMEs ganham através de tais interações deve reduzir riscos percebidos e os custos associados à internacionalização (ERIKSSON et al., 1997), resultando em maior disponibilidade de sua parte para se aventurar em mercados estrangeiros (MUSTEEN; FRANCIS; DATTA, 2010). 
Chung et al. (2000) destacam que as redes sociais são importantes na busca de novos empreendimentos e parceiros internacionais. Além disso, Manolova et al. (2002) e também Evald et al. (2011) apontam que estabelecer redes pessoais e no exterior oferecem aos decisores os conhecimentos e habilidades necessárias para conduzir negócios internacionais, produzindo uma rápida aprendizagem que irá implicar um ganho na velocidade de internacionalização.

No que se refere a conteúdo da rede, relações interpessoais e interorganizacionais, estas são vistas como os meios através dos quais atores têm acesso a uma variedade de recursos mantidos por outros atores. Dos principais benefícios das redes para o processo empresarial é o acesso que eles fornecem a informação e aconselhamento. Os relacionamentos também podem ter conteúdo ligado à reputação ou sinalização. As condições sob as quais ocorre atividade empresarial é incerta e dinâmica, sendo os detentores de recursos (potenciais investidores e empregados) propensos a buscar informações que ajudam a avaliar o potencial subjacente de um empreendimento. Os empresários buscam legitimidade para reduzir o risco percebido, associando, ou ganhando, certificação explícita de indivíduos bem vistos. As percepções de risco positivas, baseadas em ligações de rede de uma empresa, podem levar, por sua vez, a trocas subsequentes de recursos benéficos para as empresas da rede. (HOANG; ANTONCIC, 2003).

De Carolis e Saparito (2006) argumentam que o capital social afeta a cognição dos empreendedores e reduz sua percepção de riscos, aumentando, consequentemente, a probabilidade de escolher e buscar oportunidades de negócios. As alterações das cognições e a autoeficácia impulsionam para obtenção de novas informações sobre um determinado setor que um indivíduo recebe através de suas redes de contatos (OZGEN; BARON, 2007; NOWINSKI; RIALP, 2016).

No estudo de Stoian, Rialp e Rialp Criado (2016) foi evidenciado por meio de entrevistas, que os decisores salientaram a importância da confiança em suas redes de contatos. Nas palavras dos entrevistados, eles não fariam negócios se não percebessem menores riscos, pois pelo fato de a empresa ser muito pequena, poderiam ocorrer perdas irreparáveis que comprometeriam o desempenho da empresa como um todo. 
Os resultados do estudo de Li et al. (2013) realizado com empreendedores chineses mostraram que quando é formado o capital social, independentemente do seu montante, poderia produzir algum risco. No entanto, este risco não era percebido a menos que o acúmulo de capital social fosse o suficientemente elevado. Sendo assim, a percepção de risco não é influenciada de forma significante pelo capital social em termos de suas relações.

O estudo de Nowinski e Rialp (2016) mostrou que as relações de rede afetam as percepções de riscos de oportunidades internacionais durante a fase de incubação. No entanto, foram encontradas provas para demonstrar que os laços da rede influenciam o ritmo em que as oportunidades internacionais são exploradas e como eles afetam as percepções de viabilidade e conveniência. O impacto dos laços da rede é diferente para os empreendedores que no passado foram expostos aos negócios internacionais como suas percepções de risco e viabilidade são modificadas mais por laços fortes, considerando que as percepções de riscos dos empreendedores novatos são, por sua vez, afetadas principalmente por laços fracos, ou seja, relações não confiáveis por parte do gestor. Sendo assim, os empreendedores e gestores podem perceber baixos riscos em suas relações que outros pertencentes à mesma rede não perceberiam, porém tende a não considerálos nas suas decisões de internacionalizar rapidamente a empresa (NOWINSKI; RIALP, 2016).

Pesquisas recentes sugerem que empreendedores percebem situações de forma diferente do que outros (BARON, 1999; DE CAROLIS; SAPARITO, 2006; GATEWOOD; SHAVER; GARTNER, 1995; PALICH; BAGBY, 1995; SIMON; HOUGHTON; AQUINO, 1999). Pesquisas recentes no campo do empreendedorismo sugerem diversos fatores cognitivos específicos que influenciam a percepção de risco, como eles se relacionam com os empreendedores: excesso de confiança, a ilusão de controle e representatividade (PALICH; BAGBY, 1995; SIMON et al., 1999). A falha em saber os limites do conhecimento resulta em um viés cognitivo conhecido como excesso de confiança (BAZERMAN, 1990; LICHTENSTEIN; FISCHOFF, 1977; OSKAMP, 1965). Quando os indivíduos são excessivamente confiantes, eles superestimam a probabilidade de estar certo. $\mathrm{O}$ excesso de confiança ocorre porque os indivíduos podem ignorar novas informações que recebem, informações estas originadas de contatos sociais, após uma decisão inicial feita, ou eles não percebem a extensão a 
que seus planos ou estimativas como imprecisas. Indivíduos que são excessivamente confiantes tratam suas suposições como fato e podem acreditar que certas ações são menos arriscadas do que realmente são. Portanto, um indivíduo em sua rede de contatos negligencia as informações recebidas e, por isso, não percebe os riscos existentes nas oportunidades de negócios (DE CAROLIS; SAPARITO, 2006).

O estudo de Goxe (2010) mostra que os empreendedores chineses com baixos níveis de capital social contam com fortes laços (amigos, parentes ou relações de ambientes de trabalho doméstico anterior) e gastam uma quantidade importante de tempo na exploração dos fracos laços. No entanto, eles provam ser incapazes de adaptar a sua busca por laços (ou seja, selecionar os laços mais benéficos). Embora esses empresários estivessem consistentemente conectados com potenciais parceiros na China, suas características pessoais impedem o desenvolvimento de laços fracos com parceiros estrangeiros, que são percebidos como muito diferentes. Estas percepções, inversamente, fomentam o desenvolvimento de laços fortes entre eles, um comportamento possível de ser determinado por um baixo nível de orientação internacional, induzindo a uma percepção de risco da internacionalização como supérfluo e/ou muito arriscado (percepção de alto risco ambiental), não favorecendo a internacionalização. Portanto, o capital social não influencia a percepção de risco do empreendedor chinês no sentido de internacionalizar sua empresa.

Considerando as evidências e argumentos de pesquisas anteriores apresentadas neste trabalho, pode-se postular que:

$H_{3 b}$ : $O$ capital social do gestor está negativamente associado à sua percepção de risco (das atividades internacionais).

\section{8.}

\section{Impacto do capital social na velocidade de internacionalização}

O envolvimento do empreendedor com a gestão de toda a PME tem sido visto como fator importante e também com cuidado nos processos de internacionalização deste tipo de empresa (CLAVER et al., 2008; KONTINEN; OJALA, 2011). Na prática, a internacionalização das PMEs é principalmente incremental, ou seja, seguindo passo a passo com cautela (CLAVER et al., 2008; GRAVES; THOMAS, 2008). Nos estudos sobre empreendedorismo internacional 
e estudos sobre PME, as redes e o capital social têm sido vistos como importantes (COVIELLO, 2006; GRAVES; THOMAS, 2004). No entanto, as ligações entre os laços da rede das PMEs têm sido estudadas apenas muito limitadamente (ARREGLE et al., 2007; KONTINEN; OJALA, 2011), apesar de sua óbvia importância, especialmente no contexto da internacionalização deste tipo de empresa. Por esta razão, é útil estudar a relação entre capital social do empreendedor e/ou gestor e o grau de internacionalização deste tipo de empresa, e analisar as características específicas desta relação (KONTINEN; OJALA, 2011).

Os efeitos de capital social na internacionalização têm despertado interesse entre os pesquisadores, no entanto, os estudos sobre os fatores que promovem o desenvolvimento deste capital na perspectiva de internacionalização permanecem inexplorados, principalmente entre as PMEs (HOANG; ANTONCIC, 2003). Portanto, a relação existente entre o empreendedor, seu capital social desenvolvido para efeitos de internacionalização continua a ser problemática (GOXE, 2010).

Em estudos envolvendo a área de empreendedorismo internacional, os pesquisadores analisaram o valor do capital social e como os gestores obtêm vantagem competitiva de suas estratégias de inovação em redes internacionais na busca do sucesso da empresa. Quanto maior o capital social do empreendedor, maior a inovação (AKÇOMAK; WEEL 2009; CAINELLI et al., 2005) e maior o comprometimento com a rede. Portanto, será maior o comprometimento com as atividades em mercados internacionais da rede, aumentando as vendas internacionais da empresa e da rede social na qual a empresa está inserida.

A rápida entrada no mercado estrangeiro pode incorrer em riscos potenciais, as informações sobre o mercado devem ser confiáveis e precisas para respaldar a tomada de decisão. Em um mercado-alvo como em países emergentes, onde o ambiente institucional é incerto, complexo e que muitas vezes ofertam informações não muito claras (TAN, 1993, PENG, 2000; ZHAO; HSU, 2007), o capital social com base na confiança desenvolvida por identidades sociais comuns como o mesmo local de nascimento, antecedentes familiares ou instituição educacional de confiança, pode ser usada para reconhecer o clima político obscuro, a burocracia e garantir que a melhor informação possa ajudar a dissipar as preocupações dos decisores sobre os perigos de oportunistas (ZHAO; HSU, 2007). 
Quando um grupo de decisores internacionalmente expostos se comunicam entre si, cada um com seu próprio conhecimento sobre mercados específicos, é possível que possa emergir algum tipo de estrutura de conhecimento coletivo (BARKEMA; VERMEULEN, 1998; WALSH, 1995; YLI-RENKO, 2002). As ligações entre os decisores fornecem oportunidades para as empresas aprender sobre comércio exterior e maneiras de usar este conhecimento; usando ativamente tais conhecimentos, a empresas devem se posicionar melhor para iniciar rapidamente ou ampliar as operações estrangeiras para o exterior (FREEMAN et al., 2006; KARLSEN et al., 2003).

Os indivíduos com quem os decisores mantêm relacionamentos pessoais oferecem acesso à sua própria rede de relacionamentos em outros países, de simples contatos para relações profundamente confiáveis (HARRIS; WEELER, 2005). Estas relações podem então apresentar a base de novas ligações entre empresas e pessoas que auxiliaram o decisor na rápida internacionalização da sua empresa (JONES, 1999; WELCH; LUOSTARINEN, 1993), sendo através de novos contatos externos (tais como licenciados ou franqueados) ou novas ligações tanto para dentro quanto para fora (como importadores ou exportadores). (HARRIS; WEELER, 2005).

As relações nas redes são vistas como os meios pelos quais os indivíduos e empresas têm acesso a uma variedade de recursos mantidos por outros (BASTIÉ et al., 2013; HOANG; ANTONCIC, 2003). Estas relações podem melhorar o capital humano do decisor, aumentando a capacidade do indivíduo de identificar oportunidades, adquirir novos recursos e desenvolver o espírito empreendedor. No entanto, a dependência de redes de relacionamentos não está limitada a aquisições de recursos financeiros e materiais, mas também informações de oportunidades que irão facilitar a rápida internacionalização.

As redes tendem a ter um alcance maior e, portanto, é de se esperar que forneçam aos membros informações diversas e não redundantes (KOKA; PRESCOTT, 2002; MCEVILY; ZANETTI, 1999), facilitando a identificação de novas oportunidades empresariais. Enquanto as redes dispersas podem levar à identificação de um conjunto mais amplo de oportunidades internacionais, o grande volume de informações provenientes de uma rede diversificada geograficamente pode criar uma sobrecarga, abrandar a velocidade da internacionalização de processamento de informações. Redes geograficamente 
concentradas, por outro lado, podem ser mais eficazes na redução dos riscos percebidos associados em mercados internacionais, resultando em mais rápida entrada em mercados estrangeiros. (MUSTEEN, FRANCIS, DATTA, 2010).

Os contatos dos decisores também vão aumentar a propensão da empresa se internacionalizar precocemente devido ao foco de atenção ter se expandido para além das fronteiras nacionais (OVIATT; MCDOUGALL, 1997; YLI-RENKO et al., 2002). Os resultados de algumas pesquisas mostram que várias born globals são fundadas por empreendedores com experiência prévia de negócios internacionais e que desenvolveram uma rede internacional com clientes e contatos que podem levar a internacionalizar a empresas logo após o início das suas atividades (MCDOUGALL et al., 1994; CRICK; JONES, 2000; SASI; ARENIUS, 2008).

O conhecimento sobre mercados internacionais pode ser obtido através de contatos estabelecidos pelos decisores, que podem promover uma maior vontade por parte da empresa de se internacionalizar para aproveitar as oportunidades de crescimento internacional. Estes conhecimentos, por sua vez, proporcionam maior experiência de internacionalização e fazem com que a empresa tenha uma rápida diversificação geográfica (YLI-RENKO et al., 2002). Evald et al. (2011) argumentam que certos tipos de redes sociais habilitam os decisores a descobrir e explorar as oportunidades internacionais com maior eficiência em relação aos decisores com menos redes sociais, aumentando a velocidade de internacionalização da empresa (KLYVER; CHRISTENSEN, 2007; MANOLOVA et al., 2002; JOHANSON; VAHLNE, 2006).

O capital social (o uso de redes e relacionamentos pessoais ou profissionais) também tem sido consistentemente identificado como essencial para 0 desenvolvimento e sucesso das born globals (ARENIUS 2005; DIB et al., 2010; EVANGELISTA, 2005). As relações interpessoais também podem ser muito importantes no fornecimento de conhecimento de novos mercados (HAKANSSON; SNEHOTA, 1995; WALTER et al., 2001). Essa necessidade é bem reconhecida em negócios internacionais (BARTLETT; GOSHAL, 1989), especialmente pela escola de Uppsala (JOHANSON; VAHLNE, 1977, 1990, 2003), o conhecimento é um fator específico na compreensão dos países e suas culturas. 
Além disso, Harris e Wheeler (2005) afirmam que as relações internacionais do decisor devem ser vistas como um recurso crítico na condução do comportamento estratégico da empresa. A rede de relações do empreendedor frequentemente precede a formação de novo empreendimento. Seu impacto na criação de novo empreendimento internacional pode começar com a contribuição para a descoberta de oportunidades (ELFRING; HULSINK, 2003). O capital social facilita o acesso aos recursos e aumenta, consequentemente, a probabilidade de que as oportunidades sejam obtidas (ALDRICH; ZIMMER, 1986). Além disso, as redes podem contribuir para a formação de novos empreendimentos internacionais, não apenas fornecendo acesso a recursos, mas também afetando as cognições dos empresários no sentido de internacionalizar precocemente a empresa. (NOWINSKI; RIALP, 2016).

O estudo de Sharma e do Blomstermo (2003) aponta que as relações dos decisores podem influenciar as suas intenções para perseguir oportunidades de negócios internacionais desde os primórdios da empresa, tendo, assim, um efeito na precocidade de internacionalização. As redes de contatos dos decisores são formadas por laços que facilitam o caminho da internacionalização precoce por proporcionar aos decisores confiança para tomar a decisão sobre as oportunidades de negócios internacionais.

Os resultados, de Evald et al. (2011) mostraram a existência de uma correlação significativa entre o nível de intenção de exportação e a variável capital social (networking com empresários). Estes resultados em relação ao capital social também são consistentes com estudos anteriores (SHARMA; BLOMSTERMO, 2003; CHUNG et al., 2000; JOHANSON; VAHLNE, 2006). Os resultados empíricos do estudo de Evald et al. (2011) enfatizam a fase pré-fundação da empresa, quando os empreendedores iniciantes com uma rede social que inclui um ou mais empreendedores estão mais propensos a desenvolver as intenções de exportação do que aqueles empreendedores que não estão inseridos em redes sociais e tende a iniciar rapidamente as operações de exportação. 
A iniciação de exportação, especialmente por empresas menores e empreendedoras, é baseada em relações sociais. Em 31 casos de iniciação de exportação investigadas por Ellis e Pecotich (2001), os laços sociais foram encontrados para desempenhar um papel importante na decisão de começar a exportar. Os primeiros movimentos de exportação podem ser entre compradores e fornecedores que se desenvolveram por meio das relações sociais. Em linha com os achados e Ellis e Pecotich (2001), a experiência dos empresários examinados no estudo de Felzensztein et al. (2015) também sugere que ter um número maior de redes conduz a uma internacionalização mais diversificada, como consistente com a abordagem de rede para a internacionalização. Freeman et al. (2006) também descobriram que as redes são particularmente importantes para a rápida expansão (precocidade e velocidade), em mercados internacionais, permitindo que a empresa compartilhe recursos e riscos com outras empresas na rede.

Considerando os argumentos dos trabalhos apresentados anteriormente, pode-se postular que:

$H_{3 c}$ : $O$ capital social do gestor está positivamente associado à velocidade de internacionalização da empresa (em termos de precocidade e de crescimento das vendas internacionais).

\section{9.}

\section{Impacto do capital social no grau de internacionalização}

De acordo com Evald et al. (2011), a capital social do empreendedor e do gestor de PME afeta a capacidade criativa da empresa nas atividades de identificação e aquisição de recursos externos e a maneira como se usam estes recursos para iniciar o processo de internacionalização. O capital social do empreendedor também desenvolve a criatividade das empresas, permitindo que estas explorem a aplicação de ideias inovadoras, criando produtos mais competitivos para as PMEs ampliarem seu mercado no exterior (PRASHANTHAM, 2008; OMRI; BECUWE, 2014). Além de produtos mais competitivos, a criatividade da PME influenciada pelo capital social do empreendedor promove o desenvolvimento de processos produtivos e administrativos complexos mais ágeis, tornando a execução de atividades ligadas aos negócios internacionais desta PME mais simplificada, fazendo aumentar cada 
vez mais o envolvimento desta PME com a internacionalização e, por conseguinte, aumentando a abrangência da internacionalização.

Além de tais benefícios originários das informações, o capital social facilita o acesso dos indivíduos e das empresas aos recursos mais escassos ou a adquirir tais recursos como conhecimento, conselhos, ajuda, apoio, confiança em relação a uma terceira parte e solidariedade. McDougall et al. (1994) sugere que os contatos pessoais diretos de indivíduos-chave nos mercados estrangeiros podem ser usados para identificar novas oportunidades, obter aconselhamento empresarial, auxiliar na negociação estrangeira e abrir as portas para novos mercados internacionais. Yli-Renko et al. (2002), bem com Levy et al. (2013), destacam uma associação positiva entre as redes de contato internacionais de funcionários-chave e a intensidade de conhecimento da empresa e intensidade de internacionalização.

Considerando estudos realizados sobre as multinacionais, os pesquisadores encontraram evidências de que o capital social de funcionários-chave tem sido associado a maior coordenação, cooperação e compartilhamento de conhecimento dentro da rede global da empresa (GRIFFITH; HARVEY, 2004; INKPEN; TSANG, 2005; KOSTOVA; ROTH, 2003; TAYLOR, 2007; TSAI; GHOSHAL, 1998; LEVY et al., 2013). Da mesma forma, ocorre a influência dos gestores de pequenas e médias empresas no processo de internacionalização, tais como no comprometimento e obtenção de conhecimento experiencial da rede social da qual fazem parte estes gestores, como encontrado no modelo comportamental de Uppsala (JOHANSON; VAHLNE, 1990; 2006), devido à obtenção de conhecimentos específicos da rede social em relação às atividades de internacionalização deste tipo de empresa. Sendo assim, o gestor, em contato com sua rede social, obtém mais conhecimentos sobre mercados estrangeiros e transfere seus conhecimentos para a empresa, aumentando tanto o comprometimento desta com a rede social na qual está inserida quanto a profundidade de internacionalização. 
Lindmark et al. (1994), bem como Evald et al. (2011), enfatizam que as relações locais e regionais muitas vezes desempenham um papel fundamental para a orientação internacional dos novos exportadores. Esta afirmação é suportada por Denis e Depelteau (1985), que encontraram em seu estudo que os decisores de pequenas empresas dependem fortemente de informações adquiridas através de redes e transações de negócios, em vez de análises fornecidas pelos prestadores de serviços de informações, pois confiam nessas informações para obterem maiores oportunidades em vários países estrangeiros.

Muitas vezes as pessoas recorrem a fontes confiáveis de informação para orientação. Neste contexto, as relações e interações com contatos internacionais podem fornecer informações ricas (UZZI, 1997) sobre as condições do mercado externo, incluindo potenciais oportunidades e armadilhas. Os decisores necessitam desenvolver relações em um contexto relacional mais amplo. Isto implica que, embora um determinado ato possa levar a benefícios imediatos, ele também cria benefícios atrasados, tais como obrigações. Portanto, as redes de contatos dos decisores fazem com que a empresa busque aumentar a sua abrangência geográfica, pois a empresa necessita negociar e cumprir seus acordos feitos com seus parceiros da rede (FREEMAN et al., 2006).

Muitos relacionamentos originam de redes prévias, que fornecem as infraestruturas de comunicação com interesses comuns compartilhados (FREEMAN et al., 2006; HALLEN, 1992) e contatos pessoais e empresariais. A internacionalização das empresas também inclui atividades que fornecem oportunidades para construir relacionamentos com atores estrangeiros. Estas ligações fornecem oportunidades para as empresas e para os decisores aprenderem sobre comércio exterior e os vários modos de entrada; usando ativamente tais conhecimentos, as empresas devem estar em uma posição melhor para iniciar ou estender, operações estrangeiras para vários países (FREEMAN et al., 2006; KARLSEN et al., 2003). Na obtenção e utilização do conhecimento através de ligações para dentro e para fora da rede, embora as empresas enfrentem muitas restrições, eles buscam a melhoria do acesso ao conhecimento de mercado, mais oportunidades de negócios, a melhoria da qualidade de novas operações, menos tempo gasto na fase de estabelecimento de novas operações e principalmente a redução de riscos (FREEMAN et al., 2006). 
De acordo com Coviello (2006) e também Evald et al. (2011) as redes abre portas para os decisores, fornecendo o acesso ao mercado, apoio financiamento, canais de distribuição, referências e contatos para desenvolvimento interno e externo da PME. De forma similar, "Johanson e Vahlne $(2003,2006)$ salientam que relacionamentos devem ser vistos como um ingrediente-chave para o desenvolvimento de oportunidade no processo de internacionalização”. Em outra pesquisa com amostra de pequenas empresas de alta tecnologia, Fernhaber et al. (2009) mostraram que o conhecimento sobre questões internacionais é frequentemente obtido de parceiros de alianças com empresas com elevado capital de social, o que aumenta o comprometimento e a profundidade da internacionalização.

De acordo com Coviello (2006) e Evald et al. (2011), as redes abrem portas para os decisores, fornecendo o acesso ao mercado, apoio a financiamento, canais de distribuição, referências e contatos para desenvolvimento interno e externo da PME. De forma similar, Johanson e Vahlne $(2003,2006)$ salientam que os relacionamentos podem ser um "ingrediente-chave" para o desenvolvimento de oportunidade no processo de internacionalização. Em outra pesquisa com amostra de pequenas empresas de alta tecnologia, Fernhaber et al. (2009) mostraram que o conhecimento sobre questões internacionais é frequentemente obtido de parceiros de alianças com empresas com elevado capital de social, o que aumenta o comprometimento e a profundidade da internacionalização.

Musteen et al. (2010) encontraram que as redes caracterizadas por uma proporção maior de laços pessoais próximos não resultou em internacionalização mais rápida. Esta constatação, embora ao contrário do que era esperado, não é completamente surpreendente. A literatura (GRANOVETTER, 1973; 1982) fornece evidências de que laços fracos, em muitos casos, podem ser mais benéficos do que fortes laços. A falta de relação entre fortes laços pessoais e a velocidade de internacionalização também é consistente com os argumentos de Hite e Hesterly (2001). Ou seja, enquanto laços fortes são mais valiosos nas fases iniciais do ciclo de vida da empresa, laços mais fracos são mais benéficos em fases posteriores quando a empresa cresce e procura por novas oportunidades (MUSTEEN et al., 2010). Dib et al. (2010, p. 246) também descobriu "que as hipóteses relativas à utilização das redes pessoais nas pequenas empresas de software brasileiro não foram suportadas empiricamente". 
Harris e Weeler (2005) constataram que as relações raramente se originam de contatos com empresas clientes, associações, fornecedoras ou distribuidoras. Podem vir de qualquer lugar, no trabalho ou por ajustes sociais. Para estes autores, as pesquisas anteriores destacam que a interação social é muito importante. Esses relacionamentos, no entanto, necessitam amadurecer e desenvolver relações interpessoais confiáveis, e isso é feito através de extensa interação social e por um longo período de tempo, caso contrário, não irão reverter em benefícios para as empresas.

O resultado do estudo de Yli-Renko et al. (2002) mostrou não haver relação significativa entre capital social interno e o conhecimento do mercado externo por parte dos times de gestores. Isto pode ser devido ao tamanho relativamente pequeno do número de gestores, que limita a quantidade de informações armazenadas dentro da organização. No entanto, os relacionamentos positivos foram encontrados entre a intensidade de conhecimento e crescimento das vendas internacionais, por um lado, e entre o conhecimento do mercado estrangeiro e crescimento das vendas internacionais, por outro. Sendo assim, os resultados deste estudo confirmam parcialmente a relação entre capital social e o grau de internacionalização, especificamente em relação ao crescimento de vendas internacionais.

Considerando os argumentos dos trabalhos apresentados anteriormente, pode-se postular que:

$\mathbf{H}_{3 \mathrm{~d}}$ : $\mathbf{O}$ capital social do gestor está positivamente associado ao grau de internacionalização da empresa (em termos de abrangência e profundidade).

\subsection{0.}

\section{O impacto da propensão ao risco}

Sitkin e Pablo (1992, p. 10) afirmam que "o risco é uma característica das decisões, sendo definido como a extensão em que há incertezas potencialmente significativas sobre se e/ou serão obtidos resultados decepcionantes das decisões realizadas". Tal definição de risco possui três principais dimensões que são essenciais para sua compreensão: a incerteza do resultado, as expectativas do resultado e o resultado potencial. 
Propensão ao risco é "a tendência consistente que um tomador de decisões tem para tirar proveito de ações que ele ou ela tenha julgado ser arriscada" (CHEN; ZHANG; HU, 2015, p. 5). A propensão ao risco pode ser uma característica de interação pessoa-situação, sendo definida como o grau em que os tomadores de decisão acreditam que as decisões relacionadas aos riscos anteriores resultaram em sucesso ou insucesso (ALLEN et al., 2007; CHEN; ZHANG; HU, 2015). Caso o histórico de resultados seja de sucesso, o tomador de decisão é mais propenso ao risco em uma futura tomada de decisão (BYRNE, 2005; CHEN; ZHANG; HU, 2015; THALER; JOHNSON, 1990).

Propensão ao risco pode ser definida como um traço caracterizado por uma crescente probabilidade de se engajar em comportamentos que oferecem potencial perigo e oportunidade para algum benefício maior (BOTELLA et al., 2008). A propensão ao risco poderia ajudar a explicar o comportamento de risco de determinados indivíduos (DAS; TENG, 2001; FURMAN et al., 2010).

A propensão ao risco é de grande importância para o profissional da área gerencial, que muitas vezes depende de quão bem ele/ela lida com risco. A opinião geral é de que os gerentes são tomadores de risco maiores do que outros indivíduos, embora estudos empíricos demonstrem que os gerentes se diferenciam (como outras pessoas) em relação ao risco, tendo, em algumas ocasiões, maior ou menor propensão. A profissão gerencial implica a tomada de decisões arriscadas que geralmente têm consequências de longo alcance. Muitas decisões importantes são tomadas em condições de informação imperfeita, em que a propensão ao risco de um gerente exerce uma poderosa influência sobre a eficácia da decisão. $\mathrm{Na}$ maioria dos estudos relacionados a essa questão analisou-se o impacto da situação na propensão de riscos. Por outro lado, acredita-se que outras características possam influenciar a propensão ao risco também. Desta forma, há uma escassez de estudos que testem tal suposição (PAVIC; VOJINIC, 2012). A propensão ao risco é de grande importância para o profissional da área gerencial, que muitas vezes depende de quão bem ele/ela lida com risco. A opinião geral é de que os gerentes são tomadores de risco maiores do que outros indivíduos, embora estudos empíricos demonstrem que os gerentes se diferenciam (como outras pessoas) em relação ao risco, tendo, em algumas ocasiões, maior ou menor propensão. A profissão gerencial implica a tomada de decisões arriscadas que geralmente têm consequências de longo alcance. Muitas decisões importantes são tomadas em 
condições de informação imperfeita, em que a propensão ao risco de um gerente exerce uma poderosa influência sobre a eficácia da decisão. $\mathrm{Na}$ maioria dos estudos relacionados a essa questão analisou-se o impacto da situação na propensão de riscos. Por outro lado, acredita-se que outras características possam influenciar a propensão ao risco também. Desta forma, há uma escassez de estudos que testem tal suposição (PAVIC; VOJINIC, 2012).

Projetos empresariais buscam o sucesso aceitando o risco de falha. A sabedoria convencional afirma que o papel de um empreendedor requer decisões arriscadas em ambientes incertos e, portanto, indivíduos altamente avessos ao risco são menos propensos a se tornarem empresários (CALIENDO et al., 2006). A maioria dos estudos concentra o foco no risco empresarial e tenta incorporar a atitude de risco de uma pessoa como uma variável crucial nas escolhas gerenciais do empreendedor (FOURATI et al., 2011).

Rosen e Willen (2002) concluíram que a disponibilidade de um empreendedor em aceitar riscos não é um fator dominante na sua decisão de iniciar um negócio. De acordo com Cramer et al. (2002) e Fourati et al. (2011), o nexo de causalidade entre a aversão ao risco e a seleção empreendedora, embora seus resultados empíricos suportem a sabedoria convencional de que a escolha de se tornar um empreendedor, é positivamente correlacionado à atitude de risco da pessoa.

MacCrimmon e Wehrung (1986) descrevem a propensão ao risco como uma "vontade de assumir riscos" que indica claramente que esta vontade eventualmente afetará a busca por riscos reais. A literatura sobre propensão ao risco concentra-se em dois aspectos principais. $\mathrm{O}$ primeiro diz respeito às diferenças individuais que influenciam o comportamento de risco. $\mathrm{O}$ segundo aspecto diz respeito à influência situacional. Como resultado, também há opiniões contraditórias sobre a propensão de risco (HUFF et al., 1997). Uma linha de pensamento discutiu que a propensão de risco é um traço de personalidade que é estável ao longo do tempo (GREIGORIA; FAFF; HARTNETT, 2012), enquanto outra linha de pensamento defende que é uma característica que muda através de um processo de aprendizagem. Pesquisa anterior sobre a influência da personalidade no comportamento de risco argumenta que a propensão de risco é determinada pelas características individuais. Por exemplo, traços de personalidade, como autocontrole, busca por sensações diferentes e a baixa de 
impulsividade, estas, geralmente exibem comportamento de risco (MISHRA; LALUMIÈRE, 2011; HAMID et al., 2013).

Estudos também descobriram que a propensão ao risco está associada a outras características pessoais (ROGERS, 2003), tais como capacidade de inovação, criatividade e empreendedorismo (DESS; LUMPKIN, 2005; FRISHAMMAR; HORTE, 2007). Morehouse, Farley e Youngquist (1990) realizaram uma pesquisa em estudantes do ensino médio e descobriram que a aceitação ao risco pelos estudantes que são mais criativos é maior do que nos alunos avessos ao risco. Rogers (2003) argumenta que as inovações são geralmente incertas na natureza; "pessoas inovadoras" inevitavelmente aceitarão mais riscos que "pessoas adaptadoras", para explorarem mais as possibilidades e oportunidades. Pessoas adaptadoras tendem a preferir os métodos existentes, porque eles não se sentem confortáveis ao lidarem com riscos e incertezas. Pessoas inovadoras, em contrapartida, são mais abertas a riscos e incertezas (DONG, 2015).

Hambrick e Mason (1984) propuseram que as empresas com gestores mais velhos lançam mão de estratégias menos arriscadas do que as empresas com mais gestores mais jovens. Eles sugeriram algumas explicações desse comportamento gerencial: ter menos resistência mental e ser menos capaz de aprender novos comportamentos, exibindo maior compromisso com o status quo e segurança financeira/carreira, tornando-se relativamente mais importante, como gerentes e garantir certos níveis de aposentadoria (CAMPBELL, 2012).

A relevância das características individuais gerenciais para risco não é limitada a idade dos executivos. Riqueza pessoal é outra importante característica pessoal que pode influenciar a vontade dos gerentes de suportar riscos em uma empresa global. Gerentes cuja riqueza está ligada em grande parte à empresa são propensos a agir de forma avessa ao risco (GRAY; CANNELLA, 1997). Isto é devido à sua incapacidade para efetivamente diversificar seus riscos para obter riqueza pessoal (DENVERS et al., 2007). Em outras palavras, o risco representa uma coleção de várias ações estratégicas, que juntos ajudam a determinar o perfil de risco global da empresa. 
Evidências empíricas preliminares apoiam a ideia de que fatores socioeconômicos são importantes nas decisões relativas aos riscos. Um estudo realizado por MacCrimmon e Wehrung (1990) mostrou que um fator socioeconômico, que incluiu a riqueza, a renda, a autoridade e a posição, foi significativamente correlacionado com maior risco, abarcando três dos sete fatores de risco incluídos no estudo. Além disso, os resultados de Hung et al. (2012) sugerem que a diversificação de portfólio gerencial (que é provável que aumente com a riqueza externa) está positivamente relacionada com a taxa de alavancagem de desempenho da empresa, fatores que podem estar ligados ao nível educacional, à experiência e a habilidades gerenciais específicas dos decisores (CAMPBELL, 2012).

Preferência de risco ou propensão ao risco é uma característica da personalidade que, em conjunto com uma determinada situação ou contexto, determina a percepção do indivíduo do risco. Por outro lado, Weber e Milliman (1997) argumentam que a propensão ao risco é a força motriz que conduz ao comportamento, e que tal fator é dependente de um ponto de referência, em vez de um traço de personalidade (ACEDO; FLORIN, 2006).

A literatura sobre propensão ao risco está fundamentada em uma simples observação: gerentes não definem ou reagem ao risco de maneira que os modelos de decisão teórica possam prever. A teoria clássica da decisão conceitua risco como a variância da distribuição de probabilidade dos possíveis ganhos e perdas associados a uma determinada alternativa (PRATT, 1964). Na realidade, no entanto, os gerentes mais preocupados com resultados negativos (perdas) em vez de resultados positivos (ganhos), muitas vezes tendem a definir o risco apenas em termos de resultados negativos (MACCRIMMON; WEHRUNG, 1986; MARCH; SHAPIRA, 1987). Em outras palavras, eles são mais aptos a considerar o risco como um perigo, ao invés de uma teórica quantidade de resultados possíveis.

Para os gestores, uma escolha arriscada é quando a empresa pode perder dinheiro. Além disso, os gerentes não pensam em termos da probabilidade de perda, mas um pouco em termos de magnitude da perda (MARCH; SHAPIRA, 1987). Essa ênfase sobre a definição de risco como a quantidade de dinheiro que eles podem perder liderou o estudo de March e Shapira (1987), sugerindo que os gestores estão mais preocupados com a aversão à perda (KAHNEMAN; 
TVERSKY, 1979) ou ao arrependimento (BELL, 1983) que são classicamente definidos pelo risco (FLORIANI et al., 2008).

De acordo com Acedo e Florin (2006), não há muitos estudos sobre o papel da propensão ao risco dos empreendedores ou gestores principais de PME no processo de decisão de internacionalização. Agarwal (1994) enfoca o risco-país e conseguiu encontrar significado estudando o papel moderador do risco na relação entre distância cultural e a escolha do modo de entrada. Considerando que o comportamento empreendedor depende mais de atitudes individuais (KRUEGER, 2000) do que de medidas econômicas, como risco-país, faz-se importante examinar a percepção do empreendedor ou do gestor principal em relação ao risco, e o seu papel no comportamento de internacionalização (ACEDO; FLORIN, 2006).

De acordo com Harveston et al. (2000), os gerentes de empresas que se tornaram globais gradualmente possuem mais aversão ao risco e, por outro lado, de acordo com Knight e Cavusgil (1996), os gerentes de novas empresas internacionalizadas apresentam níveis mais elevados de tolerância ao risco em situações ambíguas, tais como aquelas encontradas na rápida internacionalização (ACEDO; JONES, 2007).

De acordo com Gupta e Govindarajan (1984), a atitude positiva dos gestores no sentido de risco favorece estratégias de expansão através de novos produtos e mercados. Portanto, pode-se deduzir que a propensão ao risco do gerente pode influenciar o comportamento de exportação das PMEs. Esta ideia é suportada pelo estudo McConnel (1979), bem como o trabalho de Paul et al. (1978), que sugerem que a exportação implica maior risco do que a venda no mercado interno e pode restringir gerenciadores de iniciar rapidamente, desenvolver e sustentar as operações de exportação. Da mesma forma, Dichtl et al. (1983) argumentam que a propensão ao risco dos gestores influencia o grau de envolvimento de exportação, enquanto Bauerschmidt et al. (1985) e Axinn (1988) determinam que percepções negativas sobre risco e exportação foram barreiras substanciais à exportação. Cavusgil (1984) também destaca que atitudes da administração em relação ao risco foram positivamente relacionadas com desempenho de exportação. Fernández-Ortiz e Castresana Ruiz-Carrillo (2005) afirmam que os baixos níveis de riscos percebidos baixos, juntamente com altos níveis de tolerância e 
propensão ao risco, conduzem a uma atitude positiva em relação à intensidade de exportação e vice-versa.

Uma vantagem potencial maior (relacionada a um futuro incerto) pode induzir a um comportamento de busca pelo risco, enquanto ameaças à situação atual (se não for insatisfatória) podem induzir a um comportamento de aversão ao risco (SITKIN; WEINGART, 1995). Então, o envolvimento com as exportações dependerá não apenas da propensão ao risco dos decisores, mas também da avaliação do decisor de se (e quanto) as exportações tendem a ser potencialmente mais rentáveis do que as vendas internas (SITKIN; WEINGART, 1995).

Sitkin e Weingart (1995) argumentam que a percepção de risco e a propensão ao risco não podem ser independentes: “quanto mais um indivíduo está inclinado a assumir riscos, menos arriscado, ele ou ela percebe o cenário de risco" (p.1578). Como argumentado por Janney e Dess (2006, p. 386), "um decisor que aceita tais riscos parece aceitar maiores níveis de risco em relação a seus contrapartes, mesmo que este decisor não perceba esse risco maior”. No entanto, Acedo e Galán (2011) argumentaram que a tolerância à ambiguidade (i.e., propensão ao risco) é negativamente relacionada à percepção de risco, mas descobriram uma relação não significativa estatisticamente.

O nível de envolvimento da empresa no mercado internacional reflete uma hierarquia da estrutura, conforme descrito na literatura (KUMAR; SUBRAMANIAM, 1997; PAN; TSE, 2000). Empresas que se engajam em risco de exportação comprometem poucos recursos, mas o retorno geralmente é igualmente baixo e difícil de prever ou controlar. Joint-ventures, por exemplo, ocupam o meio-termo, exigindo níveis moderados de risco e investimento, oferecendo níveis moderados de retorno e controle. Quando o gestor está disposto a arriscar e investir mais para exercer maior controle e maximizar as chances de retornos elevados, uma subsidiária integral no país estrangeiro poderia ser uma escolha melhor (GALAN; GONZALEZ-BENITO, 2006; RAMCHARRAN, 2000). Assim, o nível de envolvimento das empresas em mercados estrangeiros reflete uma diferença substancial em participação acionária, comprometimento de recursos, envolvimento de risco e controle através de várias estratégias de modo de entrada que implicam uma maior profundidade de internacionalização (CHUNG; ENDERWICK, 2001; KWON; KONOPA, 1993; JAVALGI et al. 2010). 
Liesch, Welch e Buckley (2011) argumentam que a propensão ao risco pode ser importante na tomada de decisão nos vários níveis de internacionalização, mas particularmente quando as empresas se engajam em novas atividades, como entrar em novos mercados estrangeiros usando diferentes estratégias de entrada. Nos vários estágios de internacionalização, as empresas têm descoberto que as informações e o conhecimento obtido por meio das práticas e experiências em mercados internacionais do gestor acentuam a propensão ao risco do gestor. Além disso, os traços da personalidade do empreendedor/gestor e a sua percepção apresentam-se como propulsores da tomada de risco, principalmente na internacionalização precoce.

A rápida internacionalização é uma estratégia arriscada e agressiva para as pequenas e jovens empresas porque é uma incursão que tem um custo elevado e muitos fatores desconhecidos, apresentando, assim, restrições significativas ao tamanho e idade da empresa (OVIATT; MCDOUGALL, 2005, LI et al., 2015). Portanto a propensão dos decisores das pequenas empresas para assumir riscos e ser proativo pode ser atribuída a seus estilos cognitivos e características de personalidade, ou seja, a tolerância ao risco e a propensão para agir (FORBES, 2005, LI et al., 2015). A impulsão ou determinação são determinantes da velocidade de decisão (WALLY; BAUM, 1994). Em outras palavras, a rápida internacionalização resulta da impulsão ou determinação. (LI et al., 2015). Os antecedentes do indivíduo fazem as born globals se dirigirem mais cedo para internacionalização. Estes antecedentes incluem a obtenção e organização do conhecimento, consenso e capacidade de resposta aos ambientes desconhecidos, juntamente com a propensão dos decisores para agir e assumir riscos na rápida internacionalização (LI et al., 2015).

Zahra e George (2002), bem como Dib et al. (2010), sugeriram que é a capacidade de aceitar riscos e inovar (características do decisor), que é aplicado com sucesso para a identificação precoce, avaliação e aproveitamento de oportunidades em mercados estrangeiros novos empreendimentos internacionais (ou pelas born globals). No entanto, a propensão ao risco dos decisores não é uniforme para todo o tipo de risco no início do processo de internacionalização (WU E KNOTT, 2006, BUCKLEY et al, 2016). Além disso, empresas multinacionais podem negociar uma dimensão de risco internacional mantendo o perfil de risco global sob controle. Comportamento semelhante pode ser 
observado no modelo de Uppsala (JOHANSON; VAHLNE, 1977), no qual os decisores que são avessos ao risco ou têm um inerentemente baixo nível de tolerância ao risco, tem um comportamento mais padronizado e prudente de internacionalização em termos de escolha de modo de entrada, fazendo a internacionalização ser gradual, ou seja, mais lenta do que nas Born Globals (BUCKLEY et al., 2016).

A propensão ao risco do decisor pode trazer ao decidir uma abordagem mais racional para as decisões estratégicas importantes tais como a seleção dos mercados estrangeiros e a escolha do modo de entrada; além disso, permite ao decisor buscar e analisar informações avaliando as alternativas entre as quais deve escolher. (FRANCIONI et al., 2015). Portanto, em casos quando o decisor não está com medo dos riscos relativos às decisões estratégicas relevantes, ele enfrenta-o com uma elevada consciência e a máxima atenção para as escolhas que faz. A presença de uma condição de risco maior vinda de uma percepção de ambiente hostilidade proporciona melhor compreensão das decisões estratégicas internacionais para as pequenas e médias empresas (FRANCIONI et al., 2015).

O risco abordado no estudo de Leite e Moraes (2014) foi definido como aquele enfrentado pelos empreendedores para internacionalizar a empresa que depende da disposição de comprometer recursos (LUMPKIN; DESS, 1996). Existem vários tipos de riscos no processo de internacionalização, pois a exploração de oportunidades por si só já é arriscada (JOHANSON; VAHLNE, 2009), e os gestores podem tomar decisões que sejam negativas à empresa.

A propensão aos riscos de empresas, bem como de decisores, que operam em uma cultura de informação, partilha e aprendizagem, são capazes de cultivar recursos de conhecimento e identificar as oportunidades mais rapidamente do que seus rivais (FELZENSZTEIN et al., 2015; FOSFURI; TRIBÓ, 2008). Tais empresas que vão para mercados internacionais passam de um nível mais elevado de riscos, sendo estes riscos: financeiro, recursos humanos e produção no exterior; do que outras empresas. Sendo assim, estas empresas e decisores estão dispostas a assumir o risco associado às atividades internacionais, porque eles acreditam que irão permitir-lhes trabalhar melhor com os clientes, para saber mais dos concorrentes e para cooperar de forma mais eficiente com fornecedores, distribuidores e órgãos governamentais no exterior (DIMITRATOS; 
PLAKOYIANNAKI, 2003; FELZENSZTEIN et al., 2015; PRASHANTHAM, 2011).

Uma pesquisa desenvolvida por Low e Weiler (2012) indica que a redução do risco pode ser prejudicial para o valor da empresa. No entanto, essa suposição de aversão ao risco universal pode ser flexibilizada porque os indivíduos variam em suas atitudes em relação ao risco. Portanto, o gestor irá buscar alternativas para reduzir o impacto do risco em seus negócios mesmo sendo propensão ao risco; uma vez não encontrando alternativas de redução de risco na internacionalização, adiará o início deste processo até encontrar uma forma de reduzir tais riscos.

Uma survey desenvolvida por Erramilli (1992) com empresas prestadoras de serviços dos Estados Unidos revelou que o risco é um dos fatores que influenciam significativamente a escolha do modo de entrada e o grau de internacionalização da empresa, via o aumento de investimento nas atividades internacionais. Por outro lado, a preocupação da empresa e consequentemente de seus gestores e empreendedores é na redução do impacto do risco e de rapidamente se estabelecer no mercado externo, aumentando a atratividade pelos canais de exportação. Além disso, as restrições do país anfitrião na propriedade estrangeira parecem estar associadas à maior incidência na exportação integrada como modo de entrada e ao grau de internacionalização.

O estudo de Li et al. (2015) mostra que a propensão de assumir riscos dos decisores é positivamente relacionada com a velocidade de internacionalização de pequenas e jovens empresas. Os resultados empíricos da pesquisa de Geppert et al. (2013) confirmam que os decisores de empresas globais bem-sucedidas aplicam uma abordagem de propensão aos riscos que combina cuidadosamente empreendedorismo e gestão profissional. O resultado principal do estudo de Francioni et al. (2015) sugere que os decisores tendem a seguir uma internacionalização mais racional no processo decisório estratégico, dependendo de sua propensão ao risco e o nível de educação (FRANCIONI et al., 2015). 
Segundo Obben e Magagula (2003), os gerentes que percebem que as exportações são mais arriscadas do que as vendas eram mais propensos a exportar, que sugerem que eles podem ser mais propensos a risco. Além disso, Shrader et al. (2000) encontraram em seu estudo que as pequenas empresas muitas vezes refletem as tendências comportamentais dos decisores, são capazes de atingir a internacionalização acelerada na ausência de recursos, equilibrando os riscos existentes no país ao qual a pequena empresa está entrando, o modo de entrada usado e a proporção do total da receita exposta aos riscos desse país (BUCKLEY et al. 2016).

Dib et al. (2010) descobriram que decisores born globals pareciam ser mais sensíveis aos riscos associados às operações nos mercados internacionais do que os decisores das empresas que se seguiu o caminho da internacionalização gradual. Por outro lado, os resultados do estudo de Felzensztein et al. (2015) indicam que os decisores com atitudes mais fortes ao risco (propensão ao risco) não estavam relacionados com a propensão de exportação (mais especificamente, exportação para múltiplos países), ou seja, não existe uma relação entre propensão ao risco do gestor e a abrangência das exportações das empresas.

Para as pequenas e médias empresas, o grau de internacionalização pode ser influenciado pela propensão ao risco e a percepção de riscos do decisor inerente às atividades no exterior. Os estudos anteriores apresentam diferenças empíricas nessa relação. Sendo assim, este estudo propõe as seguintes hipóteses:

$\mathrm{H}_{4 \mathrm{a}}$ : A propensão a risco do gestor está positivamente associada à velocidade de internacionalização da empresa (em termos de precocidade e de crescimento das vendas internacionais).

$H_{4 b}$ : A propensão a risco do gestor está positivamente associada ao grau de internacionalização da empresa (em termos de abrangência e de profundidade).

\subsection{1.}

\section{O impacto da percepção de risco do decisor}

Percepção de risco é definida como "a avaliação do indivíduo como arriscado uma situação é em termos de estimativas probabilísticas do grau de incerteza da situação, como que é controlada a incerteza, além da confiança nessas estimativas" (SITKIN; WEINGART, 1995, p. 1575). 
A sociologia e os estudos antropológicos mostraram que a percepção e aceitação do risco têm suas raízes em fatores sociais e culturais. Alguns estudiosos argumentam que a resposta aos riscos é mediada pela influência social transmitida por amigos, família, colegas de trabalho entre outros (SLOVIC, 1980). Em muitos casos, as percepções de risco podem formar depois, como parte da justificativa posterior para o próprio comportamento. Douglas e Wildavsky (1982) e também Slovic (1980) afirmam que as pessoas, agindo dentro de grupos sociais, minimizam certos riscos e enfatizam outros como um meio de manter e controlar o grupo.

$\mathrm{Na}$ área da pesquisa psicológica a percepção de risco originou-se em estudos empíricos de probabilidade, avaliação da utilidade e processos de tomada de decisão (EDWARDS, 1961; SLOVIC, 1980). Um grande desenvolvimento nesta área tem sido a descoberta de um conjunto de estratégias mentais, ou heurísticas, que as pessoas empregam para que o mundo incerto faça sentido. Embora estas regras sejam válidas em algumas circunstâncias, em outras, conduzem a preconceitos grandes e persistentes, com sérias implicações para a avaliação de risco. As avaliações dos especialistas parecem ser propensas a muitos preconceitos, mesmos como aqueles do público em geral, particularmente quando estes especialistas são obrigados a ir além dos limites dos dados disponíveis e confiar na intuição (SLOVIC, 1980).

Sitkin e Pablo (1992) formularam a hipótese de que em quadros positivos, que enfatizam ameaças situacionais aos recursos existentes, podem tornar os riscos inerentes a uma situação com maior perda, induzindo ao comportamento avesso ao risco, considerando que a ênfase maior está no aumento da vantagem limitada das explorações ou na recuperação de perdas que podem diminuir a importância dos riscos, aumentando, assim, a busca por oportunidades e, desta forma, induzindo ao comportamento de busca por risco. Tal explicação é coerente com a não linearidade que se encontra no cerne da teoria dos prospectos e seu suporte empírico, sugerindo que o mecanismo cognitivo através do qual ocorrem respostas comportamentais são observáveis. 
Sitkin e Pablo (1992) também destacam que a prevenção do risco é maior quando as ameaças aos ativos são relevantes (alto risco é percebido) do que quando um indivíduo percebe pouco risco fazendo pensar que não tem nada a perder. Portanto, é razoável postular que níveis mais elevados de percepção situacional do risco estariam negativamente relacionados a decisões arriscadas, desde que as pessoas tendessem a associar os resultados negativos de risco mais fortemente do que com a variabilidade do resultado (LEVITT; MARCH, 1988). Dada esta assimetria perceptiva, pode-se ressaltar que as ações tomadas em condições de maior risco situacional percebido seriam também aquelas nas quais o indivíduo percebe que teria baixo valor esperado. Tal constatação foi confirmada nos estudos de Sitkin e Weigartn (1995).

A definição de risco tem sua fundamentação na probabilidade e magnitude do risco global. A percepção de risco das pessoas baseia-se mais na magnitude do risco do que na probabilidade, significando que a magnitude da perda potencial é o fator mais influente na formação da percepção de risco (KEIL et al., 2000; REYNOLDS; NELSON, 2007). Mas em alguns casos especiais, a probabilidade pode desempenhar um papel mais importante na formação da percepção de risco do que a magnitude da perda (BONTEMPO et al., 1997; CHEN; ZHANG; HU, 2015).

A percepção de risco possui componentes ambientais e organizacionais. Isso significa que as percepções dos decisores em relação à incerteza desses componentes necessariamente variam sistematicamente através dos níveis de análise. Ou seja, nem todos os decisores de um determinado país ou tipo de indústria e/ou o porte da empresa tem percepções homogêneas da incerteza ambiental geral por parte de todos os gestores de uma determinada empresa. Percepções gerenciais do risco de cada fator podem, na verdade, variar com as características individuais e da empresa (MILLER, 1992; YASAI-ARDEKANI, 1986). Além disso, as implicações de cada risco para instabilidade do desempenho da empresa diferem entre empresas individuais, ou projetos dentro de empresas, dependendo de suas exposições, conforme determinado pelas decisões estratégicas corporativas e financeiras (LESSARD, 1988; ROBOCK, 1971; MILLER, 1992; SIMON, 1982; TING, 1988). 
Pesquisas empíricas sugerem a existência de uma diferença na hipótese de percepção de risco em que os decisores (empreendedores) parecem perceber nos níveis mais baixos de risco associados com a criação de novo empreendimento e sua internacionalização (BARBOSA et al., 2007; NABI; LIÑÁN, 2013). Isto pode ocorrer através da superestimação das chances de sucesso na criação do negócio e a busca de novos mercados (DOUGLAS, 2009; MONSEN; URBIG, 2009; NABI; LIÑÁN, 2013). Assim, esses decisores concentram e percebem pontos fortes e oportunidades ao invés de fraquezas e ameaças. Essa percepção de risco que prevê que os indivíduos possuem uma intenção de crescimento empresarial (BARBOSA et al., 2007b) e na busca por novas oportunidades (NABI; LIÑÁN, 2013; PALICH; BAGBY, 1995; SIMON et al., 2000) e, portanto, leva a uma tomada de decisão no sentido no sentido de abrir um novo negócio (NABI; LIÑÁN, 2013).

Como parte do processo de tomada de decisão, a percepção de risco pode ser entendida como a avaliação de um indivíduo em relação ao risco (CHEN; ZHANG; HU, 2015; WILLIAMSA; NOYES, 2007). Portanto, a percepção de risco do indivíduo possivelmente afetará o processo de tomada de decisão (CHEN; ZHANG; HU, 2015; REYNOLDS; NELSON, 2007). Para muitos pesquisadores existe uma relação entre a percepção de risco e a tomada de decisão (KRUEGER; DICKSON, 1994; KEIL et al., 2000, HILLSON; MURRAYWEBSTER, 2004; WILLIAMSA; NOYES, 2007). No entanto, algumas das relações identificadas não são consistentes.

Estudos anteriores (CHILD; RODRIGUES, 2003， 2004; HSIEH; RODRIGUES; CHILD, 2010) sugerem a existência de várias fontes de risco que são enfrentadas pelas empresas, tais como a incerteza ambiental, risco institucional, risco de mercado e da indústria e risco de deficiência de recurso. A literatura sobre Joint Venture Internacional (JVI) sugere que a deficiência de recursos e outras assimetrias entre as diferentes empresas podem explicar o o motivo de os parceiros decidirem cooperar através da formação de uma JVI. No entanto, a teoria também sugere que estas mesmas razões podem encorajar os parceiros para enganar e usar a parceria oportunamente para avançar nos seus interesses (CHILD; RODRIGUES, 2004; HSIEH; RODRIGUES; CHILD, 2010). As fontes de risco ou incertezas mencionadas acima têm implicações para a cooperação entre os parceiros e para os resultados de desempenho do 
empreendimento em geral (DAS; TENG, 1996; HSIEH; RODRIGUES; CHILD, 2010).

De acordo com Wiedersheim-Paul, Olson e Welch (1978), uma influência adicional sobre o tipo de comportamento adotado de pré-exportação é a percepção do tomador de decisão da incerteza associada à movimentação para o mercado exterior. O impacto do nível percebido de incerteza, inicialmente, pode influenciar o comportamento de pré-exportação. Não importa o quão forte pode ser o estímulo de exportação, a incerteza percebida pode ser demasiadamente elevada para a empresa. Ressalta-se, é claro, que um elevado nível de percepção do risco e incerteza, mesmo combinados com um baixo grau de tolerância, não necessariamente impedirá um decisor de adotar alguma forma de ação antes da exportação, dependendo do comportamento da força para iniciar à exportação. O comportamento adotado pode ser visto como uma tentativa do tomador de decisões para reduzir a incerteza da exportação.

Apesar da existência de diferenças objetivas na política e na estabilidade macroeconômica, as características dos decisores podem não refletir essas diferenças. Os decisores podem avaliar os riscos atuais em relação a suas próprias experiências passadas (MILLER, 1992; TVERSKY; KAHNEMAN, 1973). Se assim for, as percepções dos decisores não compartilhariam um ponto de referência comum entre países para fazer comparações internacionais transversais. Os decisores também parecem ter diferentes tolerâncias para ambiguidade em todos os países (HOFSTEDE, 1980; MILLER, 1992) que podem exagerar ou diminuir o risco percebido de maneira diferente em todos os países em relação à instabilidade ambiental (MILLER, 1992).

Estudos anteriores (MARCH; SHAPIRA, 1987; MILLER; LEIBLEIN, 1996; MILLER; REUER, 1996; RUEFLI et al., 1999) argumentam que a abordagem "clássica" falha ao capturar o conceito de risco percebido, sendo uma característica reconhecida pelos gestores. Do ponto de vista gerencial, o risco é muitas vezes percebido por ser associado a resultados decepcionantes ou negativos (HSIEH; RODRIGUES; CHILD, 2010; MARCH; SHAPIRA, 1987; SITKIN; PABLO, 1992), que têm um impacto significativo no valor da organização e na sua capacidade de atingir os objetivos. Portanto, o risco também pode ser definido como a percepção de possíveis instabilidades e vulnerabilidades enfrentadas pelas empresas que impõem limitações, restrições ou até mesmo 
perdas, principalmente quando se trata de aumentar a diversificação internacional (AHMED et al., 2002; HSIEH; RODRIGUES; CHILD, 2010).

Os estudos sobre o papel da percepção de risco mostram que a atividade de exportação carrega um risco maior do que operações domésticas (ACEDO; JONES, 2007; WIEDERSHEIM-PAUL et al., 1978). Neste sentido, diferenças de percepções de risco foram encontradas quando comparadas empresas internacionais e empresas domésticas. Cavusgil e Naor (1987) observaram que a percepção do risco diminui com avanço da empresa no processo de internacionalização (ACEDO; JONES, 2007; JAFFE, NEBENZAHL, PASTERNAK, 1988). Portanto, o conhecimento e em particular o conhecimento experiencial, influencia as diferenças da percepção de risco ao longo do processo de internacionalização (ACEDO; JONE, 2007; JOHANSON; WIEDERSHEIMPAUL, 1975).

Quanto mais imprevisível a empresa e os decisores percebem as variações no seu desempenho de venda, mais será a busca por outras fontes de crescimento e vendas a fim de isolar a empresa de potenciais perturbações. Aumentando o risco e a incerteza das operações presentes, reduz a percepção do risco e a incerteza da criação e comercialização de um produto novo ou vender internacionalmente. Ambas formas de diversificação fornecem uma função isolante, garantindo que uma empresa, enquanto sofre uma perda em um mercado, é menos provável que experimente uma perda em todos os mercados. Assim, onde a segurança básica da empresa é ameaçada por flutuações de mercado, pode ser desenvolvido um motivo poderoso para iniciar operações de exportação. (WIEDERSHEIM-PAUL et al., 1978).

Com o aumento do conhecimento, provavelmente a percepção de risco irá cair. No entanto, conhecimento sem a intenção pode levar a lugar nenhum. Jaffe e Pasternak (1994) afirmam que a intenção é uma combinação de atitude, de situação e de motivação; além disso, avaliar a intenção de exportação é uma função de crença, bem como de sensibilidade e de prontidão. Assim, é o decisor que determina a percepção do ambiente e a maneira de como os negócios serão feitos (ACEDO; JONES, 2007; MORGAN; KATSIKEAS, 1997). 
Leonidou et al. (1998) destaca que algumas características psicológicas estão associadas com a percepção que os decisores têm de sucesso ou fracasso em atividades internacionais. Knight e Leisch (2002) observaram a importância da obtenção de informação e seu uso durante várias fases do processo de internacionalização das empresas e também nos resultados destas empresas, verificando a influência da informação obtida na percepção de risco do indivíduo (VALLASTER, 2000). Isto implica que estratégias arriscadas serão vinculadas mais racionalmente, sendo orientada para indivíduos que têm experiência internacional. Portanto, o risco percebido pelo decisor poderá influenciar negativamente a velocidade de acesso ao mercado internacional (ACEDO; JONES, 2007).

A forma com que os gerentes lidam com o risco também estão em desacordo com a teoria clássica da decisão. March e Shapira (1987), bem como Forlani, Parthasarathy e Keaveney (2008) constataram que a maioria dos gestores acredita que o risco é controlável. Esses gestores acreditam que podem reduzir os riscos, usando suas habilidades para gerenciar os perigos. Para o caso de uma decisão de entrada no mercado estrangeiro, isto sugere que os gerentes acreditam que o risco de perder o investimento financeiro é considerável, necessitando elevado controle, tais como a aquisição de empresas no exterior, e, desta forma, compensando o risco por meio da atratividade de ganhos por essa estratégia. Isto é especialmente verdadeiro na ausência de outros fatores que podem servir para reduzir a percepção do risco de perda, ou senão aumentar a confiança do gerente no sucesso do empreendimento (tais como experiência prévia, disponibilidade de recursos, conhecimento das forças de mercado etc.). Neste caso, as decisões dos gerentes coincidirão com a perspectiva da teoria de custo de transação, ou seja, eles vão ter uma preferência por estratégias de entrada de baixo investimento, como exportação ou licenciamento, para se internacionalizar mais rápido (FORLANI; PARTHASARATHY; KEAVENEY, 2008).

Gerentes de empresas internacionais avaliam o risco associado a vários modos de entrada e o controle além da capacidade de implantar efetivamente esse controle, tendo influência das percepções de risco. Isto é importante porque há evidências de que o risco percebido pelo decisor desempenha um papel mais importante nas decisões de internacionalização do que avaliações de risco puramente normativa (FORLANI; PARTHASARATHY; KEAVENEY, 2008; 
MARCH; SHAPIRA, 1987). No entanto, os gerentes mais preocupados com resultados negativos (perdas) em vez de resultados positivos (ganhos) muitas vezes tendem a definir o risco apenas em termos de resultados negativos (MACCRIMMON; WEHRUNG, 1986; MARCH; SHAPIRA, 1987). Em outras palavras, estes gerentes são mais aptos a considerar o risco como um perigo de resultados negativos - uma escolha arriscada poderia levar a empresa e consequentemente o gerente a perder dinheiro e, sendo assim, este gerente tende a fazer a empresa a se internacionalizar gradualmente, retardando o processo de internacionalização (FORLANI; PARTHASARATHY; KEAVENEY, 2008).

Entretanto, os gerentes em uma empresa altamente capacitada para entrar no mercado internacional e com experiência internacional considerável estarão mais confiantes em situações de elevado controle e, portanto, estarão aptos a rever as estimativas de risco para baixo, ou seja, perceberão o risco em níveis menores. Gestores nesta situação provavelmente irão interpretar o risco associado como uma oportunidade. Com efeito, os gerentes em tais situações irão perceber maior risco em situações de baixo controle, onde empresa possui maiores recursos não utilizando estes recursos adequadamente, tendo assim, risco de perda de oportunidade. Estes gerentes podem lamentar o fato de que as recompensas que poderiam ter sido bem-vindas e bem aplicadas com um controle maior, lamentavelmente podem ter sido perdidas (FORLANI; PARTHASARATHY; KEAVENEY, 2008). Daí não ter uma oportunidade para controle de resultados de uma iniciativa internacional afetaria a percepção de risco dos gestores nas empresas, levando a empresa a recuar o processo de internacionalização deixando de ser aumentar o número de países e suas receitas vindas do mercado internacional (FORLANI; PARTHASARATHY; KEAVENEY, 2008).

As características pessoais dos fundadores de pequenas empresas de base tecnológica incluem a tendência em realizar pesquisa e desenvolvimento de novos produtos e propensão aos riscos, tendo impactos positivos na intensidade destas pesquisas. (ACS et al., 1997; KUIVALAINEN et al., 2007). Muitas empresas de base tecnológicas são fundadas por especialistas que descobriram novas tecnologias ou conceitos e tenham forte desejo para assumir riscos em comercializar essas novas descobertas por conta própria e rapidamente no mercado internacional (FREEMAN et al., 2010), pois percebem muito mais oportunidades do que riscos nessas operações (LI; QIAN; QIAN, 2012; 
RUGMAN; OH, 2010). Além disso, com estrutura organizacional simples, os decisores seniores deste tipo de empresa se comunicam diretamente com os funcionários de operação e existem poucas rotinas organizacionais ou do património administrativo para obstruir o processo de comercialização. (KNIGHT; CAVUSGIL, 2004; LI; QIAN; QIAN, 2012).

Evidências empíricas mostram que os empreendedores agem no sentido de aproveitar as oportunidades porque eles percebem menos riscos associados a estas oportunidades do que os outros (KRUEGER; DICKSON, 1994), sendo estas oportunidades em mercados internacionais. Keh et al. (2002) observaram que empreendedores agem quando a probabilidade de sucesso é elevada ou o nível de percepção de risco é baixo. O argumento concorrente é de que alguns indivíduos têm mais propensão ao risco em uma oportunidade do que os outros, e tendem a ficar próximo de elevados níveis de risco percebido (ACEDO, FLORIN, 2007; FORLANI; MULLINS, 2000; STEARNS; HILLS, 1996). Ambos os argumentos encontraram suporte empírico, presumivelmente por causa da existência de uma relação inversa entre as duas construções devido à alternativa usada para medir o risco (ACEDO, FLORIN, 2007).

O aparente conflito na escolha do modo de entrada é mitigado com as percepções de risco dos gerentes devido à função de controle e de capacidade, conciliando as previsões das teorias predominantes sobre o modo de entrada e, ao mesmo tempo, introduzindo uma nova perspectiva. Sendo assim, o gestor percebe o risco menor e esse gestor mostra-se mais comprometido com a internacionalização da empresa e faz com que aumente o grau de internacionalização dessa empresa, aumentando também o investimento em atividades internacionais (FORLANI et al., 2008).

Alguns pesquisadores observaram que, como o nível de percepção do risco aumentado, uma pessoa é menos propensa a se envolver em comportamento de risco (CHEN; ZHANG; HU, 2015; DUNEGAN et al., 1992). Outros pesquisadores sugerem que uma pessoa com elevado nível de risco percebido tende a tomar decisões mais arriscadas (CHEN; ZHANG; HU, 2015; KAHNEMAN; TVERSKY, 1979). A contradição revela a necessidade de se analisar a influência da percepção de risco na tomada de decisão também no contexto da diversificação internacional de empresas (CHEN; ZHANG; HU, 2015). 
O estudo de Brouthers (1995) confirmou que a escolha da empresa por qualquer estratégia de modo de entrada varia em relação à percepção de risco pelo decisor associada aos mercados estrangeiros. Assim, as decisões estratégicas são feitas por indivíduos que opera dentro da organização envolvida com negócios internacionais. Portanto, a tomada de decisões dentro das organizações exportadoras é afetada significativamente pelo nível de risco percebido pelos decisores da empresa, em particular, sendo intimamente relacionado às preferências dos decisores (CAVUSGIL; NEVIN, 1984). Especificamente, foram encontradas evidências de que as percepções de risco internacionais têm um impacto significativo sobre a escolha do modo de entrada das empresas, ao entrar em mercados estrangeiros.

Acedo e Jones (2007) descobriram que as empresas com decisores com uma grande dose de experiência internacional irão internacionalizar-se mais rápido, e que o grau de percepção de risco em relação a operações internacionais destes decisores está negativamente associada com velocidade de internacionalização. Além disso, Pla-Barber e Escribá-Esteve (2006), bem como Hilmersson e Johanson (2016) constataram que uma atitude proativa entre a equipe de gestão de marketing e a equipe de liderança promovem a internacionalização mais rápida da empresa, pois estes decisores percebem menos riscos de perdas nestas atividades (HILMERSSON; JOHANSON, 2016).

O resultado do estudo de Acedo e Jones (2007) mostram que a percepção de risco influencia significativamente a velocidade de acesso aos mercados internacionais e surge como uma variável crucial em relação à velocidade do processo de internacionalização. Além disso, indivíduos com orientação internacional parecem ter uma menor percepção de risco oriunda de operações internacionais. Estes autores destacam que é possível que a percepção de risco do decisor tolerante a situações incertas e que tem vontade de mudar as coisas seja reduzida. Essas declarações reforçam a necessidade de obtenção de informações internacionais, realizando contatos com redes de empresas e pessoas a fim de implementar as melhores decisões. Esses resultados, segundo Acedo e Jones (2007), confirmam o papel central desempenhado pelo indivíduo, ao explicar a percepção de risco no processo de internacionalização. Eles também enfatizam que o elevado nível de velocidade de internacionalização indica a necessidade de 
considerar a percepção de risco do decisor nos estudos sobre a velocidade de acesso ao mercado internacional.

Acedo e Galán (2011) descobriram em seu estudo que a percepção de risco é associada negativamente à intensidade de exportação. Cavusgil e Naor (1987) constataram que os exportadores tendem a perceber menos riscos ambientais do que os não exportadores, e Manolova et al. (2002) concluíram que os gerentes de empresas internacionalizadas têm visões mais favoráveis do ambiente.

Os resultados do estudo de Forlani et al. (2008) mostraram que os gestores de empresas menos capacitadas percebem o risco aumentar com níveis crescentes de apropriação, enquanto aqueles das empresas mais capacitadas percebem o aumento do risco com a diminuição do nível de propriedade. Estas observações aparentemente contraditórias são consistentes com a previsão da teoria de internacionalização, a qual indica que os gestores devem perceber o risco, aumentado com o aumento da participação (ANDERSON; GATIGNON, 1986; WILLIAMSON, 1975), ou seja, aumentando a profundidade de internacionalização da empresa.

Uma das conclusões da discussão do estudo de Wiedersheim-Paul et al. (1978) foi de que um grupo de 27 empresas com gestores que demonstraram agir antes da exportação tinham menos dificuldades em iniciar no processo de decisão no sentido de se tornar exportadores, sendo mais provável que continuem a crescer mais fortemente como grupos de exportadores. As forças que têm agido na busca por mercados de exportação podem continuar a apoiar a atividade de exportação. Em algumas empresas as operações de exportação foram usadas apenas como uma medida temporária. Uma possível explicação para a saída destas empresas do mercado de exportação, segundo esses autores, foi uma questão fortuita, ou seja, começou a exportar rapidamente mas percebeu o risco muito elevado. Portanto, a percepção mais elevada do risco, por parte dos gestores, diminuiu a velocidade de exportação das empresas pesquisadas.

Para as pequenas e médias empresas, o grau de internacionalização pode ser influenciado pela propensão ao risco e a percepção de riscos do decisor inerente às atividades no exterior. Os estudos anteriores apresentam diferenças empíricas nessa relação. Sendo assim, este estudo propõe as seguintes hipóteses: 
$H_{4 c}$ : A percepção de risco (das atividades internacionais) por parte do gestor está negativamente associada à velocidade de internacionalização da empresa (em termos de precocidade e de crescimento das vendas internacionais).

$H_{4 d}$ : A percepção de risco (das atividades internacionais) por parte do gestor está negativamente associada ao grau de internacionalização da empresa (em termos de abrangência e de profundidade).

\subsection{2 .}

\section{Variáveis de controle}

Nesta tese é avaliado o efeito das variáveis de controle tanto no grau de internacionalização quanto na velocidade de internacionalização. As variáveis de controle são o tamanho relativo da empresa, o grau de internacionalização da indústria e a insatisfação do mercado doméstico.

O tamanho relativo da empresa pode afetar o desempenho de exportação (SAMIEE; WALTERS, 1990). É necessário, no entanto, interpretar cuidadosamente a relação entre o tamanho e as exportações, porque a relação pode ser espúria (REID, 1981): afinal, como as empresas crescem naturalmente, elas podem crescer tanto no mercado doméstico quanto no mercado exterior, conduzido por antecedentes comuns, não porque o tamanho da empresa afeta diretamente as exportações.

Algumas indústrias podem ser menos propensas às exportações do que outras (MANOLOVA et al., 2002), possivelmente porque há um grande mercado interno para os produtos ou porque seus produtos são caros para o transporte. Além disso, algumas indústrias são naturalmente mais inovadoras, o que pode levar as empresas a vender no exterior mais facilmente (STERLACCHINI, 1999). Katsikeas et al. (2000) argumentam que os resultados das exportações da empresa devem ser julgados em comparação com suas contrapartes da indústria. Portanto, pode ser importante avaliar o efeito do grau de internacionalização da indústria a qual a PME está inserida tanto na velocidade de internacionalização quanto no grau de internacionalização. 
Karagozoglu e Lindell (1998) identificaram uma série de estímulos que motivaram e atraíram as PMEs para as atividades de exportação. Para estes autores um dos motivos pelo qual estas empresas buscam se estabelecer no mercado internacional é a insatisfação com o mercado doméstico. A insatisfação com o mercado doméstico pode ser devido à saturação do mercado doméstico para o produto específico da empresa, ameaças de empresas multinacionais e a redução da disponibilidade de recursos no mercado interno. 


\section{4 \\ Métodos e dados}

Neste capítulo serão abordados os métodos utilizados para o desenvolvimento da pesquisa empírica, sendo o mesmo subdividido em cinco seções. Após esta breve descrição das etapas da pesquisa, é apresentada então a forma de medição dos construtos, com base nas sugestões encontradas na literatura. Em seguida, apresenta-se o procedimento de coleta de dados. É apresentada na sequência a descrição do processo de amostragem e seleção de respondentes e, por fim, é descrita como foram realizadas as análises dos dados.

A Figura 2 apresenta de forma esquemática as etapas da pesquisa.

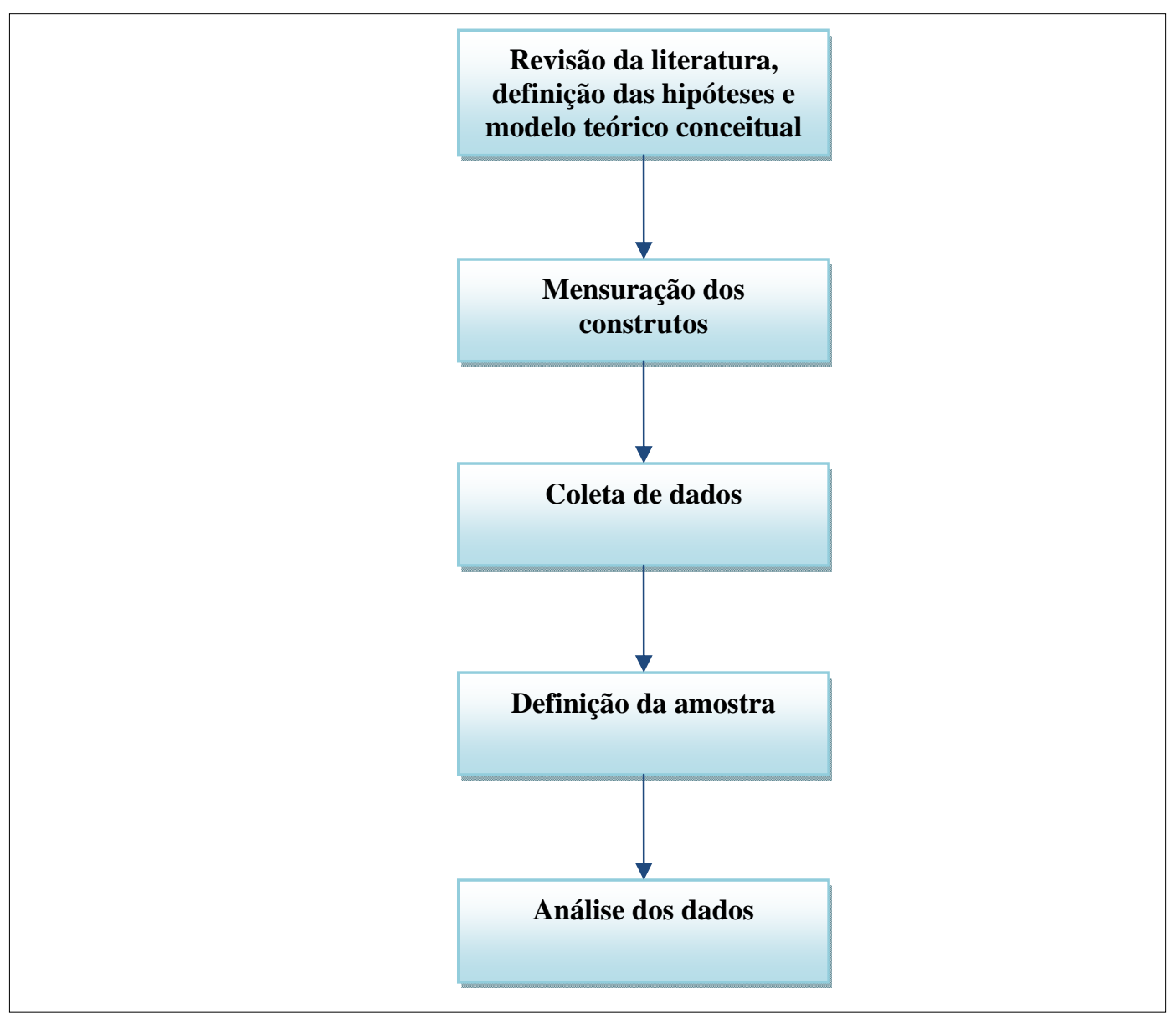

Figura 2: Etapas da pesquisa

Fonte: Própria 
$\mathrm{Na}$ primeira etapa da pesquisa foi realizada uma revisão criteriosa da literatura que deu origem as hipóteses e, por conseguinte o modelo conceitual teórico.

Na segunda etapa realizou-se a definição da mensuração dos construtos com base em uma revisão da literatura acerca das alternativas existentes de operacionalização dos itens de medição mais adequados a cada construto.

A terceira etapa ocorreu mediante a elaboração de um questionário como instrumento de coleta de dados e do pré-teste deste questionário, conforme as práticas de aplicação do método survey.

Uma vez definido o procedimento de coleta de dados, na quarta etapa, foi definido o procedimento de seleção da amostra de pequenas e médias empresas que foram convidadas a participar da pesquisa.

Por fim, na quinta etapa, ocorreu a análise dos dados mediante a técnica de modelagem de equações estruturais, mais especificamente, a técnica dos mínimos quadrados parciais (Partial Least Squares - Structural Equation Modeling, PLSSEM).

A seguir, é apresentada a justificativa para a utilização do método survey nesta pesquisa.

\section{Justificativa para aplicação do método survey}

Nesta tese foi utilizado o método survey para a obtenção dos dados a serem analisados estatisticamente. Optou-se por aplicar o questionário na forma online, distribuído via e-mail, o que permitiu uma abrangência maior de empresas respondentes em um período relativamente curto de tempo e a um baixo custo. A seguir é apresentada a forma com que foi realizada a mensuração das variáveis deste estudo.

O presente estudo se caracteriza como um estudo confirmatório e não explicativo, sendo assim, serão testadas uma teoria e as relações causais, estabelecendo a existência das relações, permitindo questionar o porquê da existência ou não de as relações existirem. Desta forma o método survey é considerado adequado para este estudo. 
Considerando busca avaliar a influência das características dos gestores na internacionalização das pequenas e médias empresas, o método survey apresentase como uma alternativa adequada, pois permite generalizar para a população destas empresas brasileiras.

\section{1. \\ Mensuração das variáveis}

Nesta etapa realizou-se uma revisão da literatura para conhecer as alternativas de operacionalização das variáveis utilizadas em estudos empíricos similares a este estudo. Buscou-se, sempre que possível, aumentar a comparabilidade entre os estudos por meio da utilização de uma forma de mensuração aceita pela literatura, com exceções nos casos que a forma de mensuração não fosse adequada a este estudo. Apesar de não ter sido exaustiva, esta revisão da literatura pode ser considerada razoavelmente representativa, devido ao número de trabalhos consultados apresentarem maior frequência de citação por outros na literatura.

O número mínimo de indicadores de cada variável latente é um requisito importante para a modelagem de equações estruturais. Hair et al. (2010) estabeleceram um mínimo de quatro indicadores por construto, considerando a operacionalização em uma perspectiva reflexiva, para que cada construto seja localmente identificável, independente dos demais construtos do modelo.

Vários pesquisadores destacam que os modelos PLS-SEM geralmente funcionam com escala nominal, ordinal e intervalar (FORNELL; BOOKSTEIN, 1982; HAENLEIN; KAPLAN, 2004; REINARTZ et al., 2009). No entanto, essa prática deve ser considerada com cautela. Pesquisadores podem decidir usar um indicador binário único para medir um construto endógeno para indicar uma situação de escolha. Este, no entanto, torna sua medida como a de um construto latente (FUCHS; DIAMANTOPOULOS, 2009), que apode apresentar problemas para aproximações no algoritmo PLS-SEM, desde que os coeficientes sejam estimados por regressões ordinary least squares (OLS) (HAIR et al., 2012). 
Da mesma forma, usar indicadores binários em modelos reflexivos viola a suposição de OLS, porque os indicadores reflexivos são regredidos sobre os escores de variável latente ao estimar pesos exteriores (HAIR et al., 2012). Correspondentemente, Jakobowicz e Derquenne (2007, p. 3668) apontam que “quando se trabalha com dados contínuos [...], o PLS não enfrenta problemas, mas quando estiver trabalhando com dados binários ou nominais não é possível supor que há qualquer distribuição contínua subjacente". De forma similar, Lohmöller (1989) e também Hair et al. (2012) argumentam que os procedimentos para a aplicação de equações lineares não podem ser usados para variáveis categóricas.

Baseado no estudo de Lohmöller (1989) e com objetivo de incluir variáveis categóricas, Jakobowicz e Derquenne (2007) desenvolveram uma versão modificada do algoritmo PLS-SEM com base em modelos lineares generalizados que, no entanto, limitou-se em medidas reflexivas. A aplicação do algoritmo de PLS-SEM padrão não leva em conta essas extensões, e assim, muitas vezes, viola princípios fundamentais de OLS quando usam variáveis categóricas. Como consequência, não se deve usar as variáveis categóricas em construtos endógenos e cuidadosamente devem interpretar o significado das variáveis categóricas em construtos exógenos. Alternativamente, as variáveis categóricas podem ser usadas para dividir o conjunto de dados para comparações multigrupo no PLS (SARSTEDT et al., 2011), portanto, no PLS as equações não podem usar variáveis categóricas (HAIR et al., 2012).

Pelas razões expostas anteriormente, nesta tese optou-se por operacionalizar as variáveis por meio de escala diferenciada semântica. A seguir são apresentadas as alternativas para operacionalização das variáveis independentes encontradas na literatura, bem como a forma como foram operacionalizadas essas variáveis neste estudo.

\subsection{1.}

\section{Operacionalização das variáveis independentes}

Neste tópico se apresenta como têm sido operacionalizadas as quatro variáveis independentes nos estudos empíricos, sendo: o capital humano, o capital social, a propensão ao risco e a percepção de risco. As tabelas, contendo de forma resumida como foram operacionalizadas as variáveis, estão organizadas em ordem alfabética de autores. 


\section{Idade do gestor}

O Quadro 3 apresenta as alternativas de operacionalização utilizadas por estudos sobre o impacto da idade do gestor na internacionalização de empresas. Buscou-se por estudos que abordavam estes assuntos envolvendo pequenas e médias empresas.

\begin{tabular}{|l|l|}
\hline \multicolumn{1}{|c|}{ ESTUDO } & \multicolumn{1}{|c|}{ OPERACIONALIZAÇÃO DA VARIÁVEL } \\
\hline Felício (2013). & $\begin{array}{l}\text { A idade em anos do gerente foi medida por uma escala } \\
\text { de cinco faixas foram consideradas (até } 35 \text { anos 36-45 } \\
46-55 ; 56-65 ; \text { mais de } 66 \text { anos de idade). }\end{array}$ \\
\hline $\begin{array}{l}\text { Fernández-Ortiz; Lombardo } \\
(2009)\end{array}$ & $\begin{array}{l}\text { Idade do empreendedor foi medida por meio de } \\
\text { variável contínua, onde o respondente indica a sua } \\
\text { idade. }\end{array}$ \\
\hline Francioni et al. (2015). & $\bullet \begin{array}{l}\text { A idade foi medida pelas seguintes faixas: } 20-30 ; 31- \\
40 ; 41-50 ; 51-60 ; \text { e mais de } 60 \text { anos. }\end{array}$ \\
\hline $\begin{array}{l}\text { Suárez-Ortega; Álamo-Vera } \\
(2005) .\end{array}$ & $\bullet \begin{array}{l}\text { Idade foi medida por uma escala de cinco pontos com } \\
\text { intervalos de idade. }\end{array}$ \\
\hline
\end{tabular}

Quadro 3: Alternativas para operacionalização do construto Capital Humano

Fonte: Própria

Conforme observado no Quadro 3, dois dos estudos empíricos utilizaram uma medida por uma escala com intervalos de idade compreendendo entre $20 \mathrm{e}$ mais de 60 anos (FELÍCIO, 2013; FRANCIONI et al., 2015), sendo esta faixa considerada para pessoas em plenas atividades laborais.

Nesta tese a idade do decisor foi medida por meio da indicação do respondente em uma escala de faixas de idade sendo: 18 a 30 anos; 31 a 40 anos; 41 a 50 anos; 51 a 60 anos; 61 a 70 anos; mais de 70 anos. Para obtenção do valor final utilizou-se a inversão do código da resposta (FELÍCIO, 2013; FRANCIONI et al., 2015), indicando que maior idade o valor codificado é menor. Este procedimento foi realizado pelo fato de que a idade era um indicador formativo do capital humano, tendo a necessidade de inverter a quantificação para que todos os indicadores tivessem a mesma direção e pudessem contribuir da mesma forma para o construto.

Este construto foi medido por apenas um indicador, não representando um problema para o modelo, visto que o PLS-SEM (modelagem de equações estruturais pelos mínimos quadrados parciais) procura maximizar as variáveis explicadas diferentemente do CB-SEM, que busca minimizar as discrepâncias entre as matrizes de correlações observadas e a matriz de correlações estimada pelo modelo. 


\section{Capital Humano}

O Quadro 4 apresenta as alternativas de operacionalização utilizadas por estudos sobre o capital humano e a internacionalização de empresas. Buscou-se por estudos que abordavam esses assuntos envolvendo pequenas e médias empresas.

\begin{tabular}{|c|c|}
\hline ESTUDO & OPERACIONALIZAÇÃO DA VARIÁVEL \\
\hline Altinay; Wang (2011) & $\begin{array}{l}\text { - Nível educacional foi medido com uma variável binária } \\
\text { sendo 1-graduado e 0-não graduado. } \\
\text { - Experiência internacional foi medida com uma variável } \\
\text { binária 1-sim e 0-não. }\end{array}$ \\
\hline Araújo; Neira (2006). & $\begin{array}{l}\text { - Nível de educação foi medida em } 5 \text { níveis: 5- Pós- } \\
\text { graduado e 1-ensino básico incompleto. } \\
\text { - Conhecimento de línguas estrangeiras foi medido pelo } \\
\text { número de idiomas que compreende e fala e a fluência em } \\
\text { inglês e francês foi medida por um a escala onde 3- } \\
\text { francês e inglês, 2-francês, 1-inglês e 0-nenhuma fluência. }\end{array}$ \\
\hline Evald M.R. (2011). & $\begin{array}{l}\text { - A educação foi medida seguindo a seguinte codificação: } 0 \\
\text { para "Não possui nível secundário", } 1 \text { para "possui nível } \\
\text { secundário incompleto", } 2 \text { para "possui nível secundário } \\
\text { completo", } 3 \text { para "nível superior" e } 4 \text { "possui nível de } \\
\text { pós-graduação". } \\
\text { A experiência internacional anterior foi medida como } \\
\text { uma variável binária sendo "Sim" (código 1) para quem } \\
\text { tem experiência e "Não" (código 0) para quem não tem. }\end{array}$ \\
\hline Felício (2013). & $\begin{array}{l}\text { - Nível de escolaridade foi medido por sete categorias } \\
\text { (educação básica }-4 \text { anos; ensino médio }-6 \text { anos }- \\
\text { ou equivalente; escola }-9 \text { anos }- \text { ou equivalente; } \\
\text { bacharel ou equivalente; mestrado ou pós-graduação; } \\
\text { PhD). }\end{array}$ \\
\hline $\begin{array}{l}\text { Fernández-Ortiz; Lombardo } \\
\text { (2009) }\end{array}$ & $\begin{array}{l}\text { - Educação e qualificação dos diretores: Quantos diretores } \\
\text { da sua empresa têm diplomas universitários? } \\
\text { - Experiência internacional adquirida pelos diretores da } \\
\text { empresa: Quantos diretores da empresa tiveram } 6 \text { ou mais } \\
\text { meses de trabalho ou experiência acadêmica no exterior? } \\
\text { - Conhecimento de línguas estrangeiras pela alta } \\
\text { administração: Quantos diretores podem fazer negócios } \\
\text { em uma língua estrangeira? }\end{array}$ \\
\hline Francioni et al. (2015). & $\begin{array}{l}\text { - Nível de ensino foi dividido em ensino médio, faculdade, } \\
\text { graduação, mestrado e PhD. } \\
\text { Experiência internacional foi medida em termos de anos } \\
\text { de experiência do decisor, adotando uma classificação de } \\
\text { cinco faixas: } 1-5 ; 6-10 ; 11-15 ; 16-20 \text {; e mais de } 20 \text { anos. }\end{array}$ \\
\hline Omri; Becuwe (2014) & $\begin{array}{l}\text { - O nível de educação foi medido pelo número de } \\
\text { programas de treinamento de trabalho e a média de anos } \\
\text { de educação. } \\
\text { A experiência foi medida por quatro indicadores: } \\
\text { primeiro item diz respeito ao número de anos após a } \\
\text { obtenção do diploma do último curso, o segundo item } \\
\text { mede a média de anos de experiência de trabalho no } \\
\text { emprego atual, o terceiro item avalia a média de anos de } \\
\text { experiência de trabalho no setor atual, e finalmente, o } \\
\text { último item refere-se a média de anos de experiência de } \\
\text { trabalho em outros setores. }\end{array}$ \\
\hline
\end{tabular}




\begin{tabular}{|c|c|}
\hline Reuber; Fischer (1997) & $\begin{array}{l}\text { - Experiência internacional - Usou-se dois indicadores } \\
\text { binários da experiência de uma equipe internacional. A } \\
\text { primeira medida refere-se diretamente à exposição do } \\
\text { decisor ao ambiente do mercado externo. } \\
\text { - A experiência internacional foi medida por uma pergunta: } \\
\text { "se, antes de fundar ou entrar para esta empresa, qualquer } \\
\text { membro da equipe de gestão atual tinha experiência em } \\
\text { vender fora do país. }\end{array}$ \\
\hline Ruzzier, et al. (2007) & $\begin{array}{l}\text { - A habilidade em negócios internacionais foi medida } \\
\text { usando uma escala para indicar a quantidade em anos da } \\
\text { experiência de trabalho internacional; } \\
\text { - Nível de educação de negócios internacionais foi medida } \\
\text { por uma escala de } 5 \text { pontos. } \\
\text { - Percepção de risco ambiental foi medida por duas escalas } \\
\text { de cinco pontos. } \\
\text { Orientação internacional foi medida por uma pergunta } \\
\text { sobre o número de dias gastos em viagens de negócios no } \\
\text { exterior e o número de dias em todas as viagens no } \\
\text { exterior. }\end{array}$ \\
\hline Sommer, Haug (2010). & $\begin{array}{l}\text { - A experiência internacional foi medida onde o grau foi } \\
\text { unipolar variando de "pouca" a "muita experiência". }\end{array}$ \\
\hline $\begin{array}{l}\text { Suárez-Ortega; Álamo-Vera } \\
(2005) .\end{array}$ & $\begin{array}{l}\text { - Proficiência em língua estrangeira, identificando aquelas } \\
\text { línguas estrangeiras, no qual o respondente pudesse } \\
\text { desenvolver negócios internacionais; e } \\
\text { - Experiência no exterior, respondendo se tinha recebido } \\
\text { qualquer formação académica ou profissional num país } \\
\text { estrangeiro durante pelo menos seis meses. Estas duas } \\
\text { últimas questões foram dummy codificada (1 se "Sim" e } 2 \\
\text { se "não"). }\end{array}$ \\
\hline Takeuchi et al. (2005). & $\begin{array}{l}\text { - Experiência internacional. Foi medida por quatro } \\
\text { indicadores: experiência em trabalhos não internacional } \\
\text { anterior; o número total de experiências de viagem prévia, } \\
\text { experiência de trabalho internacional anterior de e a } \\
\text { quantidade de viagens ou trabalho internacional dividido } \\
\text { pelo número de viagens ou experiências de trabalho } \\
\text { dentro do país. }\end{array}$ \\
\hline
\end{tabular}

Quadro 4: Alternativas para operacionalização do construto Capital Humano

Fonte: Própria

Conforme observado no Quadro 4, alguns estudos empíricos têm operacionalizado o capital humano por meio de indicadores binários, a qual pode ser problemática quando se utiliza PLS-SEM. Verifica-se também que o capital humano pode ser medido por vários itens. Neste estudo foi escolhido especificamente o nível de escolaridade do decisor, experiência internacional e o conhecimento de línguas estrangeiras como fatores formativos do construto capital humano. Optou-se por estes indicadores devido à literatura sugerir que estes indicadores podem influenciar o padrão de exportação das pequenas e médias empresas. 
O construto capital humano foi medido como um construto formativo, pois a literatura sugere que o capital humano seja relativo a algumas capacidades que a pessoas possuem e que podem ser revertidas em algum benefício para a empresa. Verifica-se que apenas o estudo de Fernández-Ortiz e Lombardo (2009) utilizou os três indicadores em conjunto, porém, mediu estes indicadores por meio de variáveis contínuas relativas ao número de decisores em uma determinada empresa que possuía algumas destas habilidades desenvolvidas.

O capital humano foi operacionalizado por meio de três indicadores em escalas diferenciais semânticas (com peso a ser determinado por um modelo PLS (mínimos quadrados parciais) de quatro variáveis relacionadas com o gerente de exportação, no momento que fundou/entrou para empresa: experiência internacional, nível de educação formal e conhecimentos de língua estrangeira.

O nível de educação formal do decisor foi medida por meio da indicação do respondente em uma escala de escolaridade, sendo: ensino fundamental (primeiro grau) incompleto; ensino fundamental (primeiro grau) completo; ensino médio (segundo grau) incompleto; ensino médio (segundo grau) completo; ensino superior incompleto; ensino superior completo; pós-graduação (MBA, mestrado ou doutorado) incompleto; pós-graduação (MBA, mestrado ou doutorado) completo. Desta forma abrangeu-se a maior parte das possibilidades de indicação dos níveis de educação formal existentes no Brasil atualmente.

A experiência internacional do decisor foi medida por meio da indicação do respondente em uma escala que contém o tempo que morou fora do Brasil em anos, sendo: nunca tinha morado fora do Brasil antes de ter ingressado ou fundado esta empresa; menos de 1 ano; entre 1 e 2 anos; entre 2 e 4 anos; entre 4 e 6 anos; mais de 6 anos. Desta forma foi possível avaliar as várias formas de experiência do decisor, o qual pode não ter morado fora, e assim não ter nenhuma experiência internacional; o respondente pode ter morado pouco tempo para fazer um curso de língua ou aperfeiçoar a comunicação em determinada língua estrangeira; abrangendo até uma pessoa que morou um tempo maior e obteve experiência profissional maior no exterior. 
Por fim, a proficiência (conhecimento) em língua estrangeira relativa às exportações desta empresa foi medida por meio da indicação do respondente em uma escala sendo: nenhum conhecimento; conhecimento básico; conhecimento médio; conhecimento avançado. Assim, o respondente pôde indicar qual era o seu conhecimento em língua estrangeira quando começou a trabalhar ou fundou a empresa independente da quantidade de línguas estrangeiras que o respondente conhecia, visto que uma pessoa pode ter um conhecimento básico de várias línguas e não conseguir se comunicar com clareza e/ou ler documentos para obter informações importantes, o que poderia levar a tomada de decisões equivocadas em relação aos negócios internacionais da empresa.

\section{Capital Social}

O Quadro 5 apresenta as alternativas de operacionalização utilizadas por estudos sobre o capital social e a internacionalização de empresas. Buscou-se os estudos que abordavam estes assuntos envolvendo pequenas e médias empresas.

\begin{tabular}{|c|c|}
\hline ESTUDO & OPERACIONALIZAÇÃO DA VARIÁVEL \\
\hline Bastié et al. (2013) & $\begin{array}{l}\text { - Foi criada uma variável dummy para indicar a existência de } \\
\text { rede sendo igual a } 1 \text { se esta rede é identificada e } 0 \text { caso } \\
\text { contrário. } \\
\text { - Foi criada uma variável dummy igual a } 1 \text { quando a } \\
\text { inicialização da internacionalização é favorecida por } \\
\text { relacionamentos com clientes ou fornecedores e } 0 \text { caso } \\
\text { contrário. }\end{array}$ \\
\hline Boso et al. (2013) & $\begin{array}{l}\text { - As relações da rede social foram medidas por meio de escala } \\
\text { sendo } 1=\text { discordo totalmente a } 7 \text { = concordo fortemente. } \\
\text { Envolvendo as seguintes afirmações: } \\
\text { o Eu posso obter informações sobre minha indústria por } \\
\text { meio dos contatos da rede mais rápido do que os } \\
\text { concorrentes; } \\
\text { o Eu tenho um relacionamento profissional com alguém } \\
\text { influente na minha indústria. } \\
\text { o Eu tenho um relacionamento informal com alguém } \\
\text { influente na minha indústria (por exemplo, jogando tênis). }\end{array}$ \\
\hline $\begin{array}{ll}\text { Bratkovic, } & \text { Antoncic, } \\
\text { Ruzzier (2009). } & \end{array}$ & $\begin{array}{l}\text { - A intensidade do contato do empreendedor na foi medida pela } \\
\text { frequência média de interação entre todas as pessoas } \\
\text { importantes com quem o empreendedor teve relação direta e } \\
\text { pessoal. } \\
\text { - As fontes de recursos para a empresa foram medidas por uma } \\
\text { escala de três pontos com a pergunta: com que frequência o } \\
\text { empreendedor interage com uma pessoa? 0-uma vez por ano } \\
\text { ou menos, 1-mais de uma vez por ano, mas menos de duas } \\
\text { vezes por semana, 2-duas vezes por semana ou mais. }\end{array}$ \\
\hline Evald M. R. (2011). & $\begin{array}{l}\text { - Relações com outros empresários: foi medida por uma } \\
\text { variável binária que se baseia na resposta "Sim" (código 1) ou } \\
\text { "Não" (código 0) à seguinte pergunta: "Você pessoalmente } \\
\text { conhece alguém que começou um negócio internacional nos } \\
\text { últimos } 2 \text { anos" }\end{array}$ \\
\hline
\end{tabular}




\begin{tabular}{|c|c|}
\hline Felzensztein et al. (2015). & $\begin{array}{l}\text { - A relação na rede foi medida com uma variável contínua de } 0 \\
\text { a } 9 \text {. Os entrevistados foram convidados a nomear cada } \\
\text { organização ou indivíduos que ajudaram no seu processo de } \\
\text { internacionalização, } \\
\text { - Relações foi medida com uma variável contínua de } 0 \text { a 9; via } \\
\text { indicação dos seguintes itens: } \\
\text { o associação nacional dos exportadores, agência de } \\
\text { promoção de exportação, } \\
\text { o agência de desenvolvimento econômico, apoio de } \\
\text { instituições privadas, } \\
\text { o apoio de universidades, } \\
0 \text { aliança com empresas internacionais, } \\
\text { o aliança com empresas nacionais, apoio de incubadoras, } \\
0 \text { nenhum, } \\
0 \text { outro, por favor especifique }\end{array}$ \\
\hline Feng et al. (2016) & $\begin{array}{l}\text { - Os seguintes itens foram medidos por uma escala de } 5 \text { pontos } \\
\text { (1, "Não concordo", a 5, "concordo totalmente"), } \\
\text { Envolvimento: é difícil para me manter informado sobre as } \\
\text { operações da minha cooperativa. } \\
\text { - Informações: quanto você se envolve para obter informações } \\
\text { sobre as operações da cooperativa e desenvolvimento. } \\
\text { - Confiança. O bloco funciona no melhor interesse dos } \\
\text { membros. } \\
\text { - Representante: Eu confio nos representantes eleitos. } \\
\text { - Negociação: quão satisfeito você está com sua cooperativa } \\
\text { como um parceiro comercial, ou seja, como custos de } \\
\text { acessibilidade e recepção? } \\
\text { - Associação: quão satisfeito você está com sua cooperativa } \\
\text { como uma organização, } \\
\text { - Lealdade. Você se considera ser um membro leal no sentido } \\
\text { de que quase sempre troca informações com a sua } \\
\text { cooperativa. }\end{array}$ \\
\hline Fornoni et al. (2011). & $\begin{array}{l}\text { - Estrutural do capital social: número de relações e outras } \\
\text { características da configuração da rede, como nível de } \\
\text { densidade, a hierarquia ou a conectividade. } \\
\text { - Para medir a dimensão relacional, o número de relações que } \\
\text { representam a existência de diferentes entre dois agentes } \\
\text { determinados e o número de relações que dois agentes } \\
\text { mantêm ao longo do tempo. } \\
\text { - Recursos: a quantidade de recursos disponíveis pelas relações. }\end{array}$ \\
\hline Levy et al. (2013) & $\begin{array}{l}\text { - Bridging foi medido por uma escala de sete pontos por meio } \\
\text { dos seguintes indicadores: } \\
\text { o Expansividade da rede transfronteiriça } \\
\text { o Acesso à informação } \\
\text { o Reciprocidade generalizada e identidade plena } \\
\text { o Satisfação com a relação da minha rede profissional em } \\
\text { outros países } \\
\text { - Bonding foi medida por uma escala de sete pontos por meio } \\
\text { dos seguintes indicadores: } \\
\text { o Apoio emocional e psicológico } \\
\text { o Confiança em vários dos meus contatos profissionais em } \\
\text { outros países para atuar em meu melhor interesse. } \\
\text { o Acesso limitado a recursos valiosos, } \\
\text { o Contatos profissionais internacionais. }\end{array}$ \\
\hline $\begin{array}{l}\text { Musteen, Francis, Datta } \\
\text { (2010). }\end{array}$ & $\begin{array}{l}\text { - Relações internacionais pessoais foi medida com o número } \\
\text { total de ligações internacionais (ambos, profissional e } \\
\text { pessoal), expressa como uma percentagem usada como a } \\
\text { medida da extensão da rede dos CEOs das PMEs } \\
\text { internacionais. }\end{array}$ \\
\hline
\end{tabular}




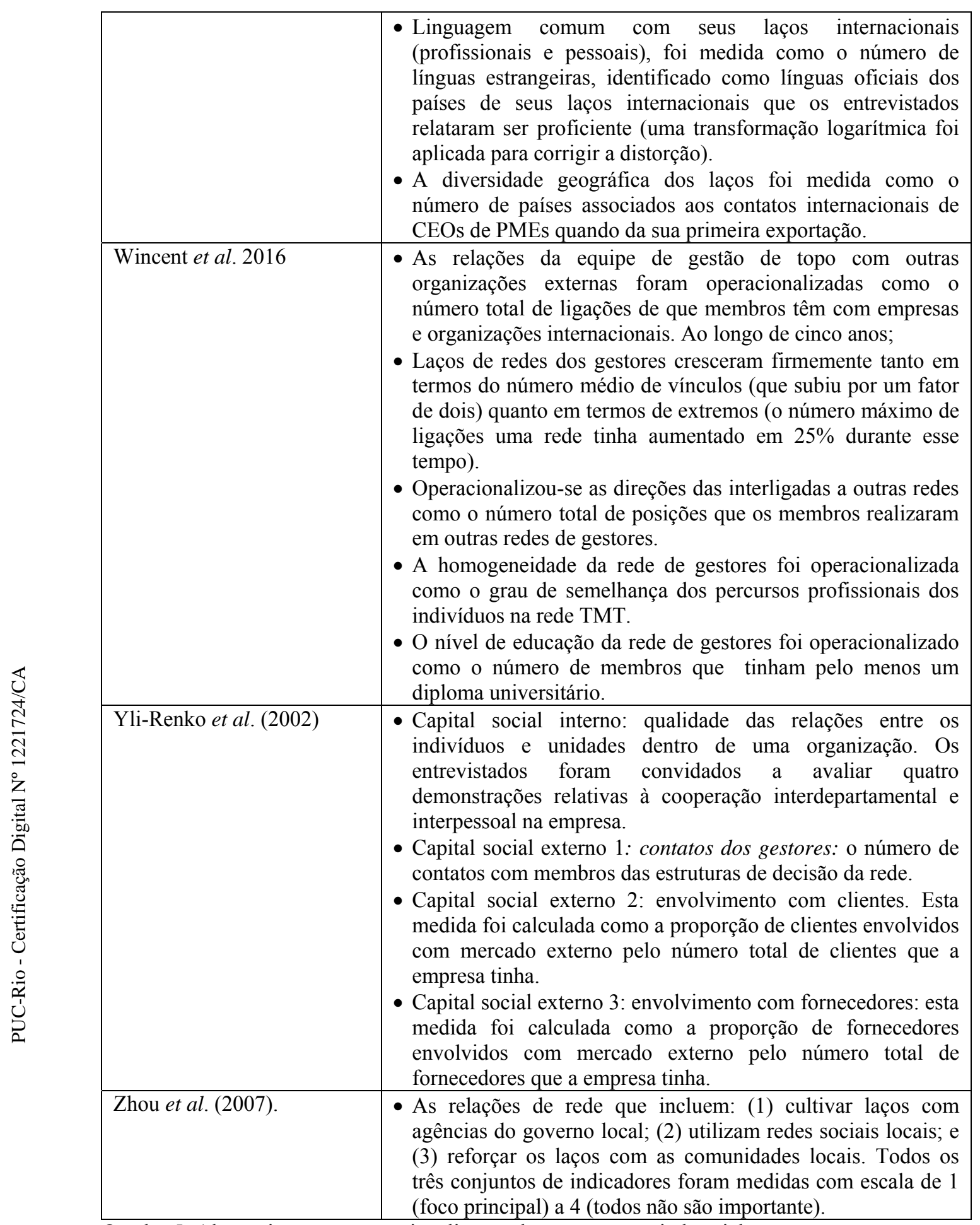

Quadro 5: Alternativas para operacionalização do construto capital social

Fonte: Própria 
Conforme observado no Quadro 5, alguns estudos empíricos têm operacionalizado o capital social por meio de indicadores binários, o que pode ser problemático quando se utiliza PLS-SEM. Verifica-se também que o capital social pode ser medido por vários itens. O capital social foi operacionalizado em termos de capital social estrutural (parcialmente empregado por Omri e Becuwe (2014)), especificamente: (i) as fontes de informações externas (por exemplo, clientes, fornecedores, concorrentes, órgãos governamentais ou outros atores) e (ii) as relações pessoais/sociais/empresariais (por exemplo, as relações informais, participação em associações e reuniões de negócios e cooperação com acesso a contatos no exterior). Todos os indicadores foram medidos por meio de escalas diferenciais semânticas.

O construto capital social foi medido como um construto formativo, pois a literatura sugere que o capital social vem das relações das pessoas como fonte de obtenção de recursos, informações e apoio, que podem ser revertidos em algum benefício para a empresa. Verifica-se que também Boso et al. (2013) e Felzensztein et al. (2015) utilizaram estes indicadores, porém, mediram estes indicadores por meio de escalas maiores das que foram utilizadas neste estudo.

\section{Propensão ao risco do gestor}

O Quadro 6 apresenta as alternativas de operacionalização utilizadas por estudos sobre a propensão ao risco. Buscou-se os estudos que abordavam estes assuntos envolvendo pequenas e médias empresas.

\begin{tabular}{|c|c|}
\hline ESTUDO & OPERACIONALIZAÇÃO DA VARIÁVEL \\
\hline Boso et al. (2013) & $\begin{array}{l}\text { - Risk-taking foi medida por uma escala diferencial } \\
\text { semântica de cinco pontos com as seguintes afirmativas: } \\
\text { o os gestores de topo da nossa empresa, em geral, tendem } \\
\text { a investir em projetos de alto risco. } \\
\text { o Esta empresa mostra uma grande quantidade de } \\
\text { tolerância para projetos de alto risco. } \\
\text { o Nossa estratégia de negócios é caracterizada por uma } \\
\text { forte tendência a correr riscos. }\end{array}$ \\
\hline Chen, Zhang, Hu (2015) & $\begin{array}{l}\text { - A medida de propensão ao risco está baseada no } \\
\text { questionário do dilema da escolha (CDQ - Choice Dilemma } \\
\text { Questionnaire) desenvolvido por Kogan e Wallach (1964). } \\
\text { Ao todo, criaram-se quatro perguntas relacionadas com o } \\
\text { construto em diferentes situações e os sujeitos fazem uma } \\
\text { escolha entre seis alternativas. O respondente situação foi } \\
\text { confrontado com um dilema para escolher entre alternativas } \\
\text { X e Y. }\end{array}$ \\
\hline
\end{tabular}




\begin{tabular}{|c|c|}
\hline Covin; Slevin (1989) & $\begin{array}{l}\text { - Foi medida por uma escala de sete pontos adaptada de } \\
\text { Covin \& Slevin (1989): Em geral, os gestores de topo da } \\
\text { minha firma têm... } \\
\text { o Uma forte tendência para projetos de baixo risco (com } \\
\text { normal e algumas taxas de retorno) } \\
\text { o Uma forte tendência para projetos de alto risco (com } \\
\text { chances de retornos muito elevados) quando } \\
\text { confrontados com situações de tomada de decisão } \\
\text { envolvendo incertezas, } \\
\text { o Adota uma postura de "esperar e ver" cautelosa a fim de } \\
\text { minimizar a probabilidade de tomar decisões } \\
\text { equivocadas ou geralmente adota uma postura ousada, } \\
\text { agressiva a fim de maximizar a probabilidade de } \\
\text { explorar oportunidades potenciais. }\end{array}$ \\
\hline Dong (2015) & $\begin{array}{l}\text { - O índice de propensão ao risco foi medido com uma escala } \\
\text { de cinco pontos, sendo } 1 \text { menor e } 5 \text { maior, envolvendo as } \\
\text { seguintes perguntas: } \\
\text { o Como você classificaria sua vontade de assumir riscos } \\
\text { durante a condução de um projeto? } \\
\text { o Como você classificaria sua vontade de assumir riscos } \\
\text { em assuntos financeiros? } \\
\text { o Como você classificaria sua vontade de assumir riscos } \\
\text { em sua ocupação? } \\
\text { o Como você classificaria a sua disposição para correr } \\
\text { riscos de sua saúde? } \\
\text { o Como você classificaria sua vontade de assumir riscos } \\
\text { tendo fé em outras pessoas? } \\
\text { o Como você classificaria sua vontade de assumir riscos } \\
\text { em relacionamentos românticos? } \\
\text { o Como você classificaria sua vontade de assumir riscos } \\
\text { para fazer mudanças importantes na sua vida? }\end{array}$ \\
\hline Felzensztein et al. (2015). & $\begin{array}{l}\text { - Foi utilizada uma escala cinco pontos onde } 1 \text { significa que a } \\
\text { sentença da esquerda é válida, e } 5 \text { significa que a sentença } \\
\text { da direita não é válida, para os seguintes itens: } \\
\text { o Situações de tomada de decisão envolvendo incerteza no } \\
\text { mercado internacional, em projetos de baixo risco } \\
\text { (normal e com algumas taxas de retorno) versus projetos } \\
\text { de alto risco (com chances de um retorno muito alto)." } \\
\text { o Natureza do ambiente, é melhor alcançar os objetivos da } \\
\text { empresa no mercado internacional através de...projetos } \\
\text { de baixo risco (normal e com algumas taxas de retorno) } \\
\text { versus projetos de alto risco (com chances de um retorno } \\
\text { muito alto)." }\end{array}$ \\
\hline Francioni et al. (2015) & $\begin{array}{l}\text { - Atitude de risco foi medida através da adoção de oito } \\
\text { perguntas de escala de tipo Likert de cinco pontos, com a } \\
\text { finalidade de avaliar a disposição psicológica do tomador de } \\
\text { decisões no sentido de risco. }\end{array}$ \\
\hline Hung et al. (2012) & $\begin{array}{l}\text { - A propensão ao risco foi medida pelas perguntas a seguir } \\
\text { por uma escala de concordância com cinco pontos: } \\
\text { o Eu gosto de correr riscos, embora eu possa falhar. } \\
\text { o Embora uma coisa nova têm uma alta promessa de } \\
\text { recompensa, não quero ser a primeira pessoa a tentá-la. } \\
\text { o Prefiro esperar até que tenha sido testado e provado } \\
\text { antes de experimentá-lo. } \\
\text { o Quando tenho de tomar uma decisão para a qual a } \\
\text { consequência não é clara, eu gostaria de optar pela } \\
\text { condição mais segura, embora isso venha render } \\
\text { recompensas limitadas. } \\
\text { o Eu gosto de experimentar coisas novas, sabendo bem } \\
\text { que alguns delas me decepcionará. }\end{array}$ \\
\hline
\end{tabular}




\begin{tabular}{|c|c|}
\hline & $\begin{array}{ll}\text { o Para ganhar recompensas maiores, estou disposto a } \\
\text { correr riscos mais elevados. } \\
\text { o Eu prefiro uma optar por alternativa testada e } \\
\text { experimentada sobre uma nova situação, embora a nova } \\
\text { alternativa diferente tenha alguma possibilidade de ser } \\
\text { melhor no final. } \\
\text { o Eu gostaria de implementar um plano só se eu tiver } \\
\text { muito certo de que ele funcionará. } \\
\text { o Procuro novas experiências, mesmo que seus resultados } \\
\text { possam ser arriscados. Regular }\end{array}$ \\
\hline Jansen et al. (2011) & $\begin{array}{l}\text { - Foi utilizada uma escala de quatro pontos, incluindo: } \\
\text { o a estimativa do tamanho do risco, que varia de baixo a } \\
\text { alto nível de risco; } \\
\text { o convencimento da decisão, que variam de alta dúvida a } \\
\text { forte convicção. }\end{array}$ \\
\hline Kwon; Lee (2009) & $\begin{array}{l}\text { - Propensão ao risco. Utilizou-se a medida de Sitkin e de } \\
\text { Weingart (1995) com a seguinte pergunta: Se você fosse o } \\
\text { principal decisor, como você classificaria sua tendência a } \\
\text { fazer a escolha? } \\
\text { o (1) escolher alternativas menos arriscadas para garantir a } \\
\text { segurança financeira, } \\
\text { o (2) escolher alternativas mais arriscadas para maximizar } \\
\text { os ganhos potenciais, } \\
\text { o (3) escolher alternativas mais arriscadas para alcançar } \\
\text { maiores metas financeiras e } \\
\text { o (4) escolha alternativas menos arriscadas para estabilizar } \\
\text { a situação financeira. }\end{array}$ \\
\hline Li et al. (2015) & $\begin{array}{l}\text { - A propensão ao risco foi medida por meio dos seguintes } \\
\text { itens: (1) uma forte tendência para projetos de alto risco; (2) } \\
\text { uma forte tendência para a tolerância a falha; (3) ousadia em } \\
\text { lidar com todas as contingências de mudanças radicais da } \\
\text { indústria, desenvolvimento tecnológico, intensidade } \\
\text { competitiva e necessidades do cliente; e (4) disponibilidade } \\
\text { para correr riscos no lançamento de empreendimentos } \\
\text { estrangeiros, especialmente em países distantes. } \\
\text { - Propensão para o risco de tomar decisão com (1) uma forte } \\
\text { tendência para projetos de alto risco; (2) uma forte } \\
\text { tendência para a tolerância de falha; (3) ousadia em lidar } \\
\text { com todas as contingências da indústria radicais mudanças, } \\
\text { desenvolvimento tecnológico, intensidade competitiva e } \\
\text { necessidades do cliente; e (4) disponibilidade para correr } \\
\text { riscos no lançamento de empreendimentos estrangeiros, } \\
\text { especialmente em países distantes. }\end{array}$ \\
\hline Pablo (1997) & $\begin{array}{l}\text { - Propensão ao risco foi operacionalizada como tendência de } \\
\text { período atual do indivíduo para riscos em uma } \\
\text { autoclassificação de tendências atuais na abordagem de } \\
\text { situações de negócio arriscado ( } 1 \text { = "tendência muito forte } \\
\text { contra riscos" para } 7=\text { "muito forte tendência para riscos") } \\
\text { - tendência na abordagem de situações de negócio arriscado } \\
\text { para outras pessoas de sua organização, para outros } \\
\text { executivos na mesma indústria e para os outros no negócio } \\
(1=\text { "muito baixa tendência a correr riscos" a } 7 \text { = "muito } \\
\text { maior tendência para assumir riscos"). }\end{array}$ \\
\hline Sitkin; Weigartn (1995) & $\begin{array}{l}\text { - Propensão ao risco: foi medida por uma escala de cinco } \\
\text { pontos por meio das respostas à seguinte pergunta: } \\
\text { - "Como decisor você enfrenta uma decisão que afeta o futuro } \\
\text { financeiro da sua organização. Tendo em conta esta } \\
\text { circunstância, como você classificaria sua tendência a... } \\
\text { o (1) escolher mais ou menos alternativas arriscadas com } \\
\text { base na avaliação dos outros a quem você deve confiar, }\end{array}$ \\
\hline
\end{tabular}




\begin{tabular}{|c|c|}
\hline & $\begin{array}{l}\text { o (2) escolher alternativas mais ou menos arriscadas que } \\
\text { dependem de análises de alta complexidade técnica, } \\
\text { o (3) escolha alternativas mais ou menos arriscadas que } \\
\text { poderiam ter um impacto importante sobre a orientação } \\
\text { estratégica de sua organização, } \\
\text { o (4) dar início a uma ação corporativa estratégica que tem } \\
\text { potencial para sair pela culatra; e } \\
\text { o (5) apoiar uma decisão quando eu estava ciente de que } \\
\text { as análises pertinentes foram feitas enquanto faltando } \\
\text { vários dados. }\end{array}$ \\
\hline Wong (2005) & $\begin{array}{l}\text { - A propensão ao risco. Por uma escala de pontos, sendo } 1 \\
\text { (muito fraca) a } 7 \text { (muito forte), para : } \\
\text { o "tomar uma decisão arriscada, com base na avaliação e } \\
\text { sugestões de outros que você acha que são de } \\
\text { confiança", "tomar uma decisão arriscada, com base nas } \\
\text { análises de altas complexidade técnica", } \\
\text { o "tomar uma decisão arriscada que poderia ter um } \\
\text { impacto importante sobre a orientação estratégica da sua } \\
\text { empresa", } \\
\text { o "iniciar uma ação estratégica que tem potencial para dar } \\
\text { errado", e "apoiar uma decisão quando eu estava ciente } \\
\text { de que as análises pertinentes foram feitas enquanto } \\
\text { faltando vários pedaços de informação". }\end{array}$ \\
\hline
\end{tabular}

Quadro 6: Alternativas para operacionalização do construto propensão ao risco do gestor

Fonte: Própria

Como a propensão ao risco desempenha um papel crítico em várias decisões, alguns estudiosos tomaram passos importantes no desenvolvimento de escalas para medir a propensão ao risco dos indivíduos em contextos diferentes, tais como investimento, decisões financeiras e decisões de marketing (JAWORSKI; KOHLI, 1993; KAPTEYN; TEPPA, 2002; SLOVIC, 1980; WEBER et al., 2002). No entanto, como Hung e Tangpong (2010) apontam, em ambiente dinâmico atual, as decisões das empresas e dos decisores tendem a ser multifacetado, envolvendo diversos aspectos dos riscos simultaneamente. Esta natureza multifacetada das decisões nos negócios fazem as escalas de propensão ao risco, na literatura, serem menos aplicáveis, devido à natureza compartimentada dessas escalas (ou seja, para as decisões financeiras, orientação para o mercado, consideração social, etc.). 
Propensão ao risco refere-se à tolerância do decisor para riscos na sua tomada de decisão. É manifestada por uma alta tolerância a ambiguidade e uma vontade de decidir (BAUM; WALLY, 2003). Tal propensão é associada à flexibilidade psicológica, o que leva a determinadas características pessoais, incluindo a informalidade, adaptabilidade, otimismo e hedonismo (COVIN; MILLER, 2014). Estes traços pessoais correspondem à assertividade e capacidade de resposta na tomada de decisão, que alerta os tomadores de decisão a tomarem ações rápidas e resolutas (LI et al., 2015).

Nesta tese foi utilizada a forma de medição adaptada do estudo de Li et al. (2015), com seis itens em uma escala semântica com cinco pontos a qual o respondente irá indicar a sua concordância ou discordância com as quatro frases: (i) tomar decisões, mesmo que a informação esteja incompleta, (ii) tentar coisas novas, (iii) preferir formas já testadas (reverso-codificado), (iv) adotar uma postura ousada, (v) desenvolver projetos arriscados, e (vi) ser tolerante a falhas.

\section{Percepção de risco}

O Quadro 7 apresenta as alternativas de operacionalização utilizadas por estudos sobre a propensão ao risco. Buscou-se os estudos que abordavam percepções de risco específicas da internacionalização e que envolviam pequenas e médias empresas.

\begin{tabular}{|c|c|}
\hline ESTUDO & OPERACIONALIZAÇÃO DA VARIÁVEL \\
\hline $\begin{array}{l}\text { Acedo e } \text { Galán } \\
\text { Acedo e } \\
\text { Acedo e Jones (2007) }\end{array}$ & $\begin{array}{l}\text { - A variável percepção dos riscos e oportunidades em } \\
\text { atividades de exportação foi medida por meio de um único } \\
\text { item em uma escala de cinco pontos de concordância com as } \\
\text { seguintes afirmativas: } \\
\text { - (1) a venda de produtos em mercados estrangeiros implica } \\
\text { risco elevado; } \\
\text { - (2) as exportações são uma importante oportunidade para } \\
\text { minha empresa; } \\
\text { - (3) atividade internacional da empresa é uma coisa positiva no } \\
\text { meu negócio; } \\
\text { - (4) minha empresa tem uma alta probabilidade de sucesso em } \\
\text { mercados estrangeiros. }\end{array}$ \\
\hline Hsieh et al. (2010) & $\begin{array}{l}\text { - A percepção de risco foi medida por: } \\
\text { - 1. risco no desempenho: qual a probabilidade do parceiro } \\
\text { estrangeiro acha que desempenho o JV declinará no futuro } \\
\text { próximo }(1=\text { 'improvável' para } 5=\text { 'altamente provável'). } \\
\text { - 2. Risco relacional: como provavelmente o parceiro } \\
\text { estrangeiro pensa que a relação }(1999) \text { com o seu parceiro } \\
\text { local irá deteriorar-se em um futuro próximo }(1=\text { 'improvável' } \\
\text { para } 5=\text { 'altamente provável') } \\
\text { - 3. Compromisso: na medida em que parceiro estrangeiro } \\
\text { acredita que o parceiro local fará o seguinte: } 1) \text { colocar o }\end{array}$ \\
\hline
\end{tabular}




\begin{tabular}{|c|c|}
\hline & $\begin{array}{l}\text { máximo de esforço para manter o JV; } 2 \text { ) estar disposto a fazer } \\
\text { mais investimento ou contribuir ainda mais recursos. (1 } \\
\text { 'pouca ou nenhuma' a } 5=\text { ' muito grande') } \\
\text { - 4. confiança: a extensão à qual parceiro estrangeiro, acredito } \\
\text { que o parceiro local fará o seguinte: } 1) \text { acompanhar o acordo } \\
\text { original; } 2 \text { ) tem interesse ativo em sua realização; } 3) \text { têm a } \\
\text { capacidade e competência para alcançar seus objetivos. (1 = } \\
\text { 'pouca ou nenhuma' a } 5=\text { ' muito grande) }\end{array}$ \\
\hline Nabi e Liñán (2013) & $\begin{array}{l}\text { - Percepção de risco foi medida usando uma escala } \\
\text { multidimensional para os seguintes itens } \\
\text { - Risco como oportunidade centrou-se sobre a start-up como } \\
\text { uma oportunidade e uma ação positiva, } \\
\text { - Começar um negócio novo é muito arriscado; } \\
\text { - A probabilidade de um novo empreendimento ser ruim é } \\
\text { muito alta; } \\
\text { - Se não começar a minha vida, eu vir a perder uma grande } \\
\text { oportunidade; } \\
\text { - Há grande incerteza quando se prevê o quão bem um novo } \\
\text { empreendimento vai fazer; } \\
\text { - No geral eu rotularia a opção de iniciar um negócio como } \\
\text { algo positivo; } \\
\text { - O grau de risco de um novo empreendimento global é alto. }\end{array}$ \\
\hline Sitkin; Weigartn (1995) & $\begin{array}{l}\text { - Percepção de risco. Uma escala de quatro itens foi adaptada } \\
\text { de MacCrimmon e Wehrung (1985, 1986a, 1986b) e } \\
\text { Wehrung, Lee, Tse e Vertinsky (1989) para medir a } \\
\text { quantidade de risco percebido associado a decisão a ser } \\
\text { tomada. }\end{array}$ \\
\hline Wong (2005) & $\begin{array}{l}\text { - Uma escala de três itens modificada de Sitkin e Weingart } \\
\text { (1995) foi usada para medir a percepção de risco, com as } \\
\text { seguintes perguntas: } \\
\text { o "Como você descreveria sua situação atual?" (a) } 1 \text { = uma } \\
\text { oportunidade significativa para } 7 \text { = ameaça significativa } \\
\text { (b) } 1 \text { = potencial para perda até } 7 \text { = potencial de ganho; (c) } \\
1 \text { = positiva situação para } 7=\text { situação negativa. } \\
\text { o Quão provável será a aceitação da proposta?" }\end{array}$ \\
\hline Cavusgil e Naor (1987) & $\begin{array}{l}\text { - Percepção de risco dos exportadores foi medida com } \\
\text { pontuação: os riscos das exportações em relação aos riscos } \\
\text { envolvidos em mercado interno, indicando em uma escala de } \\
\text { intervalo onde: } 1=\text { muito inferior ao doméstico; } 2=\text { um } \\
\text { pouco inferior ao doméstico; } 3=\text { aproximadamente o mesmo } \\
\text { que doméstico; } 4=\text { um pouco mais que o doméstico; } 5= \\
\text { muito mais que doméstico). }\end{array}$ \\
\hline Chen; Zhang; Hu (2015) & $\begin{array}{l}\text { - Percepção de risco foi medida por duas perguntas sobre os } \\
\text { níveis de risco, usando uma escala de sete pontos para cada } \\
\text { questão, os respondentes indicaram sua percepção do risco } \\
\text { global e a certeza dos resultados para cenários de diferentes } \\
\text { projetos. }\end{array}$ \\
\hline Ruzzier et al. (2007) & $\begin{array}{l}\text { - Percepção de risco foi medida por duas escalas de cinco } \\
\text { pontos para o qual os entrevistados tinham que indicar o grau } \\
\text { de risco que eles associavam com várias operações } \\
\text { internacionais. }\end{array}$ \\
\hline $\begin{array}{l}\text { Forlani et al. (2008); Forlani } \\
\text { et al. (2002) }\end{array}$ & $\begin{array}{l}\text { - A medida da percepção de risco foi avaliada por uma escala } \\
\text { de sete pontos e três itens de diferenciais semânticos, } \\
\text { conforme Forlani et al: } \\
\text { - alto risco } 1234567 \text { baixo risco } \\
\text { - risco mínimo } 1234567 \text { risco extremo } \\
\text { - não arriscado } 1234567 \text { muito arriscado }\end{array}$ \\
\hline
\end{tabular}

Quadro 7: Alternativas para operacionalização do construto percepção de risco do gestor Fonte: Própria 
Verifica-se, também, que a percepção de risco pode ser medida por vários itens. Neste estudo foram escolhidos especificamente a "percepção de riscos em atividades de exportação" e a "percepção de mais oportunidade que ameaças nas atividades de exportação", sendo estes os indicadores reflexivos do construto percepção de risco.

A percepção de risco do decisor foi medida por meio da indicação do respondente em uma escala de cinco pontos: em que entre 1 - poucos riscos a 5 muitos riscos; e 1 - mais ameaças que oportunidades a 5 - mais oportunidades que ameaças, completando a seguinte frase: "Eu julgo que, de uma forma geral, a exportação é uma atividade que apresenta ...”. Desta forma, foi possível avaliar como o decisor percebe os riscos nas atividades de exportação de maneira a não confundir com a forma de medição da propensão ao risco, como ocorre nos estudos de Wong (2005) e Chen; Zhang; Hu (2015), apresentados anteriormente no Quadro 7.

\subsection{2. \\ Operacionalização das variáveis dependentes}

\section{Grau de internacionalização}

O grau de internacionalização neste estudo é medido por meio de quatro fatores: profundidade, abrangência, precocidade e velocidade de internacionalização. A seguir são apresentadas algumas alternativas para medição destes fatores.

\section{Profundidade}

O Quadro 8 apresenta as alternativas de medição da profundidade de internacionalização. 


\begin{tabular}{|c|c|}
\hline $\begin{array}{l}\text { Capar, Kotabe (2003); Hsu } \\
\text { Bogg (2003) }\end{array}$ & $\begin{array}{l}\text { - A medida utilizada para avaliar o FSTS - Foreign Sales as } \\
\text { a Percentage of Total Sales (profundidade de } \\
\text { internacionalização) incluiu o número de países em que a } \\
\text { empresa opera } \\
\text { - a razão de ativos estrangeiros para ativos totais }\end{array}$ \\
\hline Gomes; Ramaswamy (1999) & $\begin{array}{l}\text { - Foi utilizado um índice composto, englobando três } \\
\text { dimensões (vendas, ativos e países de operação) foi } \\
\text { desenvolvido análise utilizando componentes principais. }\end{array}$ \\
\hline $\begin{array}{l}\text { Kafouros; Buckley; Clegg } \\
\text { (2012) }\end{array}$ & $\begin{array}{l}\text { - Foi utilizada a média ponderada dos dois indicadores: ativos } \\
\text { externos no total de ativos (FATA) e vendas externas dos } \\
\text { totais de vendas (FST), ou seja, (FATA + FSTS) } / 2 \text {. }\end{array}$ \\
\hline $\begin{array}{l}\text { Mol et al (2002); Mol et al. } \\
\text { (2004) }\end{array}$ & $\begin{array}{l}\text { - A profundidade foi medida pelo percentual de todo o } \\
\text { volume de vendas se originam de fontes externas: dos } \\
\text { Países Baixos, Bélgica / Luxemburgo, Dinamarca / } \\
\text { Finlândia / Noruega / Suécia, Alemanha / Austria / Suíça, } \\
\text { França / Itália / Espanha / Portugal, Reino Unido / Irlanda, } \\
\text { Grécia, Central e Europa Oriental, EUA / Canadá / } \\
\text { Austrália, Japão, resto da Ásia e o resto do mundo". }\end{array}$ \\
\hline Pangarkar; Hussain (2013) & $\begin{array}{l}\text { - A profundidade (vendas externas }) \text { de operações } \\
\text { multinacionais foi medida por: vendas estrangeiras } /[(\% \text { de } \\
\text { vendas para Asia })+(\% \text { das vendas para o resto da Ásia) } 2+ \\
(\% \text { das vendas para Europa })+(\% \text { das vendas para as } \\
\text { Américas })+(\% \text { das vendas para o resto do mundo })] \text {. }\end{array}$ \\
\hline Sullivan (1994) & $\begin{array}{l}\text { - O grau de internacionalização é medido por cinco variáveis que } \\
\text { constituem DOI INTS: FSTS, FATA, OSTS, PDIO, TMIE. O } \\
\text { intervalo de valor de uma empresa é 0,0 (absolutamente nenhum } \\
\text { envolvimento internacional) 5.0. (absolutamente total } \\
\text { envolvimento internacional). Podemos calcular a pontuação da } \\
\text { empresa através da seguinte operação: FSTS + FATA + OSTS + } \\
\text { PDIO + TMIE = DOI INTS }\end{array}$ \\
\hline Swamidass and Kotabe (1993) & $\begin{array}{l}\text { - A profundidade foi medida como a porcentagem do valor } \\
\text { total de componentes provenientes de cinco possíveis locais } \\
\text { ou opções: países da Europa, Japão, EUA, outros países } \\
\text { desenvolvidos e países menos desenvolvidos (ou seja, os } \\
\text { países em desenvolvimento). }\end{array}$ \\
\hline Tallman; Li (1996) & $\begin{array}{l}\text { - Profundidade foi medida como a proporção de vendas da } \\
\text { empresa, derivada de operações fora do país de origem para } \\
\text { o total de vendas. }\end{array}$ \\
\hline
\end{tabular}

Quadro 8: Alternativas para medir profundidade de internacionalização

Fonte: Própria

Nesta tese, a profundidade da internacionalização é medida por meio da porcentagem do volume de vendas de exportação em relação ao total de vendas no ano anterior, neste caso, o ano de 2015. Os respondentes serão solicitados a indicar entre as opções: entre $0 \%$ e $2 \%$, entre $3 \%$ e $5 \%$, entre $6 \%$ e $10 \%$, entre $11 \%$ e $20 \%$, entre $21 \%$ e $30 \%$, entre $31 \%$ e $40 \%$, entre $41 \%$ e $50 \%$, mais de $50 \%$.

\section{Abrangência}

O Quadro 9 apresenta as alternativas de medição da abrangência da internacionalização. 


\begin{tabular}{|l|l|}
\hline Mol et al. (2004) & $\begin{array}{l}\text { - O escopo internacional foi calculado como: escopo = D1 } \\
+\mathrm{D} 2+\ldots+\text { Dn, onde n é o número de países, onde a } \\
\text { empresa internacionalizou e D é a distância psíquica } \\
\text { entre o país focal e de um país estrangeiro no qual os } \\
\text { fornecedores externos estão localizados. }\end{array}$ \\
\hline Allen and Pantzalis (1996) & $\begin{array}{l}\text { - Abrangência da internacionalização foi medida pelo log do } \\
\text { número de países estrangeiros em que o MNC tem } \\
\text { subsidiárias. }\end{array}$ \\
\hline $\begin{array}{l}\text { Gomes and Ramaswamy } \\
(1999)\end{array}$ & $\begin{array}{l}\text { A medida de abrangência foi operacionalizada pelo número } \\
\text { de países em que a empresa atua. }\end{array}$ \\
\hline Hsu; Bogg (2003) & $\begin{array}{l}\text { Abrangência foi medida pelo número de países que a } \\
\text { empresa teve vendas. }\end{array}$ \\
\hline $\begin{array}{l}\text { Kafouros, Buckley, Clegg } \\
(2012)\end{array}$ & $\begin{array}{l}\text { Para medir o nível de abrangência internacional usou-se o } \\
\text { número de países em que a empresa atua. }\end{array}$ \\
\hline Pangarkar, Hussain (2013) & $\begin{array}{l}\text { Amplitude ou abrangência (dispersão das vendas externas) } \\
\text { de operações multinacionais foi medida pelo número de } \\
\text { países que a empresa atua. }\end{array}$ \\
\hline Tallman and Li (1996) & $\begin{array}{l}\text { Abrangência geográfica das operações internacionais, foi } \\
\text { medida pelo número de países estrangeiros, no qual um } \\
\text { MNE tinha o funcionamento subsidiárias em 1987. }\end{array}$ \\
\hline
\end{tabular}

Quadro 9: Alternativas para medir abarangência da internacionalização

Fonte: Própria

Nesta tese a abrangência foi medida pelo número de países para os quais a empresa exportou no ano anterior. Sendo assim, é solicitado ao respondente indicar para quantos países a empresa exportou em 2015.

\section{Velocidade de internacionalização}

\section{Precocidade (earliness)}

O Quadro 10 apresenta as alternativas para medição da precocidade da internacionalização.

\begin{tabular}{|l|l|}
\hline Amorós et al (2016) & $\begin{array}{l}\text { - A precocidade foi medida plea velocidade e porcentagem de } \\
\text { vendas geradas pelas exportações. }\end{array}$ \\
\hline Lamotte; Colovic (2015) & $\begin{array}{l}\text { - A variável precocidade foi medida a partir de dois itens: a } \\
\text { idade da empresa no momento da primeira venda no } \\
\text { exterior e a parte de vendas externas no total de vendas } \\
\text { anuais. } \\
\text { - Foi considearada precoce, as empresas para as quais as } \\
\text { vendas externas representam pelo menos } 25 \% \text { das suas } \\
\text { vendas totais anuais dentro de seus três primeiros anos de } \\
\text { estabelecimento. }\end{array}$ \\
\hline Li et al. (2015) & $\begin{array}{l}\text { Li } \text { et al. (2015) chamaram de "velocidade", mas mediram o } \\
\text { que parece ser "precocidade" (itens 1 e 2) e } \\
\text { intensidade/produndiade (item 3)) } \\
\text { - O ano [quantos anos após início] quando a empresa } \\
\text { começou a vender produtos em mercados estrangeiros. } \\
\text { O ano quando a empresa começou a investir em mercados } \\
\text { estrangeiros, no prazo de três anos de fundação. } \\
\text { A percentagem do volume de negócios (25\% ou superior) } \\
\text { obtidos de firma de estrangeiros. }\end{array}$ \\
\hline
\end{tabular}




\begin{tabular}{|l|l|}
\hline Meliá et al (2010) & $\begin{array}{l}\text { - A precocidade de internacionalização foi medida por meio } \\
\text { do número de anos desde a criação da empresa até sua } \\
\text { internacionalização. Então, os valores foram recodificados } \\
\text { em cinco períodos de tempo o mais curto (5) para a mais } \\
\text { longa (1). }\end{array}$ \\
\hline Naudé, (2009) & $\begin{array}{l}\text { Mediu-se precocidade por meio de uma variável dummy } \\
\text { 1 se a empresa começou a exportar direta ou } \\
\text { indiretamente, antes do final do seu terceiro ano de } \\
\text { atividade. }\end{array}$ \\
\hline Ricard; Saiyed (2015) & $\begin{array}{l}\text { - A medida de precocidade da internacionalização foi em } \\
\text { tempo real. Mediu-se o comportamento dos tomadores de } \\
\text { decisão em tempo real. }\end{array}$ \\
\hline Zhou (2007) & $\begin{array}{l}\text { Mediu-se a internacionalização precoce solicitando aos } \\
\text { gerentes sênior para identificar o ano quando as suas } \\
\text { empresas alcançaram mais de 20\% do total de vendas no } \\
\text { mercado externo em relação ao total de vendas. }\end{array}$ \\
\hline Zucchella; & $\begin{array}{l}\text { Precocidade foi operacionalizada como o número de anos } \\
\text { desde o início das vendas internacionais. Empresas que } \\
\text { começaram a exportar nos primeiros 3 anos foram } \\
\text { classificadas como precoce e são representativos de Born } \\
\text { Global e INVs. }\end{array}$ \\
\hline Denicolai (2007) &
\end{tabular}

Quadro 10: Alternativas para medir precocidade da internacionalização

Fonte: Própria

Nesta tese a precocidade de internacionalização da PME foi medida pelo número de anos entre a fundação da PME e sua primeira exportação regular. Desta forma, é solicitado ao respondente que escreva o ano em que a empresa foi fundada e o ano em que a empresa fez sua primeira exportação; então subtrai-se a data da primeira exportação da empresa pela data de fundação desta empresa, obtendo-se assim o número anos.

\section{Crescimento do volume de vendas no exterior}

A Tabela 11 apresenta as alternativas para medição do crescimento do volume de vendas no exterior.

\begin{tabular}{|l|l|}
\hline Acedo e Jones (2007) & $\begin{array}{l}\text { - Mediu-se a crescimento do volume de vendas no exterior } \\
\text { por meio de uma variável categórica, que recebe um } \\
\text { valor de 1 para não exportadores, 2 para os exportadores } \\
\text { que levaram mais de } 5 \text { anos para tornar-se internacional e } \\
3 \text { para as empresas que iniciar a internacionalização em 5 } \\
\text { anos ou menos apos a fundação. }\end{array}$ \\
\hline Chetty et al.(2014) & $\begin{array}{l}\text { O crescimento do volume de vendas no exterior foi medida, } \\
\text { assumindo que a 'distância coberta é a magnitude } \\
\text { cumulativa alcançada pela empresa em alguns dos } \\
\text { principais indicadores incrementais relacionados ao seu } \\
\text { processo de internacionalização. }\end{array}$ \\
\hline Hilmersson; Johanson (2016) & $\begin{array}{l}\text { Mediu-se crescimento do volume de vendas no exterior de } \\
\text { por meio da relação entre as exportações e vendas totais por } \\
\text { hora. } \\
\text { O denominador, tempo, foi medido como o tempo decorrido } \\
\text { desde o início das atividades da empresa para a data de } \\
\text { coleta de dados. }\end{array}$ \\
\hline
\end{tabular}




\begin{tabular}{|l|l|}
\hline Mohr; Batsakis (2016) & $\begin{array}{l}\text { - Mediu-se crescimento do volume de vendas no exterior, } \\
\text { como o número médio de mercados estrangeiros, dividido } \\
\text { pelo número de anos desde a primeira expansão } \\
\text { internacional da empresa. }\end{array}$ \\
\hline $\begin{array}{l}\text { Musteen, Francis, Datta } \\
(2010)\end{array}$ & $\begin{array}{l}\text { O crescimento do volume de vendas no exterior foi medida } \\
\text { como a quantidade de tempo decorrido (em anos) entre o } \\
\text { ano de fundação e o ano da sua primeira exportação. }\end{array}$ \\
\hline $\begin{array}{l}\text { Ramos; Acedo; Gonzalez } \\
(2011)\end{array}$ & $\begin{array}{l}\text { O crescimento do volume de vendas no exterior foi } \\
\text { calculada a partir da data de fundação de cada empresa e a } \\
\text { data da sua primeira exportação internacional. }\end{array}$ \\
\hline Teixeira e Coimbra (2014) & $\begin{array}{l}\text { O crescimento do volume de vendas no exterior foi medida } \\
\text { pelo intervalo de tempo entre a fundação da empresa e a } \\
\text { primeira operação internacional (por exemplo, as } \\
\text { exportações ou IDE). } \\
\text { Uma variável dummy que assume o valor 1, quando a } \\
\text { empresa é um exportador precoce (isto é, começou a a } \\
\text { exportar dentro dos primeiros três anos de negócios) e 0 } \\
\text { caso contrário, foi criada para identificar as born globals. }\end{array}$ \\
\hline $\begin{array}{l}\text { O crescimento do volume de vendas no exterior foi medida } \\
\text { pelo tempo decorrido entre o ano que a empresa foi criada e } \\
\text { o ano que entrou no seu primeiro mercado internacional. }\end{array}$ \\
\hline (2003). Matherne, Carleton
\end{tabular}

Quadro 11: Alternativas para medir o crescimento do volume de vendas no exterior

Fonte: Própria

Nesta tese o crescimento do volume de vendas no exterior da PME é medida por meio da variação das vendas de exportação nos primeiros anos de exportação. Em relação ao crescimento do volume de vendas no exterior, a taxa de crescimento dos primeiros anos pode parecer um indicador melhor, mas existem duas restrições a tal medida: os primeiros anos podem ser atípicos e os gerentes podem não recordar (ou ter fácil acesso a) desses dados. Sendo assim, utilizaremos a taxa de crescimento dos últimos dois anos como proxy (embora questionável) da taxa de crescimento médio de exportação da empresa. O respondente deverá então indicar qual foi a variação aproximada das receitas de exportação de sua empresa em 2015, com relação a 2014; considerando as seguintes opções: crescimento maior que $+10 \%$; crescimento entre $+6 \%$ e $+10 \%$; crescimento entre $+2 \%$ e $+5 \%$; entre $-2 \%$ e $+2 \%$; queda entre $-5 \%$ e $-2 \%$; queda entre $-10 \%$ e $-6 \%$; queda maior que $-10 \%$.

\subsection{3.}

\section{Variáveis de controle}

Uma vez que vários outros fatores podem afetar o desenvolvimento da internacionalização, vamos utilizar alguns controles: tamanho de empresa, tipo de indústria, resultados domésticos no passado e resultados de exportação no passado. 
Nesta tese as variáveis são avaliadas as seguintes variáveis de controle:

- O tamanho relativo da empresa: é medido por meio de uma escala de cinco pontos sendo 1 - muito menor e 5 muito maior, diante da afirmativa "O tamanho da sua empresa em comparação com o tamanho dos seus principais concorrentes no Brasil é:”.

- O grau de (in)satisfação com o mercado doméstico: é medido por uma escala de cinco pontos sendo 1 - muito insatisfeito e 5 - muito satisfeito, sendo solicitado ao respondente que "Indique seu grau de satisfação ou de insatisfação com os resultados de vendas da sua empresa no mercado doméstico (Brasil):"

- O grau de internacionalização da indústria: é medido por meio de uma escala de cinco pontos sendo 1 - mais baixo que a dos concorrentes e 5 mais alto que a dos concorrentes, solicitando ao respondente indicar sua resposta mediante a afirmação: "Em comparação com outras empresas do seu segmento de atuação no Brasil, o volume de exportação proporcionalmente às vendas totais da sua empresa é ..."

\section{2. \\ Procedimento de coleta de dados}

Para a construção de uma survey é necessária a elaboração ou construção do instrumento para coleta de dados, ou seja, do questionário, que é constituído por uma série de questões (perguntas) sobre determinado tema. Este será posteriormente apresentado aos participantes da pesquisa, denominados de respondentes (VIEIRA, 2009; MIGUEL et al., 2010). A elaboração do questionário é muito importante, pois pode ser que ocorram alguns problemas devido a dois tipos de erros: o erro associado ao respondente e o erro associado às respostas (FOWLER, 2009).

Conforme Fowler (2009), os erros associados às respostas são em geral a falta de respostas a algumas questões ou respostas que não condizem com a realidade, podendo ser causadas por vários motivos: o não entendimento da questão; não ter a informação necessária para responder; distorcer as respostas para que elas pareçam boas. Estes erros também estão relacionados à forma de mensuração definida para o instrumento. 
Vieira (2009) destaca que alguns especialistas em questionário dizem que a ordem das questões afeta a maneira como as pessoas respondem, mas isso não está comprovado. Porém, parece lógico que as questões sobre o mesmo tema sejam colocadas em sequência; não se deve pular de um tópico para outro a não ser que esteja fazendo um teste para detectar erros de respostas.

Com o objetivo de minimizar a correlação aparente entre as variáveis devido aos dados serem originados a partir de um respondente por empresa e pelo mesmo método de coleta de dados, ou seja, diminuir o efeito da variância do método comum (CMV) seguiu-se as recomendações de Chang, Van Witteloostuijn e Eden (2010) para elaboração do questionário, sendo estas:

- Os entrevistados devem ter a certeza do anonimato e da confidencialidade do estudo, que não há respostas certas ou erradas, e que eles devem o mais honestamente.

- Ter cuidado para examinar sistematicamente a construção de itens, a fim de assegurar que os termos ambíguos, vagos e desconhecidos não estão incluídos, e que o questionário como um todo e os itens individuais são formulados de forma concisa tanto quanto possível. Neste estudo, tal exame foi realizado no pré-teste do questionário.

As formas de aplicação do instrumento, conforme Hair et al. (2003), recaem em duas categorias amplas: administração do questionário para que o próprio respondente responda (autoadministrado) e a entrevista. $\mathrm{O}$ questionário autoadministrado inclui as surveys pelo correio e as surveys eletrônicas. Já a entrevista envolve o contato direto com o respondente, que é entrevistado pessoalmente com a pessoa por telefone ou em diálogo por computador.

Escolhida a forma como os instrumentos serão aplicados, vem então a etapa de aplicação dos instrumentos para coletar os dados. Ao preparar o instrumento de coleta, o pesquisador deve preparar uma solicitação para a participação dos indivíduos na pesquisa. De acordo com Cooper e Schindler (2001), uma das principais formas é enviar um texto explicando os objetivos da survey e fornecendo informações de como deverá proceder para o preenchimento do instrumento de coleta de dados, caso o questionário seja autoadministrado. Caso seja realizada a entrevista, o entrevistador deverá então informar os objetivos da pesquisa ao entrevistado. 
Nesta tese, o questionário autoadministrado pela internet (instrumento de coleta de dados) foi desenvolvido no sistema Qualtrics considerando as orientações de Dillman, Smyth e Christian (2014), relativamente ao formato visual das questões e das telas, sendo então um questionário online. O questionário online continha 10 telas, de acordo com o apresentado no Apêndice A, organizadas em 10 blocos, conforme apresentado a seguir:

- Boas vindas - tela inicial com uma breve explicação do objetivo da aplicação da pesquisa, um convite para participação, garantia de confidencialidade, o tempo estimado para o respondente concluir as respostas ao questionário, agradecimento pela participação e os nomes dos responsáveis pela pesquisa. De acordo com Dillman, Smyth e Christian (2014) a tela de boas-vindas deve ser acolhedora de forma a incentivar a participação e o comprometimento do respondente com a pesquisa e, para tanto, deve iniciar com uma explicação do objetivo do estudo para que o respondente possa identificar sua elegibilidade para a pesquisa.

- $1^{\text {a }}$ Parte - uma tela com três perguntas iniciais sobre o ano de fundação da empresa, o ano em que a empresa iniciou suas atividades de exportação e o ano em que o participante da pesquisa entrou na empresa. Caso ele seja o fundador da empresa, era esperado que o ano de fundação e o ano em que o participante entrou na empresa fossem o mesmo, identificando assim a possibilidade do participante ser um dos proprietários da empresa, além de saber se a empresa foi precoce na busca da internacionalização. $\mathrm{Na}$ sequência, são apresentadas duas perguntas de filtro, sendo: uma pergunta sobre o porte da empresa, a qual, se o respondente indicasse grande empresa, ele era levado automaticamente para a tela final de agradecimento e solicitação que enviasse o link do questionário para outras empresas de seu conhecimento. A outra pergunta era se o respondente participava diretamente do processo de internacionalização da empresa, a qual se fosse indicada não participa diretamente das decisões sobre internacionalização era também apresentada à tela final com agradecimento e solicitação que enviasse o link do questionário para outras empresas de seu conhecimento. 
- $2^{\text {a }}$ Parte - uma tela com quatro perguntas relacionadas com o capital humano: a idade do decisor, o nível de escolaridade (educação formal), o tempo em que morou fora do Brasil em anos e o conhecimento de línguas estrangeiras; sendo que o respondente era informado no início destas perguntas que deveria considerar o momento em que ele entrou ou fundou a empresa.

- $3^{\text {a }}$ Parte - duas telas com perguntas relativas ao capital social, sendo compostas de uma matriz com quatro itens para que o respondente indicasse a frequência com que utilizava as fontes de informações vindas de clientes, fornecedores, agências governamentais e do seu círculo de relacionamento empresarial. A outra tela continha uma matriz com três itens os quais o respondente indicava a frequência com que mantinha relacionamentos por meio de atividades informais, encontros nacionais e encontros internacionais.

- $4^{\mathrm{a}}$ Parte - uma tela com uma matriz com seis itens, sendo o primeiro ainda referente ao capital social e os demais itens relacionados à propensão ao risco, aos quais o respondente indicava o seu grau de concordância entre discordo totalmente e concordo totalmente.

- $5^{\text {a }}$ Parte - uma tela com uma escala semântica de cinco pontos a qual o respondente indicava sua postura diante de uma tomada de decisão, sendo 1 - cautelosa e 5 - agressiva, buscando assim conhecer a propensão ao risco do respondente. Uma pergunta para que o respondente pudesse indicar em duas escalas semânticas a sua percepção de risco, sendo uma pergunta relativa ao risco nas atividades de exportação e a outra pergunta relativa à visão do respondente das oportunidades e ameaças inseridas nas atividades de exportação.

- $6{ }^{\text {a }}$ Parte - uma tela com cinco afirmativas em que o respondente indicava seu grau de satisfação sobre as receitas no mercado doméstico e no exterior, o volume de exportação em relação ao segmento da empresa e em relação aos concorrentes no mercado doméstico. Estas perguntas são relativas à variável de controle. 
- $7^{\mathrm{a}}$ Parte - uma tela contendo uma pergunta sobre a quantidade de países que a empresa exportou em 2015 e três perguntas, sendo uma sobre o volume aproximado de exportação em 2015, uma pergunta relativa às receitas de exportação nos três primeiros anos em o respondente entrou ou fundou a empresa e por fim, uma pergunta relativa ao volume de exportação entre 2015 e 2014. Estas perguntas eram referentes à abrangência, profundidade e velocidade de internacionalização, componentes do grau de internacionalização da empresa.

- $8^{\text {a }}$ Parte - uma tela contendo uma matriz de seis itens referentes a uma escala de desejabilidade social (STEENKAMP; DE JONG; BAUMGARTNER, 2010), como variável a ser utilizada para verificar o grau de CMV; além de conter espaço para comentários.

- $9^{a}$ Parte - Finalização - uma tela de encerramento solicitando ao respondente que desejasse receber a cópia dos resultados consolidados deste estudo, preenchesse então os campos relativos ao nome da empresa, nome do respondente e e-mail de contato. Por fim, segue um agradecimento e uma solicitação de envio do link do questionário para outra empresa que pudesse participar da pesquisa.

Após a elaboração do questionário, foi então necessária a realização de um teste piloto (pré-teste) deste instrumento. O objetivo do teste piloto é detectar a existência de erros, avaliar a qualidade da mensuração, corrigir as distorções e acrescentar informações necessárias para que os respondentes possam entender melhor determinadas questões (FOWLER, 2009; VIEIRA, 2009).

Para Carmines e Zeller (1979) e Martins e Theóphilo (2009), a validade se refere ao grau em que o instrumento de coleta de dados realmente mede a variável que pretende medir. Um instrumento não é simplesmente válido, não há validade em termos gerais. Sendo assim, para que um instrumento seja considerado válido é necessário avaliar a validade de conteúdo, a validade de critério e a validade de construto. O Quadro 12 apresenta as definições de cada uma destas validades. 


\begin{tabular}{ll}
\hline \multicolumn{1}{c}{ VALIDADE } & \multicolumn{1}{c}{ DEFINIÇÃO } \\
\hline Validade de conteúdo & $\begin{array}{l}\text { Grau em que um instrumento evidencia um domínio específico } \\
\text { de conteúdo do que pretende medir. É o grau em que a } \\
\text { medição representa o conceito que se pretende medir. }\end{array}$ \\
Validade de critério & $\begin{array}{l}\text { Estabelece a validade de um instrumento de medição } \\
\text { comparando-o com algum critério externo, fazendo a } \\
\text { correlação da medida com a conduta esperada. A validade de } \\
\text { critério pode ser concomitante, na qual a correlação entre o } \\
\text { critério e a medida é elevada simultaneamente, e pode ser } \\
\text { também preditiva na qual a correlação entre o critério e a } \\
\text { medida é elevada, porém no futuro. } \\
\text { Grau em que um instrumento de medidas se correlaciona } \\
\text { consistentemente com outras medidas semelhantes derivadas } \\
\text { da mesma teoria que estão sendo medidos. Quando a } \\
\text { correlação com outras medidas semelhantes é elevada, tem-se } \\
\text { a validade convergente, caso a correlação com outras medidas } \\
\text { semelhantes é baixa ou inexistente, tem-se a validade } \\
\text { discriminante. }\end{array}$ \\
\hline
\end{tabular}

Quadro 12: Definição dos tipos de validades

Fonte: Carmines e Zeller (1979); Martins e Theóphilo (2009).

De acordo com Martins e Theóphilo (2009), “a validade de construto foi dada pela resposta à questão: em que medida o construto de um conceito social de fato reflete seu verdadeiro significado teórico"?

Foi então realizado um pré-teste no questionário inicialmente conduzido com cinco pessoas que não tinham vínculo direto com pequenas empresas, porém trabalhavam e estudavam estratégia e negócios internacionais. Este teste foi realizado com o questionário impresso. Em paralelo, foi realizado o pré-teste com seis pessoas sendo uma de microempresa, quatro de pequenas empresas e uma pessoa de média empresa, exportadoras. Este pré-teste foi realizado com o questionário online, tendo corrigido alguns itens que apresentaram problemas de interpretação e ordenamento das perguntas no teste do questionário impresso. $\mathrm{O}$ teste do questionário online apresentou um único problema com as três últimas questões que apresentavam como uma das alternativas a possibilidade do respondente indicar que não possuía a informação no momento da resposta a estas perguntas. Foi detectado que os respondentes ficavam com tendência a indicar justamente esta alternativa, sendo que um respondente chegou a fazer esta indicação e depois mudou sua resposta ao buscar as informações com outras pessoas da empresa. Diante desta constatação esta alternativa foi retirada das perguntas e o questionário foi ainda revisado por mais duas vezes entre o orientador e o orientando deste estudo. 
Para que o respondente não deixasse de responder a alguma pergunta, foi inserido um alerta para o respondente assim que ele avançava para a tela subsequente, além da possibilidade do participante poder retornar a responder as perguntas a partir do ponto em que teve que interromper tal atividade. Tal recurso tinha como objetivo a obtenção de menor perda de respostas por dados ausentes, porém, poderia haver a linearização dos dados, que foi analisado posteriormente.

\section{3.}

\section{Amostra}

A etapa após a realização do teste piloto foi a definição da amostra. De acordo com Fowler (2009, p. 30-32), “o quão bem uma amostra representa uma população depende da estrutura da amostra, do tamanho da amostra e da forma específica da seleção de procedimentos. A maioria dos procedimentos de amostragem se divide em três classes gerais":

i. A amostragem é feita de uma lista mais ou menos completa de indivíduos na população a ser estudada.

ii. A amostragem é feita de um conjunto de pessoas que vão a algum lugar ou fazem alguma coisa que as habilita a participar da amostra (por exemplo, pessoas que receberam assistência médica, ou que compareceram a um encontro). Nesses casos, não há uma lista prévia a partir da qual a amostragem ocorre; a criação da lista e o processo de amostragem devem ocorrer simultaneamente.

iii. A amostragem é feita em dois ou mais estágios, com o primeiro estágio de amostragem envolvendo algo diferente dos indivíduos que serão finalmente selecionados. Em um ou mais passos, essas unidades primárias são recolhidas, e eventualmente uma lista de indivíduos (ou outras unidades de amostragem) é criada, a partir da qual a seleção final de amostra é feita. (FOWLER, 2009, p. 32). 
O foco principal desta tese são as pequenas e médias empresas brasileiras que possuem algum tipo de investimento em atividades e operações no exterior, como exportação, escritório de vendas no exterior e/ou subsidiária no exterior. Entretanto, conforme relata Floriani (2010), não existe um banco de dados sobre IDE de empresas nacionais, devido ao Decreto Lei $n^{0} 5.844$, do Banco Central do Brasil (BACEN), que estabelece que os dados de empresas e pessoas físicas que possuem IDE são sigilosos. Desta forma, assim como Floriani (2010), o foco então serão os bancos de dados de empresas exportadoras.

A primeira alternativa é o banco de dados do Centro de Estudos do Comércio Exterior (FUNCEX), porém, este banco de dados não está disponível em site, devendo ser solicitado via contato do pesquisador com este órgão.

Esta tese adotará para a definição da população alvo a metodologia aplicada para o enquadramento e identificação das empresas por porte, que associa o número de empregados da empresa e o valor exportado pela mesma no período considerado, distribuídos por ramo de atividade (indústria e comércio/serviços), ambos de acordo com os parâmetros adotados no MERCOSUL, conforme disposto nas Resoluções MERCOSUL-GMC n 90/93 e 59/98, com os ajustes elaborados pelo Departamento de Estatística e Apoio à Exportação da Secretaria de Comércio Exterior (DEAEX/SECEX; MDIC, 2009).

A Tabela 2 apresenta os parâmetros de classificação por porte. Pelo critério adotado, prevalece o resultado apurado no maior porte.

Tabela 2: Classificação do porte de empresas.

\begin{tabular}{|c|c|c|c|c|}
\hline \multirow[t]{2}{*}{ PORTE } & \multicolumn{2}{|c|}{ INDÚSTRIA } & \multicolumn{2}{|c|}{ COMÉRCIO E SERVIÇOS } \\
\hline & $\mathrm{N}^{\mathrm{o}}$ Empregados & VALOR & $\mathrm{N}^{\mathrm{o}}$ Empregados & VALOR \\
\hline Micro Empresa & Até 10 & Até US\$ 400 mil & Até 5 & Até US\$ 200 mil. \\
\hline $\begin{array}{l}\text { Pequena } \\
\text { Empresa } \\
\end{array}$ & De 11 a 40 & Até US\$ 3,5 milhões & De 6 a 30 & Até US\$ 1,5 milhão \\
\hline $\begin{array}{c}\text { Média } \\
\text { Empresa }\end{array}$ & De 41 a 200 & Até US\$ 20 milhões & De 31 a 80 & Até US\$ 7 milhões \\
\hline $\begin{array}{c}\text { Grande } \\
\text { Empresa }\end{array}$ & Acima de 200 & $\begin{array}{c}\text { Acima de US\$ } 20 \\
\text { milhões }\end{array}$ & Acima de 80 & $\begin{array}{c}\text { Acima de US\$ } 7 \\
\text { milhões }\end{array}$ \\
\hline Pessoa Física & - & - & - & - \\
\hline
\end{tabular}

Fonte: MDIC (2009) 


\section{Quadro amostral}

A amostra para o presente estudo deverá ser composta inicialmente por microempresas, pequenas empresas e médias empresas que exportam, conforme estabelecido na Tabela 2. Foi utilizado inicialmente as informações da Confederação Nacional da Indústria - CNI, que disponibiliza no site http://www.brazil4export.com/, um Catálogo de Exportadores Brasileiros contendo informações como o nome da empresa, o telefone e o site da empresa. Essas informações são classificadas por faixa de valor de exportação da empresa. Considerando o valor de exportação da Tabela 2, foi realizado um levantamento inicial neste site, indicando a faixa até US\$ 1 milhão para o valor de exportação, encontrando 12.265 empresas. Se for indicada a faixa entre US\$ 1 milhão e US\$ 10 milhões, são apontadas 15.503 empresas, estando incluídas as microempresas, pequenas e médias empresas brasileiras.

O estado de Minas Gerais possui um site denominado de Cadastro Industrial Minas Gerais da Confederação das Indústrias do Estado de Minas Gerais - CIEMG, o site http://www.cadastroindustrialmg.com.br/empresas, que permite acessar informações sobre o porte de empresas exportadoras do Estado de Minas Gerais. É possível utilizar os dados da Tabela 2 como parâmetro para a escolha do porte da empresa, obtendo-se endereços, e-mails e telefones de contato de empresas exportadoras. Em um levantamento inicial obteve-se um total de 462 registros de micro, pequenas e médias empresas exportadoras. A partir das informações coletadas por meio dos canais das organizações acima citados, foi então elaborada duas listas de possíveis participantes da pesquisa.

Foram convidados a participar deste estudo pessoas que de alguma forma se envolviam na tomada de decisão em microempresas, pequenas empresas e médias empresas, podendo esta pessoa ser a proprietária, fundadora ou pertencer a algum cargo de gestão destas empresas. Apesar de na tela inicial do questionário haver uma menção da participação de pessoas ligadas aos portes menores da indústria brasileira e serem consideradas decisores, houve um número expressivo de respondentes de grandes empresas e que não eram envolvidos diretamente com as decisões de internacionalização da empresa, além, de não responderem o questionário na íntegra. 
O questionário ficou disponível para reposta por 75 dias entre os meses de agosto, setembro, outubro e primeira semana de novembro de 2016. O envio do questionário se deu pelo e-mail criado no setor de informática do IAG - PUC Rio de Janeiro exclusivamente para que fossem acompanhados os números de acessos e possíveis respostas ao questionário. Na campanha inicial de teste foi realizada com envio de um total de 368 e-mails programados para envio, sendo que 285 foram entregues; destes, foram observados que 11,23\% visualizaram a mensagem e destes, $18,75 \%$ clicaram no questionário, sendo os possíveis respondentes do questionário. Em 31de agosto foi realizada uma campanha com o envio de mais de 6000 e-mails, sendo que destes, 2653 foram entregues com sucesso e um percentual de 12,89\% de visualizações do questionário, sendo que destes, $14,91 \%$ clicaram no questionário, sendo então os possíveis respondentes. Foram ainda realizadas, uma campanha com o envio de 123 e-mails e outra para 368 e-mails, obtendo resultados muito próximos aos das campanhas anteriores, em termos de percentuais de visualização e cliques. Foi então realizada mais uma campanha sendo reencaminhados mais de 4000 e-mails das mesmas campanhas anteriores em 19 de setembro, porém, aumentando o número de respondentes. $\mathrm{Na}$ segunda quinzena de outubro houve um contato com o SEBRAE-MG que solicitou às empresas em que prestavam serviço um auxílio no sentido de responder ao questionário, sendo o link repassado para estas empresas aumentando o número de empresas participantes da pesquisa. As Tabelas 3 e 4 apresentam os dados relativos às campanhas de envio de questionários para as pequenas e médias empresas pré-selecionadas.

Tabela 3: Envio de e-mails para PMEs exportadoras CNI

\begin{tabular}{|c|c|c|c|c|c|c|}
\hline Campanha & $\begin{array}{l}\text { Total de e-mail } \\
\text { programados para } \\
\text { envio }\end{array}$ & $\begin{array}{l}\mathrm{N}^{\circ} \\
\text { entregue } \\
\text { sucesso }\end{array}$ & $\begin{array}{r}\text { e-mails } \\
\text { com }\end{array}$ & $\begin{array}{l}\mathrm{N} .^{\circ} \text { de e-mails com } \\
\text { problemas }\end{array}$ & $\begin{array}{l}\mathrm{N}^{\circ} \text { de contatos } \\
\text { que viram o e- } \\
\text { mail }\end{array}$ & $\begin{array}{l}N^{\circ}{ }^{\circ} \text { de } \\
\text { contatos que } \\
\text { clicaram }\end{array}$ \\
\hline $1^{\mathrm{a}}$ & 4054 & & 2660 & 1394 & 325 & 40 \\
\hline $2^{a}$ & 4054 & & 2653 & 1401 & 342 & 51 \\
\hline
\end{tabular}

Tabela 4: Envio de e-mails para PMEs exportadoras CIEMG

\begin{tabular}{|c|c|c|c|c|c|}
\hline Campanha & $\begin{array}{l}\text { Total de e-mail } \\
\text { programados } \\
\text { para envio }\end{array}$ & $\begin{array}{l}\text { N. } .^{\circ} \text { e-mails entregue } \\
\text { com sucesso }\end{array}$ & $\begin{array}{l}\text { N. }{ }^{\circ} \text { de e-mails com } \\
\text { problemas }\end{array}$ & $\begin{array}{l}\text { N. de contatos } \\
\text { que viram o e- } \\
\text { mail }\end{array}$ & $\begin{array}{l}\mathrm{N}^{\circ}{ }^{\circ} \text { de } \\
\text { contatos que } \\
\text { clicaram }\end{array}$ \\
\hline $1^{a}$ & 368 & 285 & 83 & 32 & 6 \\
\hline $2^{a}$ & 361 & 303 & 58 & 45 & 8 \\
\hline
\end{tabular}


A Figura 3 apresenta o porte das empresas participantes da pesquisa.

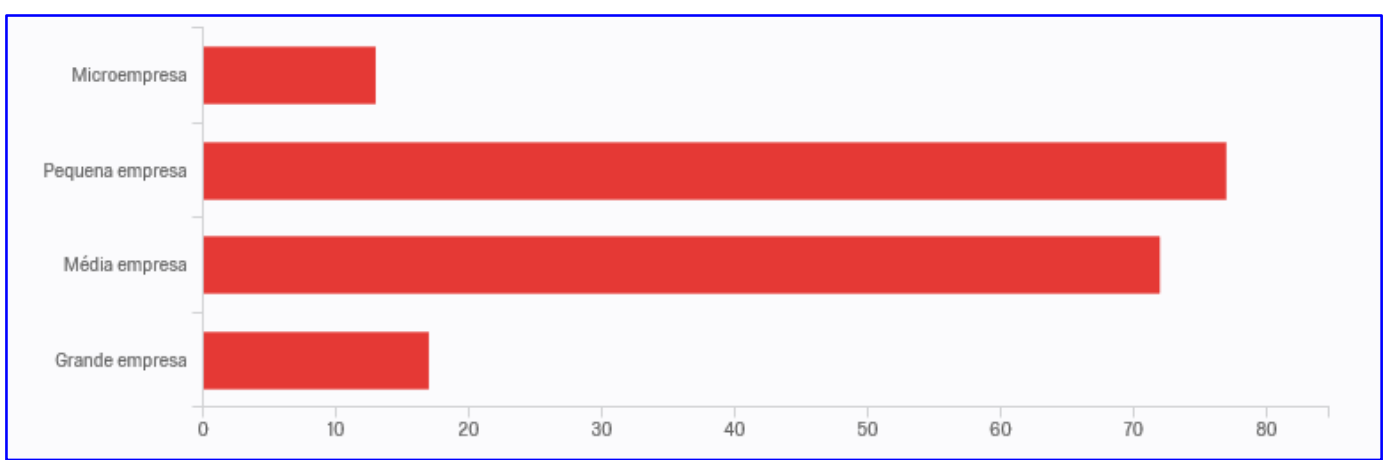

Figura 3: Porte das empresas respondentes da pesquisa Fonte: Própria

Apesar de o questionário ter sido aplicado para empresas classificadas como micro, pequenas e médias empresas, algumas grandes empresas, que não fazem parte da pesquisa e que foram relacionadas no grupo das empresas foco também responderam a pesquisa, do total de empresas participantes, 17 responderam que eram grandes empresas e não seguiram adiante na pesquisa, não sendo considerada nos resultados. Do total de participantes, 12 respondentes indicaram que não participam diretamente das decisões de internacionalização da empresa, sendo também excluídas das análises. O questionário ainda apresentou 72 casos com mais de $15 \%$ de respostas ausentes, ficando um total de 123 questionários. Destes, 71 questionários foram considerados válidos para as análises estatísticas, devido ao fato dos respondentes estarem na empresa pelo menos três anos antes da empresa exportar pela primeira vez; o que caracteriza a participação efetiva do gestor no início das atividades de exportação.

Esta amostra pode apresentar o viés de não resposta ao questionário, o que pode ser devido ao viés de autoseleção. Por exemplo, gestores com capital humano mais alto podem estar mais propensos a responder uma pesquisa acadêmica se comparados com gestores que não tem o capital humano elevado. De acordo com Fowler (2009) as pessoas que têm um interesse particular no assunto relacionado com a pesquisa em si são mais prováveis de responder o questionário do que aquelas que não são interessadas. Isso significa que uma survey com baixas taxas de resposta podem ser tendenciosas na maneira com que são relacionados diretamente aos propósitos da pesquisa. (FOWLER, 2009). 
O aumento do tamanho da amostra impacta nos resultados de estimativas estáveis dos erros e também no aumento da significância estatística, considerando uma proporção da quantidade de itens que constitui o modelo (HINKIN, 1998). Como uma popular regra para estimativas de PLS-SEM ser considerada robusta Barclay et al. (1995) sugerem o uso de um tamanho de amostra mínima de dez vezes o número máximo de caminhos (setas do modelo), com construtos tanto formativos quanto reflexivo no modelo. Embora esta regra não leve em conta efeito do tamanho, confiabilidade, o número de indicadores e outros fatores conhecidos que afetam o poder estatístico do teste e, portanto, pode ser enganosa, no entanto, fornece uma estimativa aproximada de do tamanho de amostra mínima. (HAIR et al., 2012).

$\mathrm{Na}$ prática, um estudo típico teria um nível de significância de 5\%, um poder estatístico de $80 \%$ e valores de $\mathrm{R}^{2}$ de pelo menos 0,25 . Usando esses parâmetros, o tamanho mínimo da amostra necessária pode ser visto desde as orientações sugeridas por Marcoulides e Saunders (2006) e também Wong (2013), dependendo do número máximo de setas a apontar para uma variável latente conforme especificado no modelo de equação estrutural, conforme Tabela 5.

Tabela 5: Sugestão de tamanho de amostra

\begin{tabular}{|c|c|}
\hline Amostra mínima & $\begin{array}{c}\mathrm{N}^{\circ} \text { máximo de vetores (setas) apontando para uma variável latente } \\
\text { no modelo }\end{array}$ \\
\hline 52 & 2 \\
\hline 59 & 3 \\
\hline 65 & 4 \\
\hline 70 & 5 \\
\hline 75 & 6 \\
\hline 80 & 7 \\
\hline 84 & 8 \\
\hline 88 & 9 \\
\hline 91 & 10 \\
\hline
\end{tabular}

Fonte: Marcoulides e Saunders (2006) 
A amostra com 123 casos poderia ser considerada pela regra empírica proposta por Hair et al. (2012), porém, como apresentado na Tabela 5, considerando nove vetores no modelo proposto a amostra mínima seria 88 casos. Uma alternativa para estimação do número de amostra é apresenta na Tabela 6, a qual foi utilizada nesta tese. Trata-se da análise do poder estatístico por meio do software G*Power.

\begin{tabular}{|c|c|c|}
\hline \multicolumn{3}{|c|}{$\begin{array}{l}\text { F tests - Linear multiple regression: Fixed model, } \mathrm{R}^{2} \text { deviation from } \\
\text { zero }\end{array}$} \\
\hline Analysis: & \multicolumn{2}{|c|}{ A priori: Compute required sample size } \\
\hline \multirow[t]{4}{*}{ Input: } & Effect size $\mathrm{f}^{2}$ & $=0.15$ \\
\hline & $\alpha$ err prob & $=0.10$ \\
\hline & Power ( $1-\beta$ err prob) & $=0.71$ \\
\hline & Number of predictors & $=7$ \\
\hline \multirow[t]{6}{*}{ Output: } & Noncentrality parameter $\lambda$ & $=10.6500000$ \\
\hline & Critical F & $=1.8143971$ \\
\hline & Numerator df & $=7$ \\
\hline & Denominator df & $=63$ \\
\hline & Total sample size & $=71$ \\
\hline & Actual power & $=0.7162399$ \\
\hline
\end{tabular}

Fonte: Software G*Power

O modelo proposto possui sete preditores, ou seja, número de vetores (setas) apontando para a variável dependente, seguindo as recomendações de Hair et al. (2014), ou seja, nível de significância de $10 \%$ e poder estatístico (erro probabilístico 1- $\beta$ ) ficou em 71\%, testado por meio do software G*Power 3.1.9.2. A seguir são apresentadas as técnicas de análise de dados aplicados neste estudo.

\section{4.}

\section{Técnica para analise de dados}

Considerando que vários construtos nas ciências sociais aplicadas são multifacetados e bastante complexos, e não são diretamente observáveis, o modelo deve então ser representado por múltiplas variáveis observáveis (indicadores) tendo explicita incorporação de erros. A técnica de modelagem de equações estruturais (SEM), também chamado de modelos de equações simultâneas, são multivariados (i.e., multiequação), sendo considerados modelos de regressão simultâneas; é justamente aplicada nestas demandas. Ao contrário do modelo linear multivariado mais tradicional, no SEM a variável de resposta das 
equações de regressão aparecem de um em um, como um preditor em outra equação. Na verdade, variáveis em um modelo de equação estrutural podem influenciar outro reciprocamente, diretamente ou através de outras variáveis como intermediários. Estas equações estruturais destinam-se a representar as relações causais entre as variáveis no modelo (FOX, 2002).

Uma visão da SEM é que sua popularidade nas ciências sociais reflete a legitimidade que os modelos parecem emprestar à interpretação causal de dados observacionais, quando na verdade tal interpretação é não menos problemática do que para outros tipos de modelos de regressão aplicados aos dados observacionais. Uma das interpretações é que a SEM aproxima-se do tipo de pensamento informal sobre relações causais que é comum nas ciências sociais, e que, portanto, estes modelos facilitam a tradução dessas teorias em análise de dados. Em contrapartida, os modelos de equações estruturais podem se originar da teoria formal (FOX, 2002).

Modelos de equações estruturais (BOLLEN, 1989) incluem um número de métodos estatísticos para estimar uma rede de relações causais, definidas de acordo com um modelo teórico, ligando dois ou mais conceitos complexos latentes a cada uma medida através de uma série de indicadores observáveis. A ideia básica é que a complexidade dentro de um sistema seja estudada tendo em conta uma rede de causalidade entre conceitos latentes, chamado de variáveis latentes e também medida por vários indicadores observados geralmente definidos como variáveis reflexivas.

A Partial Least Squares - PLS (mínimos quadrados parciais) para modelos de equação estrutural, também conhecido como PLS Path Modeling (PLS-PM) tem sido proposta como um procedimento de estimativa baseada em componentes diferente da abordagem clássica do LISREL com base em covariância. Em seu estudo seminal, Wold (1966) determina alguns dos princípios dos mínimos quadrados parciais para análise de componentes principais que foram ampliados para situações com mais de um bloco de variáveis. 
O procedimento PLS é um algoritmo iterativo que resolve separadamente os blocos do modelo de medição e, numa segunda etapa, as estimativas dos coeficientes do modelo estrutural. Portanto, PLS é utilizado para explicar a variância residual das variáveis latentes em qualquer regressão no modelo (FORNELL; BOOKSTEIN 1982). É por isso que PLS é considerado mais como uma abordagem exploratória do que como uma confirmação. Ao contrário da abordagem clássica baseada em covariância, PLS-SEM não visa a reprodução da matriz de covariância da amostra. PLS-SEM é considerado uma abordagem de modelagem no qual alguns pressupostos para a modelagem de equações estruturais, com relação às distribuições, o tamanho da amostra e a escala de medição, são mais flexíveis. Esta é uma característica muito interessante, especialmente nas aplicações onde tais pressupostos não são facilmente defensáveis, pelo menos na íntegra. (VINZI et al., 2010).

No entanto, isso implica uma falta do clássico quadro inferencial paramétrico que é substituído por intervalos de confiança empíricos e procedimentos com base em métodos de reamostragem para os testes de hipóteses como nos métodos jackknife e bootstrap. Portanto, PLS-SEM é mais orientado para otimizar as previsões (variâncias explicadas) do que precisão estatística das estimativas. (VINZI et al., 2010).

Nesta tese o modelo foi estimado pelo método PLS-SEM, que permite a estimativa de relações complexas de causa-efeito entre as variáveis latentes. Ao contrário do método Covariance-Based (CB-SEM), que estima os parâmetros do modelo para de dados observados. PLS-SEM é orientado para maximizar a quantidade de variância explicada (previsão) nas variáveis endógenas. As razões para escolher PLS-SEM, ao invés de CB-SEM são: presença de construções de medida formativa e uma amostra potencialmente não tão grande o suficiente. Embora o modelo tenha um grande número de parâmetros a ser estimado, a técnica de PLS-SEM não é exigente em termos de tamanho de amostra mínima e nem em relação à definição da forma de distribuição dos dados, ou seja, os dados não necessitam estar distribuídos como uma normal (HAIR et al., 2014). 
Os dados obtidos por meio das respostas ao questionário online foram analisados empiricamente via método dos mínimos quadrados parciais, uma forma de modelagem de equações estruturais. Inicialmente foi realizada um tratamento para eliminar os dados omissos ou ausentes (missing value), em seguida os dados foram avaliados em relação à normalidade, assimetria e curtose, por meio do software SPSS Statistics Basic versão 24 e as analises de variância do método (CMV) e validação do modelo teórico foram realizados por meio do software SmartPLS versão 3.1 .

\section{Procedimentos para tratamento de dados ausentes (missing value)}

Os dados ausentes foram inicialmente identificados via análise em uma planilha Excel e nos casos em estes a quantidade dados ausentes eram superiores a $15 \%$, tais casos foram eliminados, o que reduziu a amostra chegando aos 132 casos. Para os casos que permaneceram na base de dados, foi feita a imputação de dados omissos por meio do SPSS 24.

Para realizar a imputação de dados ausentes optou-se por utilizar a média dos valores mais próximos do dado ausente no SPSS. Porém, foi necessário que os dados exportados da planilha Excel fossem excluídas (deletada), pelo fato dos dados ausentes nesta planilha estivessem com o valor zero, não sendo considerado assim um dados ausente.

Em seguida procederam-se as análises de normalidade, apresentadas a seguir, e a transformação dos dados originais em Z-scores, no próprio SPSS, pois os dados analisados no SmartPLS devem estar no formato padronizado, caso contrário os resultados podem apresentar distorções que não seriam detectadas pelos testes do modelo estrutural.

\subsection{1.}

\section{Validação empírica do modelo teórico}

Apesar dos modelos estruturais parecerem idênticos, existe grandes diferenças entre a SEM e o PLS em termos de estimação e interpretação dos modelos. O PLS estima as relações em termos de mensuração do modelo estrutural e do modelo de medidas respectivamente. Além disso, o PLS trata os fatores como scores compostos individualmente, ou seja, não tenta recriar a covariância entre scores dos itens medidos. (HAIR et al., 2010). 
Em geral os modelos de PLS apresentam menos problemas com identificação estatística e com erros fatais que impeçam a estimação dos parâmetros; desta forma, os modelos ficam mais robustos. O PLS produz estimativas que maximizam a variância explicada de forma semelhante à regressão múltipla OLS. Portanto, o foco do PLS é mais sobre previsão, sendo então mais apropriado para avaliar a teoria. (HAIR et al., 2010).

O PLS pode ser uma alternativa aos modelos com medidas de um só item fornecendo estimativas confiáveis das relações entre construtos, que é o caso do modelo proposto nesta tese. Desta forma, quando o contexto de uma teoria de mensuração tiver pouco significado, o PLS pode ser uma abordagem bastante útil. Portanto o PLS não exige características de boa medição para produzir resultados.

O SEM tradicional e PLS-SEM suportam modelos reflexivos e formativos. Por tradição histórica, modelos reflexivos tem sido a norma na modelagem de equações estruturais e modelos formativos tem sido a norma na modelagem por mínimos quadrados parciais. Porém, o fato é que a escolha entre modelos reflexivos e formativos deve depender da natureza dos indicadores (GARSON, 2016).

Os pesos de medição (no modelo de medidas) com conexão entre as variáveis latentes e seus indicadores são estimados de forma diferente, dependendo se o modelo é reflexivo ou formativo. Para o modelo reflexivo, com setas indo da variável latente para os indicadores, os pesos são estimados nas covariâncias entre a variável latente e o indicador. Se o modelo é formativo, com setas indo dos indicadores para a variável latente, os pesos são estimados por regressão da variável latente em seu indicador. (GARSON, 2016).

\subsection{2. \\ Procedimentos para a verificação da variância de método comum (CMV)}

Para que a CMV não possa ocorrer Hinkin (1998) recomenda que o questionário seja respondido por mais de uma pessoa por empresa, podendo ser feita uma aplicação parcial para diferentes pessoas na empresa. Desta forma, evita-se que a consistência interna seja aumentada, fazendo com que exista uma aparente correlação entre as variáveis, o que de fato não existiria ou então seria mais fraca se fosse obtida de outra forma. Tal situação pode ocorrer 
principalmente em questionários autoadministrados (CHANG; VAN WITTELOOSTUIJN; EDEN, 2010; PODSAKOFF; ORGAN, 1986), que é o caso deste estudo.

Williams, Hartman e Cavazotte (2010) recomendam que seja definida uma variável de controle (marcadora) que não seja teoricamente relacionada com as variáveis do modelo, para capturar em uma ou mais as fontes de viés que podem ocorrer no contexto de medição para as variáveis principais que serão examinadas pelo processo de resposta ao questionário. Esta nova definição é diferente da forma com que têm sido referidas as variáveis de efeito do método medida, tais como a afetividade negativa e desejabilidade social, mesmo que ambos os tipos de variáveis do método sejam mais bem avaliadas com métodos similares de variáveis latentes. Considerando a recomendação de Williams, Hartman e Cavazotte (2010), foi inserido seis itens sem nenhuma relação com os construtos do estudo com objetivo de capturar a presença de viés de desejabilidade social sugerido por Steenkamp, De Jong e Baumgartner (2010).

Uma vez inserido os itens para capturar a possibilidade de impacto da CMV na pesquisa, foi realizado o teste de fator único de Harman, com todos os itens relacionados com o construto focal e os da escala de desejabilidade social. Como resultado o primeiro fator retirado deve explicar menos que $50 \%$ da variância dos dados, indicando que a CMV não era a principal razão para a existência de correlação entre as variáveis.

Considerando as recomendações de Chang, Van Witteloostuijn e Eden (2010), após a realização do teste de Harman, foi avaliado o nível de significância estatística, observando se o índice " $t$ " das relações entre pares de construtos eram mantidos na presença ou ausência de uma variável de controle formada pelos itens inseridos no questionário, avaliando assim a CMV. Esta análise foi realizada por meio da técnica bootstrapping no SmartPLS, considerando o nível de significância de 5\%. Para que fosse constatada a ausência da CMV os sinais das relações, bem como os níveis de significância deveriam permanecer inalterados nas relações entre os construtos. 
Em seguida, foram avaliados os pesos das relações, ou seja, os coeficientes "p" com objetivo de verificar a relevância da variável de controle, em termos absolutos, quando comparado com as demais relações entre construtos. A ausência da CMV é constatada pela apresentação de baixos coeficientes, devendo ser menores para a relação da variável de controle com os construtos do modelo, uma vez comparados com os coeficientes das relações entre os construtos do modelo.

Por fim, foi realizada uma análise de cross-loading normalizado por meio da comparação da carga dos indicadores nos seus construtos em relação à carga no construto considerado a variável de controle. Esta análise também possibilita comparar o comportamento das cargas de cada indicador (item) da variável de controle nos construtos do modelo. Para constatar que não houve a influência da $\mathrm{CMV}$, as cargas padronizadas devem ser baixas em relação aos indicadores das variáveis de marcação sobre os construtos do modelo e também menores que as cargas padronizadas dos indicadores e seus respectivos construtos. $\mathrm{O}$ valor da carga padronizada deve ser menor que 0,5 .

\subsection{3.}

\section{Análise do modelo de mensuração e estrutural}

Hair et al. (2014) recomenda que a análise da validade do construto medido de forma reflexiva seja realizada em três partes uma vez que a análise seja a PLSSEM. Uma vez que os modelos estrutural e de mensuração (medida) foram especificados, o próximo passo é a execução do algoritmo de PLS-SEM e, com base nos resultados, é avaliada a confiabilidade e a validade das medidas dos construtos do modelo de mensuração.

Em seguida, deve-se avaliar o modelo de mensuração em relação à validade convergente, à significância da contribuição de cada indicador para formar o seu construto e quanto à existência de colinearidade entre os indicadores.

Finalizando, deve-se avaliar a existência de linearidade entre as variáveis latentes do modelo estrutural, bem como a significância das relações entre construtos, a significância preditiva, o grau do seu efeito e o nível de variância explicada. 


\section{Modelo de mensuração reflexivo}

Em um modelo reflexivo, as setas vão da variável para o indicador, significando que um construto unidimensional determina os valores do indicador e representativo medido. Testes de validade convergente como a consistência interna ou alfa de Cronbach são apropriados para modelos reflexivos, mas não em modelos formativos.

A consistência interna é uma alternativa preferencial ao alfa de Cronbach como um teste de validade convergente em um modelo reflexivo, e deve ser o primeiro a ser avaliado em um modelo de mensuração reflexivo. Pode ser preferido como uma medida da confiabilidade, porque o alfa Cronbach subestima a confiabilidade da escala. Em comparação com alfa de Cronbach, a consistência interna pode levar a maiores estimativas de confiabilidade. O limite aceitável para consistência interna é o mesmo para qualquer medida de confiabilidade, incluindo a de Cronbach.

A consistência interna varia de 0 a 1 , com 1 sendo consistência interna estimada perfeita. Em um modelo adequado para fins exploratórios, a consistência interna deve ser igual ou maior que 0,60 (CHIN, 1998; GARSON, 2016; HÖCK; RINGLE, 2006); igual ou maior que 0,70 para um modelo adequado para efeitos de confirmação de uma proposição (HENSELER; RINGLE; SARSTEDT, 2012); e igual ou maior que 0,80 para ser considerado bom para uma pesquisa confirmatória (DASKALAKIS; MANTAS, 2008; GARSON, 2016). Entretanto, uma consistência interna maior que 0,90 pode indicar que os vários indicadores são variantes de menor expressão dos demais indicadores, ao invés de serem medidas verdadeiramente representativas do construto. (HAIR et al. 2014:101).

A variância média explicada (AVE) pode ser usada também como um teste de validade convergente e divergente. AVE reflete a concordância média para cada variável latente em um modelo reflexivo. Em um modelo adequado, AVE deve ser maior do que 0,50 (CHIN, 1998; GARSON, 2016; HÖCK; RINGLE, 2006) bem como maior do que cross-loadings elevadas, o que significa que os fatores devem explicar a variação de pelo menos metade de seus respectivos indicadores. AVE abaixo 0,50 significa que a variação do erro excede a variância explicada. (GARSON, 2016). 
A AVE também pode ser usado para estabelecer a validade discriminante pelo critério Fornell-Larcker: para qualquer variável latente, a raiz quadrada da AVE deve ser superior a sua correlação com qualquer outra variável latente. Isto significa que para qualquer variável latente, a variância compartilhada com seu bloco de indicadores é maior do que a variância partilhada com qualquer outra variável latente. O SmartPLS apresenta uma saída com os valores do teste de Fornell-Larcker, sendo que a raiz quadrada AVE aparece nas células na diagonal e as correlações aparecem abaixo dela. Portanto, em termos de valor absoluto, se o primeiro número (que é a raiz quadrada de AVE) em qualquer coluna é maior que os outros números (correlações), abaixo dela, há validade discriminante.

Portanto, quando alguns dos resultados dos testes apresentados anteriormente estiverem fora do estabelecido, pode ser que seja necessária a retirada de algum indicador. No entanto, a retirada de um indicador só deve ocorrer caso a validade convergente ou a validade discriminante seja aumentada, e não influenciar de forma negativa a validade do conteúdo.

\section{Modelo de mensuração formativo}

Em um modelo de medição formativa (a seta parte dos indicadores para as suas variáveis latentes), o qual um fator modelado formativamente é uma variável composta, refletindo os indicadores, que representam diferentes dimensões do fator. Porque os indicadores representam dimensões diferentes, implicando que a consistência interna e o alfa de Cronbach podem não ser altos. Da mesma forma, o fator composto necessariamente não prevê os valores do indicador, implicando que a concordância e redundância podem não ser particularmente elevados porque qualquer tipo de média de diferentes dimensões não irá prever bem qualquer dimensão. Isso faz com que os testes realizados para o modelo de mensuração reflexivo não sejam adequados para o modelo de mensuração formativo (GARSON, 2016).

Inicialmente deve ser realizada a análise da validade convergente. A validade convergente irá existir se o vetor (seta) padronizado que carrega o coeficiente do fator formativo ao fator reflexivo é alto. Chin (1998) sugere um valor de corte de 0,90 , ou pelo menos 0,80 . Isto implica que o valor de $\mathrm{R}^{2}$ para o fator reflexivo deve ser 0.81 ou pelo menos 0,64 . Observe que esse método de avaliação requer que os indicadores para o construto reflexivo sejam identificados 
de antemão e incluídos na fase de projeto da coleta de dados da pesquisa. (GARSON, 2016; HAIR et al., 2014).

A multicolinearidade pode ser um problema de acordo com Garson, (2016) e Hair et al. (2014), se a tolerância for inferior a 0,20, ou se o fator de inflação de variação (VIF) exceder 5. Alguns pesquisadores usam os valores de corte mais rigorosos de 0,25 e 4, respectivamente. O VIF é o inverso da tolerância e contém as mesmas informações (tolerância $<0,20$ corresponde a VIF $>5$ ), então foi aplicado apenas um destes testes, análise do VIF. Tolerância é $1,0-\mathrm{R}^{2}$ para o fator. Isto significa que quando $\mathrm{R}^{2}$ para um fator formativo é menor que 0,80 , a multicolinearidade não é um problema considerando o critério da tolerância < 0,20 ou VIF $>5$. O erro-padrão é dobrado quando VIF é 4.0 e tolerância é 0,25 , correspondente ao $\mathrm{Rj}=0,87$. Portanto, $\mathrm{VIF} \geq 4$ é um critério mais rigoroso o valor corte alternativo comum.

Hair et al. (2014:125) sugerem fatores formativos sinalizados com alta multicolinearidade pelo teste da tolerância ou VIF devem ser descartados do modelo ou operacionalizados de alguma maneira diferente. Garson (2016), porém, não concorda. Para este autor enquanto a multicolinearidade entre os indicadores para um fator formativo infla o erro-padrão e faz a avaliação da importância relativa das variáveis independentes não confiáveis, a tal elevada multicolinearidade não afeta a eficiência das estimativas de regressão.

Por fim, foi realizado um teste de significância com um nível de probabilidade de 0,05, assumindo que a amostragem é aleatória de uma distribuição normal. Se os dados são uma enumeração em vez de uma amostra, o significado é discutível, como todos os efeitos, porém pequenos, são reais e não há possibilidade de "outra amostra". Se a amostra for não aleatória, o nível de significância computado é em erro a um grau desconhecido. Uma significativa pode ser generalizada para a população pressupostos de normalidade e aleatoriedade forem atendidos. (GARSON, 2016; HAIR et al., 2014).

A significância pode ser estimada pelo procedimento bootstrapping que é muitas vezes usado quando os dados podem não ser considerados normais. As propriedades das estimativas distributivas do PLS não são conhecidas pela população e, portanto, o bootstrapping se torna apropriado. Como normalmente computadas, o bootstrapping simula uma grande amostra como base nos dados do pesquisador. Isso permite que o cálculo de um coeficiente de interesse seja 
determinado (ex., uma correlação) para um grande número de tais amostras, permitindo que um desvio-padrão seja calculado. A contagem de desvios-padrão dos coeficientes observados com valor 0 produz um nível de significância. (GARSON, 2016; HAIR et al., 2014).

\section{Modelo estrutural}

O modelo estrutural é examinado apenas após o modelo de medição for considerado aceitável. Tal exame permite a verificação empírica da teoria sobre as relações dos construtos. Inicialmente é avaliado a multicolinearidade. Para avaliar a multicolinearidade no modelo estrutural consideram-se os critérios de tolerância ou VIF, discutidos e anteriormente. Para a tolerância que é igual a $1.0-\mathrm{R}^{2}$, sendo $<0,20$ indica possíveis multicolinearidade. Isso equivale a dizer que $\mathrm{R}^{2}>0,80$ sugerindo um problema de multicolinearidade possível. Isso corresponde a VIF maior que 5, embora alguns usasse os valores mais rigorosos de 0,25 para tolerância e 4 para VIF. Porém, no modelo estrutural caso exista um problema de colinearidade, deve-se eliminar o construto ou fundi-lo com outro construto preditor, ou ainda, criar construtos de ordem superior.

Em seguida são avaliados os coeficientes das relações no modelo estrutural (cargas), que são os pesos dos vetores que indica a relação entre dois construtos, os elementos de conexão para o outro. Como os dados são padronizados, as cargas variam de 0 a 1 . Estas cargas devem ser significativas, para conhecer a condição de significância das cargas, utiliza-se o procedimento bootstrapping. Quanto maior o valor de " $\mathrm{t}$ ", mais forte será a carga no modelo estrutural. Uma carga não significativa pode determinar a reespecificação do modelo sem esta carga, ou por razões de importância teórica a carga pode ser mantida no modelo. No entanto, em casos incomuns, a não ligação entre alguns construtos com cargas não significativas pode afetar o significado de outras cargas no modelo.

Na sequência á avaliado o coeficiente $R^{2}$ e o efeito $f^{2}: R^{2}$, também chamado de coeficiente de determinação é a medida do tamanho do efeito global para o modelo estrutural, como na regressão. A medida de tamanho de efeito $\mathrm{f}^{2}$ é o nome para o efeito de mudança de $R^{2}$. O coeficiente $f^{2}$ pode ser calculado por: $\left(R^{2}\right.$ original $\left.-\mathrm{R}^{2}{ }_{\text {omitido }}\right) /\left(1-\mathrm{R}^{2}\right.$ original $)$. A equação do $\mathrm{f}^{2}$ exprime quanto é grande uma proporção de variância “inexplicável” é contabilizada pela mudança de $\mathrm{R}^{2}$ (HAIR et al., 2014). Considerando o exposto por Cohen (1988), o valor de 0,02 representa um 
tamanho de efeito de "pequeno"; 0,15 representa um efeito de "médio" e 0,35 representa um tamanho de efeito "alto".

Por fim, foram realizadas as análises de $\mathrm{Q}^{2}$ também conhecido como StoneGeisser $\mathrm{Q}^{2}$, aplicável apenas a fatores endógenos reflexivamente modelados, $\mathrm{Q}^{2}$ maior que 0 significa que o modelo de PLS-SEM é preditivo da variável endógena e determinado sob escrutínio. Pela mesma razão, um $\mathrm{Q}^{2}$ com um valor de 0 ou negativo indica que o modelo é irrelevante para a predição de determinado fator endógeno. Da mesma forma que tamanho de efeito $\mathrm{f}^{2}$ foi calculado com base nos valores de $\mathrm{R}^{2}$ dos modelos com e sem um fator exógeno, valores muito semelhantes pode ser usado para calcular uma medida de tamanho de efeito chamada $\mathrm{q}^{2}$, que compara valores de relevância preditiva $\mathrm{Q}^{2}$ discutidos acima, para os modelos com e sem um determinado construto latente. Como isto foi descrito acima para $\mathrm{f}^{2}$, os mesmos critérios de valores baixo/médio/alto baseado em Cohen (1988) e discutidos acima são usados para interpretar $\mathrm{q}^{2}$.

\section{5. \\ Limitações do método}

Uma das limitações do método survey, segundo Nique e Ladeira (2014), está no fato de se ter um cuidado rigoroso na elaboração do questionário, o que acarreta um grande tempo e, em muitos casos, o tempo é escasso. Para uma boa elaboração do questionário recomenda-se que o formulário seja atrativo para motivar o respondente a participar de forma voluntária da pesquisa.

PLS-SEM também está sujeita a algumas restrições relacionadas com a avaliação do ajuste do modelo (como é comumente feito no CB-SEM) e a consistência das estimativas do parâmetro. Algumas pesquisas relatam avanços do algoritmo básico de PLS-SEM para melhorar suas propriedades estatísticas, por exemplo, em termos de fornecer estimativas do parâmetro consistente. Dijkstra e Hensler (2014) destacam que o PLS-SEM fornece parâmetro consistente que estima e introduz a opção de testar o ajuste do modelo, mantendo os pontos fortes do método, porém ainda pouco avaliado na prática. 
Dijkstra e Schermelleh-Engel (2014) estendem esta abordagem aos modelos de equações estruturais não-lineares. Esforços suplementares no estendendo modelos de equações estruturais não-lineares foram feitos por Bentler e Huang (2014). Dependendo do contexto empírico específico e objetivo do estudo, as características metodológicas distintas do PLS-SEM tornou-o uma valiosa e alternativa potencialmente mais adequada para o CB-SEM e mais popular em aplicações práticas. No entanto, nenhum método é superior ao global. Em vez disso, a seleção do método apropriado depende do objetivo do estudo (RIGDON, 2012; SARSTEDT et al., 2014).

Neste estudo é possível que tenha ocorrido alguma dificuldade por parte do gestor em recordar fatos e informações de quando entrou ou fundou a empresa. Tal dificuldade pode ter levado a respostas equivocas, considerando que as perguntas relativas a estas informações foram apresentadas logo no início do questionário e outras perguntas aparecem no meio do questionário. Pode ter ocorrido também o surgimento da fadiga ao responder as últimas perguntas do questionário, o que pode também ter levado a não respostas de algumas destas perguntas, ou também cometido algum equívoco ao respondê-las.

O modelo estrutural foi estimado na mesma amostra utilizada para depuração do modelo de mensuração. Sendo assim, existe um risco de overfitting do modelo devido ao ajuste dos parâmetros do modelo aos dados da amostra. Em função dos resultados estatisticamente não significativos, pode-se aventar que cada variável possa exercer efeitos "contraditórios” sobre a internacionalização. 


\section{5}

\section{Apresentação dos resultados}

O presente capítulo está organizado em cinco seções, as quais são apresentadas a verificação de normalidade, a depuração do modelo de mensuração, estimação do modelo estrutural, avaliação do impacto da $\mathrm{CMV}$, as limitações e por fim a interpretação dos resultados.

\section{1.}

\section{Depuração do modelo de mensuração}

Na sequência, foi realizada a análise do modelo teórico por meio das saídas dos testes do SmartPLS que permitem avaliar os modelos de mensuração reflexivo e formativo, e por fim, o modelo estrutural, seguindo as recomendações de Hair et al. (2014) e Garson (2016) para a realização destas análises.

\section{Modelo de mensuração formativo}

A análise do modelo de mensuração formativo foi feita por meio da análise de colinearidade, significância e relevância dos indicadores. Foi incialmente avaliada a colinearidade por meio da saída Outer VIF Values do SmartPLS, sendo os resultados apresentados na Tabela 7 . Todos os valores ficaram menores que 4,0 significando um nível satisfatório de colinearidade entre os indicadores dos construtos no modelo de mensuração formativo.

Tabela 7: Colinearidade (VIF) do modelo de mensuração formativo

\begin{tabular}{cc}
\hline Indicadores & VIF \\
\hline ZForLang_1 & 1,850 \\
\hline ZFormEdu_1 & 1,212 \\
ZIntAssoc_1 & 1,011 \\
\hline ZIntConta_1 & 1,011 \\
ZIntlExp_1 & 1,622 \\
\hline
\end{tabular}


A análise de significância foi realizada com base na estatística " $t$ " e na análise da contribuição absoluta do indicador no seu construto, os valores das cargas "w" em cada construto, como apresentado na Tabela 8. Os resultados mostram que existem indicadores com valores abaixo do desejado $(\mathrm{t}>1,96 \mathrm{e} w>$ 0,5), o que requer que estes indicadores sejam retirados dos seus respectivos construtos. Ao verificar as relações entre estes indicadores e seus construtos por meio da literatura, optou-se por retirar os indicadores: participação em associações domésticas e relações informais, ambos relacionados com o capital social. Os indicadores: nível de educação formal, experiência internacional e proficiência em línguas estrangeiras foram mantidos, pois, encontram-se vários argumentos na literatura apoiando a influência destes indicadores no capital humano e na internacionalização. Além disso, é possível que o tamanho menor da amostra esteja influenciando os resultados.

Tabela 8: Cargas "w" e estatística " $\mathrm{t}$ " dos construtos formativos

\begin{tabular}{lccc}
\hline & Cargas “w” & Estatística “t” & P Valor \\
\hline ZForLang_1 -> Human capital & 0,227 & 0,455 & 0,629 \\
\hline ZFormEdu_1 -> Human capital & 0,393 & 0,984 & 0,325 \\
\hline ZIntlExp_1 -> Human capital & 0,645 & 1,370 & 0,171 \\
\hline ZDomAssoc_1 -> Social capital & 0,367 & 1,592 & 0,112 \\
\hline ZIntAssoc_1 -> Social capital & 0,557 & 2,389 & 0,017 \\
\hline ZIntConta_1 -> Social capital & 0,761 & 3,548 & 0,000 \\
\hline ZRelInform_1 -> Social capital & 0,154 & 0,666 & 0,506 \\
\hline
\end{tabular}

Portanto, houve a necessidade de fazer ajustes no modelo de mensuração formativo uma vez que alguns indicadores tiveram que ser retirados do modelo.

\section{Modelo de mensuração reflexivo}

O modelo mensuração reflexivo foi avaliado via estimativas da consistência interna, validade convergente e validade discriminante. A Tabela 9 apresenta os resultados de consistência interna satisfatórios, ou seja, valores maiores que $0,70 \mathrm{e}$ abaixo de 0,95 . Portanto, os resultados foram considerados satisfatórios para a validade convergente, não sendo necessário excluir nenhum indicador do modelo. 
A Tabela 9 também apresenta os resultados da variância média explicada (AVE), os quais foram ligeiramente superiores a 0,50, ou seja, a média da variância estimada de cada construto é maior que a média da variância do erro de medição. Apesar de muito próximo do limite inferior, pode-se afirmar que os indicadores têm influência na proporção de variância de seu construto.

Por outro lado, observando os resultados apresentados na Tabela 10, constata-se que alguns valores de carga são menores que 0,70 , sendo a maioria bem próxima do valor mínimo desejado, sugerindo a necessidade de retirar alguns destes indicadores do construto. Os indicadores do construto propensão ao risco, caminhos já testados (ZKnownWay_1 = -0,397) e informações completas (ZInfoComp_1 $=0,470$ ) foram retirados do modelo, porém, ao avaliar teoricamente o indicador ZDarePost_1, optou-se pela permanência dele no construto, considerando que o valor era 0,560, uma vez que mede o quanto o gestor adota uma postura cautelosa ou agressiva diante de situações em que não se pode prever as consequências, permitindo avaliar o quanto o gestor é propenso ao risco.

Tabela 9: Consistência interna e AVE dos construtos reflexivo do modelo de mensuração

\begin{tabular}{lcc}
\hline Construtos & $\begin{array}{c}\text { Consistência } \\
\text { Interna }\end{array}$ & $\begin{array}{c}\text { Variância média } \\
\text { extraída (AVE) }\end{array}$ \\
\hline DOI & 0,772 & 0,535 \\
Risk propensity & 0,815 & 0,531 \\
Speed & 0,750 & 0,601 \\
\hline
\end{tabular}

A validade discriminante foi avaliada por meio dos resultados apresentados na Tabela 8 , constatando-se que as cargas dos indicadores em cada um dos seus construtos foram maiores que as cargas dos indicadores em outros construtos, apesar de algumas das cargas nos outros construtos serem estatisticamente significativas; o que confirma parcialmente a validade discriminante. 
Tabela 10: Cargas "l" dos indicadores nos construtos do modelo de mensuração reflexivo

\begin{tabular}{cccc}
\hline Indicadores & DOI & Risk propensity & Speed \\
\hline ZBreadth_1 & 0,638 & 0,259 & 0,132 \\
\hline ZDepthAbs_1 & 0,859 & 0,106 & 0,489 \\
\hline ZDepthRel_1 & 0,679 & 0,106 & 0,175 \\
\hline ZNewThing_1 & 0,102 & 0,655 & 0,086 \\
\hline ZDarePost_1 & 0,048 & 0,560 & 0,214 \\
\hline ZRiskAccp_1 & 0,274 & 0,858 & 0,139 \\
\hline ZInfoComp_1 & 0,042 & 0,470 & 0,082 \\
\hline ZRiskTol_1 & 0,068 & 0,803 & $-0,107$ \\
\hline ZKnownWay_1 & 0,143 & $-0,397$ & 0,128 \\
\hline ZPrecocit_1 & 0,142 & 0,002 & 0,719 \\
\hline ZSpeed3Y_1 & 0,466 & 0,164 & 0,828 \\
\hline
\end{tabular}

Para confirmar a validade discriminante foram ainda realizados dois testes. O primeiro foi o Fornell-Larcker Criterion, do próprio SmartPLS, o qual apresenta uma matriz com os valores da raiz quadrada do AVE para cada construto reflexivo e as correlações entre os construtos, conforme apresentado na Tabela 11. Desta forma, os resultados mostram que cada construto é diferente dos demais, ou seja, ele é capaz de capturar as características inerentes a apenas um construto.

\begin{tabular}{|c|c|c|c|}
\hline Construtos & DOI & $\begin{array}{c}\text { Risk } \\
\text { propensity }\end{array}$ & Speed \\
\hline DOI & $0,731^{*}$ & & \\
\hline Risk propensity & 0,194 & $0,729^{*}$ & \\
\hline Speed & 0,412 & 0,115 & $0,776^{*}$ \\
\hline
\end{tabular}

Considerando as análises de validade discriminante, verificou-se a necessidade de ajustar o modelo proposto inicialmente, retirando os indicadores, como recomendado por Hair et al. (2014). 
Apesar de não ser extremadamente necessário, Hair et al. (2014) e Garson (2016) recomendam a realização da análise de colinearidade no modelo de mensuração reflexivo. Sendo assim, foi realizada a análise de colinearidade do modelo reflexivo por meio do VIF entre os construtos, incluídos os construtos relativos às variáveis de controle, apresentados na Tabela 12, oriunda da saída Inner VIF Values do SmartPLS. Todos os valores ficaram menores que 4,0, significando não haver colinearidade exagerada no modelo de mensuração reflexivo.

Tabela 12: Colinearidade (VIF) do modelo de mensuração reflexivo

\begin{tabular}{ccccc}
\hline Construtos & DOI & Risk perception & Risk propensity & Speed \\
\hline Age & & & 1,021 & 1,143 \\
\hline Human capital & 1,400 & & 1,264 & 1,346 \\
Insatsfact Dom & 1,110 & & 1,094 \\
\hline Intel Ind & 1,379 & & & 1,374 \\
\hline Risk perception & 1,200 & & & 1,139 \\
\hline Risk propensity & 1,314 & & & 1,372 \\
\hline Social capital & 1,665 & 1,000 & 1,287 & 1,653 \\
\hline Tam Rel & 1,228 & & & \\
\hline
\end{tabular}

Considerando as análises do modelo de mensuração reflexivo, foi realizado o ajuste no modelo, retirando os indicadores apontados como problemáticos na análise de validade convergente.

\section{Apresentação do modelo de mensuração depurado}

A Figura 4 apresenta o modelo revisado após as alterações realizadas por conta das análises do modelo de mensuração. 


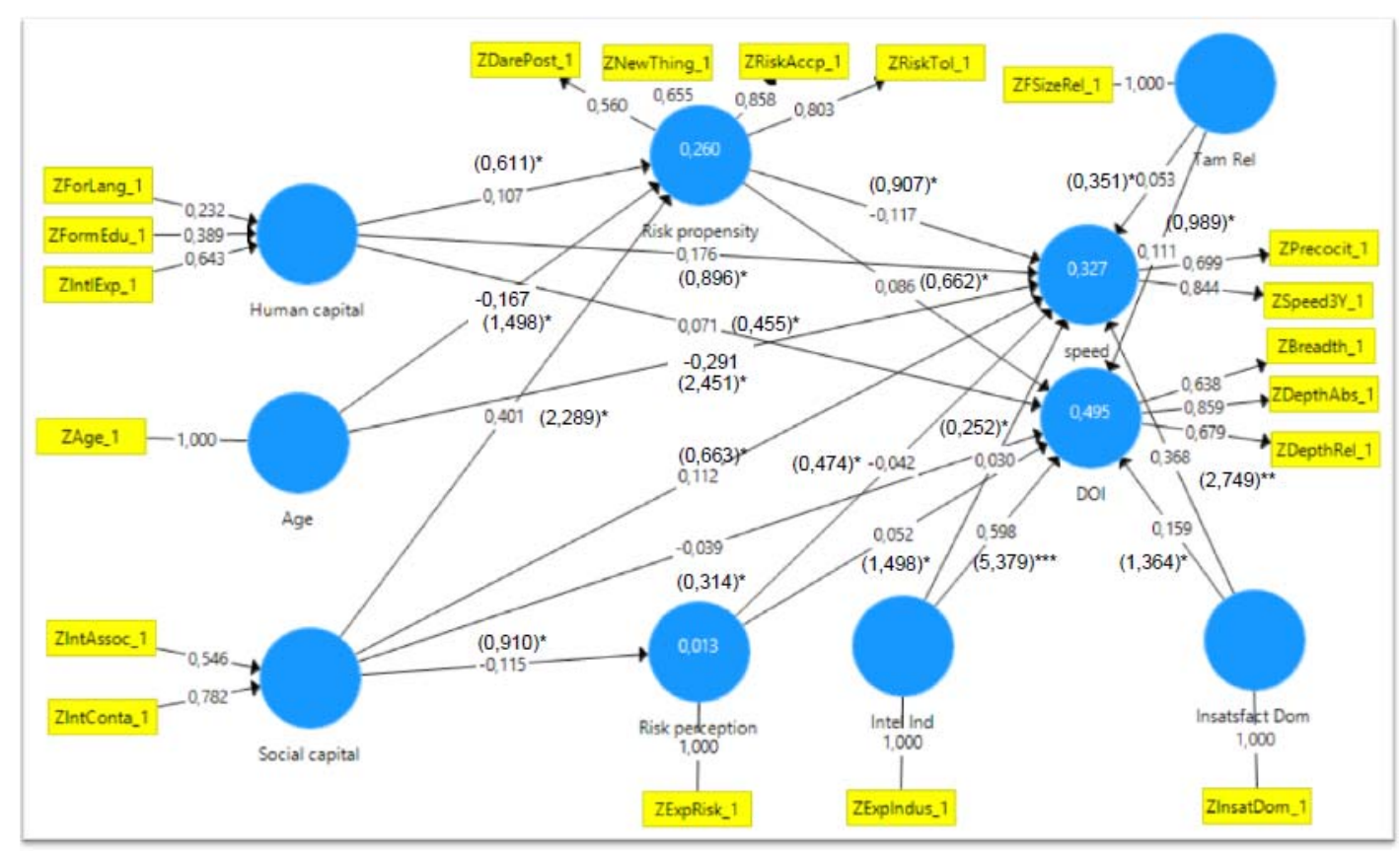

(estatisticat); " $p<0,05 ;{ }^{* *} p<0,01 ; * * * p<0,001$

Figura 4: Relações de mensuração e estruturais no modelo depurado

Portanto, pelo menos nesta amostra específica de 71 gestores e fundadores (decisores) de pequenas e médias empresas brasileiras, o impacto das características destes decisores tais como o a idade, o capital humano, o capital social, a propensão ao risco e a percepção de risco é não significante ou relativamente pequeno no grau de internacionalização destas empresas aqui no Brasil. A seguir é apresentada a interpretação dos resultados do modelo revisado a partir das adequações realizadas via análises desta seção.

\section{2.}

\section{Estimação do modelo estrutural}

Considerando que o PLS-SEM não possui uma medida de ajuste global, foi realizada a análise do modelo estrutural, avaliando a capacidade de previsão deste modelo. Para tanto, foram obtidos, inicialmente, os coeficientes de determinação $\left(\mathrm{R}^{2}\right)$ dos construtos preditores frente aos outros construtos relacionados no modelo estrutural, conforme apresentado na Tabela 13. Verifica-se que os resultados se apresentam satisfatórios sendo todos os valores maiores que 0,20 em relação à tolerância. Portanto, não houve o efeito da colinearidade no modelo estrutural. 
Tabela 13: Coeficientes $\mathrm{R}^{2}$ dos construtos preditores em relação aos demais construtos no modelo

\begin{tabular}{|c|c|c|}
\hline Construtos & $\overline{\mathbf{R}^{2}}$ & Tolerância $\left(1-R^{2}\right)$ \\
\hline Age -> Risk propensity & 0,229 & 0,771 \\
\hline Age -> speed & 0,319 & 0,681 \\
\hline Human capital -> DOI & 0,239 & 0,761 \\
\hline Human capital -> Risk propensity & 0,297 & 0,703 \\
\hline Human capital -> speed & 0,258 & 0,742 \\
\hline Insatsfact Dom -> DOI & 0,312 & 0,688 \\
\hline Insatsfact Dom -> speed & 0,418 & 0,582 \\
\hline Intel Ind -> DOI & 0,673 & 0,327 \\
\hline Intel Ind -> speed & 0,246 & 0,754 \\
\hline Risk perception -> DOI & 0,154 & 0,846 \\
\hline Risk perception -> speed & 0,075 & 0,925 \\
\hline Risk propensity -> DOI & 0,194 & 0,806 \\
\hline Risk propensity -> speed & 0,229 & 0,771 \\
\hline Social capital -> DOI & 0,295 & 0,705 \\
\hline Social capital -> Risk perception & 0,218 & 0,782 \\
\hline Social capital -> Risk propensity & 0,474 & 0,526 \\
\hline Social capital -> speed & 0,142 & 0,858 \\
\hline Tam Rel -> DOI & 0,258 & 0,742 \\
\hline
\end{tabular}

$\mathrm{R}^{2}$ obtido por meio das correlações entre as variáveis latentes (SmartPLS)

A análise de significância foi realizada por meio dos resultados da Tabela 14, efeitos diretos obtidos pela estatística "t", mostrando que foram poucas as relações consideradas significantes entre os construtos $(t>1,96)$, sendo: idade (Age) e a velocidade de internacionalização (Speed), capital social (Social capital) e propensão ao risco (Risk propensity), insatisfação com o mercado doméstico (Insatsfact Dom, uma variável de controle) e a velocidade de internacionalização (Speed), a internacionalização da indústria (Intel Ind, variável de controle) e o grau de internacionalização (DOI).

$\mathrm{Na}$ Tabela 15 são apresentados os efeitos totais obtidos pelos coeficientes "p" totais, sendo o valor mínimo desejado de 0,200. Foram consideradas relevantes as relações estabelecidas entre os construtos idade (Age) e a velocidade de internacionalização (Speed), capital social (Social capital) e propensão ao risco (Risk propensity), insatisfação com o mercado doméstico (Insatsfact Dom, uma variável de controle) e a velocidade de internacionalização (Speed), a internacionalização da indústria (Intel Ind, variável de controle) e o grau de 
internacionalização (DOI); sendo, portanto, os mesmos construtos os cujas relações apresentavam nível de significância aceitável.

Tabela 14: Estatística t dos construtos relacionados no modelo estrutural

\begin{tabular}{|lc}
\hline \multicolumn{1}{c}{ Construtos } & Estatística “t” \\
\hline Age -> DOI & 0,474 \\
\hline Age -> Risk propensity & 1,331 \\
\hline Age -> speed & 2,476 \\
\hline Human capital -> DOI & 0,532 \\
\hline Human capital -> Risk propensity & 0,603 \\
\hline Human capital -> speed & 0,868 \\
\hline Insatsfact Dom -> DOI & 1,288 \\
\hline Insatsfact Dom -> speed & 3,033 \\
\hline Intel Ind -> DOI & 5,303 \\
\hline Intel Ind -> speed & 0,251 \\
\hline Risk perception -> DOI & 0,468 \\
\hline Risk perception -> speed & 0,472 \\
\hline Risk propensity -> DOI & 0,640 \\
\hline Risk propensity -> speed & 0,698 \\
\hline Social capital -> DOI & 0,083 \\
\hline Social capital -> Risk perception & 0,928 \\
\hline Social capital -> Risk propensity & 2,220 \\
\hline Social capital -> speed & 0,482 \\
\hline Tam Rel -> DOI & 0,943 \\
\hline
\end{tabular}

Tabela 15: Coeficientes "p" totais

\begin{tabular}{lcrr}
\hline Construtos & DOI & Risk propensity & Speed \\
\hline Age & 0,014 & 0,167 & 0,271 \\
Human capital & 0,079 & 0,106 & 0,152 \\
Insatsfact Dom & 0,158 & & 0,361 \\
\hline Intel Ind & 0,599 & & 0,043 \\
Risk perception & 0,052 & & $-0,055$ \\
Risk propensity & 0,086 & & $-0,121$ \\
Social capital & $-0,010$ & 0,402 & 0,080 \\
Tam Rel & 0,111 & & \\
\hline
\end{tabular}


Os resultados apresentados na Tabela 16 mostram que os valores de $\mathrm{R}^{2}$ e $\mathrm{R}^{2}$ ajustado, consideradas medidas de acurácia do modelo, indicando que o grau de internacionalização (DOI) tem $49,5 \%$ da variância explicada pelas variáveis que a influenciam, sendo considerada uma acurácia moderada, sendo que a maior influência neste construto vem das variáveis de controle. A velocidade de internacionalização (Speed) tem $32,4 \%$ da sua variância explicada, sendo que a maior influência neste construto é do construto idade (Age), e por fim, a propensão ao risco (Risk propensity) apresenta $26 \%$ da variância explicada, sendo influenciada fortemente pelo capital social (Social capital). Estes valores apesar de $50 \%$ são considerados satisfatórios em estudos da área de estratégia.

\begin{tabular}{llr}
\multicolumn{2}{c}{ Tabela 16: $\mathrm{R}^{2}$ e $\mathrm{R}^{2}$ ajustado } \\
\hline Construtos & $\mathbf{R}^{2}$ & $\mathbf{R}^{2}$ ajustado \\
\hline DOI & 0,495 & 0,439 \\
Risk propensity & 0,260 & 0,227 \\
Speed & 0,327 & 0,249 \\
\hline
\end{tabular}

A Tabela 17 apresenta os resultados do tamanho do efeito $\left(\mathrm{f}^{2}\right)$ para os construtos relacionados no modelo estrutural, mostrando que a variável de controle internacionalização da indústria (Intel Ind) tem um tamanho de efeito grande no grau de internacionalização $\left(\mathrm{f}^{2}>0,35\right)$, indicando que a variância, medida por $\mathrm{R}^{2}$ é de fato fortemente influenciada por este construto. Os valores de $\mathrm{f}^{2}$ que indicam que o tamanho do efeito médio na relação entre os construtos exógenos nos construtos endógenos é considerado médio $\left(\mathrm{f}^{2}>0,15\right)$, sendo estes: idade (Age) e a velocidade de internacionalização (Speed), capital social (Social capital) e propensão ao risco (Risk propensity), insatisfação com o mercado doméstico (Insatsfact Dom, uma variável de controle) e a velocidade de internacionalização (Speed), a internacionalização da indústria (Intel Ind, variável de controle). As relações com tamanho de efeito considerado pequeno entre os construtos exógenos e endógenos $\left(0,15>\mathrm{f}^{2}>0,02\right)$ foram: A insatisfação com o mercado doméstico (Insatsfact Dom) e o grau de internacionalização (DOI); idade (Age) e a propensão ao risco (Risk propensity) e o capital humano (Human capital) e a velocidade de internacionalização (Speed). Os demais construtos exógenos do modelo não apresentam um tamanho de efeito considerado minimamente satisfatório. 
Tabela 17: Tamanho do efeito de $\left(\mathrm{f}^{2}\right)$ dos construtos relacionados no modelo estrutural

DOI Risk perception Risk propensity Speed

\begin{tabular}{|c|c|c|c|c|}
\hline Age & & & 0,037 & 0,174 \\
\hline Human capital & 0,007 & & 0,012 & 0,030 \\
\hline Insatsfact Dom & 0,045 & & & 0,176 \\
\hline Intel Ind & 0,515 & & & 0,002 \\
\hline Risk perception & 0,004 & & & 0,004 \\
\hline Risk propensity & 0,011 & & & 0,016 \\
\hline Social capital & 0,002 & 0,013 & 0,170 & 0,013 \\
\hline Tam Rel & 0,020 & & & \\
\hline
\end{tabular}

As medidas de relevância preditiva $\left(Q^{2}\right)$ dos construtos endógenos reflexivos são apresentadas na Tabela 18. Observa-se que os valores de $\mathrm{Q}^{2}$ para os construtos grau de internacionalização (DOI), velocidade de internacionalização (Speed) e propensão ao risco (Risk propensity) se apresentam acima de 0,15, o que significa um impacto médio dos construtos exógenos nos construtos endógenos. Já o valor da percepção de risco (Risk perception) ficou ligeiramente acima de 0,02 , sendo considerado um impacto pequeno do construto capital social (Social capital) no construto percepção de risco (Risk perception).

Tabela 18: Relevância preditiva

\begin{tabular}{cc}
\hline Construto & $\mathbf{Q}^{\mathbf{2}}$ (=1-SSE/SSO) \\
\hline DOI & 0,197 \\
Risk perception & 0,027 \\
Risk propensity & 0,166 \\
Speed & 0,164 \\
\hline
\end{tabular}

A Tabela 19 apresenta os efeitos $\mathrm{q}^{2}$ dos construtos relacionados no modelo estrutural. Garson (2016) destaca que este indicador é uma terceira alternativa para se medir avaliar a relevância preditiva dos construtos endógenos no modelo estrutural, sendo as discussões semelhantes às realizadas anteriormente para o efeito $\mathrm{f}^{2}$. Verifica-se que os valores superiores a 0,35 , o que caracteriza uma elevada relevância do construto exógeno no construto endógeno, foram das relações: internacionalização da indústria (Intel Ind) e o grau de internacionalização; a idade (Age) e a velocidade de internacionalização (Speed). O valor que representa uma relevância média foi a insatisfação com o mercado doméstico (Insatsfact Dom) e a velocidade de internacionalização. Os outros 
valores se mostraram abaixo de ou próximo a 0,02 , indicando haver um impacto pequeno ou até negligenciável destes construtos nos construtos endógenos.

\begin{tabular}{|c|c|c|c|c|}
\hline Construto & DOI & Risk perception & Risk propensity & Speed \\
\hline Age & & & 0,024 & 0,369 \\
\hline Human capital & 0,029 & & 0,016 & 0,017 \\
\hline Insatsfact Dom & 0,045 & & & 0,236 \\
\hline Intel Ind & 0,452 & & & 0,009 \\
\hline Risk perception & 0,023 & & & 0,011 \\
\hline Risk propensity & 0,018 & & & 0,014 \\
\hline Social capital & 0,013 & 0,008 & 0,170 & 0,021 \\
\hline Tam Rel & 0,015 & & & \\
\hline
\end{tabular}

\section{3.}

\section{Avaliação do impacto da CMV}

Na sequência foi realizada a análise da variância do método comum (CMV), sendo este um importante teste dos resultados do estudo, pois pode haver problemas relativos à aplicação do questionário para apenas um respondente por empresa da amostra e com uma escala de respostas semelhantes entre si (diferenciais semânticas), o que inviabiliza todo estudo. Sendo assim, verificou-se por meio do teste do fator único de Harman, relativo a análise fatorial exploratória, o quanto era explicado pela variância entre os indicadores do modelo. Este teste apresentou um resultado na qual a variância total explicada pelo primeiro fator extraído foi de apenas 18,27\%. Segundo Hair et al. (2014) permite concluir que o método comum não é explicação suficiente para a correlação entre os dados.

No entanto, é necessário avaliar se há alterações em relação à significância e o sinal das relações entre os construtos, por meio da análise da estatística " $t$ " obtidas via teste bootstrapping no SmartPLS. Conforme apresentado na Tabela 20 , os valores da estatística " $t$ " permaneceram muito próximos e os sinais não se alteraram, com e sem a variável controle (variável CMV). Portanto, tal constatação mostra aparentemente que não há influência da variância do método comum (CMV). 
Tabela 20: Estatística "t" das relações entre construtos com e sem variável CMV

\begin{tabular}{lcc}
\hline & $\begin{array}{c}\text { Estatística t com } \\
\text { Variável CMV }\end{array}$ & $\begin{array}{c}\text { Estatística t sem } \\
\text { Variável CMV }\end{array}$ \\
\hline Age -> Risk propensity & 1,335 & 1,498 \\
Age -> speed & 2,229 & 2,451 \\
\hline Human capital -> DOI & 0,437 & 0,473 \\
Human capital -> Risk propensity & 0,597 & 0,611 \\
Human capital -> speed & 0,793 & 0,896 \\
Risk perception -> DOI & 0,392 & 0,497 \\
Risk perception -> speed & 0,428 & 0,474 \\
Risk propensity -> DOI & 0,698 & 0,709 \\
Risk propensity -> speed & 0,586 & 0,662 \\
Social capital -> DOI & 0,288 & 0,314 \\
\hline Social capital -> Risk perception & 0,873 & 0,910 \\
Social capital -> Risk propensity & 2,112 & 2,289 \\
Social capital -> speed & 0,583 & 0,663 \\
\hline
\end{tabular}

Foi avaliada também os coeficientes "p" entre o construto variável CMV e os demais construtos (Tabela 21), que apresentaram cargas baixas entre o coeficiente e demais construtos, além de apresentarem em sua totalidade valores menores do que as relações entre os construtos do modelo. Os resultados indicam que a CMV não explica de forma considerável as correlações.

Tabela 21: Coeficientes "p" das relações entre os construtos do modelo estrutural e a variável CMV

\begin{tabular}{ccccccc}
\hline Construto & Speed & DOI & $\begin{array}{c}\text { Risk } \\
\text { propensity }\end{array}$ & $\begin{array}{c}\text { Risk } \\
\text { perception }\end{array}$ & $\begin{array}{c}\text { Social } \\
\text { capital }\end{array}$ & Age \\
\hline Age & $-0,266$ & - & $-0,154$ & - & - & - \\
\hline $\begin{array}{c}\text { Risk } \\
\text { perception }\end{array}$ & $-0,052$ & 0,049 & - & - & - & - \\
$\begin{array}{c}\text { Risk } \\
\text { propensity } \\
\text { Human } \\
\text { capital }\end{array}$ & $-0,103$ & 0,107 & - & - & - & - \\
$\begin{array}{c}\text { Social } \\
\text { capital }\end{array}$ & 0,158 & 0,066 & 0,096 & - & - & - \\
CMV & $-0,028$ & $-0,037$ & 0,036 & $-0,073$ & 0,058 & $-0,036$ \\
\hline
\end{tabular}

Além disso, foram avaliadas as cargas "l" (cross loading) dos indicadores e o impacto no seu construto, apresentando em todas as situações valores menores do que as cargas "l" dos indicadores da variável CMV nos construtos do modelo, conforme apresentado na Tabela 22, bem como a carga "l" de cada indicador no seu construto, apresentando-se com todos os valores maiores do que sua carga com a presença da variável CMV. Há que se ressaltar que os indicadores com carga 1,000 significa que o construto foi medido com apenas um indicador, no caso do construto idade e percepção de risco (Tabela 23). 
Tabela 22: Cargas "l” mínimas e máximas dos indicadores dos construtos do modelo

\begin{tabular}{lcc}
\hline Construtos & $\begin{array}{c}\text { Indicadores do } \\
\text { Construto do } \\
\text { Modelo }\end{array}$ & Indicadores CMV \\
\hline DOI & 0,256 a 0,954 & 0,086 a 0,243 \\
Risk propensity & 0,256 a 0,922 & 0,038 a 0,238 \\
\hline Risk perception & 1,000 & 1,000 \\
Human capital & 0,268 a 0,977 & 0,073 a 0,246 \\
Social Capital & 0,323 a 0,915 & 0,013 a 0,261 \\
Speed & 0,302 a 0,986 & 0,032 a 0,284 \\
\hline Age & 1,000 & 1,000 \\
\hline
\end{tabular}

Tabela 23: Cargas "l” dos indicadores nos seus construtos do modelo e na variável controle

\begin{tabular}{lcc}
\hline \multicolumn{1}{c}{ Indicadores } & $\begin{array}{c}\text { Construto do } \\
\text { Modelo }\end{array}$ & Construto CMV \\
\hline ZAge_1 & 1,000 & 1,000 \\
\hline ZIntlExp_1 & 0,645 & 0,296 \\
\hline ZForLang_1 & 0,227 & 0,211 \\
\hline ZFormEdu_1 & 0,393 & 0,296 \\
\hline ZIntAssoc_1 & 0,541 & 0,277 \\
\hline ZIntConta_1 & 0,786 & 0,291 \\
\hline ZExpRisk_1 & 1,000 & 1,000 \\
ZNewThing_1 & 0,655 & 0,278 \\
\hline ZRiskAccp_1 & 0,858 & 0,383 \\
\hline ZRiskTol_1 & 0,803 & 0,288 \\
\hline ZDarePost_1 & 0,560 & 0,276 \\
\hline ZBreadth_1 & 0,638 & 0,263 \\
\hline ZDepthAbs_1 & 0,859 & 0,377 \\
\hline ZDepthRel_1 & 0,679 & 0,384 \\
\hline ZPrecocit_1 & 0,719 & 0,352 \\
\hline ZSpeed3Y_1 & 0,828 & 0,316 \\
\hline
\end{tabular}

Os resultados apresentados nas análises anteriores estão de acordo com as recomendações de Williams, Hartman e Cavazotte (2010) e permitem concluir que o CMV não apresenta influência nos dados obtidos por meio da aplicação do questionário para apenas um membro por empresa. 


\section{6 \\ Discussão dos resultados}

As propriedades psicométricas ficaram abaixo do mínimo desejado, sendo assim, o modelo teórico proposto foi revisado, retirando-se os indicadores e as suas relações com seus respectivos construtos, levando em conta os resultados para o modelo de mensuração reflexivo e formativo, bem como o modelo estrutural. O modelo proposto apresenta várias hipóteses testadas nas análises anteriores, as quais foram avaliadas quanto ao seu suporte pelos resultados obtidos por estas análises.

\section{Impacto da idade do gestor na propensão ao risco}

Hipótese 1a: A idade do gestor apresenta uma relação negativa com sua propensão ao risco.

Os resultados deste estudo mostraram que a idade foi negativamente relacionada com a propensão ao risco, porém, esta relação foi não significativa. Sendo assim a hipótese $\mathrm{H}_{1 \mathrm{a}}$ não foi suportada. A não significância neste caso pode ter sido em função do tamanho reduzido da amostra. Uma possível explicação para que a idade não exercesse uma influência significativa na propensão ao risco é que o gestor foi convidado a indicar sua idade no momento em que entrou ou fundou a empresa. Porém, o gestor também indicou se concorda ou não em aceitar assumir riscos nas decisões no momento atual. Sendo assim, o decisor quando entrou ou fundou a empresa era de fato jovem e talvez aceitasse assumir mais riscos do que na atualidade.

Os resultados deste estudo, embora não apresentando significância estatística, sugere que o gestor mais jovem é mais propenso ao risco, uma vez que o sinal da relação foi negativa, estando em conformidade com o estudo de Serra et al. (2012) que apresenta resultados semelhantes em relação a influencia da idade do gestor na propensão de risco. No estudo destes autores o primeiro grupo incluía decisores com 35 anos de idade ou menos. O segundo grupo consistia de decisores entre 36 e 50 anos de idade. O último grupo incluía os decisores que tinha mais de 
50 anos de idade. As evidências empíricas do estudo destes autores não encontrou relação entre a idade média e propensão ao risco. Sendo assim a hipótese que empresas com decisores mais jovens têm uma maior propensão ao risco não foi suportada.

MacCrimmon e Wehrung (1986) analisaram a influência de certas características socioeconômicas na propensão ao risco como a idade do gestor. Os resultados do estudo destes pesquisadores sugerem que gerentes mais velhos são mais avessos ao risco em comparação com os gerentes mais jovens. Este estudo também mostrou que os gerentes com maior autoridade são mais propensos ao risco. Além disso, o estudo destes autores mostrou que os gerentes jovens mais bem sucedidos assumem mais riscos quando comparados aos gerentes menos bem sucedidos e mais velhos.

Felício (2013) descobriu por meio de seu estudo que os gestores jovens com uma predisposição para risco destacam-se na indústria de alimentos e indústria têxtil portuguesa. Também nesta indústria, os gestores jovens concentraram seus investimentos em produtos ou linhas de produtos inovadores, pesquisa e marketing. Os gestores mais jovens tem maior propensão ao risco de investir em produtos ou em linhas de produtos inovadores para diversificar seu mercado.

Entretanto, Pavic e Vojinic (2012) em um modelo de regressão ordinal encontraram que o coeficiente da variável idade do decisor é negativo, sugerindo que enquanto a idade aumenta, diminui a pontuação na variável dependente ordinal propensão ao risco. Portanto, os resultados empíricos destes autores ressaltam uma contradição na existência da relação entre a idade do decisor e a propensão ao risco deste decisor. Para estes autores os gerentes mais velhos têm maior experiência nos negócios e, portanto, eles estariam mais dispostos a correr certos riscos que os gerentes mais jovens.

Segundo Obben e Magagula (2003) pode haver alguma faixa etária dentro da qual a propensão a exportar aumenta com a idade e em algum momento a propensão a exportar pode ter uma queda com a idade. O modelo empírico proposto por Obben e Magagula (2003) mostra que quando a idade do decisor aumenta a probabilidade de uma PME ser uma exportadora também aumenta. Isto sugere que é provável que os decisores mais velhos sejam tomadores de risco maiores em comparação aos gerentes mais jovens, devido a sua maior experiência. Isto significa que os resultados não estão em conformidade com a crença comum 
que as pessoas mais velhas são avessas aos riscos (OBBEN; MAGAGULA, 2003).

O modelo empírico proposto por Obben e Magagula (2003) mostra que quando a idade do decisor aumenta a probabilidade de uma PME ser uma exportadora também aumenta. Isto sugere que é provável que os decisores mais velhos sejam tomadores de risco maiores em comparação aos gerentes mais jovens, devido a sua maior experiência. Isto significa que estes resultados não estão em conformidade com a crença comum que as pessoas mais velhas são avessas aos riscos (OBBEN; MAGAGULA, 2003).

Sendo assim, a influência da idade do gestor sobre a propensão ao risco pode ser considerada ainda controversa, considerando os achados desta tese os resultados de pesquisas anteriores.

\section{Impacto da idade do gestor sobre a velocidade de internacionalização}

Hipótese 1b: A idade do gestor apresenta uma relação negativa com a velocidade de internacionalização da empresa (em termos de precocidade e de crescimento do volume de vendas internacionais).

Os resultados deste estudo mostram que a idade foi negativamente relacionada com a velocidade de internacionalização sendo esta relação significativa, portanto, a hipótese $\mathrm{H}_{1 \mathrm{~b}}$ foi suportada. Foram consideradas as respostas dos decisores que haviam entrado na empresa pelo menos três anos antes da primeira exportação da empresa.

Os resultados deste estudo mostram que o decisor mais jovem ao entrar na PME tende a fazer com que esta empresa aumente o crescimento das vendas internacionais ou ainda que o decisor tenda a fazer com que a empresa se internacionalize mais precocemente; em outras palavras, o decisor mais jovem tende a fazer aumentar a velocidade de internacionalização da PME.

Estes resultados estão em conformidade com os argumentos de Madsen e Servais (1997) bem como de Oviatt e McDougall (1997) que afirmam que o decisor mais jovem geralmente faz a escolha de internacionalizar a empresa mais rapidamente, especialmente nas start-ups dinâmicas que visam à internacionalização desde seu início. O decisor jovem é mais flexível sendo capaz de captar novas oportunidades e dedicar o maior empenho para a empresa, que 
pode resultar no aumento das vendas no exterior (HAMBRICK e MASON, 1984; WIERSEMA e BANTEL, 1992).

Os resultados deste estudo permitem afirmar que as pequenas e médias empresas com decisores mais jovens tendem a adotar alternativas inovadoras, que é o caso das exportações (FERNÁNDEZ-ORTIZ; LOMBARDO, 2009; HAMBRICK; MASON, 1984; KARAMI 2005). Além disso, decisores mais jovens desempenham um papel mais ativo no sentido de fazer a empresa aumentar o volume de vendas por meio da exportação (FERNÁNDEZ-ORTIZ; LOMBARDO, 2009; NORBURN; BIRLEY 1988). Cavusgil (1982) também concluiu que gestores jovens têm maiores possibilidades de influenciar a atividade de exportação durante os estágios iniciais de internacionalização. Portanto, os decisores mais jovens proporcionam um aumento da velocidade da internacionalização da empresa em termos de precocidade (CAVUSGIL, 1982).

Por outro lado, os resultados deste estudo contrariam os resultados encontrados pelo estudo de Evald et al. (2011) que mostrou que decisores de born globals com mais de 50 anos são mais propensos a promover a exportação precoce destas empresas do que os decisores mais jovens do que 30. Portanto, os decisores mais velhos proporcionariam uma maior velocidade de internacionalização das born globals. Além disso, idade do gestor é geralmente correlacionada com sua experiência de trabalho, estabilidade organizacional e conhecimento do setor (TYLER; STEENSMA, 1998), o que, por conseguinte, pode aumentar suas capacidades de processamento de informações.

\section{Impacto do capital humano sobre a propensão ao risco}

Hipótese 2a: O capital humano do gestor apresenta uma relação positiva com sua propensão ao risco

Os resultados das análises deste estudo mostram que a relação entre capital humano e propensão ao risco foi positiva, porém, não significativa. Verifica-se que o indicador referente à proficiência em línguas estrangeiras apresenta um valor bem abaixo do desejado. Portanto, o capital humano do gestor parece não influenciar a propensão ao risco. Esperava-se que a propensão ao risco pudesse mediar a relação do capital humano com o grau de internacionalização, bem como a velocidade de internacionalização, porém, os resultados mostram não haver esta mediação. Uma possível explicação para que o capital humano do gestor não 
exercesse uma influência significativa na propensão ao risco é que o gestor foi convidado a indicar o nível de educação formal, a experiência internacional e a proficiência em línguas estrangeiras no momento em que entrou ou fundou a empresa. Porém, o gestor também indicou se concorda ou não em assumir riscos nas decisões no momento atual. Sendo assim, o decisor quando entrou ou fundou a empresa poderia ter um elevado nível de capital humano e talvez aceitasse assumir mais riscos do que na atualidade.

De acordo com Liesch et al. (2011) a experiência internacional pode proporcionar o conhecimento sobre as incertezas, fazendo com que o gestor opte por caminhos não tão arriscados para as decisões, não sendo assim tão propensos ao risco. O resultado do estudo de Jansen et al (2011) mostrou que o nível de experiência internacional tem um efeito negativo pequeno sobre a propensão ao risco, o que leva a crer que a experiência internacional não influencia diretamente a tomada de decisão mais arriscada.

Além disso, Finkelstein e Hambrick (1996) e Herrmann e Datta (2002) destacam que o nível de educação formal do decsior pode não necessariamente desempenhar um papel importante nas escolhas estratégicas envolvendo elevado nível de riscos porque as pessoas normalmente completam sua educação formal, muitas anos antes de serem nomeados para cargos estratégicos de decisão na empresa e consequentemente podem tomar decisões arriscadas de abrir seu prórpio negócio internacional também muito anos após a sua formação. Portanto, o capital humano pode de fato não influenciar a propensão ao risco do gestor.

\section{Impacto do capital humano sobre a velocidade de internacionalização}

Hipótese 2b: O capital humano do gestor apresenta uma relação positiva com a velocidade internacionalização da empresa (em termos de precocidade e de crescimento do volume de vendas internacionais).

Os resultados das análises apontam que a relação entre o capital humano e a velocidade de internacionalização foi positiva, no entanto, não significativa. Desta foram, a hipótese $\mathrm{H}_{2 b}$ não foi suportada. Portanto, o gestor que fundou ou entrou na empresa até três anos antes dela começar a exportar e que possui um nível mais elevado de educação formal, proficiência em língua estrangeira e experiência internacional não influencia tanto a velocidade de internacionalização da empresa. 
Os argumentos de Finkelstein e Hambrick (1996) e Herrmann e Datta (2002), colocados anteriormente, destacam que o nível de educação formal do decsior pode não necessariamente desempenhar um papel importante nas escolhas estratégicas porque eles normalmente completam sua educação formal, muitos anos antes de ser nomeado para cargos estratégicos de decisão na empresa e consequentemente podem tomar a decisão de abrir seu prórpio negócio internacional também muito anos após a sua formação. Tal cosntatação é válida também para a experiência internacional e a proficiência em linguas estrangeiras; pois o gestor muitas das vezes obteve a sua proficiência em linguas estrangeiras e a experiência internacional muitos anos antes da empresa ter iniciado a exportação, não influenciando assim na precocidade e nem na velocidade de internacionalização da empresa.

Evald et al. (2011) mostram em seu estudo que a experiência internacional prévia não melhora incondicionalmente as intenções de exportação da PME. De acordo com estes autores os decisores que anteriormente começaram um negócio são propensos a iniciar as atividades internacionais de forma similar seguindo a lógica que eles usaram em empreendimentos anteriores.

Os resultados do presente estudo também são consistentes com o estudo de McDougall et al. (2003) que mostrou que a experiência do gestor de start-up, com ou sem exportação, parece não determinar se as futuras empresas se tornarão internacionais ou não. Os decisores estabelecem e desenvolvem experiência internacional através da participação ativa nos mercados estrangeiros, aumentando gradativamente o comprometimento com a internacionalização da empresa, sendo, portanto mais lenta. (JOHANSON; VAHLNE, 1977, 1990, 2006).

Hutchinson. Quinn, Alexander (2006) encontraram em seu estudo que em uma determinada empresa com operações internacionais, a capacidade o decisor de falar línguas estrangeiras não era tão importante quanto a capacidade de compreender como é feito negócio no país estrangeiro. O diretor da empresa pesquisada por estes autores explicou que as habilidades encontradas em compreender o negócio em um país estrangeiro transcendem a capacidade de falar línguas estrangeiras. Desta forma a proficiência em língua estrangeira tende a não aumentar o volume de vendas no mercado internacional e portanto, tende a não aumentar a velocidade de internacionalização. 
Considerando os resultados deste estudo e os argumentos e resultados de alguns estudos anteriores, é possível que o capital humano tende a não influenciar a velocidade de internacionalização das PMEs. Sendo assim, a influência do capital humano do gestor na velocidade de internacionalização da PME pode ser considerada ainda controversa.

\section{Impacto do capital humano sobre o grau de internacionalização}

Hipótese 2c: O capital humano do gestor apresenta uma relação positiva com o grau de internacionalização da empresa (em termos de abrangência e de profundidade).

Os resultados mostram uma relação positiva entre o capital humano do gestor e grau de internacionalização da PME, porém, esta relação não foi significativa, portanto, a hipótese $\mathrm{H}_{2 \mathrm{c}}$ não foi suportada. Nesta tese, o capital humano foi medido por meio do nível de educação formal, a experiência internacional e a proficiência em línguas estrangeiras do gestor. $\mathrm{O}$ gestor considerou ao responder o questionário o momento em que ele entrou ou fundou a empresa. É possível que o tamanho reduzido da amostra possa ter influenciado a não significância encontrada. Desta forma, é possível afirmar que o capital humano, referente aos decisores das PMEs pesquisadas neste estudo, não exerça influência significativa para que as empresas aumentem a profundidade e a abrangência de suas atividades no mercado internacional.

Em outros estudos, como os de Felzensztein et al. (2015), a relação entre o capital humano, formado pela educação dos empreendedores chilenos, e a propensão de exportar para vários países também não foi significativa em qualquer um dos modelos. Os autores destacam que variável educação não foi correlacionada positivamente e estatisticamente com a exportação para vários países (abrangência). Estes autores, concluiram que o capital humano não é necessariamente importante para a propensão de exportação.

Além disso, o estudo de Omri e Becuwe (2014, p. 32) mostra que as variáveis relacionadas com o capital humano (nível de educação e experiência internacional) não se relacionaram significativamente com a propensão para exportação. Estes autores esclarecem que quando um decisor adquire conhecimento por meio da experiência e da formação educacional durante sua carreira, este decisor também desenvolve importantes contatos sociais que limitam 
a criatividade e reduzem a eficiência para resolver problemas complexos envolvendo a exportação. Considerando que a criatividade é essencial para a inovação dos produtos a serem exportados, o capital humano elevado do gestor poderia implicar em uma redução da abrangência de internacionalização da PME.

O estudo de Araújo e Neira (2006) mostrou que o nível de conhecimento de línguas dos gestores responsáveis pelas decisões de exportação não tem uma influência significativa na sua atitude de exportação e, portanto, não faz a empresa aumentar a profundidade e abrangência destas exportações. Estes autores explicam que a homogeneidade da amostra em relação à educação dos gestores da indústria de alimentos portuguesa e a proficiência em línguas estrangeiras parecem ser influenciadas por variáveis como o tamanho ou a presença de capital estrangeiro nestas empresas. Sendo assim, na amostra da pesquisa de Araújo e Neira (2006) o tamanho da empresa e a presença de capital estrangeiro estariam proporcionando um nivelamento (homogeneização) da educação formal e da proficiência de língua estrangeira dos gestores não permitindo avaliar o aumento da profundidade e da abrangência das exportações; porém, essa relação não foi avaliada no estudo.

No estudo de Makrini (2015) a relação entre a proficiência em línguas estrangeiras e o sucesso das exportações para vários países (abrangência) não foi significativa. Portanto, a hipótese que previa uma relação positiva entre a proficiência de língua estrangeira e o sucesso da exportação não foi suportada. Observa-se que neste estudo a proficiência em línguas estrangeiras foi medida pelo número de línguas faladas o que poderia determinar o sucesso da empresa nas exportações para vários países, porém, de acordo com Makrini (2015) a quantidade de línguas estrangeiras faladas não é suficiente para que a empresa obtenha sucesso nas exportações para vários países.

Os resultados deste estudo e os argumentos e resultados de alguns estudos apresentados anteriormente, sugere que o capital humano tende a não influenciar a o grau de internacionalização das PMEs. Sendo assim, a influência do capital humano do gestor no grau de internacionalização da PME pode ser considerada ainda controversa. 


\section{Impacto do capital social na sua propensão ao risco}

Hipótese 3a: O capital social do gestor está positivamente associado com a sua propensão ao risco

Os resultados mostram uma relação positiva e significativa entre capital social e a propensão ao risco. Portanto, a hipótese $\mathrm{H}_{3 \mathrm{a}}$ foi suportada empiricamente. Desta forma, conclui-se que quanto maior o capital social, formado pelas relações internacionais do gestor maior a sua propensão ao risco. Ao que tudo indica, as relações dos gestores via associações internacionais e contatos no exterior fazem com que estes gestores se tornem mais confiantes diante de decisões mais arriscadas.

Estes resultados estão de acordo com o resultado da pesquisa de Gao et al. (2011) que mostrou que o capital social baseado puramente em relações pessoais influência a capacidade do decisor de correr risco para obter melhor desempenho para a PME. A capacidade de usar redes de contatos existentes para acessar habilidades, conhecimentos e recursos adicionais é importante para as PMEs administrarem de forma eficaz o risco. No âmbito da dimensão cognitiva, a comunicação é necessária para acessar e usar o capital social por meio do intercâmbio de informações, identificação de problemas e gerenciamento de conflitos por parte dos decisores, proporcionando uma maior propensão ao risco do gestor.

Segundo Liesch, Welch e Buckley (2011) os decisores não trabalham isoladamente. O contexto imediato do grupo mais amplo de redes de empresas são pontos de referência importantes no sentido de lidar com os riscos pessoais sobre decisões importantes e poderiam agir para moderar o grau de risco que decisor individualmente percebe. Para Jansen et al. (2011) níveis de aceitação de riscos serão mais elevados quando o capital social for maior devido à crença que decisores com relacionamentos fortes avaliam com maior precisão a situação de risco. Sendo assim, quanto maior o capital social possivelmente mais precisa será o julgamento de situações arriscadas, aumentando assim as chances de elevação dos níveis de eficácia da decisão. O capital social mais elevado do gestor irá facilitar a identificação de riscos e fornecer confiança na situação de decisão. (JANSEN et al., 2011). 
O estudo de Jansen et al. (2011) mostra que o capital social tem um efeito positivo sobre a eficácia da decisão através da mediação do nível de aceitação de risco, bem como o nível de confiança. As informações obtidas a partir de relações em redes de contatos no exterior levam a obtenção decisões mais benéficas para a empresa por que os decisores ficam confiantes e dispostos a aceitar os mais elevados níveis de risco. Sendo assim, a eficácia da decisão em termos do alcance dos objetivos mesmo com riscos elevado pode ser influenciada pelo maior capital social do gestor. (JANSEN et al., 2011).

Li et al. (2015) descobriram que a organização de informações no nível de empresa é dependente da capacidade de resposta em combinação com propensão de assumir riscos dos decisores motivando outros decisores para agir imediatamente no sentido reduzir riscos, porque eles têm o apoio das redes de contatos e são confiantes sobre a eficiência das informações obtidas por meio de suas redes. A propensão ao risco tende a ser influenciada pelos relacionamentos do gestor via rede de contatos internacionais.

O grau de comprometimento do capital social reflete a propensão dos decisores para o risco em seu investimento e é proporcional ao risco potencial, sendo que os laços sociais através de redes de contatos podem reduzir o receio provocado pelos ambientes incertos num mercado estrangeiro. (PFEFFER; SALANCIK, 1978; ZHAO, HSU, 2007).

\section{Impacto do capital social na percepção de riscos}

$\underline{\mathrm{H}}_{3 \mathrm{~b}}$ : O capital social do gestor está negativamente associado com a sua percepção de risco (das atividades internacionais)

Os resultados mostram que a relação entre o capital social e a percepção de risco do gestor foi negativa, porém, não significativa. Considerando estes resultados, a hipótese $\mathrm{H}_{3 \mathrm{~b}}$ não foi suportada.

O estudo de Goxe (2010) mostrou que os empreendedores chineses até exploram as suas relações internacionais (relações com clientes, fornecedores, associações internacionais). Porém, estes gestores são incapazes de se adaptar culturalmente às relações com clientes, fornecedores e associações internacionais, apesar de estarem consistentemente conectados com estes potenciais parceiros. Isso se deve às características pessoais destes gestores que impedem o desenvolvimento de relações com parceiros estrangeiros, sendo percebidos como 
muito diferentes independentemente dos riscos percebidos. O desenvolvimento das relações internacionais proporciona um comportamento com baixo nível de orientação internacional, induzindo a uma percepção de risco da internacionalização sem importância para seus negócios, não favorecendo a internacionalização das empresas. Portanto, no estudo de Goxe (2010) o capital social não influencia a percepção de risco do empreendedor no sentido de internacionalizar sua empresa, apesar da existência de relações internacionais.

Considerando as diferenças de contexto em termos de país, é possível que na amostra de PMEs estudadas no presente estudo possa ocorrer o mesmo. Os decisores possuem relacionamentos via associações e contatos internacionais, porém, estes gestores ainda não se adaptaram a estas relações de forma que pudessem perceber de fato menos riscos nas atividades de exportação.

Segundo Covielo e Munro (1997), os decisores devem ser cautelosos com quais relações e como estas relações são estabelecidas, e quais habilidades de gerenciamento de rede são necessárias ao longo do tempo. Os decisores devem compreender os benefícios e os riscos associados à externalização das atividades com parceiros da rede, dada a aparente confiança em relacionamentos via rede para o crescimento internacional. Desta forma, gestores com menor confiança em relação aos seus contatos e relações podem perceber mais risco, independente da frequência com que utilizam seus contatos para tomar decisão.

Nowinski e Rialp (2016) encontraram em seu estudo que o impacto da relação é diferente para cada gestor. Estes autores consideram que a percepção de riscos dos gestores, principalmente gestores novatos, não é afetada diretamente pelas relações internacionais. Os gestores podem perceber baixos riscos em suas relações internacionais em que outros gestores pertencentes à mesma rede de relacionamentos não perceberiam e ainda assim, tendem a não considera-las nas suas decisões envolvendo internacionalização (NOWINSKI; RIALP, 2016).

\section{Impacto do capital social na velocidade de internacionalização}

$\underline{H}_{3 c}:$ O capital social do gestor está positivamente associado com a velocidade de internacionalização da empresa (em termos de precocidade e de crescimento das vendas internacionais) 
Os resultados também mostraram que a relação entre capital social e a velocidade de internacionalização foi positiva, porém, não significativa. Portanto, a hipótese $\mathrm{H}_{3 \mathrm{c}}$ não foi suportada. As relações internacionais dos gestores não são suficientes para fazer com que estas promovam a rápida internacionalização e o crescimento das vendas internacionais.

As relações são capazes de fornecer recursos (como informações) e também modificam a percepção e os modelos mentais dos empreendedores de pequenas empresas. O impacto nas cognições dos empreendedores pode ser na confiança da obtenção de oportunidades internacionais. Os empreendedores menos experientes possivelmente irão se beneficiar menos de seus contatos (NOWINSKI; RIALP, 2016) e assim tendem a não internacionalizar rapidamente a empresa. Portanto, é possível que o fato dos gestores das PMEs deste estudo seja mais jovem, com menor experiência nas relações internacionais o que levariam a não ter confiança suficiente para reconhecer as oportunidades de exportação, não fazendo aumentar a velocidade de exportação.

Dib et al. (2010, p. 246) descobriram “que as hipóteses relativas à utilização das relações pessoais (capital social) nas born globals de software brasileiro não foram suportadas empiricamente." Musteen et al, (2010) encontraram que as relações com uma proporção maior de laços pessoais próximos não resultou em internacionalização mais rápida. O mesmo foi encontrado por Granovetter (1973 e 1982) fornecendo evidências de que as relações, em muitos casos, podem não ser tão benéficas. A falta de significância entre as relações pessoais e a velocidade de internacionalização também é consistente com os argumentos de Hite e do Hesterly (2001). Para estes autores, enquanto as relações são mais valiosas nas fases posteriores do ciclo de vida da empresa, podem não ser tão benéficas em fases iniciais quando a empresa procura por novas oportunidades internacionais não favorecendo a rápida internacionalização da empresa devido a pouca maturidade destas relações (MUSTEEN et al., 2010).

\section{Impacto do capital social no grau de internacionalização}

$\underline{H}_{3 d}:$ O capital social do gestor está positivamente associado com o grau de internacionalização da empresa (em termos de abrangência e profundidade) 
Os resultados demonstram que a relação entre o capital social e o grau de internacionalização foi negativa, embora não significativa. Sendo assim, a hipótese de que $\mathrm{H}_{3 \mathrm{~d}}$ não foi suportada. $\mathrm{O}$ capital social formado pelas relações internacionais não influencia de forma significativa a abrangência e profundidade de internacionalização da PME. Além disso, o sinal negativo da relação sugere que quanto maior o capital social do gestor menor seria o grau de internacionalização em termos de abrangência e profundidade, ao contrário do esperado.

Musteen et al (2010) afirma que as relações pessoais dos gestores de PME não se traduzem necessariamente em apoio significativo na internacionalização. As redes com um grande número de relações pessoais não conduzem necessariamente a um desempenho favorável no empreendimento internacional. Dado que a confiabilidade das relações está associada com a obtenção de informações que possam ser compreendidas e utilizadas para benefício da empresa. Uma vez o gestor não conseguindo informações benéficas de suas relações, este gestor não terá confiança também para aumentar a abrangência e a profundidade de internacionalização da empresa.

Yli-Renko et al. (2002) não encontrou uma relação significativa entre capital social e o conhecimento do mercado externo por parte dos gestores. Segundo estes autores, isto pode ser devido ao tamanho relativamente pequeno das redes de contatos dos gestores, que reduz a abrangência e a quantidade de informações e recursos obtidos por meio destas relações.

Além disso, Harris e Weeler (2005) constataram que as relações raramente se originam de contatos com empresas clientes, associações e fornecedores ou distribuidoras. Podem vir de qualquer lugar, no trabalho ou ajustes sociais. Para estes autores, as pesquisas anteriores destacam que a interação social é muito importante. Esses relacionamentos, no entanto, necessitam amadurecer e desenvolver relações interpessoais confiáveis e isso é feito através de extensa interação social e por um longo período de tempo, caso contrário não irão se reverter em benefícios para as empresas. 


\section{Impacto da propensão a risco na velocidade de internacionalização}

$\underline{H}_{4 a}:$ A propensão a risco do gestor está positivamente associada com a velocidade de internacionalização da empresa (em termos de precocidade e de crescimento das vendas internacionais)

As análises do presente estudo mostram que a relação entre a propensão ao risco e a velocidade de internacionalização é negativa e não significante. Desta forma, a hipótese que $\mathrm{H}_{4 a}$ não foi suportada. Embora os resultados não tenham apresentado significância estatística, estes sugerem que o gestor com maior propensão ao risco poderia fazer com que a empresa reduzisse a velocidade de internacionalização em termos da precocidade e do crescimento das vendas internacionais.

Rosen e Willen (2002) concluíram que a disponibilidade de um gestor em aceitar riscos não é um fator dominante na sua decisão de iniciar um negócio. A propensão ao risco dos decisores não é uniforme para todo o tipo de risco no início do processo de internacionalização (Wu e Knott, 2006, Buckley et al, 2016).

A propensão ao risco do decisor pode trazer ao decidir uma abordagem mais racional para as decisões estratégicas importantes tais como a seleção de países; além disso, permite ao decisor buscar e analisar informações avaliando as alternativas entre as quais deve escolher. (FRANCIONI et al., 2015). Portanto, a presença de uma condição de risco maior vindo de uma percepção de ambiente desconhecido pode não proporcionar uma melhor compreensão das decisões estratégicas internacionais para as pequenas e médias empresas. (FRANCIONI et al., 2015).

Uma pesquisa desenvolvida por Low e Weiler (2012) indica que a redução do risco pode ser prejudicial para o valor da empresa. No entanto, essa suposição de aversão ao risco universal pode ser flexibilizada porque os indivíduos variam em suas atitudes em relação ao risco. Portanto, o gestor irá buscar alternativas para reduzir o impacto do risco em seus negócios mesmo sendo propensão ao risco; uma vez não encontrando alternativas de redução de risco na internacionalização, adiará o início deste processo até encontrar uma forma de reduzir tais riscos. 


\section{Impacto da propensão a risco no grau de internacionalização}

$\underline{H}_{4 b}$ : A propensão a risco do gestor está positivamente associada com o grau de internacionalização da empresa (em termos de abrangência e de profundidade)

Os resultados deste estudo apresentam uma relação positiva entre a propensão ao risco e o grau de internacionalização, porém, não significativa. Portanto, a hipótese de que a $\mathrm{H}_{4 \mathrm{~b}}$ não foi suportada.

Os resultados do estudo de Felzensztein et al. (2015) indicam que os decisores com atitudes mais fortes ao risco (propensão ao risco) não estavam correlacionados com a propensão de exportação (mais especificamente, exportação para múltiplos países). Para esses autores, vários fatores de nível individual podem influenciar a propensão ao risco, tal que uma opção de escolha aparentemente mais arriscada em conjunto com outras opções pode apresentar menor risco, dependendo do contexto em que o gestor está inserido e se ele conhece todas as opções disponíveis. Sem saber os conjuntos de opções de escolha completa é difícil estimar a contribuição marginal de risco na decisão final. (BUKLEY et al., 2016).

De acordo com March e Shapira (1987) os gestores preferem relativamente riscos elevados e tendem a sacrificar algum retorno esperado para aumentar a variação (resultados possíveis). Uma maior vantagem potencial (relacionada a um futuro incerto) pode induzir o comportamento de busca de risco, enquanto ameaças à situação atual (se não for insatisfatória) podem induzir comportamento avesso ao risco (SITKIN; WEINGART, 1995). Então, o envolvimento com a exportação dependerá não da propensão ao risco dos tomadores de decisão, mas também da avaliação do tomador de decisão de se (e quanto) as exportações tendem a serem potencialmente mais rentáveis do que as vendas internas.

\section{Impacto da percepção de risco na velocidade de internacionalização}

$\underline{H}_{4 c}:$ A percepção de risco (das atividades internacionais) por parte do gestor está negativamente associada com a velocidade de internacionalização da empresa (em termos de precocidade e de crescimento das vendas internacionais)

Os resultados também mostram que a relação entre a percepção de risco e a velocidade de internacionalização foi negativa, porém, não significante. Portanto, a hipótese $\mathrm{H}_{4 \mathrm{c}}$ não foi suportada. Sendo assim, a percepção dos riscos do gestor não leva a fazer a PME ser mais precoce ou veloz na sua internacionalização. 
Gerentes avaliam o risco associado com vários modos de entrada e o controle além da capacidade de implantar efetivamente esse controle, tendo influencia das percepções de risco. Há evidências de que o risco percebido pelo decisor desempenha um papel mais importante nas decisões de internacionalização do que avaliações de risco puramente normativa (FORLANI; PARTHASARATHY; KEAVENEY, 2008; MARCH; SHAPIRA, 1987). No entanto, os gerentes mais preocupados com resultados negativos (perdas) em vez de resultados positivos (ganhos) muitas vezes tendem a definir o risco apenas em termos de resultados negativos (MACCRIMMON; WEHRUNG, 1986; MARCH; SHAPIRA, 1987). Em outras palavras, estes gerentes são mais aptos a considerar o risco como um perigo de resultados negativos; uma escolha arriscada poderia levar a empresa e consequentemente o gerente a perder dinheiro, sendo assim, este gerente tende a fazer a empresa a se internacionalizar gradualmente, ou seja, irão retardar o processo de internacionalização (FORLANI; PARTHASARATHY; KEAVENEY, 2008).

A percepção de risco possui componentes ambientais e organizacionais, isso significa que as percepções dos decisores em relação à incerteza variam por meio dos níveis de análise do decisor. Ou seja, nem todos os decisores de um determinado tipo de indústria e/ou o porte da empresa tem percepções homogêneas da incerteza ambiental. Percepções gerenciais do risco de cada fator podem variar com as características individuais e da empresa (MILLER, 1992). Portanto, o contexto pode influenciar mais as decisões do gestor de tal forma que o gestor ainda que perceba menores riscos na rápida internacionalização tende perceber muito mais dificuldades do que riscos neste processo e, portanto, não fariam a PME entrar precocemente no mercado internacional.

No caso dos resultados do presente estudo a percepção de risco pode não influenciar as decisões que buscam aumentar a velocidade de internacionalização pelo fato que o gestor da PME percebe menos riscos nas atividades de exportação, porém, encontra dificuldades para iniciar o processo de internacionalização, devido a questões financeiras e burocráticas, tende a focar na sustentabilidade de seus negócios, deixando para iniciar as atividades internacionais em um momento em que tais dificuldades possam ser superadas. 


\section{Impacto da percepção de risco no grau de internacionalização}

$\underline{H}_{4 d}:$ A percepção de risco (das atividades internacionais) por parte do gestor está negativamente associada com o grau de internacionalização da empresa (em termos de abrangência e de profundidade)

Por fim os resultados mostram que a relação entre a percepção de risco e o grau de internacionalização foi positiva, ao contrário do esperado, embora não significativa. Sendo assim, a hipótese $\mathrm{H}_{4 \mathrm{~d}}$ não foi suportada.

Para Chen; Zhang; Hu (2015) algumas das relações entre percepção de risco e internacionalização de empresas foram identificadas como não consistentes. Alguns pesquisadores observaram que, como o nível de percepção do risco é aumentado em uma pessoa, ela é menos propensa a se envolver em comportamento de risco. Enquanto outros sugerem que uma pessoa com elevado nível de risco percebido tende a tomar decisões mais arriscadas (CHEN; ZHANG; HU, 2015). Portanto, existe uma contradição ao analisar a influência da percepção de risco na tomada de decisão também no contexto da internacionalização de empresas (CHEN; ZHANG; HU, 2015).

Forlani; Parthasarathy; Keaveney (2008) destaca que os gerentes mais preocupados com resultados negativos (perdas) em vez de resultados positivos (ganhos) muitas vezes tendem a definir o risco apenas em termos de resultados negativos (MACCRIMMON; WEHRUNG, 1986; MARCH; SHAPIRA, 1987). Em outras palavras, estes gerentes são mais aptos a considerar o risco como um perigo de resultados negativos, uma escolha arriscada poderia levar a empresa e consequentemente o gerente a perder dinheiro, sendo assim, este gerente tende a fazer a empresa a não aumentar a abrangência da internacionalização (FORLANI; PARTHASARATHY; KEAVENEY, 2008).

É possível que haja o impacto de outras características dos gestores que não foram avaliadas neste estudo possa explicar a forma como ocorre o processo de internacionalização das PMEs pesquisadas. Neste estudo o tamanho da amostra é considerado pequeno e mesmo modelando com um algoritmo robusto, o PLSSEM, este tamanho reduzido da amostra pode influenciar os resultados obtidos. 


\section{Variáveis de controle}

Neste trabalho foi avaliada a influência de três variáveis de controle tanto na velocidade de internacionalização quanto no grau de internacionalização. As variáveis de controle são: internacionalização da indústria, o tamanho relativo da empresa e (in)satisfação com o mercado doméstico.

Verifica-se por meio dos resultados deste trabalho uma relação positiva e significativa entre a internacionalização da indústria e o grau de internacionalização. Tal constatação sugere que na amostra de PMEs pesquisada a internacionalização da indústria à qual estas PMEs estão inseridas tende a proporcionar um aumento do grau de internacionalização destas empresas. É possível que a variável de controle internacionalização da indústria possa explicar a maior parte da variância da variável dependente grau de internacionalização, uma vez que os valores encontrados para essa relação são maiores do que as demais relações testadas neste estudo.

Os resultados deste trabalho apresentação uma relação positiva e significativa entre a variável de controle (in)satisfação com o mercado doméstico e a variável dependente velocidade de internacionalização. Sendo assim, tal observação sugere que na amostra de PMEs pesquisada a insatisfação com mercado doméstico tende a proporcionar um aumento da velocidade de internacionalização destas empresas. É possível que a variável de controle (in)satisfação com o mercado doméstico possa explicar a maior parte da variância da variável dependente velocidade de internacionalização, uma vez que os valores encontrados para essa relação são elevados.

A variável de controle tamanho relativo da empresa não apresentou relação significativa com o grau de internacionalização e nem com a velocidade de internacionalização das PMEs pesquisadas. Portanto o tamanho relativo da empresa aparentemente não influencia o grau de internacionalização e também não influencia a velocidade de internacionalização das empresas nesta amostra. 


\section{7 \\ Considerações finais}

O objetivo deste estudo foi investigar se há relação entre as características gerenciais do decisor de pequenas e médias empresas (PMEs) e o processo de internacionalização da empresa. Foi avaliado mais especificamente qual o impacto da idade, do capital humano, do capital social, da propensão ao risco e da percepção de risco do decisor sobre a velocidade de internacionalização (em precocidade e de crescimento das vendas internacionais) e o grau de internacionalização (em termos de abrangência e profundidade) de pequenas e médias empresas.

Inicialmente foi realizada uma revisão da literatura que permitiu descobrir algumas lacunas existentes e deu fundamentação teórica para gerar as hipóteses de um modelo conceitual. Foi então realizada a coleta de dados por meio de uma survey aplicada aos gestores de pequenas e médias empresas brasileiras que são exportadoras, obtendo 71 questionários considerados válidos para este estudo. $\mathrm{Na}$ sequência foi realizada a análise dos dados por meio da modelagem de equações estruturais pelo método dos mínimos quadrados parciais - PLS-SEM, obtendo assim a validação empírica do modelo.

Os resultados deste estudo mostraram que a idade do decisor influencia negativamente na velocidade de internacionalização e permite concluir que os decisores mais jovens proporcionam um aumento da velocidade de internacionalização. Estes resultados estão em acordo com vários argumentos encontrados na literatura sobre negócios internacionais, mais especificamente, o empreendedorismo internacional.

Por outro lado, os resultados deste estudo mostraram que a idade do gestor não influencia significativamente a propensão ao risco do gestor, apesar do gestor jovem poder proporcionar a entrada precoce da PME no mercado internacional; ou seja, o efeito tende a ser direto e não mediado. 
Os resultados deste estudo sugerem que o capital humano do decisor formado pelo nível de educação formal, experiência internacional e proficiência em línguas estrangeiras, não influencia de forma significativa a velocidade de internacionalização e também não influencia de forma significativa o grau de internacionalização das pequenas e médias empresas pesquisadas. Na literatura de negócios internacionais existem divergências entre os resultados dos estudos. Alguns estudos apresentaram resultados semelhantes aos encontrados no presente trabalho; porém, a literatura também apresenta estudos com resultados contrários. Desta forma, a influência do capital humano na internacionalização de PMEs tende a permanecer controverso.

Uma possível explicação para tal constatação esteja na educação formal, um dos fatores do capital humano avaliado neste estudo. A educação formal do gestor é importante para o desenvolvimento da empresa como um todo, porém, este ainda não é a grande força que impulsiona as empresas a buscarem a internacionalização por meio das exportações regulares.

Os resultados deste estudo também mostraram que o capital social influencia positivamente a propensão ao risco do gestor, indicando que quanto maior o capital social (em termos de relacionamentos) maior a propensão ao risco do decisor. O capital social neste estudo influencia positivamente e significativamente a propensão ao risco dos gestores das pequenas e médias empresas pesquisadas.

O gestor possui relações com pessoas e associações no exterior o que tende a fazer com que o gestor seja mais propenso ao risco, porém, é possível que a falta de fomento, as dificuldades burocráticas existente no processo de exportação, além da elevada carga tributária, tende a fazer com que este gestor não queira ampliar as operações de suas PMEs no mercado internacional por não verificar uma vantagem de fato para a empresa.

Os resultados do presente estudo permite concluir que o capital social do decisor formado pelas relações com associações internacionais e contatos no exterior não influencia de forma significativa a percepção de risco deste decisor sobre a exportação, a velocidade de internacionalização e também não influencia de forma significativa o grau de internacionalização das pequenas e médias empresas pesquisadas. A literatura de negócios internacionais mostra divergências entre os autores, tendo alguns autores que apresentaram resultados em que estas 
relações também não foram significativas e outros estudos apresentaram resultados com relações significativas positivas e negativas. Desta forma, a influência do capital social na percepção de riscos sobre as exportações, a velocidade e o grau de internacionalização tende a permanecer controversa.

É possível que o capital social não seja de fato tão importante como uma forma de obter informações sobre oportunidades de negócio internacional. O que pode explicar este fato é que apesar destes gestores manterem relações com associações e pessoas no exterior, estas relações podem trazer informações de difícil compreensão, podendo não se reverter em uma oportunidade realmente vantajosa para pequena e média empresa. Portanto este gestor não vai utilizar a informação obtida e assim não ampliará suas operações no exterior.

Neste estudo era esperado que a percepção de risco mediasse à relação entre o capital social e a velocidade de internacionalização e também o grau de internacionalização, porém esta mediação não ocorreu. É possível que os gestores das PMEs pesquisadas não percebam os riscos na mesma intensidade quando envolvem decisões de negócios internacionais.

O presente trabalho traz contribuições para o meio empresarial, especialmente o das pequenas e médias empresas; para o meio acadêmico; para o Governo. As principais contribuições deste trabalho para o meio acadêmico são: a integração de conceitos e pesquisas que envolvem a área de Negócios Internacionais, Gestão Estratégica e Recursos Humanos, considerados de extrema importância para a Administração e para a grande área de Ciências Sociais Aplicadas; entender os efeitos de características pessoais sobre a exportação é uma questão relevante considerando que a opção por mercados estrangeiros é complexa e apresenta ainda divergências entre os estudos.

Este estudo faz uma contribuição à pesquisa sobre negócios internacionais ao apresentar resultados que tendem a ser diferentes de estudos anteriores. Este estudo centra-se no nível individual, em contraste com a maioria dos estudos anteriores, pois apresenta resultados que sugerem que algumas características dos gestores de pequenas e médias empresas pode não ser suficientes para fazer estas empresas iniciar e manter as atividades de exportação, contradizendo assim parte da literatura sobre negócios internacionais. 
O estudo atual deve, portanto, contribuir para gerentes envolvidos em operações de exportação e para aqueles que consideram a possibilidade de iniciar tais operações busque aprimorar seus conhecimentos e habilidades sobre negócios internacionais. $\mathrm{O}$ estudo também contribui para a escolha de pessoas que ficarão responsáveis pelas decisões neste campo e também para deseja fundar sua empresa, pois apresenta a necessidade de desenvolver habilidades tais como buscar uma melhor formação educacional, o desenvolvimento de proficiência em língua estrangeira e buscar a obtenção de experiência internacional, além de fortalecer os laços desenvolvidos com contatos internacionais.

Os responsáveis por programas de promoção de exportações (Governo e instituições não governamentais) também devem encontrar os resultados deste estudo interessante. A eficácia de medidas de apoio à exportação pode ser reforçada se forem promovidas além do desenvolvimento de habilidades gerenciais em relação a operações em mercados estrangeiros, o incentivo a uma atitude positiva sobre as exportações entre gestores e empreendedores, apresentando os benefícios que as empresas podem obter por meio destas operações.

Portanto, este estudo contribui para o Governo, trazendo alternativas para a elaboração e implementação de políticas públicas visando o desenvolvimento das características gerenciais para pequenos empreendedores, como exemplo a realização de cursos de preparação em incubadoras de instituição de ensino público, promover contatos entre empreendedores e gestores de pequenas e médias empresas exportadoras e não exportadoras com instituições estrangeiras com aporte de recursos para o desenvolvimento destas operações. Além disso, é importante que as universidades possam preparar os alunos para desenvolver habilidades com foco na abertura de negócios internacionais por meio da inserção de disciplinas como empreendedorismo internacional e negócios internacionais. 


\section{Sugestões para futuras pesquisas}

É possível que parte das explicações sobre a abrangência e profundidade relativas às pequenas e médias empresas pesquisadas tenha sido influenciada pela idade da empresa, uma variável de controle que não foi abordada nesta tese. Sendo assim, sugere-se para futuras pesquisas a inserção desta variável de controle seria de no modelo para avaliar até que ponto ela possa influenciar os resultados.

O capital humano e também o capital social possuem diversos mecanismos de diferentes formas de medição, sendo que nesta tese foram utilizados os indicadores que também já haviam sido aplicados em outros estudos, pode ser que haja algum destes mecanismos que possam trazer maiores explicações para a influência tendo do capital humano quanto do capital social na internacionalização de pequenas e médias empresas. Portanto como sugestão para futuras pesquisas, seria importante testar outros mecanismos destes fatores. 


\section{8 \\ Referências bibliográficas}

AABY, N.; SLATER, S. F. Management influences on export performance: a review of empirical literature, 1978-88. International Marketing Review, v. 6, n. 4, p. 7-26, 1989.

ACEDO, F. J.; FLORIN, J. An entrepreneurial cognition perspective on the internationalization of SMEs. Journal of International Entrepreneurship, v. 4, p. 49-67, 2006.

.; GALÁN, J. L. Export stimuli revisited: the influence of the characteristics of managerial decision makers on international behavior. International Small Business Journal, v. 29, n. 6, p. 648-670, 2011.

.; JONES, M. V. Speed of internationalization and entrepreneurial cognition: Insights and a comparison between international new ventures, exporters, and domestic firms. Journal of World Business, v. 42, n. 3, p. 236252, 2007.

ACS, Z.; O'GORMAN, C.; SZERB, L.; TERJESEN, S. Could the Irish miracle be repeated in Hungary? Small Business Economics, v. 28, n. 2/3, p. 123-142, 2007.

; MORCK, R.; SHAVER, J. M.; YEUNG, B. The internationalization of small and medium-sized enterprises: a policy perspective. Small Business Economics, v. 9, n. 1, p. 7-20, 1997.

ADIDAM, P. T.; BINGI, R. P. The importance of decision confidence to strategy outcomes. Journal of Applied Business Research, v. 16, n. 2, p. 35-50, 2000.

ADLER, P. S.; KWON, S-W. Social Capital: Prospects for a New Concept. The Academy of Management Review, v. 27, n. 1, p. 17-40, jan. 2002.

AHMED, Z. U.; MOHAMED, O.; JOHNSON, J. P.; MENG, L. Y. Export promotion programs of Malaysian firms: an international marketing perspective. Journal of Business Research, v. 55, n. 10, p. 831-843, 2002.

AKÇOMAK, S.; WEEL, B. Social capital, innovation and growth: Evidence from Europe. European Economic Review, v. 53, n. 5, p. 544-567, 2009.

AKYOL, A.; AKEHURST, G. An Investigation of Export Performance Variations Related to Corporate Export Market Orientation. European Business Review, v. 15, n. 1, p. 5-19, 2003.

ALDRICH, H.; ZIMMER, C. Entrepreneurship through socials networks. California Management Review, v. 33, n. 1, p. 261-281, 1986. 
ALLEN, D. G.; RENN, R. W.; MOFFITT, K. R.; VARDAMAN, J. M. Risky business: the role of risk in voluntary turnover decisions. Human Resource Management Review, v. 17, n. 3, p. 305-318, 2007.

ALLEN, L.; PANTZALIS, C. Valuation of the operating flexibility of multinational corporations. Journal of International Business Studies, v. $27, \mathrm{n}$. 4, p. 633-653, 1996.

ALRASHIDI, Y. A. Exporting Motivations and Saudi SMEs: An Exploratory Study. World Journal of Social Sciences, v. 3, n. 6, p. 204-219, 2013.

The Influence of SMEs Decision-Makers' Individual Characteristics on Risk Perception Associated with Exporting: Evidence from Saudi Arabia. European Journal of Business and Management, v. 8, n. 2, p. 51-61, 2016.

ALTINAY, L. The relationship between an entrepreneur's culture and the entrepreneurial behavior of the firm. Journal of Small Business and Enterprise Development, v. 15, n. 1, p. 111-129, 2008.

.; ALTINAY, E. Determinants of ethnic minority entrepreneurial growth in the catering sector. The Service Industries Journal, v. 26, n. 2, p. 203-21, 2006.

AMORÓS, J. E.; BASCO, R.; ROMANÍ, G. Determinants of early internationalization of new firms: the case of Chile. International Entrepreneurship Management Journal, v. 12, p. 283-307, 2016.

ANCONA, D.; GOODMAN, P.; LAWRENCE, B.; TUSHMAN, M. Time: A new research lens. The Academy of Management Review, v. 26, n. 4, p. 645-663, 2001 .

ANDERSEN, O. Internationalization and market entry mode: a review of theories and conceptual frameworks. Management International Review, v. 37, n. 2, p. $7-42,1993$.

ANDERSSON, S. The internationalization of the firm from an entrepreneurial perspective. International Studies of Management and Organization, v. 30, n. 1, p. 63-92, 2000.

; EVANGELISTA, F. The entrepreneur in the Born Global firm in Australia and Sweden. Journal of Small Business and Enterprise Development, v. 13, n. 4, p. 642-659, 2006.

.; EVERS, N. International opportunity recognition in international new ventures - a dynamic managerial capabilities perspective. Journal of International Entrepreneurship, v. 13, n. 3, p. 260-276, 2015.

.; D_. Differences in managerial behavior between small international and no international firms. Journal of International Entrepreneurship, v. 9, n. 3, p. 233-258, 2011.

.; . Exploring managerial behavior in small international firms.

Journal of Small Business and Enterprise Development, v. 15, n. 1, p. 31-50, 2008. 
.; GABRIELSSON, J.; WICTOR, I. International activities in small firms: examining factors influencing the internationalization and export growth of small firms. Canadian Journal of Administrative Science, v. 21, n. 1, p. 22-34. 2004.

ANDERSSON, M.; JOHANSSON, S. Human capital and the structure of regional export flows. Technology in Society, v. 32, n. 2010, p. 230-240, 2010.

APFELTHALER, G. Why small enterprises invest abroad: the case of four Austrian firms with US operations. Journal of Small Business Management, v. 38 , n. 3, p. 92-8, 2000.

ARAÚJO, M. L. R.; NEIRA, M. C. V. Managerial characteristics and export performance in Spanish SMEs. Revista Científica Esic Market, n. 125, p. 191221, 2006.

ARBAUGH, J. B.; CAMP, S. M.; COX, L. W. Why don't entrepreneurial firms internationalize more? Journal of Management Issues, n. 3, p. 366-382, 2008.

ARDICHVILI, A.; CARDOZO, R.; RAY, S. A theory of entrepreneurial opportunity identification and development. Journal of Business Venturing, v. 18, n. 1, p. 105-123, 2003.

ARENIUS, P. The psychic distance postulate revised: from market selection to speed of Market penetration. Journal of International Entrepreneurship, v. 3, p. 115-131, 2005.

ARMARIO, J. M.; RUIZ, D. M.; ARMARIO, E. M. Market orientation and internationalization in small and medium sized enterprises. Journal of Small Business Management, v. 46, n. 4, p. 485-511, 2008.

ARREGLE, J.-L.; HITT, M. A.; SIRMON, D. G.; VERY, P. The development of organizational social capital: attributes of family firms. Journal of Management Studies, v. 44, n. 1, p. 73-95, 2007.

ASMUSSEN, C. G.; BENITO, G. R. G.; PETERSEN, B. Organizing foreign market activities: from entry mode choice to configuration decisions. International Business Review, v. 18, n. 2, p. 145-155, 2009.

ATHANASSIOU, N.; NIGH, D. The impact of the top management team's international business experience on the firm's internationalization: social network at work. Management International Review, v. 42, n. 2, p. 157-81, 2002.

AXINN, C. N. Export performance: do managerial perceptions make a difference? International Marketing Review, v. 5, n. 2, p. 61-71, 1998.

BAIRD, I. S.; THOMAS, H. Toward a contingency model of strategic risk taking. Academy of Management Review, v. 10, p. 230-243, 1985. 
BAIRD, I. S.; LYLES, M. A.; ORRIS, J. B. The choice of international strategies by small businesses. Journal of Small Business Management, v. 32, n. 48-59, 1994.

BAL, E.; KUNDAY, Ö. Investigating the Role of Entrepreneurial Traits and Human Capital on the Internationalization Degree of Small and Medium Enterprises in Turkey. International Journal of Business and Social Science, v. 5, n. 8, p. 192-201, jul. 2014.

BANTEL, K. A.; JACKSON, S. Top management innovation in banking: does the composition of the top team make a difference? Strategic Management Journal, v. 10, p. 107-24, 1989.

BANTEL, K. A. Strategic planning openness: The role of top demography. Group \& Organization Studies, v. 19, p. 406-424, 1994.

BARBOSA, S. D.; FAYOLLE, A.; LASSAS-CLERC, N. (2007). Assessing risk perception, self-efficacy and entrepreneurial attitudes and intention (WP 023/2007). Disponível em: <www.ncge.com/>. Acesso em: 15 abr. 2010.

; KICKUL, J.; LIAO-TROTH, M. Development and validation of a multidimensional scale of entrepreneurial risk perception. Annual Meeting of the Academy of Management, Academy of Management, Philadelphia, PA., 2007.

BARCLAY, D. W.; HIGGINS, C. A.; THOMPSON, R. The partial least squares approach to causal modeling: personal computer adoption and use as illustration. Technology Studies, v. 2, n. 2, p. 285-309, 1995.

BARNEY, J. B. Firm resources and sustained competitive advantage. Journal of Management, v. 17, n. 1, p. 99-120, 1991.

.; WRIGHT, P. M. On becoming a strategic partner: The role of human resources in gaining competitive advantage. Human Resource Management, v. 37, n.1, p. 31-46, p. 1998.

BARON, J; HANNON, M. The impact of economics on contemporary sociology. Journal of Economic Literature, v. 32, n. 3, p. 1111-1146, set. 1994.

BARON, R. Counterfactual thinking and venture formation: The potential effects of thinking about "what might have been". Journal of Business Venturing, v. 15, p. 79-91, 1999.

BARRETT, N. I.; WILKINSON, I. F. Internationalization behavior: management characteristics of Australian manufacturing firms by level of international development. In: TURNBULL, P.W.; PALIWODA, S. J. (Eds.). Research in International Marketing. London: Crook Helm, 1986, p. 213-233.

BARTLETT, C. A.; GHOSHAL, S. Transition management: Text, cases, and readings in cross-border management. Singapore: Irwin McGraw-Hill, 2000. 
BASTIÉ, F.; CIEPLY, S.; CUSSY, P. The entrepreneur's mode of entry: the effect of social and financial capital. Small Business Economics, v. 40, n. 4, p. 865-877, 2013.

BAUM, R.; WALLY, S. Strategic decision speed and firm performance. Strategic Management Journal, v. 24, n. 11, p. 1107-1129, 2003.

BAZERMAN, M. Judgment in managerial decision-making. New York: Wiley, 1990.

BECKER, G. S. Human Capital: A Theoretical and Empirical Analysis, with Special Reference to Education. New York: National Bureau of Economic Research, 1964.

BELL, J.; KATSIKEAS, C.; MORGAN, R. Editorial: Advances in export marketing theory and practice. International Marketing Review, v. 15, n. 5, p. 322-32, 2001.

BENTLER, P. M.; HUANG, W. On components, latent variables, PLS and simple methods: Reactions to Ridgeon's rethinking of PLS. Long Range Planning, v. 47, n. 3, p. 138-145, 2014.

BETTMAN, J. R. Perceived risk and its components: A model and empirical test. Journal of Market Research, v. 10, p. 184-190, 1973.

BILKEY, W. J. An attempted integration of the literature on the export behavior of firms. Journal of International Business Studies, v. 9, n. 1, p. 33-46, 1978.

BINGHAM, C. B.; DAVIS, J. P. Learning Sequences: Their Existence, Effect, and Evolution. Academy of Management Journal, v. 55, n. 3, p. 611-641, 2012.

BIRLEY, S. The role of networks in the entrepreneurial process. Journal of Business Venturing, v. 1, n. 1, p. 107-117, 1985.

BLOODGOOD, J.; SAPIENZA, H.; ALMEIDA, J. The internationalization of new high-potential US ventures: antecedent and outcomes. Entrepreneurship Theory and Practice, v. 20, n. 4, p. 61-76, 1996.

BOLLEN, K. A. Structural equations with latent variables. New York: John Wiley, 1989.

BONACCORSI, A. On the relationship between firm size and export intensity. Journal of International Business Studies, v. 23, n. 4, p. 605-635, 1992.

BONTEMPO, R. N.; BOTTOM, W. P.; WEBER, E. U. Cross-cultural differences in risk perception: a model-based approach. Risk Analysis, v. 17, n. 4, p. 479$488,1997$. 
BOSO, N.; CADOGAN, J. W.; STORY, V. M. Entrepreneurial orientation and market orientation as drivers of product innovation success: A study of exporters from a developing economy. International Small Business Journal, v. 31, n. 1, p. 57-81, 2013.

BOTELLA, J. et al. dilemmas task for eliciting risk propensity. The Psychological Record, v. 58, n. 4, p. 529-546, 2008.

BOUNCKEN, R. B.; SCHUESSLER, F.; KRAUS, S. The Theoretical Embedding Of Born Globals: Challenging Existing Internationalization Theories. International Business \& Economics Research Journal, v. 14, n. 1, p. 39-46, jan. /fev. 2015.

BOURANTAS, D.; HALIKIAS, J. Discriminating variables between systematic and nonsystematic exporting manufacturing firms in Greece. Journal of Global Marketing, v. 4, n. 2, p. 21-38, 1991.

BOWMAN, C.; SWART, J. Whose human capital? The challenge of value capture when capital is embedded. Journal of Management Studies, v. 44, n. 4, p. 488-505, 2007.

BRASIL. Termo de referência: internacionalização de empresas brasileiras. Brasília (DF): CAMEX, 2009. Disponível em: http://docplayer.com.br/3108237Termo-de-referencia-internacionalizacao-de-empresas-brasileiras.html. Acesso em: 18 nov. 2016.

BROOKS, M. R.; ROSSON, P. J. A study of export behaviour of small and medium-sized manufacturing firms in three Canadian provinces. In: CZINKOTA, M. R.; TESAR, G. (Eds.). Export Management: An International Context. New York: Praeger, 1982, p. 39-54.

BROUTHERS, K. The influence of international risk on entry mode strategy in the computer software industry. Management International Review, v. 35, n. 1, p. 7-28, 1995.

; BROUTHERS, L. E. Why service and manufacturing entry mode choices differ: the influence of transaction cost factors, risk and trust. Journal of Management Studies, v. 40, n. 5, p. 1179-1204, 2003.

BUCHHOLTZ, A. K., RIBBENS, B. A., HOULE, I. T. The role of human capital in post acquisition CEO departure. Academy of Management Journal, v. 46, p. 506-514, 2003.

BUCKLEY, P. J.; CASSON, M. C. Analyzing foreign market entry strategies: Extending the internalization approach. Journal of international business studies, v. 29, n. 3, p. 539-561, 1998.

.; CHEN, L.; CLEGG, J.; VOSS, H. Experience and FDI Risk-taking: A Microfoundational Reconceptualization. Journal of International Management, v. 22, n. 2, p. 131-146, 2016. 
.; GHAURI, P. N. Introduction and overview. In: BUCKLEY, P. J.; GHAURI, P. N. (Eds.). The Internationalization of the Firm: A Reader. London: Academic Press, p. ix-xxi,1993.

BURILlO, J. S.; MORENO, J. J. The Role of the Top Management Team in the Choice of Entry Modes - Theoretical Perspective. Entrepreneurial Business and Economics Review, v. 1, n. 2, p. 51 58, 2013.

BURT, R. S. Structural holes: the social structure of competition. Cambridge: Harvard University Press, 1992.

BYRNE, K. How do consumers evaluate risk in financial products? Journal of Financial Services Marketing, v. 10, n. 1, p. 21-36, 2005.

CAINELLI, G.; MANCINELLI, S.; MAZZANTI, M. Social capital, R\&D and industrial districts. Social Science Research Network Electronic Paper Collection. FEEM Working Paper, n. 84, p. 1-29, jun. 2005.

CALIENDO, M; FOSSEN, F. M.; KRITIKOS, A. S. Risk attitudes of nascent entrepreneurs: new evidence from an experimentally validated survey. Small Business Economics, v. 32, n. 2, p. 153-167, 2009.

CALOF, J. L.; BEAMISH, P. W. Adapting to foreign markets: explaining internationalization. International Business Review, v. 4, n. 2, p.115-32, 1995.

CAMELO-ORDAZ, C.; FERNÁNDEZ-ALLES, M. L.; MARTÍNEZ-FIERRO, S. Influence of top management team vision and work team characteristics on innovation: The Spanish case. European Journal of Innovation Management, v. 9, n. 2, p.179-201, 2006.

CAMPBELL, J. T. Top Management Team Personal Wealth, Within-Team Diversity and the Implications for Firm-Level Risk Taking. PHD Dissertation, Arizona State University, 2012.

CASILLAS, J. C.; ACEDO, F. J. Speed in the Internationalization Process of the firm International Journal of Management Reviews, v. 15, p. 15-29, 2013. .; __ MORENO, A. M. International Entrepreneurship in Family Businesses. Cheltenham, UK: Edward Elgar, 2007.

CASSEL, C.; HACKL, P.; WESTLUND, A. H. Robustness of partial leastsquares method for estimating latent variable quality structures. Journal of Applied Statistics, v. 26, n. 4, p. 435-446, 1999.

CASSON, M. Economics of International Business. Edward Elgar: Cheltenham, 2000 . 
CAVUSGIL, S. T. On the internationalization process of firms. European Research, v. 8, n. 6, p. 273-281, nov. 1980.

Organizational Characteristics Associated with Export Activity. Journal of Management Studies, v. 21, n. 1, p. 3-22, 1984.

. Some observations on the relevance of critical variables for internationalization stages. In: CZINKOTA, M. R.; TEASER, G. (Eds.). Export Management: An International Context. New York: Praeger, 1982, p. 276-286.

.; NAOR, J. Firm and management characteristics as discriminators of export marketing activity. Journal of Business Research, v. 15, n. 3, p. 221-235, 1987.

.; NEVIN, J. R. State-of-the-art in international marketing: An assessment. In: ENIS, B. M.; ROERING, K. J. (Eds.). Review of marketing. Chicago, IL: American Marketing Association, 1984, p. 195-216.

; ZOU, S. Marketing Strategy-Performance Relationship: An Investigation of the Empirical Link in Export Market Ventures. Journal of Marketing, v. 58, n. 1, p. 1-21, 1994.

CERRATO, D.; PIVA, M. The internationalization of small and medium-sized enterprises: the effect of family management, human capital and foreign ownership. Journal of Management \& Governance, v. 16, p. 617-644, 2012.

CHANDLER, G.; HANKS, S. H. Founder competence, the environment, and venture performance. Entrepreneurship Theory and Practice, v. 18, n. 3, p. 7789, 1994.

CHANDRA, Y.; STYLES, C.; WILKINSON, I. The recognition of first time international entrepreneurial opportunities: Evidence from firms in knowledgebased industries. International Marketing Review, v. 26, n. 1, p. 30-61, 2009.

CHANG, S.-J.; WITTELOOSTUIJN, A.; EDEN, L. From the Editors: Common method variance in international business research. Journal of International Business Studies, v. 41, p.178-184, 2010.

CHEN, H. Does Board Independence Influence the Top Management Team? Evidence from Strategic Decisions toward Internationalization. Corporate Governance: An International Review, v. 19, n. 4, p. 334-350, 2011.

CHEN, J. Development of Chinese small and medium-sized enterprises. Journal of Small Business and Enterprise Development, v. 13, n. 2, p. 140-147, 2006.

CHEN, Y. Q. ZHANG S. J. L.; HU S. L. J., Risk perception and propensity in bid/no-bid decision-making of construction projects. Engineering, Construction and Architectural Management, v. 22, n. 1, p. 2-20, 2015.

CHERNICK, M. R. Bootstrap methods: A guide for practitioners and researchers. 2 ed. Hoboken, N. J.: Wiley, 2008. 
CHETTY, S. Dimensions of internationalization of manufacturing firms in the apparel industry. European Journal of Marketing, v. 33, n. 1/2, p. 121-42, 1999. .; CAMPBELL-HUNT, C. Paths to internationalization among small and medium-sized firms: a global versus regional approach. European Journal of Marketing, v. 37, n. 5/6, p. 796-820, 2003. .; HAMILTON, R. T. Firm-level determinants of export performance: a meta-analysis. International Marketing Review, v. 10, p. 26-34, 1993.

CHEUNG, G. W.; LAU, R. S. Testing Mediation and Suppression Effects of Latent Variables Bootstrapping with Structural Equation Models. Organizational Research Methods, v. 11, n. 2, p. 296-325, abr. 2008.

CHILD, J.; HSIEH, L. H. Y. Decision mode, information and network attachment in the internationalization of SMEs: a configurational and contingency analysis. Journal of World Business, v. 49, n. 4, p. 598-610, 2014.

.; RODRIGUES, S. B. Corporate governance and new organizational forms: issues of double and multiple agency. Journal of Management and Governance, v. 7, n. 4, p. 337-360, 2003.

CHIN, W. W. The partial least squares approach for structural equation modeling. In: MACOULIDES, G. A. (Ed.). Modern methods for business research. Mahwah, NJ: Lawrence Erlbaum Associates, 1998, p. 295-336.

CHRISMAN, J. J.; BAUERSCHMIDT, A.; HOFER, C. W. The determinants of new venture performance. Entrepreneurship Theory and Practice, v. 22, n. 1, p. 5-29, 1999.

CHUNG, H. F. L. Export market orientation, managerial ties, and performance. International Marketing Review, v. 29, n. 4, p. 403-423, 2012.

.; ENDERWICK, P. An investigation of market entry strategy selection: Exporting vs foreign direct investment modes - A home-host country scenario. Asia Pacific Journal of Management, v. 18, p. 443-460, 2001.

CHUNG, S.; SINGH, H.; LEE, K. Complementarity, status similarity and social capital as drivers of alliance formation. Strategic Management Journal, v. 21, n. 1, p. 1-22, 2000.

CHURCHILL, G. A. A paradigm for developing better measures of marketing constructs. Journal of Market Research, v. 16, p. 64-73, fev. 1979.

CLARKE, W. M. The use of foreign languages by Irish exporters. European Journal of Marketing, v. 34, n. 1/2, p. 80-90, 2000.

CLAVER, E.; RIENDA, L.; QUER, D. Family firms' risk perception: empirical evidence on the internationalization process. Journal of Small Business and Enterprise Development, v. 15, n. 3, p. 457-471, 2008.

COHEN, J. Statistical power analysis for the behavioral sciences. Mahwah, NJ: Lawrence Erlbaum, 1988. 
COHEN, W. M.; LEVINTHAL, D. A. Absorptive Capacity: A New Perspective on Learning and Innovation. Administrative Science Quarterly, v. 35, n. 1, p. 128-152, 1990.

COLAPINTO, C.; GAVINELLI, L.; ZENGA, M.; DI GREGORIO, A. Different approaches to the pursuit of internationalization by Italian SMEs. Journal of Research in Marketing and Entrepreneurship, v. 17, n. 2, p. 229-248, 2015.

COLEMAN J. Social capital in creation of human capital. American Journal of Sociology, v. 94, p. 95-120, 1998.

COLEMAN, S. Is there a liquidity crisis for small, black-owned firms? Journal of Developmental Entrepreneurship, v. 10, n. 1, p. 29-47, 2005.

COOPER, A. C., GIMENO-GASCON, F. J.; WOO, C.Y. Initial human and financial capital predictors of new venture performance. Journal of Business Venturing, v. 9, n. 5, p. 371-395, 1994.

COOPER, D. R.; SHINDLER, P. S. Business research methods. 7 ed. New York: McGraw-Hill, 2001.

CORTEZIA, D.; LUIS, S.; SWIRSKI DE SOUZA, Y. Uma análise sobre a internacionalização de pequenas empresas brasileiras da indústria de software. Vitória. Brazilian Business Review, v. 8, n. 4, p. 24-45, 2011.

COVIELLO, N. E. The network dynamics of international new ventures. Journal of International Business Studies, v. 37, n. 5, p. 713-731, 2006.

.; GHAURI, P. N.; MARTIN, K. A. M. International competitiveness: empirical findings from SME service firms, Journal of International Marketing, v. 6, n. 2, p. 8-27, 1998.

.; JONES, M. V. Methodological issues in international entrepreneurship research. Journal of Business Venturing, v. 19, p. 485-508, 2004.

; MARTIN, K. A. M. Internationalization of Service SMEs: An Integrated Perspective from the Consulting Sector. Journal of International Marketing, v. 7, n. 4, p. 42-66, 1999.

.; MUNRO, H. Network relationships and the internationalization process

of small software firms. International Business Review, v. 6, n. 4, p. 361-86, 1997.

COVIN, J. G.; MILLER, D. International entrepreneurial orientation: conceptual considerations, research themes, measurement issues, and future research directions. Entrepreneurship: Theory and Practice, v. 38, n. 1, p. 11-44, 2014.

.; SLEVIN, D. P. Strategic management of small firms in hostile and

benign environments. Strategic Management Journal, v. 10, p. 75-87, 1989.

.; ___ The influence of organization structure on the utility of an entrepreneurial top management style. Journal of Management Studies, v. 25, n. 3, p. 217-234, 1998. 
CRAMER, J. S. et al. Low risk aversion encourages the choice for entrepreneurship: an empirical test of a truism. Journal of Economic Behaviour and Organization, v. 48, n. 1, p. 29-36, 2002.

CRICK, D.; JONES, M. V. Small high technology firms and international high technology markets. Journal of International Marketing, v. 8, n. 2, p. 63-85, 2000 .

.; SPENCE, M. The internationalization of 'high performing' UK hightech SMEs: A study of planned and unplanned strategies. International Business Review, v. 14, n. 2, p. 167-185, 2005.

CYERT, R.; MARCH, J. G. A behavioural theory of the firm. Prentice Hall: Englewood Cliffs, 1963.

DALLI, D. The exporting process: the evolution of small and medium sized firms toward Internationalization. Advances in International Marketing, v. 6, p. 85$110,1994$.

DANIELS, J. D.; BRACKER, J. Profit performance: Do foreign operations make a difference? Management International Review, v. 29, n. 1, p. 46-56, 1989.

DAS, T. K.; TENG, B. S. Strategic risk behaviour and its temporalities: between risk propensity and decision context. Journal of Management Studies, v. 38, n. 4, p. 515-534, 2001.

DASKALAKIS, S.; MANTAS, J. Evaluating the impact of a service-oriented framework for healthcare interoperability. In: ANDERSON, S. K.; KLEIN, G. O.; SCHULZ, S.; ARTS, J.; MUSSOLINI, M. C. (Eds.). Health beyond the horizon - get IT there: Proceedings of MIE2008 (Studies in Health Technology and Informatics). Amsterdam, Netherlands: IOS Press, 2008, p. 285-290.

DATTA, D. K.; RAJAGOPALAN, N. Industry structure and CEO characteristics: An empirical study of succession events. Strategic Management Journal, v. 19, p. 833-852, 1998.

DAVIDSSON, P.; HONIG, B. The role of social and human capital among nascent entrepreneurs. Journal of Business Venturing, v. 8, 3, p. 301-331, 2003.

DE CAROLIS, D. M; LITZKY, B. E.; EDDLESTON K. A. Why networks enhance the progress of new venture creation: The influence of social capital and cognition. Entrepreneurship: Theory and Practice, v. 33, n. 2, p. 527-545, 2009.

.; SAPARITO, P. Social capital, cognition, and entrepreneurial opportunities: A theoretical framework. Entrepreneurship: Theory and Practice, v. 30, n. 1, p. 41-56, 2006.

DE CHIARA, A.; MINGUZZI, A. Success factors in SMEs' internationalization processes: An Italian investigation. Journal of Small Business Management, v. 40, n. 2, p. 144-153, 2002. 
DENIS, J. E.; DEPELTEAU, D. Market knowledge, diversification and export expansion. Journal of International Business Studies, v. 16, n. 3, p. 77-89, 1985.

DESS, G. G.; LUMPKIN, G. T. The Role of Entrepreneurial Orientation in Stimulating Effective Corporate Entrepreneurship. Academy of Management Executive, v. 19, n. 1, p. 147-156, 2005.

DEVERS, C. E. et al. Executive compensation: A multidisciplinary review of recent developments. Journal of Management, v. 33, p. 1016-1072, 2007.

DIAS, A. C. A. M.; CAPUTO, A. C.; MARQUES, P. H. M. Motivações e impactos da internacionalização de empresas: um estudo de múltiplos casos na indústria brasileira. Revista do BNDES, n. 38, p. 139-180, 2012.

DIB, L. A.; ROCHA, A.; SILVA, J. F. The internationalization process of Brazilian software firms and the born global phenomenon: Examining firm, network, and entrepreneur variables. Journal of International Entrepreneurship, v. 8, p. 233-253, 2010.

DICHTL, E. et al. The export-decision of small and medium-sized firms: A review. Management International Review, v. 24, n. 2, p. 49-60, 1984.

DIJKSTRA, T. K.; SCHERMELLEH-ENGEL, K. Consistent partial least squares for nonlinear structural equation models. Psychometrika, v. 79, n. 4, p. 585-604, 2014.

DILMAN, D. A.; SMYTH, J. D.; CHRISTIAN, L. M. Internet, phone, mail, and mixed-mode surveys: the tailored design method. New Jersey: Wiley, 2014.

DIMITRATOS, P.; PLAKOYIANNAKI, E.; PITSOULAKI, A. The Global Smaller Firm in International Entrepreneurship. International Business Review, v. 19, p. 589-606, 2010.

DODD, C. Export market orientation and performance: An analysis of Australian exporters. Proceedings of the ANZMAC 2005 Conference: Marketing in International and Cross-cultural Environments, Purchase, Freemantle, Western Australia, 2005.

DONG, H.-K. The Effects of Individual Risk Propensity on Volunteering. Nonprofit Management \& Leadership, v. 26, n. 1, p. 5-18, 2015.

DOUGLAS, E. J. Perceptions - looking at the world through entrepreneurial lenses. In: CARSRUD, A. L.; BRANNBACK, M. (Eds.). Understanding the Entrepreneurial Mind: Opening the Black Box. New York: Springer, 2009, p. 322.

DOUGLAS, M.; WILDAVSKY, A. Risk and culture. Berkeley: University of California Press, 1982. 
DUNEGAN, K. J.; DUCHON, D.; BARTON, S. L. Affect, risk and decision critically: replication and extension in a business setting. Organizational Behaviour and Human Decision Process, v. 53, n. 3, p. 335-351, 1992.

DUNNING, J. H. International Production and the Multinational Enterprise. London: Allen and Unwin, 1981. Towards an eclectic theory of international production: some empirical tests. Journal of international business studies, v. 11, n. 1, p. 9-31, 1980.

EISENHARDT, K. M. Making fast strategic decisions in high-velocity environments. Academy of Management Journal, v. 32, n. 3, p. 543-576, 1989. .; MARTIN, J. A. Dynamic capabilities: what are they? Strategic Management Journal, v. 21, n. 10-11, p. 1105-1121, 2000.

ELFRING, T.; HULSINK, W. Networks in Entrepreneurship: The Case of HighTechnology Firms. Small Business Economics, v. 21, n. 4, p. 409-422, 2003.

ELLIS, P.; PECOTICH, A. Social factors influencing export initiation in small and medium sized enterprises. Journal of Marketing Research, v. 38, n. 1, p. 119-130, 2001.

ENDERWICK, P.; AKOORIE, M. The Employment of Foreign Language Specialists and Export Success - The Case of New Zealand. International Marketing Review, v. 11, n. 4, p. 4-18, 1994.

ERIKSSON, K. et al. Experiential knowledge and cost in the internationalization process. Journal of International Business Studies, v. 28, p. 337-360, 1997.

ERIKSON, T. Entrepreneurial capital: The emerging ventures most important asset and competitive advantage. Journal of Business Venturing, v. 17, n. 3, p. 275-290, 2002.

ERRAMILLI, M. K. Influence of Some External and Internal Environmental Factors on Foreign Market Entry Mode Choice in Service Firms. Journal of Business Research, v. 25, p. 263-276, 1992.

ETEMAD, H. (Ed.). The process of internationalization in emerging SMEs and emerging economies. Cheltenham, UK; Northampton, MA, USA: Edward Elgar, 2013.

EVALD, M. R.; KLYVER, K.; CHRISTENSEN, P. R. The effect of human capital, social capital, and perceptual values on nascent entrepreneurs' export intentions. Journal of International Entrepreneurship, v. 9, n. 1, p. 1-19, 2011.

FAN, T.; PHAN, P. H. International new ventures: revisiting the influences behind the 'born-global' firm. Journal of International Business Studies, v. 38, n. 7, p. 1113-1131, 2007. 
FELÍCIO, A. J.; CALDEIRINHA, V. R.; RODRIGUES, R. Global mindset and the internationalization of small firms: The importance of the characteristics of entrepreneurs. International Entrepreneurship and Management Journal, v. 8 , n. 4, p. 467-485, 2012.

FELZENSZTEIN, C. et al. Networks, entrepreneurial orientation, and internationalization scope: evidence from Chilean small and medium enterprises. Journal of Small Business Management, v. 53, n. 1, p. 145-160, 2015.

FENG, L.; FRIIS, A.; NILSSON, J. Social Capital among Members in Grain Marketing Cooperatives of Different Sizes. Agribusiness, v. 32, n. 1, p. 113-126, 2016.

FERNÁNDEZ-ORTIZ, R.; LOMBARDO, G. F. Influence of the capacities of top management on the internationalization of SMEs. Entrepreneurship and Regional Development, v. 21, n. 2, p. 131-154, 2009.

; Managerial and learning skills in exporting SMEs. Cuadernos de Gestión, v. 5, n. 2, p. 75-94, 2005.

FERNHABER, S.; MCDOUGALL-COVIN, P. P.; SHEPHERD, D. A. International entrepreneurship: leveraging internal and external knowledge sources. Strategic Entrepreneurship Journal, v. 3, p. 297-320, 2009.

FILLIS, I. Small firm internationalization: an investigative survey and future research directions. Management Decision, v. 39, n. 9, p. 767-783, 2001.

FINKELSTEIN, S.; HAMBRICK, D. C. Strategic Leadership: Top Executives and their Effects on Organization. Minneapolis/St Paul: West Publishing Company, 1996.

.; Top Management Tenure and Organizational Outcomes: The

Moderating Role of Managerial Discretion. Administrative Science Quarterly, v. 35, n. 3 , p. $484-503,1990$.

FLAMHOLTZ, E., LACEY, J. Personnel management: Human capital theory and human resource accounting. Los Angeles: Institute of Industrial Relations, UCLA. 1981.

FLETCHER D. International entrepreneurship and small business. Entrepreneurship Reg., v. 4, n. 16, p. 289-305, 2004.

FLORIANI, D. E. O grau de internacionalização, as competências e o desempenho da PME brasileira. Tese de doutorado. Universidade de São Paulo, São Paulo, 2010.

FLORIANI, D. E.; FLEURY, M. T. O Efeito do Grau de Internacionalização nas Competências Internacionais e no Desempenho Financeiro da PME Brasileira. Revista de Administração Contemporânea, Rio de Janeiro, v. 16, n. 3, p. 438458, 2012. 
FORBES, D. P. Managerial determinants of decision speed in new ventures. Strategic Management, v. 26, n. 4, p. 355-366, 2005.

FORLANI, D.; MULLINS, J. W. Perceived risks and choices in entrepreneur's new venture decisions. Journal of Business Venturing, v. 14, n. 4, p. 305-322, 2000 .

.; PARTHASARATHY, M.; KEAVENEY, S. M. Managerial risk perceptions of international entry-mode strategies. International Marketing Review, v. 25, n. 3, p. 292-311, 2008.

FORNELL, C. G.; BOOKSTEIN, F. L. Two structural equation models: LISREL and PLS applied to consumer exit-voice theory. Journal of Marketing Research, v. 19, n. 4, p. 440-452, 1982.

.; LARCKER, D. F. Evaluating structural equation models with unobservable variables and measurement error. Journal of Marketing Research, v. 18, n. 1, p. 39-50, 1981.

FORNONI, M.; ARRIBAS, I.; VILA, J. E. Measurement of an individual entrepreneur's social capital: a multidimensional model. International Entrepreneurship and Management Journal, v. 7, p. 495-507, 2011.

FORSGREN, M. The concept of learning in the Uppsala internationalization process model: a critical review. International Business Review, n. 11, p. 257$277,2002$.

FORZA, C. Survey research in operations management: a process-based perspective. International Journal of Operations \& Production Management, v. 22, n. 2, p. 152-194, 2002.

FOSFURI, A.; TRIBÓ, J. Exploring the Determinants of Potential Absorptive Capacity and Its Impact on Innovation Performance. Omega, v. 36, n. 2, p. 173187, 2008.

FOSS, N. J.; LINDENBERG, S. Micro foundations for strategy: A goal-framing perspective on the drivers of value creation. Academy of Management Perspectives, v. 27, n. 2, p. 85-102, 2013.

FOURATI, H.; AFFES, H. Financial Constraints, Human and Social Capital, and Risk-Taking Attitude in the Foundation of New Firms. Strategic Change: Briefings in Entrepreneurial Finance, v. 20, n. 5-6, p. 219-232, 2011.

FOWLER, F. J. Survey Research Methods. 4 ed. Newbury Park, CA: Sage Publications, 2009.

FOX, J. Structural Equation Models Appendix to An $\mathbf{R}$ and S-PLUS Companion to Applied Regression. 2002. Disponível em: $<$ http://legacy.fordham.edu/economics/vinod/sim-eq-in-R.pdf $>$ Acesso em 10 set. 2016. 
FRANCIONI, B.; MUSSO, F.; CIOPPI, M. Decision-maker characteristics and international decisions for SMEs. Management Decision, v. 53, n, 10, p. 22262249, 2015.

FREEMAN, S.; EDWARDS, R.; SCHRODER, B. How Smaller Born-Global Firms Use Networks and Alliances to Overcome Constraints to Rapid Internationalization. Journal of International Marketing, v. 14, n. 3, p. 33-63, 2006.

.; HUTCHINGS, K.; CHETTY, S. Born-Globals and Culturally Proximate Markets. Management Internacional Review, v. 52, p. 425-460, 2012.

FREITAS, H.; OLIVEIRA, M.; SACOL, A. Z.; MOSCAROLA, J. O método de pesquisa survey. Revista de Administração. São Paulo, v. 35, n. 3, p. 105-112, 2000.

FRENCH, M. R. Export market orientation: Performance, timing, and extent of internationalization. D.B.A. Dissertation, Nova Southeastern University, Florida, United States, 2006.

FRISHAMMAR, J.; HORTE, S. A. The Role of Market Orientation and Entrepreneurial Orientation for New Product Development Performance in Manufacturing Firms. Technology Analysis and Strategic Management, v. 19, n. 6, p. 765-788, 2007.

FUCHS, C.; DIAMANTOPOULOS, A. Using single-item measures for construct measurement in management research. Conceptual issues and application guidelines. Die Betriebswirtschaft, v. 69, n. 2, p. 195-210, 2009.

FURMAN, N.; SHOOTER, W.; SCHUMANN, S. The roles of heuristics, avalanche forecast, and risk propensity in the decision making of backcountry skiers. Leisure Science, v. 32, n. 5, p. 453-469, 2010.

GAERARTZ, G. The effect of ownership on the organization structure of small firms. Administrative Science Quarterly, v. 29, p. 232-237, 1984.

GALAN, J. I.; GONZALEZ-BENITO, J. Distinctive determinant factors of Spanish foreign direct investment in Latin America. Journal of World Business, v. 41, p. 171-189, 2006.

GAO, S.; SUNG, M. C.; ZHANG, J. Risk management capability building in SMEs: A social capital perspective. International Small Business Journal, v. 31, n. 6, p. 677-700, 2011.

GARNIER, G. Comparative export behaviour of small Canadian firms in the printing and electrical industries. In: CZINKOTA, M. R.; TESAR, G. (Eds.). Export Management: An International Context. New York: Praeger, 1982, p. 113-131. 
GARSON, G. D. Partial Least Squares: regression and structural equation models. Asheboro, NC: Statistical Associates Publishing, 2016.

GATEWOOD, E.; SHAVER, K.; GARTNER, W. A longitudinal study of cognitive factors influencing start-up behaviours and success at venture creation. Journal of Business Venturing, v. 10, p. 371-391, 1995.

GELETKANYCZ, M. A.; HAMBRICK, D. C. The external ties of top executives: implications for strategic choice and performance. Administrative Science Quarterly, v. 42, p. 654-681, 1997.

GENCTURK, E., CHILDERS, T. L., RUEKERT, R. W. International marketing involvement: the construct, dimensionality, and measurement. Journal of International Marketing, v. 3, n. 4, p. 11-37, 1995.

GEORGE, G.; WIKLUND, J.; ZAHRA, S. A. Ownership and the internationalization of small firms. Journal of Management, v. 31, n. 2, p. 210 233, 2005.

GEPPERT, M. et al. Managerial Risk-taking in International Acquisitions in the Brewery Industry: Institutional and Ownership Influences Compared. British Journal of Management, v. 24, p. 316-332, 2013.

GERDNE, T. The Importance of Human Capital in Export Performance: A Study of the Swedish Municipalities. Master's Thesis within Economics, Jönköping University, 2005.

GERRANS, P.; FAFF, R.; HARTNETT, N. Individual financial risk tolerance and the global financial crisis. 2012. Disponível em: $<$ https://www.pwlcapital.com/pwl/media/pwl-media/PDF-

files/Clough\%20Assets/2012-05-04-Financial-Risk-Tolerance-Paper.pdf $>$. Acesso em: 10 set. 2016.

GEYSKENS, I., STEENKAMP, J. B. E. M.; KUMAR, N. Make, buy, or ally: a transaction cost theory meta analysis. Academic Management Journal, v. 49, n. 3, p. 519-543, 2006.

GIMENO, J. et al. Survival of the fittest? Entrepreneurial human capital and the persistence of underperforming firms. Administrative Science Quarterly, v. 42, n. 4, p. 750-783, 1997.

GOMES, L.; RAMASWAMY, K. An Empirical Examination of the Form of the Relationship between Multinationality and Performance. Journal of International Business Studies, v. 30, p. 173-187, 1999.

GOTTFREDSON, L. S. Forward to "Intelligence and social policy". Intelligence, v. 24, n. 1, p. 1-12, 1997.

GOXE, F. Human and social capital interplay among internationalizing SMEs. Journal of Knowledge-based Innovation in China, v. 2, n. 1, p. 73-88, 2010. 
GRADSTEIN, M.; JUSTMAN, M. The political economy of education human capital, social capital, and public schooling. European Economic Review, v. 44, n. 4-6, p. 879-890, 2000.

GRANOVETTER, M. Economic actions and social structure: The problem of embeddedness. American Journal of Sociology, v. 91, p. 481-510, 1985. 1360-1380, 1973. The strength of weak ties. American Journal of Sociology, v. 78, p. . The strength of weak ties. A network theory revisited. In: MARSDEN, P. W.; LIN, N. (Eds.). Social structure and network analysis. Beverly Hills: Sage Publications, p. 105-130. 1982.

GRANT, R. M.; JAMMINE, A. P.; THOMAS, H. 1988. Diversity, diversification and profitability among British manufacturing companies, 1972-1984. Academy of Management Journal, v. 31, p. 771-801, 1988.

GRAVES, C.; THOMAS, J. Determinants of the Internationalization Pathways of Family Firms: An Examination of Family Influence. Family Business Review, v. 21, n. 2, p. 51-167, 2008.

GRAY, B. J. Profiling managers to improve export promotion targeting. Journal of International Business Studies, v. 28, p. 387-420, 1997.

GRAY, S. R.; CANNELLA, A. A. The role of risk in executive compensation. Journal of Management, v. 23, p. 517-540, 1997.

GREENE, P. G.; BRUSH, C. G.; HART, M. M. From initial idea to unique advantage: the entrepreneurial challenge of constructing a resource base. Academy of Management Executive, v. 15, n. 1, p. 64-78, 2001.

GREGERSEN, H. B.; MORRISON A. J.; BLACK, J. S. Developing leaders for the global frontier. Sloan Management Review, v. 40, n. 1, p. 21-32, 1998.

GREVE, A. Networks and entrepreneurship - an analysis of social relations, occupational background, and use of contacts during the establishment process. Scandinavian Journal Management, v. 11, n. 1, p. 1-24, 1995.

GRIFFITH, D. A.; HARVEY, M. G. The influence of individual and firm level social capital of marketing managers in a firm's global network. Journal of World Business, v. 39, p. 244-254, 2004.

GUIMARÃES, E. P. Competitividade internacional e política comercial externa: a experiência brasileira no final dos anos 80 e início dos anos 90 . Rio de Janeiro: IE/UFRJ, 1996. (Série Documentos, 24).

GULATI, R.; NOHRIA, N.; ZAHEER, S. Strategic networks. Strategic Management Journal, v. 21, n. 3, p. 203-215, 2000.

; SINGH, H. The architecture of cooperation: managing coordination costs and appropriation concerns in strategic alliances. Administrative Science Quarterly, v. 43, n. 4, p. 781-814, 1998. 
GUPTA, A. K.; GOVINDARAJAN, V. Business unit strategy, managerial characteristics and business unit effectiveness at strategy implementation. Academy of Management Journal, v. 27, n. 1, p. 25-41, 1984.

.; SMITH, K. G.; SHALLEY, C. E. The interplay between exploration and exploitation. Academy of Management Journal, v. 49, n. 4, p. 693-706, 2006.

GUTHRIE, J. P.; OLIAN, J. D. Does context affect staffing decisions? The case of general managers. Personnel Psychology, v. 44, p. 263-92, 1991.

HAENLEIN, M.; KAPLAN, A. M. A beginner's guide to partial least squares analysis. Understanding Statistics, v. 3, n. 4, p. 283-297, 2004.

HAIR, J. F.; BABIN, B.; MONEY, A. H.; SOMOUEL, P. Essentials of business research methods. New Jersey: John Wiley \& Sons, 2003.

.; BLACK, W. C.; BABIN, B. J.; ANDERSON, R. E. Multivariate data analysis. 7 ed. Upper Saddle River, N.J.: Pearson, 2010.

.; HULT, G. TOMAS M.; RINGLE, CHRISTIAN M.; SARSTEDT, MARKO. A primer on partial least squares structural equation modeling (PLS-SEM). Thousand Oaks, CA: Sage Publications, 2014.

.; RINGLE, C. M.; SARSTEDT, M. Partial least squares structural equation modeling: Rigorous applications, better results, and higher acceptance. Long Range Planning, v. 46, n. 1/2, p. 1-12, 2013.

PLS-SEM: Indeed a silver bullet. Journal of Marketing Theory and Practice, v. 19, n. 2, p. 139-152, 2011.

.; SARSTEDT, M.; RINGLE, C. M.; MENA, J. A. An assessment of the use of partial least squares structural equation modeling in marketing research. The Journal of the Academy of Marketing Science, v. 40, p. 414-433, 2012.

HAIR, J. R. et al. Essentials of business research methods. New Jersey: John Wiley \& Sons, Inc, 2003.

HAKANSSON, H.; SNEHOTA, I. Developing relationships in business networks. London: Routledge, 1995.

HALIKIAS, J.; PANAYOTOPOULOU, L. Chief executive personality and export involvement. Management Decision, v. 41, n. 4, p. 340-349, 2003.

HALLEN, L. Infrastructural Networks in International Business. In: FORSGREN, M.; JOHANSON, J. A. (Eds.). Managing Networks in International Business. Philadelphia: Gordon and Breach, 1992, p. 77-92.

HAMBRICK, D. C., FINKELSTEIN, S. MOONEY A. C. Executive job demands: New insights for explaining strategic decisions and leader behaviours. Academy of Management Review, v. 30, n. 3, p. 472-491, 2005.

HAMBRICK, D. C.; FUKUTOMI, G. D. S. The seasons of a CEO tenure. Academy of Management Review, v. 16, n. 4, p. 719-742, 1991.

.; MASON, P. A. Upper echelons: The organization as a reflection of its top managers. Academy of Management Review, v. 9, p. 193-206, 1984. 
HAMID, F. S.; RANGEL, G. J.; TAIB, F. M.; THURASAMY, R. The relationship between risk propensity, risk perception and risk-taking behaviour in an emerging Market. International Journal of Banking and Finance, v. 10, n. 1, p. 1-14, 2013.

HARRIS, S.; WHEELER, C. Entrepreneurs' relationships for internationalization: functions, origins and strategies. International business review, v. 14, n. 2, p. 187-207, 2005.

HARVESTON, P. D.; KEDIA, B. L.; DAVIS, P. S. Internationalization of born global and gradual globalizing firms: The impact of the manager. Advances in Competitiveness Research, v. 8, n. 1, p. 92-99, 2000.

HASTIE, R. Problems for judgment and decision making. Annual Review of Psychology, v. 52, p. 653-683, 2001.

HEATH, C.; TVERSKY, A. Preference and belief: Ambiguity and competence in choice under uncertainty. Journal of Risk and Uncertainty, v. 4, n. 1, p. 5-28, 1991.

HENNART, J.-F. The Accidental Internationalists: A Theory of Born Globals. Entrepreneurship: Theory and Practice, v. 38, n. 1, p. 117-135, jan. 2014.

HENSELER, J.; HUBONA, G.; RAY, P. A. Using PLS path modeling in new technology research: updated guidelines. Industrial Management \& Data Systems, v. 116, n. 1, p. 2-20, 2016.

.; RINGLE, C. M.; SARSTEDT, M. Using partial least squares path modeling in international advertising research: Basic concepts and recent issues. In: OKZAKI, S. (Ed.). Handbook of partial least squares: Concepts, methods and applications in marketing and related fields. Berlin: Springer, p. 252-276. 2012.

HESSELS, J.; TERJESEN, S. Entrepreneurial Career Capital, Innovation and New Venture Export Orientation. Scientific Analysis of Entrepreneurship and SMEs. Netherlands Ministry of Economic Affairs, 2008.

HILL, J.; NANCARROW, C.; WRIGHT, L. T. Lifecycles and crisis points in SMEs: a case approach. Marketing Intelligence \& Planning, v. 20, n. 6, p. 361369, 2002.

HILLSON, D.; MURRAY-WEBSTER, R. Understanding and Managing Risk Attitude. Hampshire: Lucidus Consulting, 2004.

HILMERSSON. M. Small and medium-sized enterprise internationalization strategy and performance in times of market turbulence. International Small Business Journal, v. 32, n. 4, p. 386-400, 2014.

.; JOHANSON, M. Speed of SME Internationalization and Performance. Management International Review, v. 56, n. 1, p. 67-94, 2016. 
HINKIN, R. T. A brief tutorial on the development of measures for use in survey questionnaires. Organizational Research Methods, v. 1, n. 1, p. 104-121, 1998.

HITE, J. M.; HESTERLY, W. The evolution of firm networks: From emergence to early growth of the firm. Strategic Management Journal, v. 22, p. 275-287, 2001.

HITT, M. A.; HOSKISSON, R. E.; KIM, H. International diversification: effects on innovation and firm performance in product-diversified firms. Academic Management Journal, v. 40, n. 4, p. 767-98, 1997. et al. Strategic entrepreneurship: Entrepreneurial strategies for wealth creation. Strategic Management Journal, v. 22, p. 479-491, 2001.

HOANG, H.; ANTONCIC, B. Network-based research in entrepreneurship: a critical review. Journal of Business Venturing, v. 18, n. 2, p. 165-187, 2003.

HÖCK, M.; RINGLE, C. M. Strategic networks in the software industry: An empirical analysis of the value continuum. IFSAM VIIIth World Congress, Berlin, 2006.

HOFSTEDE, G. Culture's Consequences: International Differences in WorkRelated Values. London: Sage, 1980.

HOLLENSTEIN, H. Determinants of International Activities: Are SMEs Different? Small Business Economics, v. 24, p. 431-450, 2005.

HOLMUND, M.; KOCK, S. Relationships and the internationalization of Finnish small and medium-sized companies. International Small Business Journal, v. 16, n. 4, p. 46-64, 1998.

HOLZMÜLLER, H. H.; STÖTTINGER, B. Structural Modeling of Success Factors in Exporting: Cross-Validation and Further Development of an Export Performance Model. Journal of International Marketing, v. 4, n. 2, p. 29-55, 1996.

HONIG, B.; DAVIDSSON, P. The role of social and human capital among nascent entrepreneurs. Academy of Management Proceedings \& Membership Directory, B 1-6, p. 1-6, 2000.

HSIEH, L. H. Y.; RODRIGUES, S. B.; CHILD, J. Risk perception and postformation governance in international joint ventures in Taiwan: The perspective of the foreign partner. Journal of International Management, v. 16, p. 288-303, 2010 .

HSU, C.-C.; BOGGS, D. J. Internationalization and Performance: Traditional Measures and Their Decomposition. Multinational Business Review, v. 11, n. 3, p. 23-50, 2003. 
HSU, W. T.; CHEN, L. C.; CHENG, C. Y. Internationalization and firm performance of SMEs The moderating effects of CEO attributes. Journal of World Business, v. 48. p. 1-12, 2013.

HUFF, R. A. et al. Validation of the Sitkin-Weingart business risk propensity scale. Management Research News, v. 20, n. 12, p. 39-48, 1997.

HUNG, K.-T.; TANGPONG, C.; LI, J.; LI, Y. Robustness of General Risk Propensity Scale in Cross-cultural Settings. Journal of Managerial Issues, Vv. 24, n. 1, p. 78-96, 2012.

HUTCHINSON, K.; QUINN, B.; ALEXANDER, N. SME retailer internationalization: case study evidence from British retailers. International Marketing Review, v. 23, n. 1, p. 25-53, 2006.

IEDERAN, O. C.; CURŞEU, P. L.; VERMEULEN, P. Effective decision-making: The role of cognitive complexity in strategic decisions. Studia Psychologica, v. 51, n. 4, p. 293-304, 2009.

INKPEN, A. C.; TSANG, E. W. K. Social capital, networks, and knowledge transfer. Academy of Management Review, v. 30, n. 1, p. 146-65, 2005.

IRELAND, R. D.; HITT, M. A.; SIRMON, D. G. A model of strategic entrepreneurship: The construct and its dimensions. Journal of Management, v. 29, p. 963-989, 2003.

.; VAIDYANATH, D. Alliance management competitive advantage. Journal of Management, v. 28, p. 413-446, 2002.

.; HOSKISSON, R. E.; HITT, M. A. Administração estratégica. 10. ed. São Paulo: Cengage Learning, 2014.

ISMAIL, M. D. Building SMEs Competitive Advantage in Export Markets: The Role of Human Capital and Relationship Quality. Jurnal Pengurusan, v. 40, p. 3-13, 2014.

JACKMAN, R. W.; MILLER, R. A. Social capital and politics. Annual Review of Political Science, v. 1, p. 47-73, 1998.

JAFFE, D. E.; NEBENZAHL, I. D.; PASTERNAK, H. The export behaviour of small and medium-sized Israeli manufacturers. Journal of Global Marketing, v. 2, n. 2, p. 27-49, 1988.

; PASTERNAK, H. An attitudinal model to determine the export intention of non-exporting, small manufacturers. International Marketing Review, v. 11, n. 3, p. 17-32, 1994.

JAKOBOWICZ, E.; DERQUENNE, C. A modified PLS path modeling algorithm handling reflective categorical variables and a new model building strategy. Computational Statistics \& Data Analysis, v. 51, n. 8, 3666-3678, 2007.

JANES, J. Survey construction. Library Hi Tech, v. 17, n. 3, p. 321-325, 1999. 
JANNEY, J. J.; DESS, G. D. The risk concept for entrepreneurs reconsidered: New challenges to the conventional wisdom. Journal of Business Venturing, v. 21, n. 3, p. 385-400, 2006.

JANSEN, R. J. G et al. Information processing and strategic decision-making in small and medium-sized enterprises: The role of human and social capital in attaining decision effectiveness. International Small Business Journal, v. 31, n. 2, p. 1-25, 2011.

JAVALGI, R.; DISIT, A., SCHERER, R. F. Outsourcing to emerging markets: theoretical perspectives and policy implications. Journal of International Management, v. 15, p. 156-168, 2009.

.; TODD, P. Entrepreneurial orientation, management commitment, and human capital: the internationalization of SMEs in India. Journal of Business Research, v. 64, n. 9, p. 1004-1010, 2011.

JAWORSKI, B. J.; KOHLI, A. K. Market orientation: antecedents and consequences. Journal of Marketing, v. 57, p. 53-70, 1993.

JIMÉNEZ BURILLO, S.; JIMÉNEZ MORENO, J. J. The Role of the Top Management Team in the Choice of Entry Modes - Theoretical Perspective. Entrepreneurial Business and Economics Review, v. 1, n. 2, p. 51-58, 2013.

JOCUMSEN, G. How do small business managers make strategic marketing decisions? A model of process. European Journal of Marketing, v. 38, n. 5/6, p. 659-674, 2004.

JOHANSON, J.; MATTSSON, L.-G. Internationalization in Industrial Systems: A Network Approach. In: BUCKLEY, P.J.; GHAURI, P. (eds.). The Internationalization of the Firm: a Reader. London: Academic Press, 1988, p. 303-321.

;) VAHLNE, J.-E. Commitment and opportunity development in the internationalization process: a note on the Uppsala internationalization process model. Management International Review, v. 46, n. 2, p. 165-178, 2006.

.; $\quad$. The internationalization process of the firm - a model of knowledge development and increasing foreign market commitments. Journal of International Business Studies, v. 8, n. 1, p. 23-32, 1977.

.; The mechanism of internationalisation. Marketing International Review, v. 7, n. 4, p. 11-23, 1990. The Uppsala internationalization process model revisited: from liability of foreignness to liability of outsidership. Journal of International Business Studies, v. 40, n. 9, p. 1411-1431, 2009.

; . The Uppsala model on evolution of the multinational business enterprise - from internalization to coordination of networks. International Marketing Review, v. 30, n. 3, p. 189-210, 2013.

.; WIEDERSHEIM-PAUL, F. The internationalization of the firm: four $\overline{\text { Swedish }}$ cases. Journal of Management Studies, v. 12, p. 305-322, 1975.

JONES, G. R.; HILL, C. W. L. Transaction Cost Analysis of Strategy-structure Choice. Strategic Management Journal, v. 9, p. 159-172, 1988. 
JONES, M. V. First steps in internationalisation: concepts and evidence from a sample of small high technology firms. Journal of International Management, v. 7, n. 3, p. 191-210, 2001.

$\therefore$ COVIELO, N. E. Internationalisation. Conceptualising an Entrepreneurial Process of Behaviour in Time. Journal of International Business Studies, v. 36, n. 3, p. 284-303, maio 2005.

.; TANG, Y. K. International Entrepreneurship research (19892009): A domain ontology and thematic analysis. Journal of Business Venturing, v. 26, p. 632-659, 2011.

JOYNT, P.; WELCH, L. A strategy for small business internationalization. International Marketing Review, v. 2, p. 64-73, 1985.

KAFOUROS, M. I.; BUCKLEY, P. J.; CLEGG, J. The effects of global knowledge reservoirs on the productivity of multinational enterprises: The role of international depth and breadth. Research Policy, v. 41, p. 848-861, 2012.

KAHNEMAN, D.; TVERSKY, A. Prospect theory: an analysis of decision under risk. Econometrica, v. 47, p. 263-293, 1979.

KALE, P.; SINGH, H.; PERLMUTTER, H. Learning and protection of proprietary assets in strategic alliances: Building relational capital. Strategic Management Journal, v. 21, p. 217-237, 2000.

KAPTEYN, A.; TEPPA, F. Subjective Measures of Risk Aversion Fixed Costs and Portfolio Choice. Tilburg: Tilburg University, 2002.

KARAGOZOGLU, N.; LINDELL, M. Internationalisation of small and mediumsized technology-based firms: an exploratory study', Journal of Small Business Management, vol. 36, no. 1. 1998.

KARAMI, A. An exploration of the chief executive officers' (CEOs) perception of strategic management process: The case of British high-tech SMEs. Journal of Corporate Ownership and Control, v. 24, p. 62-70, 2005.

KATSIKEAS, C. S.; LEONIDOU, L. C.; MORGAN, N. A. Firm-level export performance assessment: review, evaluation, and development. Journal of the Academy of Marketing Science, v. 28, n. 4, p. 493-511, 2000a.

KATSIKEAS, C. S.; LEONIDOU, L. C.; MORGAN, N. A. Development. Journal of the Academy of Marketing Science, v. 28, n. 4, p. 493-511, 2000 b.

KEDIA, B. L.; MUKHERJI, A. Global managers: developing a mindset for global competitiveness. Journal of World Business, v. 34, n. 3, p. 230-251, 1999.

KEH, H. T., FOO, M. D., LIM B. C. Opportunity evaluation under risky conditions: the cognitive process of entrepreneurs. Entrepreneurship: Theory and Practice, v. 27, n. 2, p. 125-148, 2002. 
KEIL, M. et al. An investigation of risk perception and risk propensity on the decision to continue a software development Project. The Journal of Systems and Software, v. 53, n. 2, p. 145-157, 2000.

KEMPER, J.; ENGELEN, A.; BRETTEL, M. How Top Management's Social Capital Fosters the Development of Specialized Marketing Capabilities: A CrossCultural Comparison. Journal of International Marketing, v. 19, n. 3, p. 87$112,2011$.

KEUPP, M. M.; GASSMANN, O. The past and the future of international entrepreneurship: A review and suggestions for developing the field. Journal of Management, v. 35, n. 3, p. 600-633, 2009.

KIKER, B. F. The concept of human capital in the history of economic thought. Tese. Tulane University, 1965.

KOR, Y. Y.; SUNDARAMURTHY, C. Experience-based human capital and social capital of outside directors. Journal of Management, v. 35, n. 4, p. 9811006, 2009.

KIN, I. Toward a contingency framework of export entrepreneurship: conceptualizations and empirical evidence. Small Business Economics, v. 20, p. 49-68, 2003.

; YOUNG, S. Exporting as an entrepreneurial act an empirical study of Nigerian firms. European Journal Marketing, v. 35, n. 5/6, p. 566-586, 2001.

KIM, W. C.; HWANG, P.; BURGERS, W. P. Global diversification strategy and corporate profit performance. Strategic Management Journal, v. 10, n. 1, p. 4557, 1989.

KISS, A. N.; DANIS, W. M.; CAVUSGIL, S. T. International entrepreneurship research in emerging economies: A critical review and research agenda. Journal of Business Venturing, v. 27, p. 266-290, 2012.

KLYVER, K.; CHRISTENSEN, P. R. Exporting entrepreneurs: do they activate their social network in different ways than domestic entrepreneurs? International Journal of Entrepreneurship and Small Business, v. 2, n. 2, p.185-204, 2007.

KNIGHT, G. Entrepreneurship, and marketing strategy: The SME under globalization. Journal of International Marketing, v. 8, n. 2, p. 12-32, 2000. .; International services marketing: Review of research, 1980-1998. Journal of Services Marketing, v. 13, n. 4/5, p. 347-361, 1999.

.; CAVUSGIL, S. T. Innovation organizational capabilities and the bornglobal firm. Journal of International Business Studies, v. 35, n. 2, p. 124-141, 2004.

; $\quad$ The born global firm: A challenge to traditional internationalization theory. In: C. R. TAYLOR, C. R. (Ed.). Advances of international marketing. New York: JAI Press, 1996, p. 11-26.

.; LEISCH, P. W. Information internalization in internationalizing the firm. Journal of Business Research, v. 55, n. 12, p. 981-995, 2002. 
KNOWLES, D.; MUGHAN, T; LLOYD-REASON, L. Foreign language use among decision-makers of successfully internationalized SMEs Questioning the language-training paradigm. Journal of Small Business and Enterprise Development, v. 13, n. 4, p. 620-641, 2006.

KOCHHAR, R., HITT, M. A. Toward an Integrative Model of International Diversification. Journal of International Management, v. 1, n. 1, p. 33-72, 1995.

KOGUT, B. Designing global strategies: Comparative and Competitive Value Chains. Sloan Management Review, v. 27, n. 4, p. 15-28, 1985a.

Designing global strategies: Profiting from operational flexibility. Sloan Management Review, v. 26, p. 27-38, 1985b.

. The Effect of National Culture on the Choice of Entry Mode. Journal of International Business Studies, v. 19, p. 411-432, 1988.

KOHLI A. K.; JAWORSKI, B. J. Market orientation: the construct, research propositions, and managerial implications. The Journal of Marketing, v. 54, n. 2, p. 1-18, 1990.

KOHN, T. O. Small firms as international players. Small Business Economics, v. 9, p. 45-51, 1997.

KOKA, B. R.; PRESCOTT, J. E. Strategic alliances as social capital: A multidimensional view. Strategic Management Journal, v. 23, p. 795-816, 2002.

KOLLMANN, T.; CHRISTOFOR, J. International entrepreneurship in the network economy: Internationalization propensity and the role of entrepreneurial orientation. Journal of International Entrepreneurship, v. 12, p. 43-66, 2014.

KONTINEN, T.; OJALA, A. The Internationalization of Family Businesses: A Review of Extant Research. Journal of Family Business Strategy, v. 1, n. 2, p. 97-107, 2010.

KOR, Y. Y.; LEBLEBICI, H. How do interdependencies among human-capital deployment, development, and diversification strategies affect firms' financial performance? Strategic Management Journal, v. 26, p. 967-985, 2005.

KORSAKIEN, R.; DISKIEN, D.; DRUTEIKIEN, G. The role of human capital and organizational learning in internationalization of smes Business and Management. Enterprise Management, Vilnius Gediminas Technical University, 2014.

KOSTOVA, T.; ROTH, K. Social capital in multinational corporations and a micro-macro model of its formation. Academy of Management Review, v. 28, n. 2, p. 297-317, 2003. 
KROPP, F.; LINDSAY, N. S.; SHOHAM, A. Entrepreneurial, market, and learning orientations and international entrepreneurial business venture performance in South African firms. International Marketing Review, v. 23, n. 5, p. 504-523, 2006.

KRUEGER, N. The cognitive infrastructure of opportunity emergence. Entrepreneurship: Theory and Practice, v. 24, n. 3, p. 5-23, 2000.

.; DICKSON P. R. How believing in ourselves increases risk taking: Perceived self-efficacy and opportunity recognition. Decision Sciences, v. 25, n. 3, p. 385-400, 1994.

KUIVALAINEN, O. et al. The effect of environmental turbulence and leader characteristics on international performance: are knowledge- based firms different? Canadian Journal of Administrative Sciences, v. 21, n. 1, p. 35-50, 2004.

.; SUNDQVIST, S.; SERVAIS, P. Firms' degree of born-globalness, international entrepreneurial orientation and export performance. Journal of World Business, v. 42, n. 3, p. 253-67, 2007.

KUMAR, V.; SUBRAMANIAM, V. A contingency framework for the mode of entry decision. Journal of World Business, v. 32, n. 1, p. 53-72, 1997.

KUNDU S. K.; KATZ J. A. Born-international SMEs: BI-level impacts of resources and intentions. Small Business Economics, v. 20, n. 1, p. 25-47, 2003.

KWON, Y. C.; KONOPA, L. J. Impact of host country market characteristics on the choice of foreign market entry mode. International Marketing Review, v. 10, p. 60-73, 1993.

.; HU, M. Y. Market orientation among small Korean exporters. International Business Review, v. 9, n. 1, p. 61-75, 2000.

LAGES, L. F.; MONTGOMERY, D. B. Export performance as an antecedent of export commitment and marketing strategy adaptation: Evidence from small and medium-sized exporters. European Journal of Marketing, v. 38, n. 9/10, p. 1186-1214, 2004.

.; $\quad$ The relationship between export assistance and performance improvement in Portuguese export ventures: An empirical test of the mediating role of pricing strategy adaptation. European Journal of Marketing, v. 39, n. 7/8, p. 755-784, 2005.

LAMOTTE, O.; COLOVIC, A. Early Internationalization Of New Ventures From Emerging Countries: The Case of Transition Economies. M@n@gement, v. 18, n. 1, p. 8-30, 2015.

LANDRY, R.; AMARA, N.; LAMARI, M. Does social capital determine innovation? To what extent? Technological forecasting and social change, $\mathrm{v}$. 69, n. 7, p. 681-701, 2002. 
LANZARA, R. Strategic differentiation and adaptation among small and mediumsized Italian exporting manufacturers. In: ROSSON, P. J.; REID, S. D. (Eds.). Managing Export Entry and Expansion. New York: Praeger, 1987, p. 41-53.

LEE, M. D.; DRY, M. J. Decision making and confidence given uncertain advice. Cognitive Science, v. 30, n. 6, p. 1081-1095, 2006.

LEITE. Y. V. P.; MORAES, W. F. A. Facetas do Risco no Empreendedorismo Internacional. Revista de Administração Contemporânea, Rio de Janeiro, v. 18, n. 1, p. 96-117, jan./fev. 2014.

LEONIDOU, L. C. Organizational determinants of exporting: conceptual, methodological, and empirical insights. Management International Review, $\mathrm{n}$. 1, p. 7-52, special issue, 1998.

.; KATSIKEAS, C. S. The export development process: na integrative review of empirical models. Journal of International Business Studies, v. 27, n. 3, p. 517-551, 1996.

.; __ . et al. An analytical review of the factors stimulating smaller firms to export: Implications for policy-makers. International Marketing Review, v. 24, n. 6, p. 735-770, 2007.

; PIERCY, N. F. Identifying managerial influences on exporting: past research and future directions. Journal of International Marketing, v. 6, n. 2, p. 74-102, 1998.

; SAMIEE, S. Marketing strategy determinants of export performance: a meta-analysis. Journal of Business Research, v. 55, n. 1, p. 5167, 2002.

LEPAK, D. P.; SNELL, S. A. The Human Resource Architecture: Toward a Theory of Human Capital Allocation and Development. The Academy of Management Review, v. 24, n. 1, p. 31-48, 1999.

LESSARD, D. R. Country risk and the structure of international financial intermediation. In: STONE, C. C. (Ed.). Financial risk: Theory, evidence and implications. Boston, Mass.: Kluwer Academic Publishers, 1988, p. 197-233.

LEVITT, B.; MARCH, J. G. Organizational learning. Annual Review of Sociology, v. 14, p. 319-340, 1988.

LEVY, O.; PEIPERL, M.; BOUQUET, C. Transnational social capital: a conceptualization and research instrument. International Journal of Cross Cultural Management, v. 13, n. 3, p. 319-338, 2013.

LI, L.; LI, D.; DALGIC, T. Internationalization process of small and mediumsized enterprises: toward a hybrid model of experiential learning and planning. Management International Review, v. 44, n. 1, p. 93-117, 2004.

.; QIAN, G.; QIAN, Z. Early internationalization and performance of small hightech "born-globals". International Marketing Review, v. 29, n. 5, p. 536-561, 2012. 
.; __ . S . Speed of internationalization: mutual effects of individual- and company level antecedents. Global Strategy Journal, v. 5, n. 4, p. 303-320, 2015.

LI, Y.; WANG, X.; HUANG, L.; BAI, X. How does entrepreneurs' social capital hinder newbusiness development? A relational embeddedness perspective. Journal of Business Research, v. 66, p. 2418-2424, 2013.

LICHTENSTEIN, S.; FISCHOFF, B. Do those who know more also know more about how much they know? Organizational Behaviour and Human Performance, v. 20, p. 159-183, 1977.

LIESCH, P. W.; KNIGHT, G. A. Information internalization and hurdle rates in small and medium enterprise internationalization. Journal of International Business Studies, v. 30, n. 2, p. 383-394, 1999.

; WELCH, L. S.; BUCKLEY, P. J. Risk and uncertainty in internationalization and international entrepreneurship studies. Management International Review, v. 51, n. 6, p. 851-873, 2011.

LIN, N. Building a network theory of social capital. Connections, v. 22, n. 1, p. 28-51. 1999.

Social Capital: A Theory of Social Structure and Action. Cambridge: Cambridge University Press, 2001.

LINDMARK, L et al. Småföretagens internationalisering - en jämförende studie. Nord REFO, v. 7, p. 26-40, 1994.

LINGHUI, T.; KOVEOS, P. E. A Framework to Update Hofstede's Cultural Value Indices: Economic Dynamics and Institutional Stability. Journal of International Business Studies, v. 39, n. 6, p. 1045-1063, 2008.

LLOYD-REASON, L.; MUGHAN, T. Strategies for internationalization within SMEs: the key role of the owner-manager. Journal of Small Business, v. 9, n. 2, p. 120-129, 2002.

LOHMÖLLER, J.-B. Latent variable path modeling with partial least squares. Heidelberg: Physica-Verlag, 1989.

LOPEZ, F. D. Perspectivas teóricas contemporâneas nos estudos das organizações: apresentação de um modelo de análise da formação de joint ventures internacionais. Cadernos EBAPE.BR, v. 2, n. 3, p. 1-21, 2004.

LÓPEZ-DUARTE, C.; VIDAL-SUÁREZ, M. M. External uncertainty and entry mode choice: Cultural distance, political risk and language diversity. International Business Review, v. 19, p. 575-588, 2010.

LOW, A. Managerial risk-taking behavior and equity-based compensation. Journal of Financial Economics, v. 92, p. 470-490, 2009. 
LOW, S. A.; WEILER, S. Employment Risk, Returns, and Entrepreneurship. Economic Development Quarterly, v. 26, n. 3, p. 238-251, 2012.

LUMPKIN, G. T.; DESS, G. G. Clarifying the entrepreneurial orientation construct and linking it to performance. Academy of Management, v. 21, n. 1, p. 135-172, 1996.

MACADAR, B. M. A internacionalização de grandes empresas brasileiras e as experiências do Grupo Gerdau e da Marcopolo. Ensaios FEE, Porto Alegre, v. 30, n. 1, p. 7-34, 2009.

MACKINNON, D. P.; DWYER, J. H. Estimating mediating effects in prevention studies. Evaluation Review, v. 17, p. 144-158, 1993.

;; LOCKWOOD, C. M. et al. A comparison of methods to test the significance of mediation and other intervening variable effects. Psychological Methods, v. 7, p. 83-104, 2002.

.; __ WILLIAMS, J. Confidence limits for the indirect effect:

Distribution of the product and resampling methods. Multivariate Behavioral Research, v. 39, p. 99-128, 2004. ; WARSI, G.; DWYER, J. H. A simulation study of mediated effect measures. Multivariate Behavioral Research, v. 30, p. 41-62, 1995.

MADSEN, T. K.; SERVAIS, P. The internationalization of born globals: an evolutionary process? International Business Review, v. 6, n. 6, p. 561-583, 1997.

MACCRIMMON, K. R.; WEHRUNG, D. A. Characteristics of risk taking executives. Management Science, v. 36, n. 4, p. 442-435, 1990.

The Free Press, 1986.

Taking Risks: The Management of Uncertainty. New York:

367-387, 1986. . The risk in-basket. The Journal of Business, v. 57, n. 3, p.

MAKRINI, H. How does management perceive export success? An empirical study of Moroccan SMEs. Business Process Management Journal, v. 21, n. 1, p. 126-151, 2015.

MALHOTRA, N. K. Marketing research: an applied orientation. 6 ed. Upper Saddle River, NJ: Prentice Hall, 2010.

MANOLOVA, T. S. et al. Internationalization of Small Firms Personal Factors Revisited. International Small Business Journal, v. 20, n. 1, p. 9-31, 2002.

et al The differential effect of men and women entrepreneurs' human capital and networking on growth expectancies in Bulgaria. Entrepreneurship Theory and Practice, v. 31, n. 3, p. 407-426, 2007.

MARCH, J. G.; SHAPIRA, Z. Managerial perspectives on risk and risk taking. Management Science, v. 33, n. 11, p. 1404-1418, 1987.

MARCH, J. G.; SHAPIRA, Z. Variable risk preferences and the focus of attention. Psychological Review, v. 99, n. 1, p. 172-83, 1992. 
MARCOULIDES, G. A.; SAUNDERS, C. Editor's Comments - PLS: A Silver Bullet? MIS Quarterly, v. 30, n. 2, p. iii-ix, 2006.

MARIOTTI, S.; PISCITELLO, L. Localized capabilities and the internationalization of manufacturing activities by SMEs. Entrepreneurship \& Regional Development, v. 13, p. 65-80, 2001.

MAROCO, J. Análise de equações estruturais: fundamentos teóricos, software e aplicações. 2. ed. Porto: Report Number, 2014.

MARTINS, G. A.; THEÓPHILO, C. R. Metodologia da investigação científica para ciências sociais aplicadas. 2. ed. São Paulo: Atlas, 2009.

MATHEWS, J. A. Dragon multinationals: New players in 21st century globalization. Asia Pacific. Journal of Management, v. 23, p. 5-27, 2006.

MAUREL, C. Determinants of export performance in French wine SMEs. International Journal of Wine Business Research, v. 21, n. 2 p. 118-142, 2009.

MCDOUGALL, P. P. et al. The effects of industry growth and strategic breadth on new venture performance and strategy content. Strategic Management Journal, v. 15, n. 7, p. 537-554, 1994.

.; OVIATT, B. M. International entrepreneurship: the intersection of two research paths. Academy of Management Journal, v. 43, n. 5, p. 902-906, 2000. ; _ _ SCHRADER, R. C. A comparison of international and domestic new ventures. Journal of International Entrepeneurship, v. 1, n. 1, p. 59-82, 2003.

.; SHANE, S.; OVIATT, B. M. Explaining the formation of international new ventures: the limits of international business research. Journal of Business Venturing, v. 9, n. 6, p. 469-487, 1994.

MCEVILY, B.; ZAHEER, A. Bridging ties: A source of firm heterogeneity in competitive capabilities. Strategic Management Journal, v. 20, p. 1133-1156, 1999.

MCGRATH, R. G. et al. Does culture endure, or is it malleable? Issues for entrepreneurial development. Journal of Business Venturing, v. 7, p. 441-458, 1992.

MCNAUGHTON, R. The number of export markets that a firm serves: Process models versus the born-global phenomenon. Journal of International Entrepreneurship, v. 1, n. 3, p. 297-311, 2003.

MELIÁ, M. R.; PÉREZ, A. B.; DOBÓN, S. R. The influence of innovation orientation on the internationalization of SMEs in the service sector. The Service Industries Journal, v. 30, n. 5, p. 777-791, 2010.

MIESENBOCK, K. J. Small business and exporting: a literature review. International Small Business Journal, v. 6, n. 2, p. 42-61, 1988. 
MIGUEL, P. A. C. (Coord). Metodologia de pesquisa em engenharia de produção e gestão de operações. Rio de Janeiro: Elsevier, 2010.

MILLER, D.; TOULOUSE, J. M. Chief executive personality and corporate strategy and structure in small firms. Management Science, v. 32, n. 11, p. 13891409, 1986.

MILLER, K. D. A Framework for Integrated Risk Management in International Business. Journal of International Business Studies, v. 23, n. 2, p. 311-331, 1992.

.; LEIBLEIN, M. J. Corporate risk-return relations: returns variability versus downside risk. Academy of Management Journal, v. 39, n. 1, p. 91-122, 1996.

.; REUER, J. J. Measuring organizational downside risk. Strategic Management Journal, v. 17, n. 9, p. 671-691, 1996.

MIOCEVIC, D. B.; CRNJAK-KARANOVIC, B. The Export Market Orientation - export performance relationship in emerging markets: the case of Croatian SME exporters. International Journal of Business and Emerging Markets, v. 4, n. 2, p. 107-122, 2012.

MISHRA, S.; LALUMIÈRE, M. L. Individual differences in risk-propensity: Associations between personality and behavioral measures of risk. Personality and Individual Differences, v. 50, n. 6, p. 869-873, 2011.

MOHR, A.; BATSAKIS, G. Internationalization Speed and Firm Performance: A Study of the Market-Seeking Expansion of Retail MNEs. Management International Review, 2016.

MOLA, M. J. et al. A technological contingency perspective on the depth and scope of international outsourcing. Journal of International Management, v. 10, p. 287-305, 2004.

MONSEN, E.; URBIG, D. Perceptions of efficacy, control, and risk, a theory of mixed control. In: CARSRUD, A. L.; BRANNBACK, M. (Eds.). Understanding the Entrepreneurial Mind: Opening the Black Box. New York: Springer, 2009, p. 259-284.

MOON, J.; LEE, H. On the internal correlates of export stages development: an empirical investigation in the Korean electronics industry. International Marketing Review, v. 7, n. 5, p. 626, 1990.

MOREHOUSE, R. E.; FARLEY, F.; YOUNGQUIST, J. V. Type T Personality and the Jungian Classification System. Journal of Personality Assessment, v. 54, n. 1-2, p. 231-235, 1990. 
MORGAN, R. E.; KATSIKEAS, C. S. Export stimuli: Export intention compared with export activity. International Business Review, v. 6, n. 5, p. 477-500, 1997.

Exporting Problems of Industrial Manufacturers. Industrial Marketing Management, v. 27, p. 161-176, 1998.

MORGAN, R. M.; HUNT, S. D. The commitment-trust theory of relationship marketing. Journal of Marketing, v. 58, n. 3, p. 20-38, 1994.

MOROSINI, P.; SHANE, S. National cultural distance and cross-border acquisition performance. Journal of International Business Studies, v. 29, n. 1, p. 137-159, 1998.

MULLINS, J. W.; FORLANI, D. Missing the boat or sinking the boat: A study of new venture decision making. Journal of Business Venturing, v. 20, n. 1, p. 4769, 2005.

MUMFORD, M. D. Planning in organizations: complexity, history, and performance. In: YAMMARINO F. J.; DANSEREAU, F. (Eds.). Research in multi-level issues: The many faces of multi-level issues. Oxford: England, Elsevier, p. 89-93, v. 1. 2002.

MURRAY, J. Y. et al.Assessing measurement invariance of export market orientation: a study of Chinese and non-Chinese firms in China. Journal of International Marketing, v. 15, n. 4, p. 41-62, 2007.

; GAO, G. Y.; KOTABE, M. Market orientation and performance of export ventures: the process through marketing capabilities and competitive advantages. Journal of the Academy of Marketing Science, v. 39, n. 2, p. 252$269,2011$.

MUSTEEN, M.; FRANCIS, J.; DATTA, D. K. The influence of international networks on internationalization speed and performance: A study of Czech SMEs. Journal of World Business, v. 45, n. 3, p. 197-205, 2010.

NABI, G.; LIÑÁN, F. Considering business start-up in recession time. International Journal of Entrepreneurial Behavior \& Research, v. 19, n. 6, p. 633-655, 2013.

NAHAPIET, J.; GHOSHAL, S. Social capital, intellectual capital, and the organizational advantage. Academy of Management Review, v. 23, n. 2, p. 242266, 1998.

NAKOS, G.; BROUTHERS, K. D. Entry Mode Choice of SMEs in Central and Eastern Europe. Entrepreneurship: theory and practice, v. 27, n. 1, p. 47-63, 2002.

; _ _ BROUTHERS, L. E. The impact of firm and managerial characteristics on small and medium-sized Greek firm's export performance. Journal of Global Marketing, v. 11, n. 4, p. 23-47, 1998.

NARDI, P. M. Doing Survey Research: a guide to quantitative methods. 2 ed. Boston: Pearson Education, Inc, 2006. 
NAUDÉ, W. "Rushing in where angels fear to tread"? Journal of Chinese Economic and Foreign Trade Studies, v. 2, n. 3, p. 163-177, 2009.

NIQUE, W.; LADEIRA, W. Pesquisa de marketing: uma orientação para o mercado brasileiro. São Paulo. Atlas, 2014.

NKONGOLO-BAKENDA, J-M. et al. Structural and competitive determinants of globally-oriented small and medium-sized enterprises: an empirical analysis. Journal of International Entrepeneurship, v. 8, p. 55-86, 2010.

NORBURN, D., S. BIRLEY. The top management team and corporate performance. Strategic Management Journal, v. 9, p. 225-37, 1988.

NOWINSKI, W.; RIALP, A. The Impact of Social Networks on Perceptions of International Opportunities. Journal of Small Business Management, v. 54, n. 2, p. 445-461, 2016.

OBBEN, J.; MAGAGULA, P. Firm and managerial determinants of the export propensity of small and medium-sized enterprises in Swaziland. International Small Business Journal, v. 21, n. 1, p. 73-91, 2003.

OMRI, W.; BECUWE, A. Managerial characteristics and entrepreneurial internationalization: A study of Tunisian SMEs. Journal of International Entrepreneurship, v. 12, n. 1, p. 8-42, 2014.

OSKAMP, S. Overconfidence in case-study judgments. Journal of Consulting Psychology, v. 29, p. 261-265, 1965.

OVIATT, B. M.; MCDOUGALL, P. P. A framework for understanding accelerated international entrepreneurship. In: WRIGHT, R. (Ed.). Research in Global Strategic Management. Stamford: JAI Press, 1999, p. 23-40, v. 7.

.; _ Defining international entrepreneurship and modeling the speed of internationalization. Entrepreneurship theory and practice, v. 29, n. 5, p. 537-554, 2005.

.; . Toward a theory of international new ventures. Journal of International Business Studies, v. 25, n. 1, p. 45-61, 1994.

OZGEN, E.; BARON, R. A. Social Sources of Information in Opportunity Recognition: Effects of Mentors, Industry Networks, and Professional Forums. Journal of Business Venturing, v. 22, n. 2, p. 174-192, 2007.

PALICH, L. E.; BAGBY, D. Using cognitive theory to explain entrepreneurial risk-taking: Challenging conventional wisdom. Journal of Business Venturing, v. 10, p. 425-438, 1995.

PAN, Y.; TSE, D. The hierarchical model of market entry modes. Journal of International Business Studies, v. 31, p. 535-554, 2000. 
PANGARKAR, N.; HUSSAIN, S. The Internationalization of Singaporean Small and Medium-Size Enterprises. International Studies of Management \& Organization, v. 43, n. 2, p. 30-55, 2013.

PAPADOPOULOS, N. Inventory, taxonomy and assessment of methods for international market selection. International Marketing Review, v. 5, p. 47-60, 1988.

.; DENIS, J. E. Inventory, taxonomy and assessment of methods for international market selection. International Marketing Review, v. 5, n. 3, p. 3851,1988 .

PARK, T.; RHEE, J. Antecedents of knowledge competency and performance in born globals: The moderating effects of absorptive capacity. Management Decision, v. 50, n. 8, p. 1361-1381, 2012.

PAVIC, I.; VOJINIC, P. The Influence of Demographical and Professional Characteristics on Managers' Risk Taking Propensity. Advances in Management and Applied Economics, v. 2, n. 4, p. 171, 2012.

PENG, M. W.; LU, Y. L.; SHENKAR, O.; WANG, D. Treasures in the China shop: A review of management and organizational research on Greater China. Journal of Business Research, v. 52, p. 95-110, 2001.

Managerial Ties and Firm Performance in a Transition

Economy: The Nature of a Micro-macro Link. Academy of Management Journal, v. 43, n. 3, p. 486-502, 2000.

.; WANG, D.; JIANG, Y. An institution-based view of international business strategy: a focus on emerging economies. Journal of International Business Studies, v. 39, p. 920-936, 2008.

PFEFFER, J.; SALANCIK, G. R. The External Control of Organization: A Resource Dependence Perspective. New York: Harper \& Row, 1978.

PIAZZA-GEORGI, B. The role of human and social capital in growth: Extending our understanding. Cambridge Journal of Economics, v. 26, n. 4, p. 461-479, 2002.

PLA-BARBER, J.; ESCRIBÁ-ESTEVE, A. Accelerated internationalization: Evidence from a late investor country. International Marketing Review, v. 23, p. 255-278, 2006.

PLATTEAU, J.-P. Behind the Market stage where real societies exist [Parts I \& II]. Journal of Development Studies, v. 30, p. 533-577, 753-817, 1991.

PODSAKOFF, P. M.; MACKENZIE, S. B.; LEE, J. Y.; PODSAKOFF, N. P. Common method biases in behavioral research: A critical review of the literature and recommended remedies. Journal of Applied Psychology, v. 88, n. 5, p. 879903, 2003.

.; ORGAN, D. W. Self-reports in organizational research: Problems and prospects. Journal of Management, v. 12, n. 4, p. 531-544, 1986. 
PRAHALAD, C. K.; G. HAMEL, G. The Core Competence of the Corporation. Harvard Business Review, v. 68, n. 3, p. 79-91, 1990.

PRASHANTHAM, S. New venture internationalization as strategic renewal. European Management Journal, v. 26, n. 6, p. 378-387, 2008.

Social Capital and Indian Micromultinationals. British Journal of Management, v. 22, n. 1, p. 4-20, 2011. Toward a knowledge-based conceptualization of internationalization.

Journal of International Entrepreneurship, v. 3, n. 1, p. 37-52, 2005.

.; DHANARAJ, C. The dynamic influence of social capital on the international growth of new ventures. Journal of Management Studies, v. 47, n. 6, p. 967-994, 2010.

.; MNE ties and new venture internationalization: Exploratory

insights from India. Asia Pacific Journal of Management, v. 32, p. 901-924, 2015.

PRATT, J. W. Risk aversion in the small and in the large. Econometrica, v. 32, p. 122-136, 1964.

PIERCY, N. Export Strategy: Markets and Competition. London: George Allen \& Unwin, 1982.

QIAN, G. Multinationality, product-diversification, and profitability of emerging US small and medium-sized enterprises. Journal of Business Venturing, v. 17, p. 611-633, 2002.

RAMASWAMY, K. Multinationality and performance: An empirical examination of the moderating effect of configuration. Proceedings of the Academy of Management, p. 142-146, 1993.

; KROECK, K. G.; RENFORTH, W. Measuring the degree of internationalization of a firm: a comment. Journal of International Business Studies, v. 26, n. 1, p. 167-177, 1996.

RAMCHARRAN, H. Foreign direct investment in Central and Eastern Europe: An analysis of regulatory and country risk factors. American Business Review, v. 18 , p. $1-8,2000$.

RAMOS, E.; ACEDO, F. J.; GONZALEZ, M. R. Internationalisation speed and technological patterns: A panel data study on Spanish SMEs. Technovation, v. 31, p. 560-572, 2011.

RAUCH, A.; RIJSDIJK, S. A. The effects of general and specific human capital on long-term growth and failure of newly founded businesses. Entrepreneurship: Theory and Practice, v. 37, n. 4, p. 923-941, 2013.

RAUCH, J. E. Business and social networks in international trade. Journal of Economic Literature, v. 39, n. 4, p. 1177-1203, 2001.

REEB, D. M.; C. KWOK, C.; BAEK, H. Y. Systematic Risk of the Multinational Corporation. Journal of International Business Studies, v. 29, p. 263-278, 1998. 
REID, S. D. Firm internationalization, transaction costs, and strategic choice. International Marketing Review, v. 1, n. 2, p. 45-56, 1983. Information acquisition and export entry decisions in small firms. Journal of Business Research, v. 12, p. 141-57, 1984.

The decision-maker and export entry and expansion. Journal of International Business Studies, v. 12, n. 2, p. 101-11, 1981.

REINARTZ, W. J.; HAENLEIN, M.; HENSELER, J. An empirical comparison of the efficacy of covariance-based and variance based SEM. International Journal of Market Research, v. 26, n. 4, p. 332-344, 2009.

REUBER, A. R.; FISCHER, E. The influence of the management team's international experience on the internationalization behaviours of SMEs. Journal of International Business Studies, v. 28, n. 4, p. 807-25, 1997.

REYNOLDS P. D. Sociology and entrepreneurship: concepts and contributions. Entrepreneurship Theory and Practice, v. 16, n. 2, p. 47-70, 1991.

REYNOLDS, W. W.; NELSON, R. M. Risk perception and decision processes underlying informed consent to research participation. Social Science and Medicine, v. 65, n. 10, p. 2105-2115, 2007.

RIALP, A.; RIALP, J.; KNIGHT, G. A. The phenomenon of early internationalizing firms: what do we know after a decade (1993-2003) of scientific inquiry? International Business Review, v. 14, p. 147-166, 2005.

RICARD, A.; SAIYED, A. A. Attitude Toward Internationalization And Early Internationalization: Comparison of Indian and French SMEs' Decision Makers. M@n@gement, 2015, v. 18, n 1, p. 54-77, 2015.

RICHTER, R. On the social structure of markets: a survey of some sociological arguments. 6th Annual Conference of the International Society for New Institutional Economics at MIT. Cambridge/Massachusetts, 2002.

RIGDON, E. E. Rethinking partial least squares path modeling: In praise of simple methods. Long Range Planning, v. 45, n. 5/6, p. 341-358, 2012.

ROBOCK, S. H. Political risk: Identification and assessment. Columbia Journal of World Business, v. 6, n. 4, p. 6-20, 1971.

ROGERS, E. M. Diffusion of Innovations. 5 ed. New York: Free Press, 2003.

ROOKS, G.; RAUB, W.; SELTEN, R.; TAZELAAR, F. How inter-firm cooperation depends on social embeddedness: a vignette study. Acta Sociologica, $v$. 43, p. 123-137, 2000.

ROSEN, H, WILLEN, P. Risk, return and self-employment. Discussion paper, Princeton University, 2002. 
ROXAS, H. B.; CHADEE, D. A resource-based view of small export firms' social capital in a southeast Asian country. Asian Academy of Management Journal, v. 16, n. 2, p. 1-28, 2011.

RUEFLI, T. W.; COLLINS, J. M.; LACUGNA, J. R. Risk measures in strategic management research: auld Lang syne? Strategic Management Journal, v. 20, n. 2, p. 167-194, 1999.

RUGMAN, A.; OH, C. H. Does the regional nature of multinationals affect the multinationality and performance relationship? International Business Review, v. 19, n. 5, p. 479-88, 2010.

RUZZIER, M., ANTONCIC, B., HISRICH, R. D.; KONECNIK, M. Human capital and SME internationalization: A structural equation modeling study. Canadian Journal of Administrative Sciences, v. 24, n. 1, p. 15-29, 2007. .; _ $\quad$ KONECNIK, M. The resource-based approach to the internationalisation of SMEs: Differences in resource bundles between internationalized and non-internationalized companies. Zagreb International Review of Economics \& Business, v. 9, n. 2, p. 95-116, 2006.

SAMIEE, S.; WALTERS, P. G. Influence of firm size on export planning and performance. Journal of Business Research, v. 20, n. 3, p. 235-248, 1990.

SARSTEDT, M. et al. Uncovering and treating unobserved heterogeneity with FIMIXPLS: which model selection criterion provides an appropriate number of segments? Schmalenbach Business Review, v. 63, n. 1, p. 34-62, 2011.

. et al. Partial least squares structural equation modeling (PLS-SEM): A useful tool for family business researchers. Journal of Family Business Strategy, v. 5, n. 1, p. 105-115, 2014.

SASI, V.; ARENIUS, P. International new ventures and social networks: Advantage or liability? European Management Journal, v. 26, n. 6, p. 400-411, 2008 .

SCHLEGELMILCH, B. B. Controlling country-specific and industry-specific influences. European Journal of Marketing, v. 20, n. 2, p. 54-72, 1986.

SCHNEIDER, M. et al. Institutional arrangements and the creation of social capital: The effects of public school choice. American Political Science Review, v. 91, p. 82-93, 1997.

SCHUEFFEL, P.; BALDEGGER, R.; AMANN, W. Behavioral patterns in bornagain global firms. The Multinational Business Review, v. 22, n. 4, p. 418-441, 2014.

SCHULTZ, T. W. Investment in human capital. American Economic Review, v. 51, p. 1-17, 1961.

SCHUMPETER, J. The Theory of Economic Development. Cambridge: Cambridge University Press, 1934. 
SCHWENS, C.; KABST, R. Early internationalization. A transaction cost economics and structural embeddedness perspective. Journal of International Entrepreneurship, v. 7, p. 323-340, 2009.

SEBRAE. Importância da exportação para equilíbrio da empresa. 2014. Disponível em: <http://www.sebrae.com.br/customizado/internacionalizacao-damicro-epequena-empresa/conheca-o-projeto/comoexportar/integra_bia?ident_unico=13583>. Acesso em: 18 nov. 2015.

SERRA, F.; POINTON, J.; ABDOU, H. Factors influencing the propensity to export: A study of UK and Portuguese textile firms. International Business Review, v. 21, p. 210-224, 2012.

SHANE, S.; VENKATARAMAN, S. The promise of entrepreneurship as a field of research. Academy of Management Review, v. 25, n. 1, p. 217-226, 2000.

SHARMA D. D.; BLOMSTERMO, A. The internationalization process of born globals: a network view. International Business Review, v. 12, n. 6, p. 739-753, 2003.

SHRADER, R. C.; OVIATT, B. M.; MCDOUGALL, P. P. How new ventures exploit trade-offs among international risk factors: lessons for the accelerated internationization of the 21st century. Academic Management Journal, v. 43, p. 1227-1247, 2000.

SIMMONDS, K.; SMITH, H. The first export order: A marketing innovation. British Journal of Marketing, v. 2, n. 2, p. 93-100, 1968.

SIMON, J. D. Political risk assessment: Past trends and future prospects. Columbia Journal of World Business, v. 17, n. 3, p. 62-71, 1982.

SIMON, M.; HOUGHTON, S.; AQUINO, K. Cognitive biases, risk perception and venture formation: How individuals decide to start companies. Journal of Business Venturing, v. 15, p. 113-134, 1999.

SINGH, H.; MAHMOOD, R. Determining the Effect of Export Market Orientation on Export Performance of Small and Medium Enterprises in Malaysia: An Exploratory Study. Advances in Management \& Applied Economics, v. 3, n. 6, p. 223-232, 2013.

SINGH, J. Performance, slack, and risk taking in organizational decision making. Academy of Management Journal, v. 29, n. 3, p. 562-585, 1986.

SITKIN, S. B.; PABLO, A. L. Reconceptualizing the determinants of risk behavior. Academy of Management Review, v. 17, n. 1, p. 9-38, 1992.

.; WEINGART, L. R. Determinants of risky decision-making behavior: A test of the mediating role of risk perceptions and propensity. Academy of Management Journal, v. 38, n. 6, p. 1573-1592, 1995. 
SLOVIC, P. Information Processing, Situation Specificity, and the Generality of Risk-Taking Behavior. Journal of Personality and Social Psychology, v. 22, n. 1, p. 128-134, 1972.

SLOVIC, P.; FISCHHOFF, B.; LICHTENSTEIN, S. Facts versus fears: Understanding perceived risk. In: KAHNEMAN, D.; SLOVIC, P.; TVERSKY, A. (Eds.). Judgment under uncertainty: Heuristics and biases. Cambridge: Cambridge University Press, p. 465-472. 1980.

SMALlBONE, D. et al. The diversity of ethnic minority enterprises. Paper presented at the RENT XIII, London, 25-26 November, 1999. .; RAM, M.; DEAKINS, D.; BALDOCK, R. Accessing finance and business support by ethnic minority businesses in the UK. Paper presented at Public Policy and the Institutional Context of Immigrant Businesses Conference, Liverpool, p. 22-25, p. 22-25. March 2001.

SMITH, J. B.; MITCHELL, J. R.; MITCHELL, R. K. Entrepreneurial scripts and the new transaction commitment mindset: Extending the expert information processing theory approach to entrepreneurial cognition research. Entrepreneurship: Theory and Practice, v. 33, n. 4, p. 815-844, 2009.

SOUSA, C. Export Performance Measurement: An Evaluation of the Empirical Research in the Literature. Academy of Marketing Science Review, v. 8, n. 9, p. $1-22,2004$.

SOUSA, C. M. P.; MARTINEZ-LOPEZ, F. J.; COELHO, F. The determinants of export performance: a review of the research in the literature between 1998 and 2005. International Journal of Management Reviews, v. 10, n. 4, p. 343-374, 2008 .

STEARNS, T. M.; HILLS, G. E. Entrepreneurship, and new firm development: a definitional introduction. Journal of Business Research, v. 36, p.1-4, 1996.

STEEN, J. T.; LIESCH, P. W. A note on penrose an growth, resource bundles and the Uppsala model of internationalization. Management International Review, v. 47, n. 2, p. 193-206, mar. 2007.

STEENKAMP, J.-B. E. M.; JONG, M. G.; BAUMGARTNER, H. Socially Desirable Response Tendencies in Survey Research. Journal of Marketing Research, v. 47, n. 2, p. 199-214, abr. 2010.

STERLACCHINI, A. Do innovative activities matter to small firms in non-R\&Dintensive industries? An application to export performance. Research Policy, v. 28, n. 8, p. 819-832, 1999.

STOIAN, M. C. Human capital in export-based internationalisation "managerial determinants and their influence upon the export behaviour of the firm: four case-studies of catalan exporting SMEs. European Doctoral Programe. Universitat Autònoma de Barcelona, 2007. 
et al. Internationalisation of Central and Eastern European small firms.

Journal of Small Business and Enterprise Development, v. 23, n. 1, p. 105$121,2016$.

SUÁREZ-ORTEGA, S. M.; ÁLAMO-VERA, F. R. SMES' internationalization: firms and managerial factors. International Journal of Entrepreneurial Behaviour \& Research, v. 11, n. 4, p. 258-279, 2005.

SULLIVAN, D. Measuring the Degree of Internationalization of a Firm: A Reply. Journal of International Business Studies, v. 27, n. 1, p. 179-192, 1996. Measuring the Degree of Internationalization of a Firm. Journal of International Business Studies, v. 25, n. 2, p. 325-342, 1994.

SVETLICIC, M.; JAKLIC, A.; BURGER, A. Internationalization of small and medium-size enterprises from selected central European economies. Eastern European Economics, v. 45, n. 4, p. 36-65, 2007.

SWIFT, J. S. Foreign language ability and international marketing. European Journal of Marketing, v. 25, p. 36-49, 1991.

TABARES, A.; ALVAREZ, C.; URBANO, D. Born Globals From the ResourceBased Theory: a Case Study in Colombia. Journal of Technology Management \& Innovation, v. 10, n. 2, p. 154-165, 2015.

TALLMAN, S.; LI, J. Effects of International Diversity and Product Diversity on the Performance of Multinational Firms. The Academy of Management Journal, v. 39, n. 1 p. 179-196, fev. 1996.

TAN, J. Perceived Environment, Strategic Orientation, Ownership Effect and Performance Implications in a Transition Economy. Ph.D. Dissertation, Blacksburg, Virginia: Virginia Polytechnic Institute and State University, 1993.

TAYLOR, R. N. Age and experience as determinants of managerial information processing and decision making performance. Academy of Management Journal, v. 18, n. 1, p. 74-81, 1975.

TAYLOR, S. Creating social capital in MNCs: the international human resource management challenge. Human Resource Management Journal, v. 17, n. 4, p. 336-354, 2007.

TEIXEIRA, A. A. C.; COIMBRA, C. The determinants of the internationalization speed of Portuguese university spin-offs: An empirical investigation. Journal of International Entrepeneurship, v. 12, p. 270-308, 2014.

TERJESEN, S.; HESSELS, J.; LI, D. Comparative International Entrepreneurship: A Review and Research Agenda. Journal of Management, v. 42, n. 1, p. 299-344, jan. 2016.

TERPSTRA, V. International marketing. New York: Dryden Press, 1983. 
THALER, R. H.; JOHNSON, E. J. Gambling with the house money and trying to break even: the effects of prior outcomes on risky choice. Management Science, v. 36, n. 6, p. 643-660, 1990.

TING, W. Multinational risk assessment and management. Westport, Conn.: Greenwood Press, 1988.

TOFTEN, K.; OLSEN, S. O. Export market information use, organizational knowledge, and firm performance: a conceptual framework. International Marketing Review, v. 20, n. 1, p. 95-110, 2003.

TOOKEY, D. A. Factors Associated with Success in Exporting. Journal of Management Studies, v. 1, n. 1, p. 48-66, 1964.

TSAI, W.; GHOSHAL, S. Social capital and value creation: the role of intrafirm networks. Academy of Management Journal, v. 41, n. 4, p. 464-476, 1998.

TURNBULL, P. W.; WELHAM, G. F. The characteristics of European export marketing staff. European Journal of Marketing, v. 19, n. 2, p. 31-41, 1985.

UGHETTO, E. Growth of born globals: the role of the entrepreneur's personal factors and venture capital. International Entrepeneurship Management, v. 12, n. 3, p. 839-857, 2016.

UNCTAD. World Investment Report 2005: Transational Corporations and the Internationalization of R\&D. New York/Geneva: United Nations, 2005.

URSIC, M. L.; CZINKOTA, M. R. The relationship between managerial characteristics and exporting behavior. Developments in Marketing Science, $\mathrm{V}$. 12 , n. 12 , p. 208-10, 1989.

UZZI, B. Social structure and competition in interfirm networks: The paradox of embeddedness. Administrative Science Quarterly, v. 42, p. 36-67, 1997.

VAHLNE, J. E.; JOHANSON, J. The Uppsala model on evolution of the multinational business enterprise-from internalization to coordination of networks. International Marketing Review, v. 30, n. 3, p. 189-210, 2013.

VALLASTER, C. Conducting field research in Asia: Fundamental differences as compared to western societies. Culture and Psychology, v. 6, n. 4, p. 461-477, 2000 .

VATNE, E. Local resource mobilization and internationalisation strategies in small and medium sized enterprises. Environment and Planning A, v. 27, n. 1, p. 63-80, 1995.

VIDA, I.; REARDON, J.; FAIRHURST, A. Determinants of international retail involvement: the case of large US retail chains. Journal of International Marketing, v. 8, n. 4, p. 37-60, 2000. 
VIEIRA, S. Como elaborar questionários. São Paulo: Atlas, 2009.

VINZI, V. E. et al. Handbook of Partial Least Squares: Concepts, Methods and Applications. Heidelberg: Springer, 2010.

WALKER, G.; KOGUT, B.; SHAN, W. Social capital, structural holes and the formation of an industry network. Organization Science, v. 8, n. 2, p. 109-125, 1997.

WALTER, A.; RITTER, T.; GEMUNDEN, H. G. Value creation in buyer-seller relationships: Theoretical considerations and empirical results from a supplier's perspective. Industrial marketing management, v. 30, n. 4, p. 365-377, 2001.

WARD, E. A. Motivation of expansion plans of entrepreneurs and small business managers. Journal of Small Business Management, v. 31, n. 1, p. 32-38, 1993.

WEBER, E. U.; BLAIS, A. R.; BETZ, N. E. A domain-Specific Risk-Attitutde Scale: Measuring Risk Perceptions and Risk Behaviors. Journal of Behavioral Decision Making, v. 15, n. 4, p. 263-290, 2002.

.; MILLIMAN R. A. Perceived risk attitudes: relating risk perception to risky choice. Management Science, v. 43, n. 2, p. 123-144, 1997.

WELCH, D. E.; WELCH, L. S. The internationalization process and networks: A strategic management perspective. Journal of International Marketing, v. 4, n. 3, p. 11-28, 1996.

. et al. Network development in international project marketing and the development of external facilitation. International Business Review, v. 5, n. 6, p. 579-602, 1996.

WELCH, L. S.; LUOSTARINEN, R. Internationalisation: evolution of a concept. Journal of General Management, v. 2, p. 34-55, 1988.

WERNERFELT, B. A. A resource-based view of the firm. Strategic Management Journal, v. 5, n. 2, p. 171-180, 1985.

WESTHEAD, P.; UCBASARAN, D.; WRIGHT, M. Decisions, actions, and performance: Do novice, serial, and portfolio entrepreneurs differ? Journal of Small Business Management, v. 43, p. 393-417, 2005.

.; WRIGHT, M.; UCBASARAN, D. The internationalization of new and small firms: a resource-based view. Journal of Business Venturing, v. 16, n. 4, p. 333-358, 2001.

WEST, J.; GRAHAM, J. L. A linguistic based measure of cultural distance and its relationship to managerial values. Management International Review, v. 44, n. 3, p. 239-260, 2004.

WIDERSHEIM-PAUL, F.; OLSON, H. C.; WELCH, L. S. Pre-Export Activity: The First Step in Internationalization. Journal of International Business Studies, v. 9, n. 1, p. 47-58, 1978. 
WIERSEMA, M. F.; BANTEL, K. A. Top Management Team Demography and Corporate Strategic Change. Academy of Management Journal, v. 35, p. 91$121,1992$.

WINSTED, K.; PATTERSON, P. G. Internationalization of services: the service exporting decision. Journal of Services Marketing, v. 12, n. 6, p. 294-312, 1998.

WILLIAMS, D. J. Retailer internationalisation: an empirical enquiry. European Journal of Marketing, v. 26, n. 8/9, p. 8-24, 1992.

.; NOYES, J. M. How does our perception of risk influence decisionmaking? Implications for the design of risk information. Theoretical Issues in Ergonomics Science, v. 8, n. 1, p. 1-35, 2007.

WILLIAMS, J. E. M.; CHASTON, I. Links between the linguistic ability and international experience of export managers and their export marketing intelligence behaviour. International Small Business Journal, v. 22, p. 463-486, 2004.

WILLIAMS, L. J.; HARTMAN. N.; CAVAZOTTE, F. Method Variance and Marker Variables: A Review and Comprehensive CFA Marker Technique. Organizational Research Methods, v. 13, n. 3, p. 477-514, 2010.

WILLIAMSON, J. Profit growth and sales maximization. Economica, v. 33, n. 129, p. 1-16, 1996.

WILLIAMSON, O. E. Markets, hierarchies and the modern corporation: an unfolding perspective. Journal of Economic Behavior and Organization, v. 17, p. 335-352, 1992.

. Strategy research: governance and competence perspectives. Strategic Management Journal, v. 20, p. 1087-1108, 1999.

. The Economics of Organization: The Transaction Cost Approach.

American Journal of Sociology, v. 87, n. 3, p. 548-577, 1981.

The mechanisms of governance. New York: Oxford University Press, 1996.

. Transaction-cost economics the governance of contractual relations.

Journal of Law and Economics, v. 22, n. 2, p. 233-261, 1979.

WILSON, H. Internationalization of small and medium-sized enterprises (SMEs). International business theories, policies and practices. UK: Pearson Education, 2000.

WINCENT, J.; THORGREN, S.; ANOKHIN, S. Costly Ties: Social Capital as a Retardant of Network-Level Entrepreneurial Orientation. Journal of Small Business Management, 2016.

WINCH G. M.; MAYTORENA, E. Making good sense: Assessing the quality of risky decision-making. Organization Studies, v. 30, n. 2-3, p. 181-203, 2009. 
WINCH, G. W.; BIANCHI, C. Drivers and dynamic processes for SMEs going global. Journal of Small Business and Enterprise Development, v. 13, p. 7388, 2006.

WOLD, H. Modeling in complex situations with soft information. Toronto: Third World Congress of Econometric Society, 1975.

Soft modeling: The basic design and some extensions. In: JÖRESKOG, K. G.; Wold, H. (Eds.). Systems under indirect observations: Part II. Amsterdam: North-Holland, 1982, p. 1-54.

WOLFF, J. A.; PETT, T. L. Small-firm performance: Modeling the role of product and process improvements. Journal of Small Business Management, v. 44, p. 268-84, 2006.

WONG, E. The Role of Risk in Making Decisions under Escalation Situations. Applied Psychology: An International Review, v. 54, n. 4, p. 584-607, 2005.

WONG, K. K.-K. Partial Least Squares Structural Equation Modeling (PLS-SEM) Techniques Using SmartPLS. Marketing Bulletin, v. 24, p. 1-32, 2013.

WOOLCOCK, M. Social capital and economic development: Toward a theoretical synthesis and policy framework. Theory and Society, v. 27, p. 151208, 1998.

WRIGHT, M.; WESTHEAD, P.; UCBASARAN, D. Internationalization of small and medium sized enterprises (SMEs) and international entrepreneurship: a critique and policy implications. Regional Studies, v. 41, n. 7, p. 1013-1030, 2007.

WROON, V.; PAHL, B. Relationship between age and risk-taking among managers. Journal of Applied Psychology, v. 55, p. 399-405, 1971.

WU, B.; KNOTT, A. M. Entrepreneurial risk and market entry. Management Science, v. 52, p. 1315-1330, 2006.

YANG, K. Individual Social Capital and its Measurement in Social Surveys. Survey Research Methods, v. 1, n. 1, p.19-27, 2007.

YASAI-ARDEKANI, M. Structural adaptations to environments. Academy of Management Review, v. 11, p. 9-21, 1986.

YLI-RENKO, H.; AUTIO, E; TONITI, V. Social capital, knowledge, and the international growth of technology-based new firms. International Business Review, v.11, p. 279-304, 2002. .; JANAKIRAMAN, R. How customer portfolio affects new product development in technology-based entrepreneurial firms. Journal of Marketing, v. 72, p. 131-148, 2008. 
YU, J.; GILBERT, A.; OVIATT, B. Effects of Alliances, times, and network cohesion on the initiation of foreign sales by new ventures. Strategic Management Journal, v. 32, p. 424-446, 2011.

ZAFARULLAH, M.; ALI, M., YOUNG, S. The internationalization of the small firm in developing countries - exploratory research from Pakistan. Journal of Global Market, v. 11, n. 3, p. 21-40, 1998.

ZAHRA, S. A.; BRETT, P. M.; CARLETON, J. M. Technological Resource Leveraging and the Internationalisation of New Ventures. Journal of International Entrepreneurship, v. 1, n. 2, p. 163-186, 2003.

.; GARVIS, D. M. International corporate entrepreneurship and firm performance: the moderating effect of international environmental hostility. Journal of Business Venturing, v. 15, p. 469-492, 2000.

.; GEORGE, G. International entrepreneurship: The current status of the field and future research agenda. In: HITT, M. A. et al. (Eds.). Strategic entrepreneurship: Creating a new mindset. Oxford: Blackwell, 2002, p. 255-288. .; KORRI, J. S.; YU, J. F. Cognition and international entrepreneurship: implications for research on international opportunity recognition and exploitation. International Business Review, v. 14, p. 129-146, 2005.

; NEUBAUM, D. O. Environmental adversity and entrepreneurial activities of new ventures. Journal of Developmental Entrepreneurship, v. 3, n. 2, p. 123-40, 1998.

ZAJAC, E. J.; OLSEN, C. P. From transaction cost to transactional value analysis: implications for the study of interorganizational strategies. Journal Management, v. 31, n. 1, p. 131-145, 1993.

ZAPKAU, F. B.; SCHWENS, C.; KABST, R. Foreign Direct Investments and Domestic Employment of German SMEs: The Moderating Effect of Owner Management. Journal of Small Business Management, v. 52, n. 3, p. 451-476, 2014.

ZHANG, J. The problems of using socials networks in entrepreneurial resource acquisition. International Small Business Journal, v. 28, n. 4, p. 338-361, 2010.

ZHANG, M.; TANSUHAJ, P.; MCCULLOUGH, J. International entrepreneurial capability: the measurement and a comparison between born global firms and traditional exporters in China. Journal of International Entrepreneurship, v. 7, n. 4, p. 293-322, 2009.

ZHANG, Y.; LI, H.; ZHOU, L. FDI spillovers in an emerging market: the role of foreign firms' country origin diversity and domestic firms' absorptive capacity. Strategic Management Journal, v. 31, p. 969-989, 2010.

ZHAO, H. HSU, C. Social Ties and Foreign Market Entry: An Empirical Inquiry. Management International Review, v. 47, n. 6, p. 815-844, 2007. 
ZHOU, L. The effects of entrepreneurial proclivity and foreign Market knowledge on early internationalization. Journal of World Business, v. 42, p. 281-293, 2007.

ZOU, S.; STAN, S. The determinants of export performance: a review of the empirical literature between 1987 and 1997. International Marketing Review, v. 15, n. 5, p. 333-353, 1998.

ZUCCHELLA, A.; PALAMARA, G.; DENICOLAI, S. The drivers of the early internationalization of the firm. Journal of World Business, v. 42, p. 268-280, 2007. 


\section{Apêndice A - questionário aplicado}

\section{Primeiro Bloco}

Este estudo é conduzido pela PUC-Rio e tem como objetivo avaliar a influência das características dos decisores sobre a internacionalização de pequenas e médias empresas brasileiras.

Todas as informações serão consideradas estritamente confidenciais. Os resultados serão apresentados de forma agregada, de maneira a impossibilitar a identificação de respostas individuais.

O preenchimento deste questionário deve levar cerca de 15 minutos e o mesmo deve ser respondido por um gestor envolvido em decisões de exportação.

Agradecemos por sua valiosa contribuição!

Helder Silva - Doutorando da PUC-Rio

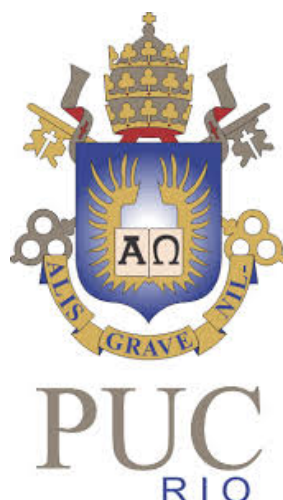

Jorge Carneiro - Professor de Estratégia e de Negócios Internacionais da PUC- 


\section{Segundo Bloco}

Em que ano sua empresa foi fundada?

Em que ano sua empresa começou a exportar?

Em que ano você ingressou na empresa?

Qual o porte da sua empresa?
( ) Microempresa
( ) Pequena empresa
( ) Média empresa
( ) Grande empresa

Qual o seu envolvimento no processo de internacionalização da empresa?

( ) Participo diretamente desde a fase de concepção e de implantação da estratégia de internacionalização

( ) Participo diretamente desde a fase de implantação da estratégia de internacionalização

( ) Participo diretamente; contudo quando ingressei o processo já vinha sendo conduzido

( ) Não participo diretamente das decisões de internacionalização 


\section{Terceiro Bloco}

Por favor, responda às questões a seguir considerando o momento em que você ingressou ou fundou esta empresa.

Qual era a sua idade quando você ingressou ou fundou esta empresa?
( ) 18 a 30 anos
( ) 31 a 40 anos
( ) 41 a 50 anos
( ) 51 a 60 anos
( ) 61 a 70 anos
( ) Mais de 70 anos

Qual o seu nível de educação escolar formal quando você ingressou ou fundou esta empresa?
( ) ensino fundamental (primeiro grau) incompleto
( ) ensino fundamental (primeiro grau) completo
( ) ensino médio (segundo grau) incompleto
( ) ensino médio (segundo grau) completo
( ) ensino superior incompleto
( ) ensino superior completo
( ) pós-graduação (MBA, mestrado ou doutorado) incompleto
( ) pós-graduação (MBA, mestrado ou doutorado) completo

Por quantos anos você morou fora do Brasil antes de ter ingressado ou fundado esta empresa?
( ) nunca tinha morado fora do Brasil antes de ter ingressado ou fundado esta empresa
( ) menos de 1 ano
( ) entre 1 e 2 anos
( ) entre 2 e 4 anos
( ) entre 4 e 6 anos
( ) mais de 6 anos

Qual era o seu nível de conhecimento da principal língua estrangeira exigida no processo de exportação quando você ingressou ou fundou esta empresa?
( ) nenhum conhecimento
( ) conhecimento básico
( ) conhecimento médio
( ) conhecimento avançado 


\section{Quarto bloco}

Indique a frequência com que você utiliza cada uma das seguintes fontes de informação para dar suporte às suas Nunca $\gg>$ $\gg>$ >> Frequenteatividades de exportação. mente

Clientes

○

○

O

○

Fornecedores

○

○

○

O

Agências governamentais

○

○

○

○

Empresas de seu círculo de relacionamento

0

○

○

O

\begin{tabular}{|c|c|c|c|c|c|}
\hline Indique a frequência com que você...: & Nunca & $\gg>$ & $\gg>$ & $\gg>$ & $\begin{array}{r}\text { Frequente- } \\
\text { mente }\end{array}$ \\
\hline $\begin{array}{l}\text { Realiza atividades informais (ex: jogar futebol/voleibol) com } \\
\text { pessoas influentes do seu setor }\end{array}$ & O & $\bigcirc$ & ○ & $\bigcirc$ & O \\
\hline $\begin{array}{l}\text { Participa de encontros nacionais em associações de classe ou } \\
\text { feiras relacionadas aos seus produtos / serviços }\end{array}$ & O & O & $\bigcirc$ & ○ & O \\
\hline $\begin{array}{l}\text { Participa de encontros internacionais em associações de classe } \\
\text { ou feiras relacionadas aos seus produtos / serviços }\end{array}$ & O & ○ & ○ & O & O \\
\hline
\end{tabular}




\section{Quinto bloco}

Indique seu grau de concordância ou discordância com cada uma das seguintes afirmativas:

Quando eu comecei a trabalhar nesta empresa, meus contatos no exterior me ajudaram a obter acesso a pessoas ou organizações 0 importantes para a exportação

Aceito assumir riscos em decisões de exportação

Eu prefiro caminhos já testados, mesmo sabendo que coisas novas podem eventualmente vir a dar melhores resultados

Eu me sinto à vontade para desenvolver projetos que tenham $\underline{\text { risco }}$

Só me sinto seguro para tomar decisões quando tenho todas as informações

Eu tento coisas novas, mesmo sabendo que algumas poderão dar errado

$\bigcirc$

discordo concordo

totalmente $\quad<<<<<<<>\gg>>>>>$ totalmente

$\bigcirc$

$\bigcirc$

$\bigcirc$

$\bigcirc$

$0 \quad 0 \quad 0$

$\bigcirc$

$0 \quad 0 \quad 0 \quad 0$

$0 \quad 0 \quad 0$

$0 \quad 0$

Ũ 


\section{Sexto bloco}

Nas perguntas a seguir, marque a opção de resposta que melhor representa a sua opinião.

Quando tenho que tomar uma decisão cujas consequências são difíceis de prever, eu usualmente...

adoto uma postura cautelosa como forma

de reduzir as chances de tomar decisões adoto uma postura agressiva como forma de aumentar as chances de aproveitar oportunidades

Eu julgo que, de uma forma geral, a exportacão é uma atividade que apresenta...

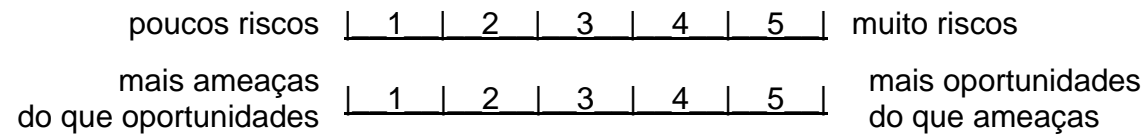




\section{Sétimo bloco}

Indique seu grau de satisfação ou de insatisfação com os resultados de vendas da sua empresa no mercado doméstico (Brasil):

$$
\begin{array}{l|l|l|l|l|l|l|l|}
\text { muito insatisfeito } & 1 & 2 & 3 & 4 & 5 & \text { muito satisfeito }
\end{array}
$$

Indique seu grau de satisfação ou de insatisfação com os resultados de vendas da sua empresa no mercado internacional (exterior):

$$
\text { muito insatisfeito } \begin{array}{|l|l|l|l|l|l|l|}
1 & 2 & 3 & 3 & 4 & 5 & \text { muito satisfeito }
\end{array}
$$

De forma geral, o volume de exportação proporcionalmente às vendas totais das empresas do seu segmento de atuação no Brasil é ...

$$
\begin{array}{l|l|l|l|l|l|l|l}
\text { muito baixo } & 1 & 2 & 2 & 3 & 4 & 5 & \text { muito alto }
\end{array}
$$

Em comparação com outras empresas do seu segmento de atuação no Brasil, o volume de exportação proporcionalmente às vendas totais da sua empresa é ...

$$
\begin{array}{l|l|l|l|l|l|l|l|l}
\text { mais baixo que a dos concorrentes } & 1 & 1 & 2 & 3 & 4 & 5 & \text { mais alto que a dos concorrentes }
\end{array}
$$

O tamanho da sua empresa em comparação com o tamanho dos seus principais concorrentes no Brasil é:

muito menor \begin{tabular}{|l|l|l|l|l|l|l|l}
1 & 2 & 3 & 4 & 5 & muito maior
\end{tabular}




\section{Oitavo bloco}

Para quantos países a sua empresa exportou em 2015?

Qual foi o volume aproximado de exportação, em relação às vendas totais de sua empresa, em 2015?
( ) entre $0 \%$ e $2 \%$
( ) entre $3 \%$ e $5 \%$
( ) entre $6 \%$ e $10 \%$
( ) entre $11 \%$ e $20 \%$
( ) entre $21 \%$ e $30 \%$
( ) entre $31 \%$ e $40 \%$
( ) entre $41 \%$ e $50 \%$
( ) mais de $50 \%$

Qual foi a variação aproximada das receitas de exportação de sua empresa nos primeiros três anos após você ter ingressado na empresa?
( ) crescimento maior que $+30 \%$
( ) crescimento entre $+16 \%$ e $+30 \%$
( ) crescimento entre $+6 \%$ e $+15 \%$
( ) entre $-5 \%$ e $+5 \%$
( ) queda entre $-6 \%$ e $-15 \%$
( ) queda entre $-16 \%$ e $-30 \%$
( ) queda maior que $-30 \%$

Qual foi a variação aproximada das receitas de exportação de sua empresa em 2015, com relação a 2014?

( ) crescimento maior que $+10 \%$

( ) crescimento entre $+6 \%$ e $+10 \%$

( ) crescimento entre $+2 \%$ e $+5 \%$

( ) entre $-2 \%$ e $+2 \%$

( ) queda entre $-5 \%$ e $-2 \%$

( ) queda entre $-10 \%$ e $-6 \%$

( ) queda maior que $-10 \%$ 


\section{Nono bloco}

Esta última etapa do questionário será utilizada apenas para a fins de validação estatística da pesquisa.

Por favor, marque a opção que melhor representa seu sentimento de satisfação ou de insatisfação com relação a cada item listado.

\begin{tabular}{|c|c|c|c|c|c|c|}
\hline \multirow[b]{2}{*}{ A maneira como as pessoas dirigem } & \multicolumn{3}{|c|}{$\begin{array}{l}\text { muito } \\
\text { insatisfeito }<<\end{array}$} & \multicolumn{3}{|c|}{ satisfeito } \\
\hline & O & O & O & & O & O \\
\hline Música popular & O & ○ & O & & O & O \\
\hline As pessoas que você conhece & O & O & O & & O & O \\
\hline A qualidade dos alimentos que você compra & O & O & O & & O & O \\
\hline Os seus vizinhos & O & O & O & & O & $\mathrm{O}$ \\
\hline Os filmes que são produzidos hoje & O & O & O & & O & O \\
\hline
\end{tabular}

Caso você deseje, por favor, utilize o espaço a seguir para comentários adicionais: 


\section{Décimo bloco}

Caso deseje receber cópia dos resultados consolidados deste estudo, por favor, indique seus dados de contato:
Nome da empresa:
Seu nome:
Seu cargo na empresa:

e-mail:

Agradecemos se você enviar o link a seguir para outros gestores de exportação de sua rede de relacionamentos.

Link para a pesquisa:

https://pucrio.co1.qualtrics.com/SE/?SID=SV 9Lx4L7bpAUsHrcV

Caso deseje, entre em contato conosco:

Prof. Helder Silva (aluno de doutorado) Prof. Jorge Carneiro (orientador desta tese)

Tel.: 32 99171-1783

Tel.: 21 99163-4177

e-mail: helder.silva@ifsudestemg.edu.br

e-mail: jorgemtc@iag.puc-rio.br

MUITO OBRIGADO PELA SUA COLABORAÇÃO. 